\title{
Essential fatty acids, pregnancy, and pregnancy outcome : relationship between mother and child
}

Citation for published version (APA):

Al, M. D. M. (1994). Essential fatty acids, pregnancy, and pregnancy outcome : relationship between mother and child. [Doctoral Thesis, Maastricht University]. Rijksuniversiteit Limburg. https://doi.org/10.26481/dis.19940922ma

Document status and date:

Published: 01/01/1994

DOI:

10.26481/dis.19940922ma

Document Version:

Publisher's PDF, also known as Version of record

\section{Please check the document version of this publication:}

- A submitted manuscript is the version of the article upon submission and before peer-review. There can be important differences between the submitted version and the official published version of record.

People interested in the research are advised to contact the author for the final version of the publication, or visit the DOI to the publisher's website.

- The final author version and the galley proof are versions of the publication after peer review.

- The final published version features the final layout of the paper including the volume, issue and page numbers.

Link to publication

\footnotetext{
General rights rights.

- You may freely distribute the URL identifying the publication in the public portal. please follow below link for the End User Agreement:

www.umlib.nl/taverne-license

Take down policy

If you believe that this document breaches copyright please contact us at:

repository@maastrichtuniversity.nl

providing details and we will investigate your claim.
}

Copyright and moral rights for the publications made accessible in the public portal are retained by the authors and/or other copyright owners and it is a condition of accessing publications that users recognise and abide by the legal requirements associated with these

- Users may download and print one copy of any publication from the public portal for the purpose of private study or research.

- You may not further distribute the material or use it for any profit-making activity or commercial gain

If the publication is distributed under the terms of Article $25 \mathrm{fa}$ of the Dutch Copyright Act, indicated by the "Taverne" license above, 


\section{Essential Fatty Acids, Pregnancy, and Pregnancy Outcome}

relationship between mother and child 


\section{CIP-GEGEVENS KONINKLIJKE BIBLIOTHEEK, DEN HAAG}

\section{Al, Monique Denise Maria}

Essential fatty acids, pregnancy, and pregnancy outcome: relationship between mother and child / Monique Denise Maria Al. [S.1.: s.n.] (Den Haag: Pasmans). - I1 1. Thesis Maastricht. - With ref. - With summary in Dutch. ISBN 90-9007453-8

Subject headings: essential fatty acids; pregnancy; diet

Druk: Pasmans Den Haag 


\title{
Essential Fatty Acids, Pregnancy, and Pregnancy Outcome
}

relationship between mother and child

\section{PROEFSCHRIFT}

\author{
ter verkrijging van de graad van doctor \\ aan de Rijksuniversiteit Limburg te Maastricht, \\ op gezag van de Rector Magnificus, Prof. dr. H. Philipsen, \\ volgens het besluit van het College van Dekanen, \\ in het openbaar te verdedigen op donderdag 22 september 1994 \\ om 14.00 uur
}

door

Monique Denise Maria Al 
Promotores:

Prof. dr. F. ten Hoor

Prof. dr. J. de Haan

Co-promotor:

Dr. G. Homstra

Beoordelingscommissie: Prof. dr. G.J. van der Vusse (voorzitter)

Prof. dr. ir. R.J.J. Hermus

Prof. dr. D. Horrobin (Efamol Research Institute,

Kentville, Nova Scotia, Canada)

Prof. dr. H.J. Huisjes (Rijksuniversiteit Groningen)

Prof. dr. ir. F.J. Kok (Landbouwuniversiteit, Wageningen)

Prof. dr. P.W. de Leeuw

Studies of this thesis were financially supported by Nutricia BV, Zoetermeer, The Netherlands.

Financial support by the Netherlands Heart Foundation for the publication of this thesis is gratefully acknowledged.

I also wish to express my gratitude to the Foundation Dr. Ir. J.H.J. van de Laar and Nutricia BV for sponsoring the publication costs. 
Aan mijn ouders 



\section{CONTENTS}

Chapter 1

Introduction

Chapter 2

Biochemical EFA status of mothers and their neonates after normal pregnancy

Chapter 3

Fatty acid composition of serum lipids of mothers and their babies after normal and hypertensive pregnancies

Chapter 4

Nutrient intake of women during normal pregnancy with special emphasis on fat intake

Chapter 5

Maternal essential fatty acid patterns during normal pregnancy and its relationship with the neonatal essential fatty acid status

Chapter 6

The essential fatty acid status of mother and child in pregnancy-induced hypertension: a prospective longitudinal study

Chapter 7

The effect of linoleic acid supplementation during pregnancy on the neonatal essential fatty acid status

Chapter 8

Gieneral discussion

Summary

Samenvatting

Dankwoord

Curriculum vitae

Appendices 


\section{CHAPTER 1}

\section{Introduction}

\section{Essential fatty acids}

More than sixty years ago, Burr and Burr (1) described that rats, who had received a fat-free diet for several months, developed symptoms like growth retardation, scaly dermatitis, increased trans-epidermal loss of water and reproductive failure. Supplementation with small amounts of polyunsaturated fatty acids of the (n-6) and (n-3) family improved the deficiency symptoms $(1,2)$. This study demonstrated that these so-called essential fatty acids (EFAs) are not only a source of energy but have other essential functions as well.

Since men, in contrast to plants, lack $\Delta-12$ - and $\Delta$-15-desaturase, they cannot synthesize the fatty acids linoleic acid $(18: 2(n-6)(1), L A)$ and $\alpha$-linolenic acid (18:3(n-3), LnA ) de novo. Therefore, LA and LnA must be derived from the diet (3). Once in the body, these parent EFAs can be desaturated and elongated to longer chain, more unsaturated derived EFAs of the (n-6) and (n-3) family, respectively (see figure 1). For the synthesis of long chain polyenes (polyunsaturated fatty acid with 20 or more carbon atoms and at least one more double bond than their parent essential fatty acid, LCPs), the activity of $\Delta-6$-desaturase is rate limiting. The substrate affinity of this enzyme is in the order 18:3(n-3)>18:2(n-6)>18:I(n-9). In addition, the activity of $\Delta-6$ desaturation is influenced by the concentration of the reaction substrate as well as product. This latter also applies to the $\Delta-5$-desaturase activity $(4,5)$. In mammals, there is no interconversion between the fatty acids of the different families .

Fatty acids of the (n-3) and (n-6) family are found especially in membrane phospholipids, where they serve important functions. Linoleic acid is essential in maintaining the epidermal water barrier $(6,7)$. In addition, LA is the precursor of dihomo- $\gamma$-linolenic acid (20:3(n-6), DHGL) and arachidonic acid (20:4(n-6), AA), which are substrates for the production of the eicosanoids of the 1- and 2-series, respectively $(8,9)$. AA is also an important structural fatty acid in the brain $(10,11)$, Evidence for a specific function for 18:3(n-3) other than being a precursor of (n-3) long chain polyenes has not yet been reported (12). The most important fatty acids derived from $\mathrm{LnA}$ are timnodonic acid (20:5(n-3), TA) and cervonic acid (22:6(n-3),

\footnotetext{
(1) The nomenclature used for fatty acids is as follows: the number of carbon atoms, followed by a colon and the number of double bonds; between brackets the fatty acid family is indicated by designation of the position of the first double bond from the methyl end of the carbon chain.
} 
CA) ${ }^{(2)}$. TA is the precursor of eicosanoids of the 3-serie (13). CA is found in very high levels in neural and retinal cells $(10,11,14)$, where it performs an array of membrane associated functions.

Since essential fatty acids are important constituents of all cell membranes, they are of specific significance during fetal life, when processes like brain development and organogenesis are taking place in a limited time interval (15). Fatty acid analyses of total lipids from fetal brain tissues showed that during the last trimester of pregnancy the quantitative accretion of total $(\mathrm{n}-3)$ and $(\mathrm{n}-6)$ fatty acids increases progressively as gestation progresses $(16,17)$. For fetal liver tissue a lineair increase was observed (18). These data indicate that the fetal demand for $(n-3)$ and $(n-6)$ fatty acids is high during intra-uterine development.

If insufficient essential fatty acids (EFAs) are available to meet the EFA requirement, the body starts to synithesize "surrogate" fatty acids. The presence of these fatty acids thus indicates a shortage of EFAs. One of the best known essential fatty acid deficiency markers is Mead acid (20:3(n-9), MA). This fatty acid is derived from oleic acid (18:1(n-9), OIA) and is synthesized when there are not enough EFAs to "occupy" the $\Delta-6$ desaturase (see also figure 1). Because an adequate supply of either LA, LnA or their derived LCPS prevents synthesis of MA, the presence of MA indicates a general shortage of all parent and derived essential fatty acids. The ratio triene/tetraene (MA/AA) is often used as an essential fatty acid deficiency marker (19).

Another essential fatty acid deficiency marker is Osmond acid (22:5(n-6), OA). If there is an isolated shortage of cervonic acid, the production of $\mathrm{OA}$ increases, which is the "surrogate" fatty acid for cervonic acid. Since the synthesis of OA also depends on the availability of its precursor, adrenic acid $(22: 4(n-6), A d A)$, the ratio $22: 5(n-$ 6)/22:4(n-6) (Cervonic acid deficiency index, CADI) is considered a reliable marker of a cervonic acid deficiency (20).

\section{The essential fatty acid status of pregnant women and their newborns}

Differences in the concentration of plasma lipids between pregnant women and their infants at birth were recognized as early as 1912 by Hermann and Newmann (21). It was, however, not until the early sixties that differences in plasma levels between the mother and her newborn infant for fatty acids were reported. The fatty acid composition of the newborn was characterized by lower levels of linoleic acid (18:2(n-6), LA) and $\alpha$-linolenic acid (18:3(n-3), LnA) and higher levels of arachidonic acid (20:4(n-6), AA) and cervonic acid (22:6(n-3), CA) (22-26). Crawford et al (26) demonstrated with guinea pigs that in the phospholipids the concentrations of $\mathrm{LA}$ and $\mathrm{LnA}$ diminished and those of their derived long chain polyenes (LCPs) increased from the maternal liver, to placenta, fetal liver and finally

(2) In the literature, timnodonic acid and cervonic acid are frequently referred to as eicosapentaenoic acid (EPA) and docosahexaenoic acid (DHA), respectively. 


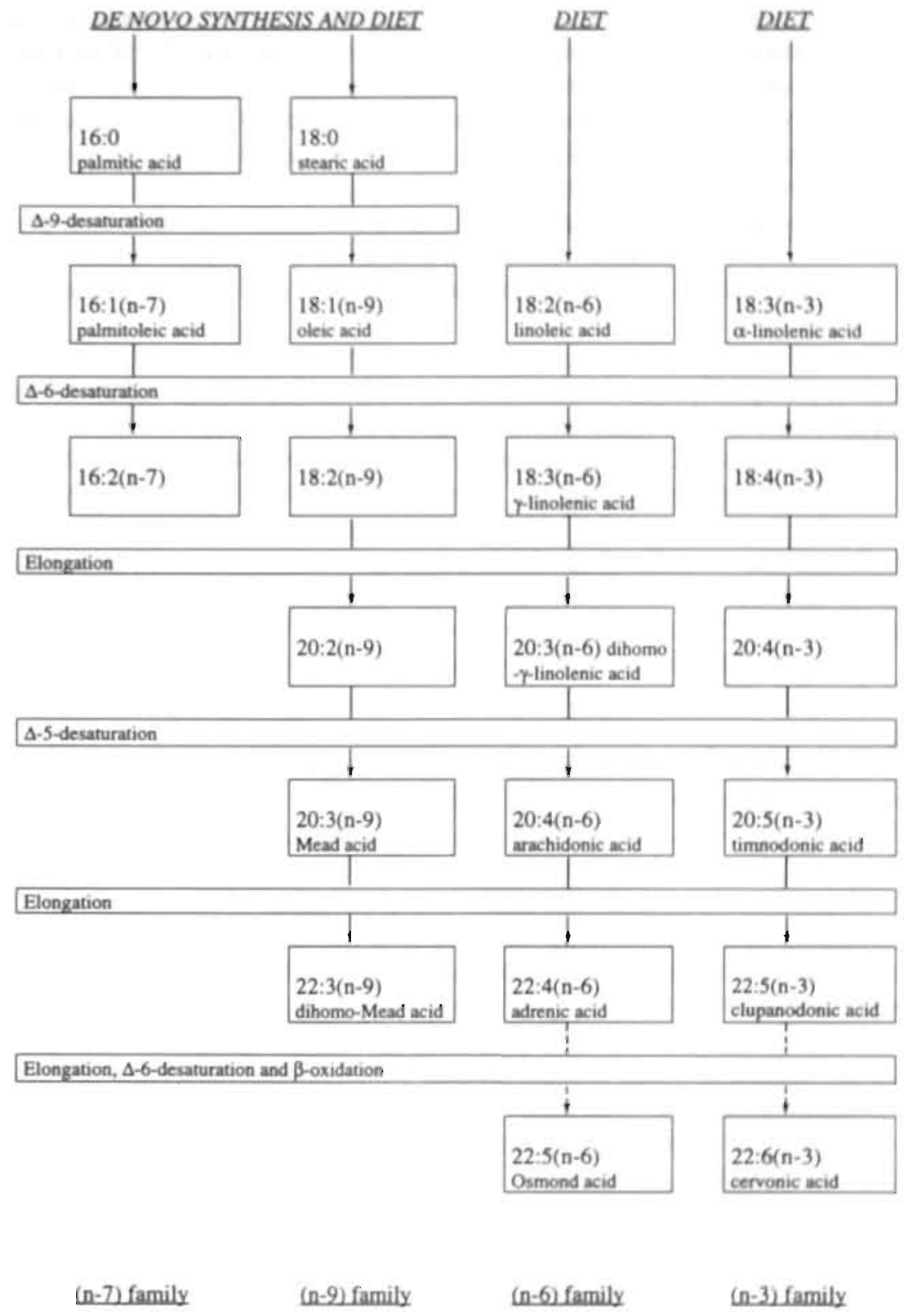

Figure 1. The main pathway of fatty acid synthesis and interconversion. 
the brain. Observations in man suggested a similar trend: the proportion of LA and LnA decreased and of the (n-6) and (n-3) LCPs increased in the phospholipids from maternal blood, cord blood, fetal liver and fetal brain. The term "biomagnification" (26) has been used to describe this increase in (n-6) and (n-3) LCPs. It is, however, not exactly known in which way the fetus does obtain its essential fatty acids $(12,27)$. The fetus can derive them from the maternal circulation by passage across the placenta, by metabolism within the placenta, or by synthesis in fetal liver. Because the fetus cannot synthesize the parent EFAs ( $L A$ and $L n A$ ), these fatty acids must be derived from the maternal circulation. Since fatty acid synthesis in human placenta and fetal tissue is probably rather low (28-31), it is likely that most of the fetal (n-6) and (n-3) LCPs are derived from the maternal circulation by placental transfer.

Fatty acids are transported in blood either as free fatty acids, or in the form of triglycerides, phospholipids or cholesterol-esters. The relative importance of each of the potential sources to the total transfer of (n-6) and (n-3) fatty acids is not known (for a review: see ref. 12). It has been shown that free fatty acids may cross the placenta in either direction but that the movement of phospholipids and triglycerides may be restricted or absent $(12,27,29,32,33)$. This may be important in light of the biomagnification process. One hypothesis to explain the concentration gradient of ( $\mathrm{n}$ 6) and (n-3) LCPs (biomagnification process) is that at the fetal side of the placenta the $(\mathrm{n}-6)$ and $(\mathrm{n}-3)$ LCPs are compartmentalized in a lipid fraction which cannot recross the placental barrier and will, therefore, be preserved to ensure an appropriate fetal development $(31,34,35)$.

Hornstra et al (36) determined the fatty acid composition of the walls of umbilical vein and arteries. Since these blood vessels do not have vasa vasorum, they receive their EFAs from the blood they contain and, consequently, the vascular wall fatty acid composition may be considered a longer term reflection of the EFA status of the fetal supply (vein) and return (arteries). Relatively high amounts of Mead acid (20:3(n-9), MA) were observed in vessel wall phospholipids from cord arteries, in contrast to the fatty acid composition of adult colonic arteries which did hardly contain MA. This led to the suggestion that the EFA status of neonates may not be adequate. Moreover, the ratio between 22:5(n-6) and 22:4(n-6) (CADI) was found to be much higher in umbilical cord than in adult colonic vessel walls, suggesting a fetal shortage of cervonic acid as well (36). These observations may imply that the essential fatty acid requirement of the fetus is not adequately covered. Crawford et al $(37,38)$ observed the highest concentration of MA and 22:5(n-6)/22:4(n-6) ratio in the umbilical artery of the lowest birht weight baby and suggested that there was more than a physiological demand at stake. To further elucidate these findings, more information has to be obtained on the maternal EFA status, because the developing fetus depends on the mother for an adequate supply of EFAs. 


\section{Outline of the thesis}

The aim of this thesis is to investigate the EFA composition of the maternal diet and the maternal EFA status in relation to the neonatal EFA status and the outcome of pregnancy. First, the neonatal EFA status in relation to the maternal EFA status at delivery was studied (Chapter 2). For the assessment of the EFA status, the fatty acid composition of phospholipids (PLs) from plasma, blood cells, placental tissue and/or umbilical cord vessel walls was determined. Since, in general, PLs have a slower turnover than free fatty acids, triglycerides and cholesterolesters, the EFA profile of PLs is considered suitable to document the overall EFA status of a given individual $(39,40)$.

In situations where the placenta function is impaired, the transfer of nutrients from mother to fetus may be insufficient. To what extent the neonatal EFA status was affected by such an event was studied in cases with pregnancy-induced hypertension $(\mathrm{PIH})$, which is, in a high percentage, characterized by a reduced uteroplacental perfusion and function (41) (Chapter 3).

The results of these two initial studies led to the main study of this thesis, which is described in the following Chapters.

Hardly any information is available on the maternal EFA status throughout normal pregnancy. Rosing et al (42) described the fatty acid composition of serum lecithin from twenty pregnant women in the second half of normal pregnancy. Although most of the $(n-6)$ and $(n-3)$ fatty acids remained constant between 24 and 36 weeks of pregnancy (linoleic acid showed a slight decrease till the end of gestation) it cannot be excluded that in the first half of pregnancy major changes took place. Moreover, no data were available on the nutrient intake of these women. As it has been shown that fatty acid metabolism is under influence of dietary factors (4), changes in maternal diet can have an effect on the fatty acid composition of serum lipids. Furthermore, it is important to know how the plasma fatty acid levels of pregnant women are related to their fatty acid intake during pregnancy. In Chapter 4 the EFA composition of the maternal diet throughout normal pregnancy is described. Because the Netherlands Nutrient Databank (43) provides only data on one essential fatty acid, linoleic acid, the analyses are restricted to total fat, saturated fat, monounsaturated fat, polyunsaturated fat and linoleic acid. More detailed information on the course of the maternal EFA status during normal pregnancy is reported in Chapter 5. In that study, from 110 pregnant women a blood sample was taken regularly from the 10th week of gestation until delivery. A subsample of 43 women gave also a blood sample approximately six months after delivery. In addition, data on the neonatal EFA status was collected. The results confirmed again the marginal EFA status of newborn infants. 
As is shown in Chapter 3 and by others (44-46), PIH is associated with alterations in the maternal EFA status. However, these studies share the disadvantage that they are retrospective case-control studies with small number of subjects and using material collected in late pregnancy or post-partum. As a consequence, no information is available whether the alteration of the EFA status took place before or after the development of PIH. Therefore, a prospective longitudinal study was started to investigate the relationship between the EFA status of mother and child and the occurrence of PIH. The results of this study are given in Chapter 6.

To study if maternal supplementation during pregnancy with linoleic acid (18:2(n-6), LA) could be useful in improving the fetal EFA status, pregnant women were supplemented with approximately 10 gram LA per day from the 20th week of gestation, until delivery. The results are described in Chapter 7 and compared with two control groups, in which no intervention took place. One control group consisted of pregnant women with habitual low plasma LA levels and the other of pregnant women with habitual high plasma LA levels.

Finally, the overall conclusions and the implications for further research are discussed in Chapter 8.

\section{REFERENCES}

1. Burr GO, Burr MM. Deficiency disease, produced by the rigid exclusion of fat from the diet. $\mathbf{J}$ Biol Chem 1929; 82: 345-67.

2. Burr GO, Burr MM. On the nature and role of the fatty acids essential in nutrition. J Biol Chem 1930; 86: 587-621.

3. Hornstra G. Biochemical physiology of dietary fats. In: Dietary fats and arterial thrombosis. PhD Thesis, University of Limburg, Maastricht, The Netherlands, 1980: 8-32.

4. Brenner RR. Nutritional and hormonal factors influencing desaturation of essential fatty acids. Prog Lipid Res 1981:20:41-7.

5. Holman RT. Nutritional and biochemical evidences of acyl interaction with respect to essential polyunsaturated fatty acids. Prog Lipid Res 1986: 25: 29-39.

6. Hansen HS. Jensen B. Essential function of linoleic acid esterified in acylglucosylceramide and acylceramide in maintaining the epidermal water permeability barrier. Evidence from feeding studies with oleate, linoleate, arachidonate, columbinate and $\alpha$-linolenate. Biochim Biophys Acta $1985 ; 834: 357-63$.

7. Hansen HS. The essential nature of linoleic acid in mammals. TIBS 1986; 11:263-5.

8. Bergstrum S, Danielsson $H$, Samuelsson $B$. The enzymatic formation of prostaglandin $E_{2}$ from arachidonic acid. Biochim Biophys Acta 1964; 90: 207-10.

9. Dorp DA van, Beerthuis RK, Nugteren DH, Vonkeman H. The biosynthesis of prostaglandins. Biochim Biophys Acta 1964; 90: 204-7.

10. Svennerholm L. Distribution and fatty acid composition of phosphoglycerides in normal human brain. J Lipid Res 1968; 9: 570-9.

11. Sastry PS. Lipids of nervous tissue: composition and metabolism. Prog Lipid Res 1985; 24: 69176. 
12. Innis SM. Essential fatty acids in growth and development. Prog Lipid Res 1991;30: 39-103.

13. Struyck CB, Beerthuis RK, Pabon HJJ, Dorp van DA. Specificity of the enzyme conversion of polyunsaturated fatty acids into prostaglandins. Recl Trav Chim Pays-Bas 1966; 85: 1233-50.

14. Fliesler SJ, Anderson RE. Chemistry and metabolism of lipids in the vertebrate retina. Prog Lipid Res 1983; 22: 79-131.

15. Galli C, Socini A. Dietary lipids in pre- and post-natal development. In: Perkins EG, Visek WJ, eds. Dietary fats and health. Champaign (IL): Am Oil Chem Soc 1983; 16: 278-301.

16. Clandinin MT, Chappell JE, Leong S, Heim T, Swyer PR, Chance GW. Intrauterine fatty acid rates in human brain: implications for fatty acid requirements. Early Hum Dev 1980; 4 : 121-9.

17. Martinez M. Tissue levels of polyunsaturated fatty acids during early human development. J Pediatr 1992;120: S129-38.

18. Clandinin MT, Chappell JE, Heim T, Swyer PR, Chance GW. Fatty acid accretion in fetal and neonatal liver: implications for fatty acid requirements. Early Hum Dev 1980; 5: 1-6.

19. Holman RT. The ratio of trienoic:tetraenoic acids in tissue lipids as a measure of essential fatty acid requirement. J Nutr 1960; 70: 405-10.

20. Holman RT. The deficiency of essential fatty acids. In: Kunau W, Holman RT, eds. Polyunsaturated fatty acids. Champaign (IL): Am Oil Chem Soc 1977; 4: 163-82.

21. Hermann E, Newmann J. Über den lipoid-gehalte des blutes normaler und schwanger fraten sowie neugeborener kinder. Biochem Ztschr 1912; 43:47-51.

22. Hansen AE, Wiese HF, Adam DJD, et al. Influence of diet on blood serum lipids in pregnant women and newborn infants. Am J Clin Nutr 1964: 15: 11-9.

23. Berg Hansen I, Friis-Hansen B, Clausen J. The fatty acid composition of umbilical cord serum. infan serum and maternal serum and its relation to the diet. Zeitschrift fur Ernihnungswissenschaft 1969; 9: 352-63.

24. Olegård R, Svennerholm L. Fatty acid composition of plasma and red cell phosphoglycerides in full term infants and their mothers. Acta Pædiat Scand 1970; 59: 637-47.

25. Friedman Z, Danon A. Lamberth EL. Mann WJ. Cord blood fatty acid composition in infants and in their mothers during the third trimester. J Pediatr 1978; 92: 461-6.

26. Crawford MA, Hassam AG. Williams G. Essential fatty acids and fetal brain growth. Lancet 1976; i: 452-3.

27. Coleman RA. The role of the placenta in lipid metabolism and transport. Sem Perinat 1989; 13: 180-91.

28. Zimmerman T, Hummel L, Moller U, Kinzl U. Oxidation and synthesis of fatty acids in human and rat placental and fetal tissues. Biol Neonate 1979; 36: 109-12.

29. Booth C. Elphick MC. Hendrickse W. Hull D. Investigation of $\left[{ }^{14} \mathrm{C}\right]$ linoleic acid conversion into $\left[{ }^{14} \mathrm{C}\right]$ arachidonic acid and placental transfer of linoleic and palmitic acids across the perfused human placenta. J Dev Physiol 1981; 3:177-89.

30. Chambaz. J, Ravel D, Manier M-C, Pepin D, Mulliez N, Bereziat G. Essential fatty acids interconversion in the human fetal liver. Biol Neonate 1985; 47: 136-40.

31. Kuhr DC, Crawford MA. Placental essential fatty acid transport and prostaglandin synthesis. Prog Lipid Res 1986; 25: 345-53.

32. Huli D, Elphick MC. In: Chamberlain G, Wilkinson A, eds. Placental transfer. London: Pitman, 1979: 159-65.

33. Elphick MC, Filshie GM, Hull D. The passage of fat emulsion across the human placenta. $\mathrm{Br}$ J Obstet Gynaecol 1978; 85: 610-8.

34. Robertson AF, Sprecher H. A review of human placental lipid metabolism and transport. Acta Pædiat Scand 1968; suppl. 183: 1-18.

35. Kuhn DC, Crawford MA, Stuart MJ, Botti JJ, Demers LM. Alterations in transfer and lipid distribution of arachidonic acid in placentas of diabetic pregnancies. Diabetes 1990; 39: 914-8.

36. Hornstra G, van Houwelingen AC. Simonis M, Gerrard JM. Fatty acid composition of umbilical arteries and veins: possible implications for the fetal EFA status. Lipids 1989; 24: 511-7. 
37. Crawford MA, Doyle W, Drury P, Lennon A, Costeloe, Leighfield M. N-6 and N-3 fatty acids during early human development. J Int Med 1989; 225 (suppl. 1): 159-69.

38. Crawford MA, Costeloe K, Doyle W, Leighfield MJ, Lennon EA., Meadows N. Potential diagnostic value of the umbilical artery as a definition of neural fatty acid status of the fetus during its growth: the umbilical artery as a diagnostic tool. Biochem Soc Trans 1990; 18: 761-6.

39. Holman RT. Control of polyunsaturated acids in tissue lipids. J Am Coll Nutr 1986; 5: 183-211.

40. Hornstra G. Essential fatty acids, pregnancy, and pregnancy complications: a roundtable discussion. In: Sinclair A, Gibson R, eds. Essential fatty acids and eicosanoids. Champaign (IL): Am Oil Chem Soc, 1992: 177-82.

41. Brown MA. Pregnancy-induced hypertension: current concepts. Review. Anaesth Intens Care 1989; 17: 185-97.

42. Rosing U, Johnson P, Ölund A, Samsioe G. Relative fatty acid composition of serum lecithin in the second half of the normal pregnancy.Gynecol Obstet Invest 1982; 14:225-35.

43. NEVO Table. Nederlandse voedingsstoffenbestand 1989/1990. Voorlichtingsbureau voor de Voeding, Den Haag 1989. (Netherlands food composition table: in Dutch).

44. Rosing U, Johnson P, Ölund A, Samsioe G. The fatty acid composition of serum lecithin after pregnancy complicated by preeclampsia. Arch Gynecoll 1984; 236: 109-17.

45. Ogburn PL, Turner SI, Williams PP. Johnson SB, Holman RT. Essential fatty acid patterns in precclampsia. Zentraibl Gynăkol 1986; 108: 983-9.

46. Wang Y, Kay HH, Killam AP. Decreased levels of polyunsaturated fatty acids in preeclampsia. Am J Obstet Gynecol 199I; 164: 812-8. 


\title{
CHAPTER 2 \\ Biochemical EFA status of mothers and their neonates after normal pregnancy
}

Monique D.M. Al, Gerard Hornstra, Yvonne T. van der Schouw, Marèse T.E.W. Bulstra-Ramakers and Henk J. Huisjes

Early Human Development 1990; 24: 239-248

\begin{abstract}
The essential fatty acid (EFA) status of neonates was compared with that of theif mothers by determining the fatty acid compositions of phospholipids (PL), isolated from umbilical arterial and venous tissue, blood cells (BC) and plasma, from maternal venous plasma and $\mathrm{BC}$, and from non-infarcted placental tissue.

The PL of umbilical arterial tissue (efferent fetal vessels) contained fewer fatty acids of the (n-6) family and more of the (n-9) family than umbilical venous tissue (afferent fetal vessel). The relative amounts of $(n-6)$ and (n-3) fatty acids were less in arterial than in venous plasma. Mead acid, 20:3(n-9), the presence of which indicates a poor EFA status, was 5 times higher in the efferent than in afferent cord vessels. In neonatal plasma and $\mathrm{BC}$ it was twice as high as compared with maternal levels. In general, the fatty acid composition of the placenta PL showed a comparable pattern as neonatal venous plasma PL.

These findings demonstrate that the biochemical EFA status of neonates after a normal pregnancy is not optimal. The significant correlations between neonatal and matemal EFAs indicate that the neonatal EFA status depends on the EFA content of the maternal diet.
\end{abstract}




\section{INTRODUCTION}

During the last trimester of pregnancy, fetal demands for long-chain polyunsaturated fatty acids (LCPs), especially 20:4(n-6) (arachidonic acid, AA) and 22:6(n-3) (cervonic acid, $\mathrm{CA}$ ) are high (1). AA and CA are the chain-elongated and desaturated products of the essential fatty acids (EFAs) 18:2(n-6) (linoleic acid, LA) and 18:3(n-3) $(\alpha$-linolenic acid), respectively. Since man is unable to synthesize these essential fatty acids, fetal EFAs and their long chain derivatives are ultimately derived from the maternal diet.

LCPs of the (n-3) and (n-6) families comprise $20-25 \%$ of the brain fatty acids, largely as constituents of cellular membranes $(2,3)$. Brain growth takes mainly place before birth and, therefore, it is important that the availability of essential fatty acids and their longer chain, more unsaturated derivatives is guaranteed during the development of the human fetus.

In an earlier study (4) we demonstrated that under normal conditions the EFA status of neonates may be marginal. The phospholipids of the umbilical arteries (efferent fetal vessels) were shown to contain significantly less fatty acids of the linoleic (n-6) and linolenic acid (n-3) families and more of the oleic acid (n-9) family than the umbilical vein (afferent fetal vessel). Elevated levels of (n-9) fatty acids in combination with reduced amounts of LA and AA indicate a possible EFA deficiency $(5,6)$.

The aim of the present investigation is not only to verify' our earlier results which were based on a relatively small set of samples and restricted to cord tissue only, but mainly to extend our knowledge about the fetal EFA status and its relation to the maternal EFA status. Therefore, we also determined the relative fatty acid composition of phospholipids (PL), isolated from umbilical venous and arterial plasma and blood cells $(\mathrm{BC})$, from non-infarcted placental tissue and from maternal venous plasma and $\mathrm{BC}$.

\section{MATERIAL AND METHODS}

\section{Study population}

The study group comprised 15 healthy women and their neonates ( 8 girls and 7 boys). The mean age of the mothers was 27 years (range 20-33 years). All mothers gave their informed consent. Umbilical vessel walls and placentas were obtained frorn 13 persons only. The two other placentas and umbilical vessel walls had to be sent to the pathological-anatomical laboratory for examination, because one mother had a manual placenta removal and the other had an extra placenta. All pregnancies were uncomplicated and the infants were all born at term (mean 40 weeks, range $38-41$ weeks) after vaginal delivery. The mean birthweight was $3451 \mathrm{~g}$ (range 3125-4185 g). 
There were no differences between the birthweight of boys and girls. The Apgar score 1 minute after birth was 9 (range 6-10) and 3 minutes after birth 10 (range 9-10). Maternal blood was taken under nearly fasting conditions (mothers had not been eating and aimost did not drink during labor). Umbilical venous and arterial blood was collected separately, immediately after the cord had been clamped. Shortly after birth, placentas and cord vessels were rinsed with cold saline and frozen at $-30^{\circ} \mathrm{C}$ until further treatment. In a small subset of 5 mothers, venous plasma and $\mathrm{BC}$ were also collected approximately ten days before delivery (this blood was taken under conditions of complete fasting). Fatty acid compositions were compared with those just after delivery, to investigate possible fatty acid changes due to labor. There were no significant differences observed.

All material was collected at the Department of Obstetrics and Gynaecology, State University of Groningen, The Netherlands and transported to Maastricht.

\section{Biochemical analyses}

The plasma was separated from the blood cells by centrifugation and after plasma collection, the $\mathrm{BC}$ were washed with physiological saline. Plasma and $\mathrm{BC}$ were frozen and stored at $-30^{\circ} \mathrm{C}$ until lipid extraction.

The placentas were cut into pieces for homogenization. An EDTA/NaCl-solution (Na2-EDTA-2 $\mathrm{H}_{2} \mathrm{O} 28.64 \mathrm{~g}, \mathrm{NaCl} 7.00 \mathrm{~g}, \mathrm{H}_{2} \mathrm{O} 1000.0 \mathrm{ml}$ ) was added to the placentas $(w / v=1 / 1)$, after which they were homogenized in a blender. Umbilical cord vessels were homogenized according to the method described earlier (4).

Total lipid extraction was performed as described by Bligh and Dyer (7). The PL fraction was separated by thin layer chromatography according to van der Vusse et al (8). The PL fraction was hydrolyzed and the fatty acids were methylated with borontrifluoride. The fatty acid composition of the PL was then determined by gas liquid chromatography, as described by Rand et al (9).

\section{Statistical analyses}

Wilcoxon's signed rank test was used for statistical analyses. The relation between the fatty acids of maternal and umbilical venous plasma or umbilical vessel wali phospholipids was studied by linear regression analyses, and Pearson's correlation coefficients were calculated.

\section{RESULTS}

Fatty acid composition data (area \% of total fatty acids) are given in Tables 1 and 2. For clarity, data are mainly presented for those fatty acids or fatty acid combinations which reflect the EFA status.

The resuits of cord vessels walls (Table 1) largely confirm earlier data (4): the umbilical arteries (UA) contained relatively fewer fatty acids of the essential (n-6) family and more of the non-essential (n-7) and (n-9) families than the umbilical vein 
Table I. Fatty acid composition (area \% of total fatty acids) of umbilical artery (UA) and vein (UV) vessel wall and arterial blood cell (BC) phospholipids (mean \pm s.e.m.).

\begin{tabular}{|c|c|c|c|}
\hline Fatty acidq & $\begin{array}{l}\text { UA } \\
(n=13)\end{array}$ & $\begin{array}{l}\text { UV } \\
(n=13)\end{array}$ & $\begin{array}{l}\mathrm{BC}(\mathrm{A}) \\
(\mathrm{n}=15)\end{array}$ \\
\hline $20: 5(n-3)$ & nd $\S$ & nd & $0.2 \pm 0.03$ \\
\hline $22: 5(\mathrm{n}-3)^{\#}$ & $0.4 \pm 0.22$ & $0.6 \pm 0.08^{a}$ & $1.8 \pm 0.37$ \\
\hline $22: 6(n-3)(C A)$ & $4.7 \pm 0.19$ & $4.5 \pm 0.18$ & $4.7 \pm 0.27$ \\
\hline$\Sigma(n-3)$ & $5.2 \pm 0.28$ & $5.3 \pm 0.20$ & $7.0 \pm 0.48$ \\
\hline $18: 2(n-6)(L / A)$ & $1.9 \pm 0.06$ & $2.8 \pm 0.16^{b}$ & $5.9 \pm 0.57$ \\
\hline $20: 3(n-6)$ & $1.5 \pm 0.10$ & $2.0 \pm 0.06^{b}$ & $2.1 \pm 0.16$ \\
\hline $20: 4(n-6)(A A)$ & $11.4 \pm 0.47$ & $15.9 \pm 0.50^{b}$ & $14.0 \pm 0.71$ \\
\hline $22: 4(n-6)$ & $3.1 \pm 0.20$ & $5.2 \pm 0.35^{b}$ & $4.0 \pm 0.27$ \\
\hline $22: 5(n-6)(O A)$ & $3.5 \pm 0.15$ & $3.3 \pm 0.17$ & $1.4 \pm 0.07$ \\
\hline$\sum(n-6)$ & $21.5 \pm 0.76$ & $29.2 \pm 0.57^{b}$ & $27.5 \pm 0.87$ \\
\hline$\Sigma(n-6) L C P s$ & $19.6 \pm 0.72$ & $26.4 \pm 0.53^{b}$ & $21.6 \pm 1.06$ \\
\hline $20: 3(n-9)(M A)$ & $3.3 \pm 0.25$ & $0.7 \pm 0.08^{b}$ & $0.6 \pm 0.06$ \\
\hline $22: 3(n-9)$ & $1.5 \pm 0.11$ & $0.4 \pm 0.06^{b}$ & $0.3 \pm 0.05$ \\
\hline$\sum[(\mathrm{n}-7)+(\mathrm{n}-9)]$ & $28.1 \pm 0.85$ & $19.4 \pm 0.36^{b}$ & $19.4 \pm 0.85$ \\
\hline$\sum$ PUFA & $31.5 \pm 0.60$ & $36 . \mathrm{I} \pm 0.55^{\mathrm{b}}$ & $35.6 \pm 1.06$ \\
\hline$\Sigma$ MUFA & $23.4 \pm 0.55$ & $17.9 \pm 0.27 \mathrm{~b}$ & $18.3 \pm 0.85$ \\
\hline$\sum$ SAFA & $40.3 \pm 0.32$ & $41.5 \pm 0.35^{\mathrm{a}}$ & $41.9 \pm 0.64$ \\
\hline EFA def.index & $0.3 \pm 0.03$ & $0.04 \pm 0.01^{b}$ & $0.04 \pm 0.01$ \\
\hline CADI & $1.2 \pm 0.07$ & $0.7 \pm 0.06^{\mathrm{b}}$ & $0.4 \pm 0.03$ \\
\hline
\end{tabular}

1: (n-6) LCPs, (n-6) long chain polyunsaturated fatty acids; S.AF A, saturated fatty acids; MUFA, monounsaturated fatty acids; PUFA, polyunsaturated fatty acids; EFA def. index, 20:3(n-9)/20:4(n-6); CADI, Cervonic acid deficiency index: 22:5(n-6)/22:4(n-6).

§: nd, not detectable.

\#: plus 24:2(n-6) as a minor component.

a: significant difference from arterial values $0.01<p<0.05$; b: significant difference from arterial values $0.001<p<0.01$.

(UV). The proportions of Mead acid (MA) and of its elongation product dihomoMead acid in the UA PL, the presence of which in adults indicates EFA deficiency, were four to five times that in the UV PL, whereas the proportion of arachidonic acid (AA) was lower. Consequently, the ratio MA:AA, the EFA deficiency index, was eight times that in the vein, indicating a considerable deficiency of EFA in the arterial wall. The cervonic acid deficiency index (CADI), given by the ratio of the proportion of the Osmond acid $(\mathrm{OA})$ to its immediate precursor, was also raised in UA wall PL 
Table 2. Fatty acid composition (area \% of total fatry acids) of fetal arterial (PA) and venous plasma (PV). placenta and maternal venous plasma (PM) phospholipids (mean \pm s.e.m.). For abbrevations, see Table 1.

\begin{tabular}{|c|c|c|c|c|}
\hline Fatty acidף & $\begin{array}{l}\text { PA } \\
(n=15)\end{array}$ & $\begin{array}{l}P V \\
(n=15)\end{array}$ & $\begin{array}{l}\text { Placenta } \\
(n=13)\end{array}$ & $\begin{array}{l}P M \\
(n=15)\end{array}$ \\
\hline $20: 5(n-3)$ & $0.7 \pm 0.23$ & $0.5 \pm 0.14$ & $0.1 \pm 0.02$ & $0.5 \pm 0.04$ \\
\hline $22: 5(n-3)^{\#}$ & $1.1 \pm 0.09$ & $1.4 \pm 0.17$ & $1.3 \pm 0.06$ & $0.7 \pm 0.03$ \\
\hline $22: 6(n-3)(C A)$ & $6.1 \pm 0.39$ & $6.7 \pm 0.41$ & $4.8 \pm 0.26$ & $3.9 \pm 0.23$ \\
\hline$\Sigma(n-3)$ & $7.9 \pm 0.39$ & $8.6 \pm 0.40^{\mathrm{a}}$ & $6.3 \pm 0.28$ & $5.7 \pm 0.22$ \\
\hline $18: 2(n-6)(L A)$ & $7.5 \pm 0.42$ & $7.8 \pm 0.30$ & $9.5 \pm 0.29$ & $23.1 \pm 0.55$ \\
\hline $20: 3(n-6)$ & $4.4 \pm 0.29$ & $4.9 \pm 0.3 \mathrm{t}^{\mathrm{a}}$ & $4.3 \pm 0.25$ & $2.9 \pm 0.20$ \\
\hline $20: 4(n-6)$ & $18.6 \pm 0.48$ & $19.8 \pm 0.52^{\mathrm{a}}$ & $21.1 \pm 0.34$ & $9.4 \pm 0.46$ \\
\hline $22: 4(n-6)$ & $1.9 \pm 0.36$ & $1.4 \pm 0.12$ & $1.6 \pm 0.10$ & $0.5 \pm 0.03$ \\
\hline $22: 5(n-6)(O A)$ & $1.4 \pm 0.12$ & $1.3 \pm 0.13$ & $1.0 \pm 0.06$ & $0.7 \pm 0.06$ \\
\hline$\Sigma(n-6)$ & $34.1 \pm 0.76$ & $35.6 \pm 0.82$ & $37.6 \pm 0.35$ & $36.8 \pm 0.66$ \\
\hline$\Sigma(n-6)$ LCPs & $26.6 \pm 0.81$ & $27.7 \pm 0.69$ & $28.1 \pm 0.38$ & $13.6 \pm 0.58$ \\
\hline $20: 3(n-9)(M A)$ & $0.9 \pm 0.11$ & $0.9 \pm 0.13$ & $0.2 \pm 0.03$ & $0.5 \pm 0.12$ \\
\hline$\Sigma[(n-7)+(n-9)]$ & $15.3 \pm 0.47$ & $15.2 \pm 0.56$ & $12.1 \pm 0.26$ & $15.7 \pm 0.42$ \\
\hline$\Sigma$ PUFA & $43.2 \pm 0.90$ & $45.6 \pm 0.97^{\mathrm{a}}$ & $44.4 \pm 0.28$ & $43.5 \pm 0.77$ \\
\hline$\sum$ MUFA & $14.0 \pm 0.37$ & $13.7 \pm 0.46$ & $11.6 \pm 0.26$ & $14.7 \pm 0.45$ \\
\hline$\sum$ SAFA & $42.4 \pm 0.87$ & $40.4 \pm 0.96$ & $39.4 \pm 0.28$ & $41.3 \pm 1.17$ \\
\hline EFA def. index & $0.05 \pm 0.01$ & $0.05 \pm 0.01$ & $0.01 \pm 0.00$ & $0.06 \pm 0.01$ \\
\hline CADI & $1.0 \pm 0.16$ & $1.1 \pm 0.17$ & $0.6 \pm 0.04$ & $1.4 \pm 0.13$ \\
\hline
\end{tabular}

compared to that in the vein. In contrast, there was no significant difference in the fatty acid composition of PL from the cells (BC) of UV and UA blood (data for $\mathrm{BC}(\mathrm{V})$ not shown), and, as shown in Table 1, this was closer to that of the UV wall than that of the arteries. The differences between UA and UV plasma were also small (Table 2) and the proportions of individual acids were, in general, of the same order as in the PL of non-infarcted placental tissue. However, as shown in Table 2 and Figure 1 , the fatty acid composition of PL from maternal plasma was very different from that in the fetus. The relative amount of linoleic acid (LA) was three times that in cord plasma PL, whereas those of AA, cervonic acid (CA) and its precursor were only half the fetal levels $(P<0.001)$. As expected, the proportion of MA, and hence the EFA deficiency index, were low in maternal plasma PL.

On examing results from individual pregnancies, it was clear that the composition of the fetal plasma PL varied with that of the maternal plasma PL. Not only were there 


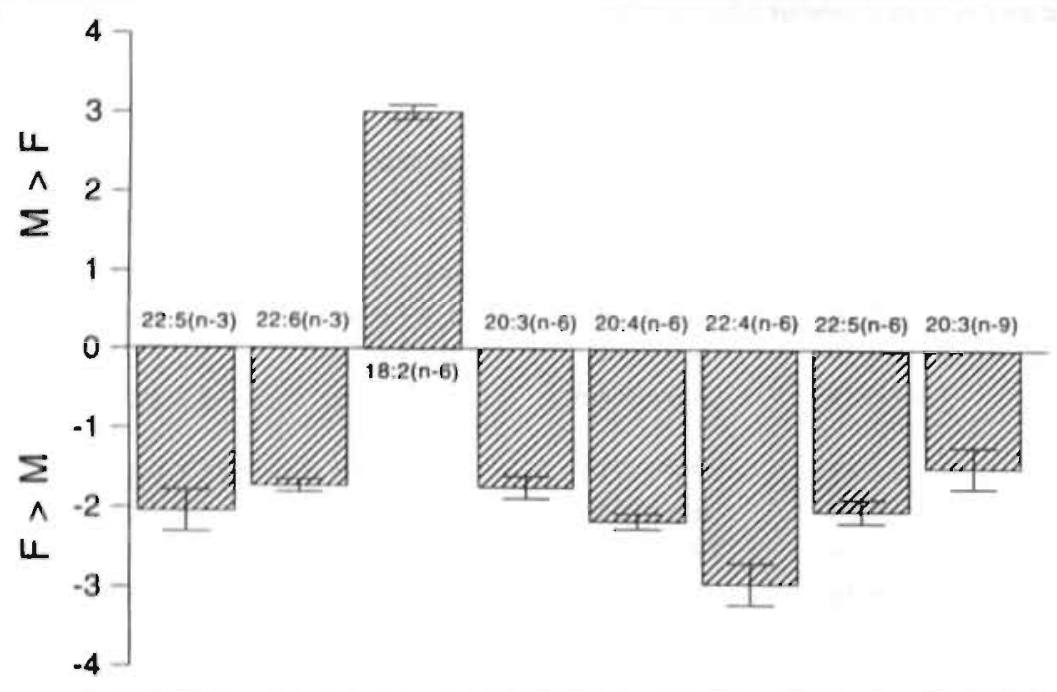

Figure 1. Ratios between maternal $(M)$ and fetal $(F)$ fatty acid conients in venuus plasma phospholipids (mean \pm s.e.m.; $n=15$ ).
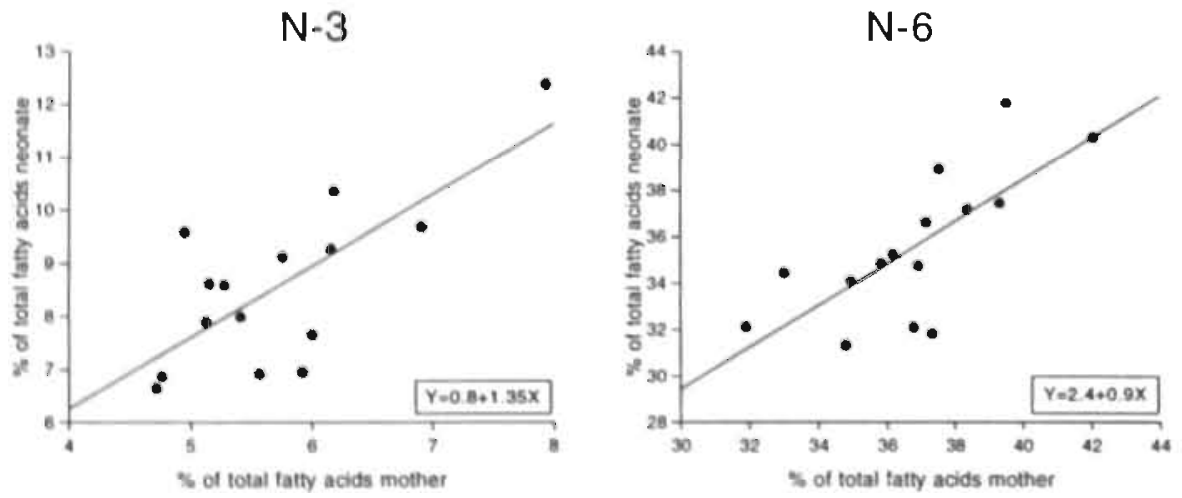

Figure 2. The relationship benween the sum of the (n-3) or $(n-6)$ fatty acids in the venous plasmat phospholipids of neonates and that of their mothers.

$\Sigma(n-3): r=0.74, p=0.002, n=15 ; \Sigma(n-6): r=0.73, p=0.002, n=15$. 
significant positive correlations $(\mathrm{P}<0.01)$ between mother and fetus for the sum of the (n-3) and (n-6) fatty acids (Figure 2), but also for some specific saturated and mono-unsaturated fatty acids and for CA, LA and OA (results not shown).

\section{DISCUSSION}

The present investigation confirms and extends the results of our previous study (4), in which evidence was obtained for a marginal EFA status of the newborn. The efferent blood vessel walls have lower proportions of LA and AA and higher relative amounts of 20:3(n-9) (Mead acid, MA) and its elongation product 22:3(n-9) than the afferent blood vessel wall.

Ongari et al (10) also observed MA in the umbilical artery. MA was rarely observed in adult blood vessels and 22:3(n-9) was not observed at all (4). Because the various fatty acids compete for the same enzymic elongation-desaturation system, the amounts of linoleic and $\alpha$-linolenic acid were apparently insufficient to occupy the $\Delta-6$ desaturase, which allows oleic acid to become converted to Mead acid (20:3(n-9), MA). Therefore Mead acid and its elongation product 22:3(n-9) are considered reliable markers of an essential fatty acid deficiency (6).

It should be realized that all our data refer to relative fatty acid compositions; consequently, an increase of one fatty acid inevitably means a decrease of at least one other fatty acid. Such errors can be magnified enormously when ratios are used, if the numerator and denominator are affected in opposite directions. Therefore, all ratios presented have to be seen in this light. For further studies, absolute fatty acid composition measurements are required to understand more about placental transfer and fetal uptake of EFAs and their metabolites.

The classical biochemical indicator of a borderline EFA status is the EFA deficiency index, given by the ratio between Mead acid and arachidonic acid (MA/AA ratio). A value of 0.2 or more in human serum PL is considered as the upper limit of normality (11). The EFA deficiency index in arterial tissue is 0.3 (Table 1), which supports the idea that the neonatal EFA status is poor indeed, from a biochemical point of view. The EFA deficiency indeces in fetal BC (Table 1) and plasma (Table 2) do not indicate an EFA deficiency. This seems in contrast to the findings for umbilical arterial tissue, but it should be realized that during each passage of the placenta, the fetal blood will take up new maternal EFAs. Consequently, only small arterio-venous differences are to be expected in the EFA status of circulating blood. This applies to phospholipids in particular, the turn-over rate of which is much lower as compared to free fatty acids. Since the walls of umbilical arteries are exclusively in contact with arterial (efferent) blood, any minor deviation from an optimal fatty acid composition in the blood will be "added up" in the arterial walls and, consequently, this tissue gives a more reliable and longer-term reflection of the average EFA status of the 
arterial blood than the post-partum blood itself. This consideration, and the fact that the MA content of fetal plasma and $\mathrm{BC}$ phospholipids is almost twice as high as the maternal levels (Figure 1) suggests that the biochemical EFA status of the fetus is not optimal indeed.

The presence of these EFA deficiency indicators do not necessarily reflect a shortage of EFAs, however. An alternative explanation may be that the high proportions of 20:3(n-9) and 22:3(n-9) in umbilical arterial tissue may simply reflect a high desaturase activity in arterial vessel compared to venous vessel walls. However, the ratio between total ( $\mathrm{n}-6)$ long chain polyenes (LCPs) and LA (this ratio is an indicator of total desaturase activity) in the umbilical arteries (10.4 \pm 0.29$)$ is not significantly different from that in the umbilical vein $(9.9 \pm 0.59)$, whereas MA is about five times higher in the arteries. This suggests that this higher MA content in umbilical arteries does not simply result from a high desaturase activity. It should be mentioned that the ratio between ( $n-6)$ LCPs and LA, as used here, does not represent the true desaturase activity. In further studies this activity needs to be measured more precisely.

Another reason for the poor apparent EFA status could be the specific selection by the placenta for incorporation and transfer of the 20 and 22 carbon chain polyunsaturated fatty acids at the expense of linoleic acid, to satisfy the demand for (n-3) and (n-6) LCPs for fetal brain growth $(3,12,13)$. Consequently, there is less substrate available for the enzyme $\Delta-6$-desaturase and some switching to oleic acid desaturation might be expected. However, this can only partly, explain the elevated levels of MA, because the activity of $\Delta$-6-desaturase is also controlled by a feed-back mechanism; higher amounts of arachidonic acid redice $\Delta-6$-desaturation (14).

The relative amounts of 22:5(n-6) are slightly higher in PL of umbilical arterial tissue than in umbilical venous tissue, whereas most other (n-6) fatty acids are significantly lower (Table 1). Moreover, the ratio between 22:5(n-6) and its direct precursor $22: 4(\mathrm{n}-6)$ is significantly higher in the arteries as compared to the vein $(\mathrm{P}<0.01$, see Table 1). This ratio has been used as the Cervonic Acid Deficiency Index (CADI) and, therefore, the present finding may point to a relative shortage of fetal CA also $(15,16)$. The CADi value for maternal plasma PL $(1.4 \pm 0.13)$ is significantly higher than that for fetal venous plasma PL $(1.1 \pm 0.17, p=0.03)$. Since the adult and fetal CA requirements may differ from one another, this higher maternal $C A D I$ value does not necessarily imply that the CA status of the mother is insufficient. It may reflect, nonetheless, an increased maternal CA requirement to improve fetal CA supply.

In conclusion, the biochemical LA status of neonates after a normal pregnancy does not seem to be optimal. In addition, the fetus seems to have a high $\mathrm{CA}$ requirement. Since not all the data invariably indicate a marginal EFA status of the fetus, the situation is not that serious. It may become problematic, however, if there is a disturbed maternal-to-fetal fatty acid transfer. Crawford et al (12) observed the highest concentration of MA and its elongation product $22: 3(n-9)$ in the umbilical artery of 
the lowest birthweight baby. Therefore, in further studies the fetal EFA status should be measured after conditions associated with impaired placental circulation (e.g. intra uterine growth retardation, pre-eclampsia, etc.) Since we demonstrated a close association between the maternal and fetal (n-3) and (n-6) fatty acids (Figure 2), it may be possible to improve the fetal/neonatal EFA status by increasing the maternal EFA intake during pregnancy.

\section{ACKNOWLEDGEMENTS}

The authors wish to thank all mothers for their co-operation. We also wish to thank Nutricia BV, Zoetermeer, The Netherlands, for financial support.

\section{REFERENCES}

1. Clandinin MT, Chappell JE, Leong S, Heim T, Swyer PR, Chance GW. Intrauterine fatty acid accretion rates in human brain: implications for fatty acid requirements. Early Hum Dev 1980; 4 : $121-9$.

2. Crawford MA, Hassam AG, Williams G. Essential fatty acids and fetal brain growth. Lancet 1976; 1: 452-3.

3. Kuhn DC, Crawford M. Placental essential fatty acid transport and prostaglandin synthesis. Prog Lipid Res 1986; 25: 345-53.

4. Hornstra G, Houwelingen AC v, Simonis AMG, Gerrard JM. Fatty acid composition of umbilical arteries and veins: possible implications for the fetal EFA-status. Lipids 1989; 24: $511-7$.

5. Friedman Z, Danon A, Lamberth EL, Mann WJ, Cord blood fatty acid composition in infants and in their mothers during the third trimester. J Pediatr 1978; 92: 461-6.

6. Mead JF. The metabolism of the polyunsaturated fatty acids. In: Holman RT, ed. Progress in the chemistry of fats and other lipids. Oxford: Pergamon Press, 1971: 161-89.

7. Bligh EG, Dyer WJ. A rapid method for total lipid extraction and purification. Can J Biochem Physiol 1959; 37: 911-7.

8. Vusse van der GJ, Roemen ThHM, Prinzen FW, et al. Uptake and tissue content of fatty acids in dog myocardium under normoxic and ischemic conditions. Circ Res 1982; 50: 538-46.

9. Rand ML, Hennissen AAHM, Hornstra G. Effect of dietary sunflower seed oil and marine oil on platelet membrane fluidity, arterial thrombosis. and platelet responses, in rats. Atherosclerosis 1986; $62: 267-76$.

10. Ongari MA, Ritter JH, Orchard MA, Waddell KA, Blair 1A, Lewis PJ. Correlation of prostacyclin synthesis by human umbilical artery with status of essential fatty acid. Am J Obstet Gynecol 1984; 149: 455-60.

11. Holman RT, Smythe L, Johnson S. Effect of sex and age on fatty acid composition of human serum lipids. Am J Clin Nutr 1979; 32: 2390-9.

12. Crawford MA, Doyle W, Drury P, Lennon A, Costeloe K, Leighfield MS. N-6 and n-3 fatty acids during early human development. J Int Med 1989; 225 (suppl. 1): 159-69.

13. Olegard R, Svennerholm L. Fatty acid composition of plasma and red cell phosphoglycerides in full term infants and their mothers. Acta Pædiat Scand 1970; 59:637-47.

14. Brenner RR. Nutritional and hormonal factors influencing desaturation of essential fatty acids. Prog Lipid Res 1981; 20: 41-7. 
15. Holman RT. The deficiency of essential fatty acids. In: Kunau W, Holman RT, eds. Polyunsaturated fatty acids. Proceedings of American Oil Chemists Society Symposium. Champaign (IL): Am Oil Chem Soc, 1977, vol 4: 163-82.

16. Neuringer M, Connor WE, Lin DS, Barstad L, Luck S. Biochemical and functional effects of prenatal and postnatal $w 3$ fatty acid deficiency on retina and brain in rhesus monkeys. Proc Natl Acad Sci 1986; 83: 4021-5. 


\title{
CHAPTER 3
}

\section{Fatty acid composition of serum lipids of mothers and their babies after normal and hypertensive pregnancies}

Yvonne T. van der Schouw, Monique D.M. Al, Gerard Hornstra, Marèse T.E.W. Bulstra-Ramakers and Henk. J Huisjes

Prostaglandins, Leukotrienes and Essential Fatty Ácids 1991; 44: 247-252

\begin{abstract}
The biochemical essential fatty acid (EFA) status of neonates born after normal and hypertensive pregnancies (PIH) and that of their mothers was assessed by measuring the fatty acid composition of phospholipids (PL), triglycerides (TG) and cholesteral esters (CE) of umbilical cord serum and maternal serum, respectively.

Relative contents of linoleic acid of serum PL and CE were significantly lower in mothers with PIH compared to normal pregnancies. Most other (n-6) polyenes in PL tended to be higher under hypertensive conditions. Total maternal $(n-3)$ polyenes of serum PL were significantly higher in PIH, mainly due to clupanodonic acid, 22:5(n3), and cervonic acid, 22:6(n-3). Total maternal (n-7) and (n-9) fatty acids were also significantly higher in PIH (PL and CE).

The results indicate that $\mathrm{PIH}$ is associated with a relative increased unsaturation of maternal serum PL, which might facilitate the placental transfer of long-chain, polyunsaturated fatty acids. As a result, the neonatal EFA status after PIH only slightly differs from normal.
\end{abstract}




\section{INTRODUCTION}

The essential fatty acid (EFA) status of normal neonates seems marginal, if not insufficient. This applies to linoleic acid, $18: 2(\mathrm{n}-6)$, and cervonic acid, $22: 6(\mathrm{n}-3)$, in particular $(1,2)$. Linoleic acid is the ultimate dietary precursor of arachidonic acid, 20:4(n-6), which, together with cervonic acid, is of essential importance in fetal brain development.

Although the marginal EFA status of normal neonates is unlikely to have pathological consequences, the situation may become more serious under conditions where the placental perfusion is compromized. This may be the case in the most frequent medical complication of pregnancy, hypertensive pregnancy, which syndrome is associated with elevated activation of blood platelets, spiral artery thrombosis and placental infarction (3).

In the present study we investigated whether pregnancy induced hypertension (PIH) affects the neonatal EFA status in any significant way.

\section{POPULATION, MATERIALS AND METHODS}

\section{Study population}

The EFA status of mothers and their newborn babies was assessed by measuring the relative fatty acid composition of the total phospholipids isolated from serum prepared from venous blood, taken immediately upon vaginal delivery from both a forearm vein (mother) and the umbilical vein (child). The blood was taken under almost fasting conditions (mothers had not been eating and almost did not drink during labor). Fifteen sets of samples were collected after normal pregnancy and fourteen were obtained after pregnancy complicated with PIH, defined as: "a first diastolic blood pressure below $90 \mathrm{mmHg}$, a subsequent increase of at least $25 \mathrm{mmHg}$, and a maximum reading of at least $90 \mathrm{mmHg}$ (4). Multiple pregnancies were not included. All women with PIH were hospitalized for this syndrome. None of them used any anti-hypertensive medication. One maternal sample of the last group got lost during transportation.

To investigate any influence of labor on the post-partum EFA status, five additional sets of samples were collected after Caesarean sections, performed for anatomical reasons.

All deliveries took place at the Department of Obstetrics and Gynaecology, State University, Groningen, The Netherlands and all mothers gave their informed consent.

\section{Biochemical analyses}

In all serum samples the relative fatty acid composition of the phospholipids was measured. Additionally, fatty acid composition of triglycerides and cholesterol esters was measured in ten sets of normal and ten sets of pregnancies complicated with PIH. 
Table 1. Clinical features of mothers and their neonates after normal and hypertensive pregnancies (mean \pm s.e.m.).

\begin{tabular}{llc}
\hline & $\begin{array}{l}\text { Normal } \\
(\mathrm{n}=15)\end{array}$ & $\begin{array}{l}\text { PIH } \\
(\mathrm{n}=14)\end{array}$ \\
\hline Age (years) & $26.2 \pm 1.13$ & $28.5 \pm 1.68$ \\
Number of primiparae & 8 & 5 \\
Gestational age (weeks) & $39.5 \pm 0.19$ & $38.7 \pm 0.44^{\mathrm{a}}$ \\
Birth weight (grams) & $3377 \pm 110$ & $2966 \pm 236$ \\
Apgar score (1 minute) & $8.6 \pm 0.21$ & $7.4 \pm 0.53^{\mathrm{b}}$ \\
Apgar score (3 minutes) & $9.6 \pm 0.16$ & $9.0 \pm 0.30^{\mathrm{a}}$ \\
\hline
\end{tabular}

a: tendency for difference, $0.05<p<0.10$; b: significant difference, $0.01<p<0.05$.

Table 2. Relative fatty acid composition (\%of total fatty acids) of venous serum phospholipids of mothers after Caesarian sectio and vaginal delivery (mean \pm s.e.m.).

\begin{tabular}{lcc}
\hline Fatty acid & $\begin{array}{l}\text { Caesarian section } \\
(\mathrm{n}=5)\end{array}$ & $\begin{array}{l}\text { Vaginal } \\
(\mathrm{n}=15)\end{array}$ \\
\hline $20: 5(\mathrm{n}-3)$ & $0.3 \pm 0.03$ & $0.4 \pm 0.06$ \\
$22: 5(\mathrm{n}-3)^{\#}$ & $0.9 \pm 0.08$ & $0.8 \pm 0.04$ \\
$22: 6(\mathrm{n}-3)$ & $4.0 \pm 0.39$ & $4.5 \pm 0.22$ \\
$18: 2(\mathrm{n}-6)$ & $21.5 \pm 0.88$ & $21.7 \pm 0.66$ \\
$20: 3(\mathrm{n}-6)$ & $3.2 \pm 0.27$ & $3.1 \pm 0.13$ \\
$20: 4(\mathrm{n}-6)$ & $8.8 \pm 0.62$ & $8.7 \pm 0.37$ \\
$22: 4(\mathrm{n}-6)$ & $0.3 \pm 0.09$ & $0.4 \pm 0.03$ \\
$22: 5(\mathrm{n}-6)$ & $0.7 \pm 0.08$ & $0.7 \pm 0.04$ \\
& & $1.7 \pm 0.09$ \\
$16: 1(\mathrm{n}-7)$ & $1.8 \pm 0.22$ & $11.9 \pm 0.43$ \\
$18: 1(\mathrm{n}-9)$ & $11.4 \pm 0.24$ & $0.2 \pm 0.02^{\mathrm{b}}$ \\
$20: 1(\mathrm{n}-9)$ & $0.3 \pm 0.18$ & $0.1 \pm 0.04^{\mathrm{c}}$ \\
$20: 2(\mathrm{n}-9)^{*}$ & $0.4 \pm 0.12$ & $0.6 \pm 0.08^{\mathrm{a}}$ \\
$20: 3(\mathrm{n}-9)$ & $0.3 \pm 0.18$ & $0.1 \pm 0.03^{\mathrm{a}}$ \\
$22: 1(\mathrm{n}-9)$ & tr & $1.6 \pm 0.07$ \\
$24: 1(\mathrm{n}-9)$ & $1.8 \pm 0.08$ & \\
& & $29.8 \pm 0.31$ \\
$16: 0$ & $30.1 \pm 0.53$ & $0.5 \pm 0.02$ \\
$17: 0$ & $0.1 \pm 0.09$ & $9.1 \pm 0.14$ \\
$18: 0$ & $8.7 \pm 0.40$ & $0.5 \pm 0.03$ \\
$20: 0$ & $0.5 \pm 0.04$ & $0.3 \pm 0.03$ \\
$21: 0$ & $0.2 \pm 0.05$ & $1.3 \pm 0.09$ \\
$22: 0$ & $1.1 \pm 0.20$ & $0.3 \pm 0.03$ \\
$23: 0$ & $0.3 \pm 0.05$ & \\
$24: 0$ & $0.9 \pm 0.13$ & \\
\hline & & \\
& &
\end{tabular}

\#: plus 24:2(n-6) as a minor component; $¥$ : tentative identification; tr: trace.

a: tendency for difference. $0.05<p<0.10$; b: significant difference, $0.01<p<0.05$;

c: significant difference, $p<0.01$. 
The serum samples were stored for about one to 12 months at $-60{ }^{\circ} \mathrm{C}$ before the biochemical analyses were performed at the Department of Human Biology, State University Limburg, The Netherlands. Lipids were extracted according to the method of Bligh and Dyer (5). Phospholipids (PL), cholesterol esters (CE) and triglycerides (TG) were separated by thin layer chromatography as described by Van der Vusse et al. (6). The different lipid fractions were hydrolyzed and the fatty acids were methylated with methanolic boron-trifluoride. Fatty acid composition of the lipid fractions was analyzed using gas liquid chromatography as described by Rand et al. (7). Samples of mothers and their neonates were always analyzed in the same analytical series.

\section{Statistical analyses}

Because the relative concentrations of a number of the various fatty acids were not normally distributed, differences between pregnancy groups and mother-child differences were tested with the non-parametric two-sided Wilcoxon-Mann-Whitney two-sample test. The relation between the sum of the (n-6) long chain polyenes $([20: 3(n-6)+20: 4(n-6)+22: 4(n-6)+22: 5(n-6)],(n-6) L C P s)$ and linoleic acid was investigated using linear regression analysis. Regression coefficients were tested with a two-sided F-test.

\section{RESULTS}

Table 1 summarizes the relevant elinical information on the study population. No differences were seen between women with normal pregnancies and pregnancies complicated with PIH for maternal age and number of pregnancies. Gestational age tended to be higher in the normal group. No statistically significant difference between the groups was found for birth weight of the children. Apgar score one minute after birth was significantly lower in the neonates from mothers with PIH compared to the normal neonates. Apgar score three minutes after birth showed the same tendency; however, the difference was no longer significant.

There were no important differences in the fatty acid composition of serum PL between mothers after normal delivery as compared with Caesarean section (Table 2). Therefore, any significant interference of labor on maternal fatty acid composition of serum lipids can be excluded. This is also observed by Ruyle et al. (8).

In Tables 3, 4 and 5 the fatty acid compositions of the serum lipid fractions of neonatal and maternal serum are given.

In the neonatal serum PL, TG and CE, hardly any differences were observed between normal pregnancies and pregnancies complicated by PIH for any of the essential fatty acids (Tables $3,4,5$ ). 
Table 3. Relative fatty acid composition (\% of total fatty acids) of venous serum phospholipids of neonates and mothers after normal and hypertensive pregnancies (mean \pm s.e.m.).

\begin{tabular}{|c|c|c|c|c|}
\hline Fatty acidף & $\begin{array}{l}\text { Neonates } \\
\text { normal } \\
(\mathrm{n}=15)\end{array}$ & $\begin{array}{l}\text { PIH } \\
(n=14)\end{array}$ & $\begin{array}{l}\text { Mothers } \\
\text { normal } \\
(n=15)\end{array}$ & $\begin{array}{l}\text { PIH } \\
(n=13)\end{array}$ \\
\hline $20: 5(n-3)$ & $0.4 \pm 0.06$ & $0.5 \pm 0.08$ & $0.4 \pm 0.06$ & $0.5 \pm 0.06^{\mathrm{a}}$ \\
\hline $22: 5(n-3)^{\#}$ & $1.9 \pm 0.12$ & $1.9 \pm 0.19$ & $0.8 \pm 0.04$ & $1.0 \pm 0.06^{b}$ \\
\hline $22: 6(n-3)$ & $7.4 \pm 0.41$ & $7.7 \pm 0.68$ & $4.5 \pm 0.22$ & $5.4 \pm 0.33^{b}$ \\
\hline$\Sigma(n-3)$ & $9.7 \pm 0.39$ & $10.1 \pm 0.82$ & $6.1 \pm 0.26$ & $7.4 \pm 0.36^{b}$ \\
\hline $18: 2(n-6)$ & $7.4 \pm 0.45$ & $7.5 \pm 0.45$ & $21.7 \pm 0.66$ & $18.2 \pm 0.68^{c}$ \\
\hline $20: 3(n-6)$ & $5.7 \pm 0.35$ & $5.5 \pm 0.33$ & $3.1 \pm 0.13$ & $3.5 \pm 0.16^{\mathrm{a}}$ \\
\hline $20: 4(n-6)$ & $18.4 \pm 0.49$ & $18.7 \pm 0.62$ & $8.7 \pm 0.37$ & $9.1 \pm 0.43$ \\
\hline $22: 4(n-6)$ & $1.1 \pm 0.05$ & $1.2 \pm 0.07$ & $0.4 \pm 0.03$ & $0.5 \pm 0.04$ \\
\hline $22: 5(n-6)$ & $1.1 \pm 0.06$ & $1.0 \pm 0.12$ & $0.7 \pm 0.04$ & $0.8 \pm 0.05$ \\
\hline$\Sigma(n-6)$ & $33.8 \pm 0.86$ & $33.8 \pm 1.06$ & $34.8 \pm 0.48$ & $32.1 \pm 0.92^{\mathrm{c}}$ \\
\hline$\Sigma(n-6)$ LCPs & $26.4 \pm 0.66$ & $26.3 \pm 0.81$ & $13.1 \pm 0.38$ & $14,0 \pm 0,43^{a}$ \\
\hline $16: 1(n-7)$ & $1.3 \pm 0.05$ & $1.6 \pm 0.09 c$ & $1.7 \pm 0.09$ & $1.9 \pm 0.10$ \\
\hline $18: 1(n-9)$ & $8.9 \pm 0.41$ & $11.2 \pm 0.77^{\mathrm{a}}$ & $11.9 \pm 0.43$ & $13.4 \pm 0.40^{b}$ \\
\hline $20: 1(n-9)$ & $0.1 \pm 0.02$ & $0.1 \pm 0.02$ & $0.2 \pm 0.02$ & $0.2 \pm 0.02$ \\
\hline $20: 2(n-9)^{\#}$ & $0.1 \pm 0.03$ & $0.1 \pm 0.02$ & $0.1 \pm 0.04$ & $0.1 \pm 0.03$ \\
\hline $20: 3(n-9)$ & $0.6 \pm 0.05$ & $0.5 \pm 0.10$ & $0.6 \pm 0.08$ & $0.8 \pm 0.08$ \\
\hline $22: 1(n-9)$ & $0.4 \pm 0.10$ & $0.4 \pm 0.10$ & $0.1 \pm 0.03$ & $0.1 \pm 0.03$ \\
\hline $24: 1(n-9)$ & $2.6 \pm 0.11$ & $2.4 \pm 0.08$ & $1.6 \pm 0.07$ & $1.9 \pm 0.11^{\mathrm{a}}$ \\
\hline$\Sigma[(n-7)+(n-9)]$ & $14.0 \pm 0.90$ & $16.3 \pm 1.20$ & $16.3 \pm 0.52$ & $18.4 \pm 0.52^{b}$ \\
\hline $16: 0$ & $27.0 \pm 0.45$ & $27.0 \pm 0.64$ & $29.8 \pm 0.31$ & $30.0 \pm 0.50$ \\
\hline $17: 0$ & $0.3 \pm 0.06$ & $0.3 \pm 0.07$ & $0.5 \pm 0.02$ & $0.4 \pm 0.06$ \\
\hline 18:0 & $11.9 \pm 0.41$ & $10.6 \pm 0.54$ & $9.1 \pm 0.14$ & $8.9 \pm 0.24$ \\
\hline $20: 0$ & tu & tr & $0.5 \pm 0.03$ & $0.5 \pm 0.03$ \\
\hline 21:0 & $0.5 \pm 0.11$ & $0.5 \pm 0.11$ & $0.3 \pm 0.03$ & $0.4 \pm 0.05$ \\
\hline $22: 0$ & $1.5 \pm 0.05$ & $1.3 \pm 0.10^{b}$ & $1.3 \pm 0.09$ & $1.1 \pm 0.06^{\mathrm{b}}$ \\
\hline $23: 0$ & tr & $\mathrm{tr}$ & $0.3 \pm 0.03$ & $0.3 \pm 0.03$ \\
\hline $24: 0$ & $0.8 \pm 0.08$ & $0.7 \pm 0.07$ & $0.6 \pm 0.03$ & $0.5 \pm 0.04$ \\
\hline$\Sigma$ PUFA & $44.1 \pm 0.87$ & $44.4 \pm 1.15$ & $41.2 \pm 0.54$ & $40.0 \pm 1.05$ \\
\hline$\Sigma$ MUFA & $13.3 \pm 0.37$ & $15.7 \pm 1.18$ & $15.6 \pm 0.53$ & $17.5 \pm 0.50^{b}$ \\
\hline$\sum$ SAFA & $41.9 \pm 0.79$ & $40.4 \pm 1.19$ & $42.5 \pm 0.25$ & $42.1 \pm 0.43$ \\
\hline
\end{tabular}

I: (n-6)LCPs, (n-6) long chain polyenes; SAFA, saturated fatty acids; MUFA, monounsaturated fatty acids; PUFA, polyunsaturated fatty acids.

\#: plus $24: 2(n-6)$ as a minor component. $\%$ : tentative identification. tr: trace.

a: tendency for difference, $0.05<p<0.10$; b: significant difference, $0.01<p<0.05$;

c: significant difference, $\mathrm{p}<0.01$. 
In mothers, a significant difference between normal pregnancies and pregnancies complicated with PIH was found (Tables 3 and 5) for linoleic acid, 18:2(n-6), (PL, $\mathrm{CE})$; the linoleic acid status of mothers with PIH appeared significantly reduced compared to that of mothers with uncomplicated pregnancies. Also, significant differences for the non-essential fatty acids of the (n-7) and (n-9) family were observed (PL, CE). In the PL of maternal serum, timnodonic acid, 20:5(n-3), tended to be higher and clupanodonic acid, 22:5(n-3), and cervonic acid, 22:6(n-3), were significantly higher, which resulted in a significantly higher amount of total $(\mathrm{n}-3)$ polyenes in PIH compared to normal pregnancies. These differences were not observed for TG and CE (Tables 4 and 5).

Striking differences exist between the maternal and neonatal fatty acid composition of the serum lipid fractions. This is shown in Tables 3,4 and 5. Differences are particularly pronounced for linoleic acid (PL, CE), which is much higher in maternal than in neonatal serum, and for arachidonic acid, 20:4(n-6) (PL, TG, CE), for which the opposite is true. Mead acid, 20:3(n-9), the marker of a combined linoleic and $\alpha$ linolenic acid deficiency, is higher in neonatal than in maternal serum (TG, CE). In general, the shorter chain and/or the less unsaturated fatty acids are higher in mothers than in their children, whereas the reverse is true for the longer chain and/or more unsaturated fatty acids (PL, TG, CE).

The maternal-neonatal differences are not always consistent for the various lipid fractions. In some cases the differences were even in opposite directions. Consistent differences were found for 20:3(n-6), 20:4(n-6) and 22:6(n-3) only (neonatal values significantly higher than maternal values). In most cases the patterns observed were essentially similar for normal pregnancies and those complicated by PIH, although occasionally significant differences occurred (data not shown, but available on request).

\section{DISCUSSION}

The results of this study indicate that the linoleic acid status of mothers with PIH is reduced as compared with that of mothers after normal pregnancies. The sum of the fatty acids of the (n-7) and (n-9) families was significantily higher after pregnancies complicated by PIH, which also indicates a suboptimal linoleic acid status $(9,10)$.

Theoretically, the lower linoleic acid status in PIH may be the result of a lower dietary intake of linoleic acid. If this is true, a supplementary consumption of about seven grams of linoleic acid per day could possibly overcome the difference between normal mothers and mothers with PlH. This can be estimated by extrapolation of the regression equation for the relation between linoleic acid intake and the linoleic acid amount in serum TG, as calculated by Houwelingen et al. (11). 
Table 4. Relative fatry acid composition (\% of total fatty acids) of venous serum triglycerides of neonates and mothers after normal and hypertensive pregnancies (mean \pm s.e.m.).

\begin{tabular}{|c|c|c|c|c|}
\hline Fatty acid & $\begin{array}{l}\text { Neonates } \\
\text { normal } \\
(n=10)\end{array}$ & $\begin{array}{l}\text { PIH } \\
(n=8)\end{array}$ & $\begin{array}{l}\text { Mothers } \\
\text { normal } \\
(n=10)\end{array}$ & $\begin{array}{l}\text { PIH } \\
(n=8)\end{array}$ \\
\hline $18: 3(n-3)$ & $1.6 \pm 0.66$ & $1.0 \pm 0.16$ & $1.3 \pm 0.11$ & $1.2 \pm 0.11$ \\
\hline $22: 5(n-3)^{\#}$ & $0.3 \pm 0.06$ & tr $b$ & $0.3 \pm 0.06$ & tr b \\
\hline $22: 6(n-3)$ & $2.8 \pm 0.32$ & $3.2 \pm 0.52$ & $0.2 \pm 0.04$ & $0.2 \pm 0.06$ \\
\hline$\Sigma(n-3)$ & $4.6 \pm 0.76$ & $4.4 \pm 0.68$ & $1.6 \pm 0.11$ & $1.5 \pm 0.10$ \\
\hline $18: 2(n-6)$ & $13.8 \pm 0.95$ & $13.2 \pm 0.78$ & $14.6 \pm 0.91$ & $11.5 \pm 1.50$ \\
\hline $18: 3(n-6)$ & $1.3 \pm 0.28$ & $1.0 \pm 0.17^{\mathrm{a}}$ & $0.3 \pm 0.04$ & $0.3 \pm 0.04$ \\
\hline $20: 3(n-6)$ & $1.1 \pm 0.15$ & $1.1 \pm 0.12$ & $0.3 \pm 0.03$ & $0.2 \pm 0.04$ \\
\hline $20: 4(n-6)$ & $3.5 \pm 0.33$ & $3.0 \pm 0.39$ & $0.5 \pm 0.06$ & $0.4 \pm 0.06$ \\
\hline $22: 4(n-6)$ & $0.8 \pm 0.05$ & $0.7 \pm 0.04$ & $0.1 \pm 0.01$ & to b \\
\hline $22: 5(n-6)$ & $1.2 \pm 0.13$ & $0.9 \pm 0.15$ & $0.1 \pm 0.02$ & $0.1 \pm 0.02$ \\
\hline$\Sigma(n-6)$ & $21.4 \pm 1.41$ & $20.0 \pm 1.26$ & $16.0 \pm 0.95$ & $12.5 \pm 1.58$ \\
\hline$\Sigma(n-6)$ LCPs & $7.6 \pm 0.68$ & $6.7 \pm 0.83$ & $1.3 \pm 0.13$ & $1.1 \pm 0.12$ \\
\hline $16: 1(n-7)$ & $7.7 \pm 0.64$ & $7.9 \pm 0.43$ & $6.4 \pm 0.28$ & $6.8 \pm 0.47$ \\
\hline $18: 1(n-9)$ & $33.4 \pm 1.19$ & $32.8 \pm 1.68$ & $36.8 \pm 0.95$ & $37.6 \pm 1.24$ \\
\hline $20: I(n-9)$ & $0.5 \pm 0.13$ & $0.4 \pm 0.09$ & $0.9 \pm 0.08$ & $0.7 \pm 0.09$ \\
\hline $20: 2(n-9)^{*}$ & tr & tr & $0.4 \pm 0.03$ & $0.3 \pm 0.04$ \\
\hline $20: 3(n-9)$ & $0.8 \pm 0.15$ & $0.8 \pm 0.18$ & $0.3 \pm 0.06$ & $0.2 \pm 0.03$ \\
\hline$\Sigma[(n-7)+(n-9)]$ & $42.4 \pm 1.04$ & $41.9 \pm 1.88$ & $44.8 \pm 1.02$ & $45.6 \pm 1.11$ \\
\hline $16: 0$ & $22.9 \pm 0.99$ & $25.8 \pm 0.85^{\mathrm{a}}$ & $29.1 \pm 0.60$ & $31.5 \pm 1.58$ \\
\hline $17: 0$ & $1.3 \pm 0.36$ & $1.5 \pm 0.38$ & $1.7 \pm 0.14$ & $1.7 \pm 0.22$ \\
\hline 18:01 & $3.7 \pm 0.38$ & $4.4 \pm 0.53$ & $3.2 \pm 0.26$ & $3.1 \pm 0.12$ \\
\hline $21: 0$ & $0.8 \pm 0.21$ & $0.8 \pm 0.21$ & $\mathrm{tr}$ & $0.1 \pm 0.04^{b}$ \\
\hline$\sum$ PUFA & $26.9 \pm 1.78$ & $25.3 \pm 1.78$ & $18.2 \pm 1.02$ & $14.6 \pm 1.71$ \\
\hline$\Sigma$ MUFA. & $41.7 \pm 0.94$ & $41.1 \pm 1.85$ & $44.1 \pm 1.02$ & $45.1 \pm 1.15$ \\
\hline$\sum$ SAFA & $28.6 \pm 1.36$ & $32.4 \pm 0.58^{b}$ & $34.1 \pm 0.68$ & $36.5 \pm 1.51$ \\
\hline
\end{tabular}

For abbrevations see Table 3

The lower linoleic acid status of mothers with PIH may also result from a higher fetal demand for more desaturated and/or more elongated ( $\mathrm{n}-6)$ fatty acids [(n-6)LCPs], as a result of which more of the available linoleic acid is used for conversion. Indeed, the ratio between the (n-6)LCPs and their precursor linoleic acid in maternal PL is significantly higher in PIH $(0.8 \pm 0.03$ versus $0.6 \pm 0.04, p=0.002)$. This suggests more active elongation and desaturation processes during PIH, possibly to meet an increased demand for polyenes in this situation. To investigate this in more detail, linear regression equations were calculated with $(\mathrm{n}-6) \mathrm{LCPs}$ as the dependent $(\mathrm{Y})$, and 
Table 5. Relative fatty acid composition (\% of total fatty acids) of venous serum cholesterol esters of neonates and mothers after normal and hypertensive pregnancies (mean \pm s.e.m.).

\begin{tabular}{|c|c|c|c|c|}
\hline Fatty acidf & $\begin{array}{l}\text { Neonates } \\
\text { nornal } \\
(\mathrm{n}=10)\end{array}$ & $\begin{array}{l}\text { PIH } \\
(n=8)\end{array}$ & $\begin{array}{l}\text { Mothers } \\
\text { normal } \\
(n=10)\end{array}$ & $\begin{array}{l}\text { PIH } \\
(n=8)\end{array}$ \\
\hline $18: 3(n-3)$ & tr & tr & $0.9 \pm 0.09$ & $1.0 \pm 0.05$ \\
\hline $20: 5(n-3)$ & $0.2 \pm 0.06$ & $0.4 \pm 0.11$ & $0.2 \pm 0.06$ & $0.3 \pm 0.05$ \\
\hline $22: 6(n-3)$ & $0.8 \pm 0.15$ & $1.1 \pm 0.13$ & $0.2 \pm 0.03$ & $0.3 \pm 0.06$ \\
\hline$\sum(n-3)$ & $1.0 \pm 0.20$ & $1.6 \pm 0.15^{a}$ & $1.4 \pm 0.13$ & $1.5 \pm 0.11$ \\
\hline $18: 2(n-6)$ & $19.0 \pm 0.60$ & $20.6 \pm 0.90^{\mathrm{a}}$ & $49.7 \pm 1.78$ & $42.9 \pm 2.28^{b}$ \\
\hline $18: 3(n-6)$ & $0.6 \pm 0.07$ & $0.7 \pm 0.10$ & $0.5 \pm 0.05$ & $0.6 \pm 0.08$ \\
\hline $20: 3(n-6)$ & $1.0 \pm 0.19$ & $1.4 \pm 0.17^{b}$ & $0.5 \pm 0.08$ & $0.5 \pm 0.08$ \\
\hline $20: 4(n-6)$ & $11.7 \pm 1.11$ & $12.3 \pm 1.30$ & $3.7 \pm 0.30$ & $3.3 \pm 0.20$ \\
\hline$\Sigma(n-6)$ & $32.4 \pm 1.55$ & $36.5 \pm 1.72^{\mathrm{a}}$ & $54.4 \pm 1.82$ & $47.4 \pm 2.22^{b}$ \\
\hline$\Sigma(n-6) \operatorname{LCPs}$ & $13.3 \pm 1.21$ & $15.4 \pm 1.24$ & $4.7 \pm 0.37$ & $4.5 \pm 0.17$ \\
\hline $16: 1(n-7)$ & $8.8 \pm 0.50$ & $8.5 \pm 0.45$ & $6.2 \pm 0.65$ & $8.4 \pm 1.25$ \\
\hline $18: 1(n-9)$ & $32.9 \pm 0.95$ & $30.7 \pm 1.28^{b}$ & $22.7 \pm 1.09$ & $26.5 \pm 0.92^{b}$ \\
\hline $20: 3(n-9)$ & $0.2 \pm 0.06$ & $0.2 \pm 0.06$ & tr & tr \\
\hline$\Sigma[(n-7)+(n-9)]$ & $41.9 \pm 0.90$ & $39.4 \pm 1.05^{b}$ & $28.8 \pm 1.60$ & $34.9 \pm 1.94^{b}$ \\
\hline $16: 0$ & $19.5 \pm 1.12$ & $19.6 \pm 0.85$ & $12.8 \pm 0.34$ & $13.2 \pm 0.42$ \\
\hline $17: 0$ & $0.4 \pm 0.11$ & $0.7 \pm 0.18$ & $0.4 \pm 0.05$ & $0.4 \pm 0.04$ \\
\hline $18: 0$ & $2.9 \pm 0.41$ & $2.0 \pm 0.32$ & $0.6 \pm 0.06$ & $0.9 \pm 1.19$ \\
\hline $24: 0$ & $0.2 \pm 0.13$ & $0.1 \pm 0.04^{b}$ & tr & tr \\
\hline$\Sigma$ PUFA & $33.6 \pm 1.74$ & $38.3 \pm 1.75^{\mathrm{a}}$ & $55.9 \pm 1.83$ & $48.9 \pm 2.19 \mathrm{~b}$ \\
\hline$\Sigma$ MUFA & $41.7 \pm 0.89$ & $39.2 \pm 1.02 \mathrm{~b}$ & $28.8 \pm 1.60$ & $34.9 \pm 1.94 \mathrm{~b}$ \\
\hline$\sum$ SAFA & $23.1 \pm 1.44$ & $22.4 \pm 1.11$ & $13.8 \pm 0.42$ & $14.5 \pm 0.60$ \\
\hline
\end{tabular}

For abbrevations see Table 3

linoleic acid as the independent $(\mathrm{X})$ variable. In normal pregnancy the regression equation is $\mathrm{Y}=21.8-0.4 \mathrm{X},(\mathrm{r}=-0.71, \mathrm{n}=15, \mathrm{p}=0.003)$. In pregnancies complicated by PIH this relation tends to be positive, $\mathrm{Y}=10.2+0.2 \mathrm{X},(\mathrm{r}=0.32, \mathrm{n}=13, \mathrm{p}=$ $0.280)$. The slopes of the two regression lines differ significantly $(p=0.001)$, which, together with the switch of the sign of the regression coefficient, is an indication for more active elongation and desaturation in PIH. Consequently, the lower linoleic acid status in mothers with PIH may be of metabolic rather than of dietary origin. The more active desaturation and elongation of linoleic acid may reflect a maternal attempt to compensate for a less efficient placental transfer of (n-6)LCPs, possibly resulting from the fact that in PIH the placenta is partially infarcted (3). 
Total (n-3) polyenes are also significantly higher in maternal plasma PL after pregnancies complicated by PIH than after normal pregnancies, which is mainly caused by clupanodonic acid and cervonic acid. Theoretically, this could be an indication of an increased maternal dietary intake of these (n-3) polyenes, for example a higher fish consumption (10). However, the lack of difference for (n-3) LCP amounts in TG and CE does not support the theory of an increased cervonic acid intake. A more likely explanation for the higher amounts of ( $n-3)$ polyenes in serum PL of mothers with PIH could be an increased mobilization from maternal stores. These higher amounts of $(\mathrm{n}-3)$ polyenes may serve to increase the maternal-fetal $(\mathrm{n}-3)$ gradient, which would compensate for the PIH associated reduction in placental transfer area.

Because of these adaptation mechanisms, the neonatal EFA status after PIH does not differ significantly from normal. Whether or not the fetus is involved in the generation of a signal to stimulate maternal linoleic acid conversion or (n-3) polyenes mobilization from maternal stores remains a challenging question.

This study indicates that maternal EFA metabolism is altered in hypertensive pregnancy; linoleic acid seems to be more actively desaturated and elongated and ( $\mathrm{n}$ 3) polyenes are possibly mobilized from maternal stores. The resulting higher levels of (n-3) and (n-6)LCPs could compensate for a impaired placental transfer of these fatty acids, as a result of which the neonatal EFA status after PIH hardly differs from normal. Whether or not maternal EFA supply will be benificial in the prevention or treatment of PIH needs to be studied.

\section{ACKNOWLEDGEMENTS}

The authors are grateful to AMG Simonis for helping with the fatty acid analyses. They also thank all mothers for their cooperation in this study.

\section{REFERENCES}

1. Hornstra G, Houwelingen AC v., Simonis M, Gerrard JM. Fatty acid composition of umbilical arteries and veins: possible implications for the fetal EFA status. Lipids 1989; 24: 511-7.

2. Al MDM, Hornstra G, Schouw van der YT, Bulstra-Ramakers TEW, Huisjes HJ. Biochemical EFA status of mothers and their neonates after normal pregnancy. Early Hum Dev 1990; 24: 239-48.

3. Brosens 1, Renaer M. On the pathogenesis of placental infarcts in pre-eclampsia. J Obstet Gynaecol Br Cwlth 1972; 79: 794-9.

4. Redman CWG, Jefferies M. Revised definition of pre-eclampsia. Lancet 1988; 1: 809-12.

5. Bligh EG, Dyer WJ. A rapid method for total lipid extraction and purification. Can J Biochem Physiol 1959; 37: 911-7.

6. Vusse van der GJ, Roemen ThHM, Prinzen FW, et al. Uptake and tissue content of fatty acids in dog myocardium under normoxic and ischemic conditions. Circ Res 1982; 50: 538-46. 
7. Rand ML, Hennissen AAHM, Hornstra G. Effect of dietary sunflower seed oil and marine oil on platelet membrane fluidity, arterial thrombosis and platelet responses in rats. Atherosclerosis 1986; 62: 267-276.

8. Ruyle M, Connor WE, Anderson GJ, Lowensohn RI. Placental transfer of essential fatty acids in humans: Venous-arterial difference for docosahexaenoic acid in fetal umbilical erythrocytes. Proc Natl Acad Sci 1990; 87: 7902-6.

9. Brenner RR. Nutritional and hormonal factors influencing desaturation of essential fatty acids. Progr Lipid Res 1981; 20: 41-7.

10. Holman RT. Control of polyunsaturated fatty acids in tissue lipids. J Am Coll Nutr 1986; 5: 183-211.

11. Houwelingen AC v., Kester ADM, Kromhout D, Hornstra G. Comparison between the habitual intake of polyunsaturated fatty acids and their concentrations in serum lipid fractions. Eur $\mathrm{J}$ Clin Nutr 1989; 43: 11-20. 


\title{
CHAPTER 4
}

\section{Nutrient intake of women during normal pregnancy with special emphasis on fat intake}

\author{
Monique D.M. Al, Anita Badart-Smook, Adriana C. v. Houwelingen, Tom H.M. \\ Hasaart and Gerard Hornstra
}

Based on: Fat intake of women during normal pregnancy: relationship with neonatal EFA status, submitted for publication

\begin{abstract}
As part of an-going study on the essential fatty acid status during pregnancy in relation to the outcome of pregnancy, the nutrient intake of 176 women throughout normal pregnancy was studied with special emphasis on the amount and type of fat consumed. The subjects completed a food frequency questionnaire (FFQ) before 13, at 22. and at 32 weeks of gestation. At 22 weeks of gestation a diet history (DH) was carried out and a maternal blood sample was taken. No significant changes in the mean daily intake of total fat, saturated fat, mono-unsaturated fat, polyunsaturated fat, and linoleic acid during pregnancy were observed. Less than $30 \%$ of the women met the recommendations for amount and type of dietary fat. The intakes of linoleic acid and polyunsaturated fatty acids ( $\%$ of total fat intake) of pregnant women assessed with the FFQ and DH correlated well with the amounts of these fatty acids in plasma phospholipids. It is concluded that the fat content and composition of the maternal diet does not change during a normal pregnancy. In addition, the individual dietary composition with respect to these nutrients seems consistent during gestation.
\end{abstract}




\section{INTRODUCTION}

A large number of papers has been published on nutritional aspects related to pregnancy (see for reviews: ref. 1-3). However, most studies have focussed on the intake of energy, protein, vitamins and minerals, without considering the intake of polyunsaturated fatty acids (PUFAs). It is well known that PUFAs play a major role during fetal development (4). In addition, some of them are important in human parturition as precursors of prostaglandins (5). Moreover, PUFAs and their metabolites are increasingly being linked to the incidence of pregnancy-induced hypertension (6-9). Therefore, PUFAs and specifically essential fatty acids may be of great importance in the diet of pregnant women. However, so far no prospective studies have been reported on this issue. To prepare for such a study, we decided to investigate the nutrient intake of a group of Dutch pregnant women in each trimester of their (normal) pregnancy, with special emphasis on the intake of fat. Dietary intakes were recorded to assess the fat content and composition of the maternal diet and as a biological marker a blood sample was taken to determine the fatty acid composition of plasma phospholipids.

\section{SUBJECTS AND METHODS}

\section{Study population}

Pregnant women were asked to participate in the study at their first antenatal medical visit. The selection criteria for entering the study were a gestational age less than 13 weeks at entry, and a diastolic blood pressure below $90 \mathrm{~mm} \mathrm{Hg}$. Women suffering from any metabolic, cardiovascular, neurological or renal disorder were excluded. Out of the 302 women who were willing to participate, 78 women experienced complications during pregnancy, and 48 women had an incomplete data set. Finally, 176 Dutch women ( $78.6 \%$ of the eligible population) with normal singleton pregnancies were studied. The mean (s.d.) age of the mothers was 28.8 (4.1) years. The number of primipara was 113 and of multipara 63. All infants were born at term $(280.1 \pm 8.03$ days), and the birthweight $(3347 \pm 391$ gram) was appropriate for gestational age ( $>$ Percentile 2.3 and < Percentile 97.7) based on the Dutch intrauterine growth curves, making allowance for sex and parity (10). One-hundred-five boys and seventy-one girls were born. The protocol was approved by the Ethics Committee of the University Hospital and written consent was obtained from each participant.

\section{Dietary intake}

The dietary intake of products rich in fat was investigated each trimester by using a self-administered semi-quantitative food frequency questionnaire (FFQ) that asked about the intakes of the previous two months. The FFQ was specifically designed to collect data on the fat consumption of the participating women. With the help of an experienced dietitian (AB-S), the foods included in the questionnaire were selected according to their contribution to the mean daily fat consumption of pregnant women 
(11) and according to their fat content (12). Appendix A shows the seven main food groups with most of their foods. Frequency of consumption had to be recorded and the amount eaten had to be indicated in household units or grams for some typical individual serving size (e.g. meat). In total, three FFQs (first trimester, before 13 weeks of gestation - FFQ1; second trimester, at 22 weeks -FFQ2; third trimester, at 32 weeks - FFQ3) were sent to the participants. The returned questionnaires were checked for completeness by the dietitian and, if necessary, corrected after a telephone interview with the participant concerned.

At mid pregnancy, just after FFQ2 had been filled in, a cross-check diet history (13) was carried out to collect extended dietary data. The participants were visited at home by the dietitian and questioned about their usual food consumption of the previous two months. During this interview, food quantities were specified in household measures. Usual portion sizes were estimated with the aid of food models or replicates; portions. of foods frequently consumed were weighed on a balance having a precision of 0.5 gram. All foods and drinks were coded according to the system of the Netherlands. Nutrient Databank (NEVO), developed in the Netherlands and converted into energy' and nutrients by using the extended computerized version of the Netherlands Food Table (12).

\section{Blood collection}

Within two weeks before or after the diet history was carried out, a venous blood sample was collected from 80 of the participating pregnant women into disodium EDT A containing tubes. Plasma was separated from the erythrocytes by centrifugation and stored at $-80^{\circ} \mathrm{C}$ until fatty acid analysis.

\section{Fatty acid analysis}

Preparation of a total lipid extract from $100 \mu \mathrm{l}$ plasma was performed with a modified Folch extraction by the addition of $3 \mathrm{ml}$ methanol:chloroform $(1: 2$, vol:vol $)(14,15)$, L-a-dinonadecanoyl was used as an internal standard. Aminopropyl bonded phase columns were used to separate phospholipids from the total lipid extract (16). The fatty acid (FA) constituents of the phospholipids were transmethylated to the corresponding methylesters (FAME) by reaction with $14 \% \mathrm{BF} 3$ in methanol at $100^{\circ} \mathrm{C}$ for one hour (17). Temperature-programmed GC-FID (Gas Chromatograph-Flame Ionisation Detector) on a $50 \mathrm{~m}$ x $0.25 \mathrm{~mm}$ CP-Sil $5 \mathrm{CB}$, df $=0.12 \mu \mathrm{m}$ column (Chrompack $\left(\right.$ Middelburg, The Netherlands) with $\mathrm{N}_{2}$ as carrier gas was used for the analysis of fatty acid methyl esters. In total 39 fatty acids were identified and the following fatty acids are reported: SSAFA (sum of the saturated fatty acids 14:0, 15:0, 16:0, $18: 0,20: 0,22: 0,23: 0$ and 24:0), MUFA (sum of the mono-unsaturated fatty acids $16: 1(n-7), 18: 1(n-7), 20: 1(n-7), 18: 1(n-9), 20: 1(n-9), 22: 1(n-9)$ and $24: 1(n-9)), \Sigma$ PUFA (sum of the poly-unsaturated fatty acids 18:3(n-3), 20:3(n-3), 20:4(n-3), $20: 5(n-3), 22: 3(n-3), 22: 5(n-3), 22: 6(n-3), 18: 2(n-6), 18: 3(n-6), 20: 2(n-6), 20: 3(n-6)$, $20: 4(n-6), 22: 2(n-6), 22: 4(n-6), 22: 5(n-6), 24: 2(n-6), 18: 2(n-9), 20: 3(n-9)$ and $22: 3(n-$ 9)) and linoleic acid (18:2(n-6), LA). 
Table 1. Fat and fatty acid intake (g/day) during pregnancy, measured by food frequency questionnaire and diet history (mean $\pm s . d$., $n=176)^{*}$.

\begin{tabular}{lllll}
\hline Nutrient & 1st trimester & 2nd trimester & 3rd trimester & diet history \\
\hline TF & $92.7 \pm 33.1$ & $88.1 \pm 31.3$ & $88.6 \pm 39.0$ & $99.5 \pm 33.2^{\mathrm{a}}$ \\
SAF & $38.1 \pm 12.8$ & $36.7 \pm 13.3$ & $36.9 \pm 14.3$ & $41.5 \pm 13.9^{\mathrm{a}}$ \\
MUF & $35.7 \pm 12.1$ & $34.3 \pm 12.5$ & $34.0 \pm 13.7$ & $38.1 \pm 13.2^{\mathrm{a}}$ \\
PUF & $18.1 \pm 11.5$ & $16.5 \pm 8.0$ & $16.9 \pm 15.5$ & $19.0 \pm 8.2^{\mathrm{a}}$ \\
LA & $15.4 \pm 10.3$ & $14.0 \pm 7.1$ & $14.3 \pm 13.6$ & $16.2 \pm 7.5^{\mathrm{a}}$ \\
\hline
\end{tabular}

*: No significant differences at the 0.05 level in nutrient intake between trimesters.

ข: TF, total fat; SAF, saturated fat; MUF,mono-unsaturated fat; PUF, polyunsaturated fat; LA, linoleic acid.

a: significant difference between FFQ2 and DH $(p<0.0001)$.

\section{Statistical analysis}

Because the quantitative amounts $(\mathrm{g} /$ day) of the intake of total fat, saturated fat, monounsaturated fat, polyunsaturated fat and linoleic acid were not normally distributed, these variables were analyzed by non-parametric methods. Differences between two groups were tested using the Wilcoxon's signed-rank test for paired observations and the Mann-Whitney test for unpaired observations. The Kruskal Wallis test was used to investigate differences between more than two groups. Spearman rank correla-tion coefficients between intakes at three trimesters for total fat, saturated fat, monounsaturated fat, polyunsaturated fat and linoleic acid were calculated to assess relative changes in dietary composition within persons.

The effect of parity, smoking and education of the mother on nutrient intake estimated by diet history (DH), was tested by means of the Student's t-test (two groups) or Tukey (more than two groups) for the normaily distributed variables. Otherwise nonparametric tests were used (see above).

Although it was not the purpose of the study, the study design made it possible to assess the validity of the food frequency questionnaire (FFQ). Therefore, several tests were performed (18): the difference in intake between FFQ2 and $\mathrm{DH}$ was tested with the Wilcoxon's signed-rank test; Spearman rank correlation coefficients were calculated between nutrient intakes according to FFQ2 and the diet history; furthermore, the joint classification of nutrient intakes assessed by $\mathrm{FFQ} 2$ and $\mathrm{DH}$ was investigated with the aid of contingency tables. The women were divided into quintiles according to the nutrient intake by FFQ2 and DH. Subjects were grossly misclassified when they were classified from one extreme category to the other extreme category. Finally, Pearson correlation coefficients were calculated between the intake of saturated fat, monounsaturated fat, polyunsaturated fat and linoleic acid intake (\% of total fat) on the one hand and their relative amounts ( $\%$ of total fatty acids) in plasma phospholipids on the other.

The statistical analyses were performed by use of the SPSS-PC program (19). 
Table 2. Nutrient intake per day midway gestation, measured by the diet history (mean $\pm s . d$., $n=176$ ).

\begin{tabular}{lrl}
\hline Nutrient & Mean \pm s.d. & RDA $\$, \#$ \\
\hline Energy (MJ) & $9.8 \pm 2.54$ & 9.3 \\
\% of energy intake & & \\
Protein & $14.9 \pm 2.75$ & $10-15$ \\
Carbohydrate & $47.9 \pm 5.76$ & $50-55$ \\
TF & $38.1 \pm 5.56$ & $30-35$ \\
SAF & $15.9 \pm 2.51$ & $\leq 10$ \\
MUF & $14.6 \pm 2.45$ & 10 \\
PUF & $7.3 \pm 2.13$ & 10 \\
LA & $6.2 \pm 2.04$ & - \\
Cholesterol (mg/MJ) & $27.2 \pm 7.29$ & $\leq 33$ \\
Calcium (mg) & $1237 \pm 502$ & $800-1000$ \\
\hline
\end{tabular}

ๆ: TF, total fat; SAF, saturated fat; MUF, mono-unsaturated fat; PUF, polyunsaturated fat; LA, linoleic acid.

§: RDA, recommended daily amount.

\#: The RDA for total fat intake should be between 30 and $35 \%$ of energy intake and for SAF intake maximal $10 \%$ of energy intake. For the MUF and PUF intake no recommendations have been made. However, under ideal circumstances this will be $10 \%$ of energy intake (Netherlands Nutrition Council 1989, ref. 20).

\section{RESULTS}

The mean daily intake of total fat (TF), saturated fat (SAF), monounsaturated fat (MUF), polyunsaturated fat (PUF) and linoleic acid (LA), according to the three FFQs and diet history (DH) of 176 women, is shown in Table 1. Between the three trimesters, no significant differences in TF, SAF, MUF, PUF and LA consumption were observed. The mean nutrient intakes of TF, SAF, MUF, PUF and LA according to the questionnaire were significantly $(\mathrm{p}<0.0001)$ lower than according to the diet history (Table 1).

Nutrient intakes assessed with the diet history method are shown in Table 2, and compared with the Dutch (20) recommended daily amounts (RDA) for pregnant women. The mean daily intake of total energy (MJ), TF ( $\%$ of energy intake), SAF (\% of energy intake) and MUF (\% of energy intake) was above the RDA's; the mean daily intake of carbohydrates (\% of energy intake) and polyunsaturated fat (\% of energy intake) was below the RDA's. About 27 percent of the women met the goal for fat intake ( $\leq 35 \%$ of energy intake), 2 percent of the women for SAF intake ( $\leq 10 \%$ of energy intake) and 82 percent for cholesterol ( $\leq 33 \mathrm{mg} / \mathrm{MJ})$. About 26 percent of the subjects had a carbohydrate intake between 50 and $55 \%$ of energy intake. Although the mean calcium intake was above the RDA, 20 percent of the women had 
Table 3. Spearman rank correlation coefficients for nutrient intake between different stages of pregnancy $(n=176)^{\oint, *}$.

\begin{tabular}{lllll}
\hline Nutrient & I vs II & I vs III & II vs III & II vs DH \\
\hline TF $(\mathrm{g})$ & 0.52 & 0.42 & 0.61 & 0.64 \\
SAF $(\mathrm{g})$ & 0.49 & 0.44 & 0.58 & 0.61 \\
MUF $(\mathrm{g})$ & 0.53 & 0.44 & 0.62 & 0.65 \\
PUF $(\mathrm{g})$ & 0.65 & 0.57 & 0.66 & 0.66 \\
LA $(\mathrm{g})$ & 0.69 & 0.58 & 0.67 & 0.67 \\
\hline
\end{tabular}

§: I, FFQ-1st trimester; II, FFQ-2nd trimester; III, FFQ-3rd trimester; DH, Diet History.

$*:$ p $<0.001$ for all correlation coefficients presented.

I: TF,total fat; SAF, saturated fat; MUF, mono-unsaturated fat; PUF, polyunsaturated fat; LA, linoleic acid.

Table 4. The fatty acid camposition (\% of total fatty acids) of maternal plasma phospholipids (PLs) around 20 weeks of gestation $(n=80)$ and the correlation coefficient with fatty acid intake $(\%$ of total' fait).

\begin{tabular}{|c|c|c|c|}
\hline Fatty acid!! & $\begin{array}{l}\text { plasma PLs } \\
\text { mean } \pm \text { s.d. }\end{array}$ & $\begin{array}{l}\text { FFQ2 } \\
\text { I }(95 \% \mathrm{Cl})\end{array}$ & $\begin{array}{l}\text { DH } \\
\mathrm{r}(95 \% \mathrm{CI})\end{array}$ \\
\hline ¿SAFA & $42.5 \pm 1.40$ & $-0 . \mathrm{j} 0(-0.3 \mathrm{i}$ to 0.13$)$ & $-0.02(-0.24$ to 0.20$)$ \\
\hline ¿MUFA & $12.2 \pm 1.42$ & $-0.00(-0.22$ to 0.22$)$ & $-0.02(-0.24$ to 0.20$)$ \\
\hline ¿PUFA & $41.1 \pm 1.62$ & $0.35(0.14 \text { to } 0.53)^{\mathrm{a}}$ & $0.45(0.26 \text { to } 0.61)^{\mathrm{c}}$ \\
\hline $18: 2(n-6)$ & $21.6 \pm 2.9 !$ & $0.37(0.16 \text { to } 0.55)^{b}$ & $0.43(0.23 \text { to } 0.59)^{\mathrm{c}}$ \\
\hline
\end{tabular}

I: ¿SAFA, sum of saturated fatty acids; IMUFA, sum of the mono-unsaturated fatty acids; $\Sigma$ PUFA, sum of the polyunsaturated fatty acids; 18:2(n-6), linoleic acid.

a: $p<0.002 ; b: \bar{p}<0.001 ; c: p<0.0001$. FFQ: food frequency questionnaire. DH: diet history.

a calcium intake below $800 \mathrm{mg}$. Approximately 55 percent of the women did not consume any alcohol. Only 2 persons consumed more than 10 gram (corresponds with one alcoholic consumption) alcohol a day.

No significant differences were observed for the nutrient intakes between smokers ( $\mathrm{n}$ $=42)$ and non-smokers $(n=134)$ and between nullipara and primi/multipara. Women with the highest education (university and higher vocational education, $n=36$ ) had significantly $(p<0.05)$ lower mean intake of MUF (13.7 vs $15.3 \%$ of energy intake) and higher mean intake of protein ( 15.8 vs $13.9 \%$ of energy intake) and calcium (1454 vs $1134 \mathrm{mg}$ ) compared to the mean intake of women with the lowest education (primary school and lower vocational education, $n=39$ ).

In Table 3, Spearman rank correlation coefficients for the intake of TF, SAF, MUF, 
PUF and LA between the different trimesters and between FFQ2 and DH are summarized. All correlations were highly significant ( $p<0.001)$. The correlations between the first trimester and the other two were not as strong as between the second and third trimester. The Spearman correlation coefficient between FFQ2 and DH ranged from $0.61(95 \% \mathrm{Cl}: 0.51-0.70)$ for SAF to $0.67(95 \% \mathrm{Cl}: 0.58-0.74)$ for LA. When comparing the classification of nutrient intake, assessed by FFQ2, with the classification according to DH, 2 women $(1.1 \%)$ were grossly misclassified for the intake of TF and SAF, 1 woman $(0.6 \%)$ for PUF, no women for MUF and LA. At least 75 percent of the women were classified in the same or an adjacent category. For the intake of MUF and LA. it was even 80 percent.

In Table 4 the fatty acid composition of the maternal plasma phospholipids and its correlation coefficients with the intake assessed by the FFQ2 and DH are shown. Significant correlations between dietary intake ( $\%$ of total fat) and the relative amount in plasma phospholipids ( $\%$ of total fatty acids) were observed for PUF and for LA. No significant correlations were found for SAF and MUF.

\section{DISCUSSION}

This study shows that there was no measurable change in the mean daily intake of total fat (TF), saturated fat (SAF), monounsaturated fat (MUF), polyunsaturated fat (PUF) and linoleic acid (LA) of Dutch women during normal pregnancy. In addition, the significant correlations between the different trimesters for the intakes of TF, SAF, MUF, PUF and LA indicate that the individual dietary composition, with respect to the fat intake, is rather stable during pregnancy.

Berg and Bruinse (3) observed a consistent dietary behavior in 67 healthy Dutch gravidae, too. However, they found a significantly lower fat intake in the third trimester compared to the first, assessed with the diet history method. A reduced fat intake in late pregnancy was also reported by other investigators $(21,22)$. Using the 7 day weighed dietary record, Doyle et al. (23) observed the lowest fat intake in the first trimester; it has to be noticed, however, that $95 \%$ of the women participating in that study had an energy intake below the recommended dietary allowances in all three trimesters. This inconsistency in result could be due to the different methods used to assess nutrient intake. In a recent study among 50 American pregnant women, in which a food frequency questionnaire was used also, no differences in nutrient intake were observed between the second and third trimester (24).

Each method to assess dietary intake has specific advantages and disadvantages $(25,26)$. The method to be preferred in nutrition surveys depends on the purpose of the study, the accuracy of the methods, the target group and the availability of resources (27). We have chosen for a combination of two methods, the FFQ and the diet history (DH). The food frequency questionnaire represents a cheap, simple and quick method 
since it can be completed by the subjects themselves, without special training (27). The FFQ used in this study, was specially developed to collect data on the fat consumption of the participating women in the course of pregnancy. To estimate the total energy intake and other dietary components of the pregnant women, the diet history method was carried out, mid gestation.

The FFQ and DH methods both have a strong subjective component. The information collected by the interviewer is based entirely on an individual's memory and report (27). An advantage of our study is that only one dietitian was involved, so observer differences can be excluded. It is, however, important to know the validity of both methods used. Because there is no gold standard for the assessment of dietary intake, only the relative validity can be determined. The $\mathrm{DH}$ is considered to be a reliable method (27) and the results of the diet history in our study were in agreement with the mean nutrient intake of pregnant women reported by a nationwide dietary survey carried out in the Netherlands recently (11). Together with the significant positive correlation between intake of PUF and LA and their relative amounts in plasma phospholipids, this implies that the results of the DH are reliable.

The relative validity of the FFQ was evaluated by comparison with the results of the $\mathrm{DH}$ and with a biological marker. The mean daily intake of TF, SAF, MUF, PUF and LA according to FFQ2 was lower than the intake according to the diet history. This may be due to the fact that the number of food items listed in the FFQ was not exhaustive and the diet history method yields higher values in general (28). However, the FFQ was designed to classify individuals by their intake of fat. The FFQ was able to classify more than 75 percent of the women correctly. Less than 2 percent was grossly misclassified. These percentages are comparable with those reported by others $(29,30)$. In addition, significant positive correlations were observed between FFQ2 and the diet history for the intake of TF, SAF, MUF, PUF and LA (Table 3) and between the LA and PUF intake and their concentrations in plasma phospholipids. So, the FFQ used in this study seems to be a valid method to rank participants adequately according to their dietary intake of TF, SAF, MUF, PUF and LA. However, according to our own experience and that of others $(24,30)$, training the study population in how to use a FFQ may even further improve the validity of the results derived from the FFQ.

A difference was observed between the intake of MUF ( $\%$ of energy intake), protein (\% of energy intake) and calcium of women with the highest educational level compared with the lowest. However, compared to the RDAs these differences were not disturbing. This in contrast to the small part of the women who met the goals for total fat intake ( $27 \%$ ) and SAF intake ( $2 \%$ ), according to the Dutch quidelines for a healthy diet. Although all women had a normal pregnancy, it is possible that a suboptimal maternal diet during gestation may affect the post-natal development of the child, since evidence is now emerging that maternal nutrition, and fetal and infant growth, may have an imprinting effect on the risk of cardiovascular disease in adult life (31). 
In conclusion, no change was observed throughout uncomplicated pregnancy for the mean daily intake of total, saturated, monounsaturated and polyunsaturated fat and of linoleic acid of Dutch women. In addition, the individual dietary composition with respect to these nutrients seems consistent during normal gestation. Finally, the FFQ used in this study is able to reasonably rank subjects adequately according to the intake of the nutrients investigated. This allows us to use this FFQ for a future comparison between uncomplicated and complicated pregnancies.

\section{ACKNOWLEDGEMENT}

The authors wish to thank the women for their participation and are grateful to A.BL Assen for analysing the plasma samples.

\section{REFERENCES}

1. Rosso P. Nutrition and metabolism in pregnancy. Oxford: Oxford University Press, 1990.

2. National Academy of Sciences. Nutrition during pregnancy. Part I, Weight gain. Part II, Nutrient supplements. 1990.

3. Berg van den $\mathrm{H}$, Bruinse $\mathrm{HW}$. On the role of nutrition in normal human pregnancy. $\mathrm{PhD}$ thesis 1983. State University Utrecht, Utrecht, The Netherlands.

4. Uauy R, Treen M, Hoffman DR. Essential fatty acid metabolism and requirements during development. Seminars in Perinatology 1989; 13:118-30.

5. Lundin-Schiller S. Mitchell MD. The role of prostaglandins in human parturition (review). Prost Leukotr and Essential Fatty Acids 1990; 39: 1-10.

6. Dyerberg J, Bang HO. Pre-eclampsia and prostaglandins (letter). Lancet 1985; i: 1276.

7. Andersen HJ, Andersen LF, Fuchs AR. Diet, pre-eclampsia and intra-uterine growth retardation. Lancet $1989 ; i: 1146$.

8. Wang, Y, Kay HH \& Killam AP. Decreased levels of polyunsaturated fatty acids in preeclampsia. Am J Obstet Gynecol 1991; 164: 812-8.

9. Schouw vd YT, Al MDM, Hornstra G, Bulstra-Ramakers MTEW, Huisjes HJ. Fatty acid composition of serum lipids of mothers and their babies after normal and hypertensive pregnancies. Prost Leukotr Essential Fatty Acids 1991; 44: 247-52.

10. Kloosterman GJ. On intrauterine growth. Int J Gynaecol Obstet 1970; 8: 895-912.

11. Ministry of Welfare, Public health and Culture, Ministry of Agriculture and Fischeries. What does Holland eat. Results of the food consumption survey 1987-1988. Rijswijk, The Netherlands, 1988 (in Dutch).

12. NEVO Foundation. Dutch food composition table 1989-1990. Voorlichtingsbureau voor de Voeding. The Hague, The Netherlands (in Dutch).

13. Beal VA. The nutritional history in longitudinal research. I Am Diet Assoc 1967; 51: 426-32.

14. Folch J, Lees M, Sloane Stanley GH. A simple method for the isolation and purification of total lipides from animal tissues. J Biol Chem 1957; 226: 497-509.

15. Hoving EB, Jansen G, Volmer M. Doormaal van JJ, Muskiet FAJ. Profiling of plasma cholesterol esters and triglyceride fatty acids as their methylesters by capillary gas chromatography, preceded by a rapid aminopropyl-silica column chromatographic separation of lipid classes. J Chromatogr 1988; 434: 395-409. 
16. Kaluzny MA, Duncan LA, Merritt MV, Epps DE. Rapid separation of lipid classes in high yield and purity using bonded phase columns. J Lipid Res 1985; 26: 135-40.

17. Morrison WR, Smith LM. Preparation of fatty acid methylesters and dimethyl-acetals from lipids with boron fluoride-methanol. J Lipid Res 1964; 5: 600-8.

18. Willett WC. Reproducibility and validity of food frequency questionnaires. In: Willett WC, ed. Nutritional Epidemiology. New York/Oxford: Oxford University Press, 1990: 92-126.

19. Nie NH, Hull CH, Jenkins JG, Steinbrenner K, Bent DH, eds. SPSS-X: statistical package for the social sciences. New York: McGraw-Hill, 1983.

20. Netheriands Nutrition Council. Guidelines for a healthy diet. The Hague: Voedingsraad, 1989 (in Dutch).

21. Beal VA. Nutritional studies during pregnancy. I. Changes in intakes of calories, carbohydrate, fat, protein and calcium. J Am Diet Assoc 1971; 58: 312-20.

22. Haste FM, Brooke OG, Anderson HR, et al. Nutrient intakes during pregnancy: observations on the influence of smoking and social class. Am J Clin Nutr 1990; 51: 29-36.

23. Doyle $W$, Crawford MA, Laurance BM, Drury P. Dietary survey during pregnancy in a low socio-economic group. Human Nutrition: Applied Nutrition 1982; 36A: 95-106.

24. Greeley S, Storbakken L, Magel R. Use of a modified food frequency questionnaire during pregnancy. J Am Coll Nutr 1992; 11: 728-34.

25. Marr JW. Individual dietary surveys, purposes and methods. World Rev Nutr Diet 1971; 13: 105-64.

26. Staveren van WA. Dietary intake methods: their validity and reproducibility. PhD thesis, 1985 . Agriculture University, Wageningen, The Netherlands.

27. Cameron ME, Staveren van WA. Manual on methodology for food consumption studies. Oxford: Oxford Medical Publications, 1988.

28. Block G. A review of validations of dietary assessment methods. Am J Epidemiol 1982; 115 : 492-505.

29. Willett WC, Sampson L, Stampfer MJ, et ai. Reproducibility and validity of a semiquantitative food frequency questionnaire. Am J Epidemiol 1985; 122: 51-65.

30. Feunekes GiJ, Staveren van WA, Vries de JHM, Burema J. Hautvast JGAJ. Relative and biomarker-based validity of a food-frequency questionnaire estimating intake of fats and cholesterol. Am J Clin Nutr 1993; 58: 489-96.

31. Barker DIP, Gluckman PD, Godfrey KM, Harding JE, Owens JA, Robinson JS. Fetal nutrition and cardiovascular disease in adult life. Lancet 1993; 341: 938-41. 


\section{CHAPTER 5}

Maternal essential fatty acid patterns during normal pregnancy and its relationship with the neonatal essential fatty acid status

Monique D.M. Al, Adriana C. v. Houwelingen, Arnold D.M. Kester, Tom H.M. Hasaart, Andre E.P. de Jong and Gerard Hornstra

British Journal of Nutrition, accepted

\section{ABSTRACT}

Although essential fatty acids (EFAs) and their longer-chain, more unsaturated derivatives play a major role during pregnancy, hardly any information is available with respect to the course of the maternal EFA status during an uncomplicated pregnancy and its relationship with the neonatai EFA status. Therefore, a longitudinal study was started in which 110 pregnant women gave repeatedly a blood sample from the 10th week of gestation until delivery. After birth, a blood sample from the umbilical vein and a maternal venous sample were collected as well, and six months after delivery, a final blood sample from the mother was taken $(n=43)$. The absolute $(\mathrm{mg} / \mathrm{L})$ and relative $(\%$ of total fatty acids) amounts of the fatty acids in plasma phospholipids were determined. The total amounts of fatty acids increased significantly during pregnancy. This pattern was similar for the individual fatty acids and fatty acid families. The relative amounts of linoleic acid [18:2(n-6)] did not change during pregnancy, whereas the relative amounts of arachidonic acid [20:4(n6)] decreased. Despite a maternal mobilization of cervonic acid (22:6(n-3), CA), suggested by a temporarily increase in the CA status until 18 weeks of gestation, the CA status steadily declined thereafter. This was associated with a progressive increase of the cervoric acid deficiency index in maternal blood throughout pregnancy and resulted in a sub-optimal neonatal CA status. The overall maternal EFA status steadily declined during pregnancy also. Therefore, to ensure an adequate EFA status of mother and fetus during gestation, it may be advisable to supplement pregnant women with $\mathrm{EFA}, \mathrm{CA}$ in particular. 


\section{INTRODUCTION}

Essential fatty acids (EFAs) and their longer-chain, more unsaturated derivatives play a major role during pregnancy. They provide the precursors for prostaglandins and leukotrienes and they are important constituents of all cell membranes, especially those in the brain, and in the nervous and vascular systems. During the third trimester of pregnancy, rapid synthesis of brain tissue occurs (1) and the quantitative accretion in the human brain of the long chain polyenes arachidonic acid $(20: 4(n-6), A A)$ and cervonic acid (22:6(n-3), CA) increases steadily with gestation $(2,3)$. CA plays an important role in the visual process and the amount of $\mathrm{CA}$ in the human retina also increases with maturation (4). Evidence is growing that CA is essential for a normal development of brain and retina (5-7).

Recently, it has been suggested that fish-oil, rich in fatty acids of the (n-3) family, might reduce the occurrence of obstetric complications such as preterm delivery (8) and pregnancy induced hypertension (9-13). But not only $(n-3)$ fatty acids seem to be important to establish a normal pregnancy, because decreased maternal levels of linoleic acid (18:2(n-6), LA) have been observed in pregnancy-induced hypertension $(14,15)$ and intra-uterine growth retardation $(16)$. Therefore, fatty acids like LA, AA and CA may be of great importance in the diet of pregnant women. However, most studies relating pregnancy complications to EFA status are based on retrospective case-control designis, using material collected in late pregnancy or post-partum. Therefore, these studies do not allow any conclusion with respect to a possible cause and effect relationship. Such a conclusion would require prospective longitudinal monitoring of the maternal EFA status and the comparison of the maternal EFA courses during normal and complicated pregnancies. Hardly any information is presently available with respect to the course of the maternal EFA status during uncomplicated pregnancy. Therefore, we performed a longitudinal study to investigate the EFA status of women during normal pregnancy. In addition, the relationship between maternal and neonatal EFA status was investigated.

\section{SUBJECTS, MATERIALS AND METHODS}

\section{Study design}

At their first antenatal medical visit, pregnant women were asked to participate in the study. The selection criteria for entering the study were a gestational age less than 16 weeks, singleton pregnancy, Caucasian race, diastolic blood pressure below $90 \mathrm{~mm}$ $\mathrm{Hg}$, and the absence of any metabolic, cardiovascular, neurological or renal disorder. In total 140 women entered the study. Excluded were women who developed pregnancy-induced hypertension $(n=11)$ or gestational diabetes $(n=2)$, women who delivered their babies before 37 weeks of gestation $(n=8)$, or after 42 weeks. $(n=5)$, and women whose babies were not appropriate for gestational age $(<\mathrm{P} 2.3(\mathrm{n}=3)$ and $>$ P97.7 $(\mathrm{n}=1))$. Finally, 110 women with an uncomplicated pregnancy met the 
Table 1. Characteristics of the study population $\$$.

Variable

\begin{tabular}{|c|c|c|}
\hline Age mother (yr) & 29.5 & $19-43$ \\
\hline Gestational age (wks & 40.4 & $37-42$ \\
\hline Birthweight (g) & 3403 & $2130-4410$ \\
\hline Apgar score (5 min) & 10 & $6-10$ \\
\hline Parity at entry (n) & 47 & \\
\hline 1 & 46 & \\
\hline 2 & 14 & \\
\hline 3 & 3 & \\
\hline Sex (n) male & 62 & \\
\hline female & 48 & \\
\hline
\end{tabular}

\$: Mean and range (minimum-maximum) given, except for parity and sex.

inclusion criteria. Their relevant clinical information is summarized in Table 1. Maternal venous blood samples were collected into EDTA-tubes at 10 weeks of gestation $(n=45)$, at 14 weeks $(n=98)$, at 18 weeks $(n=101)$, at 22 weeks $(n=97)$, at 26 weeks $(n=98)$, at 30 weeks $(n=105)$, at 32 weeks $(n=103)$, at 34 weeks $(n=100)$, at 36 weeks $(n=101)$, at 38 weeks $(n=86)$ and at 40 weeks $(n=39)$. Immediately after delivery, a blood sample from the umbilical vein $(\mathrm{n}=98)$ and a maternal venous blood sample ( $n=95$ ) were collected also. At least six months post-partum, 43 women gave a blood sample once more. The protocol was approved by the Ethics Committee of the University and written consent was obtained from each participant.

\section{Biochemical analyses}

Plasma was separated from the erythrocytes by centrifugation and stored at $-80^{\circ} \mathrm{C}$ until fatty acid analysis. Fatty acid composition of the phospholipid fraction was performed using $100 \mu \mathrm{l}$ plasma samples. A total lipid extract was prepared via a modified Folch extraction (17,18). Before lipid extraction, $50 \mu \mathrm{l}$ of an internal standard (IS) solution was added. The IS solution consisted of $62 \mathrm{mg}$ 1,2,dinonadecanoyl-sn-glycero-3-phosphocholine $\quad\left(\mathrm{PC}(19: 0)_{2}\right), \quad 40 \quad \mathrm{mg} \quad 10$ heptadecenoic acid (C17:1) to check carry over of free fatty acids during the phospholipid separation procedure (see below), and $100 \mathrm{mg}$ BHT, dissolved in 100 $\mathrm{ml} \mathrm{MeOH}$. Aminopropyl bonded silica columns (500 mg) were used to separate phospholipids from the total lipid extract (19). The phospholipids were saponified and the fatty acids (FA) transmethylated to the corresponding methylesters (FAME) by reaction with $14 \% \mathrm{BF} 3$ in methanol at $100^{\circ} \mathrm{C}$ for one hour (20). The FAMEs were separated and quantified by using a HP 5890 II gas chromatograph, fitted with a $50 \mathrm{~m}$ CP Sil5 CB non-polar capillary column with $0.25 \mathrm{~mm}$ ID and $0.12 \mu \mathrm{m}$ film thickness (Chrompack®, Middelburg, The Netherlands) and a split ratio of 1:40. The injection temperature was $250^{\circ} \mathrm{C}$ and the detector temperature $300^{\circ} \mathrm{C}$. The starting 
temperature of the column was $160^{\circ} \mathrm{C}$. After 2 minutes, the temperature increased up to $220^{\circ} \mathrm{C}$ with a rate of $2^{\circ} \mathrm{C} / \mathrm{min}$ and finally to $280^{\circ} \mathrm{C}$ with a rate of $6^{\circ} \mathrm{C} / \mathrm{min}$. The flow rate of the carrier gas $\left(\mathrm{N}_{2}\right)$ was $35 \mathrm{ml} / \mathrm{min}$. A standard FAME mixture was used to identify the fatty acid methylesters by means of the retention times. Quantifying the amount of FAMEs was based on the ratio between the peak area 19:0 and the peak area of the fatty acid methylesters in the sample multiplied by the amount of 19:0 present in the internal standard solution. The results were expressed in absolute amounts (mg/L plasma) as well as in relative amounts (\% of total fatty acids).

\section{Essential fatty acid status parameters}

Two indices were calculated to describe the essential fatty acid status of the mother and her newborn. The cervonic acid deficiency index (CADI) $(21,22)$, defined as the ratio between $22: 5(n-6)$ and $22: 4(n-6)$, was used because a deficit of $22: 6(n-3)$ is accompanied by an increase in the conversion of $22: 4(n-6)$ to $22: 5(n-6)$, resulting in higher CADI values (6). The other index was the essential fatty acid status (EFA status) (22), defined as the ratio between the sum of the (n-3) and (n-6) fatty acids and the sum of the (n-7) and (n-9) fatty acids. In general, if the supply of (n-3) and (n-6) fatty acids is sufficient, the desaturation of oleic acid to the long chain polyenes of the $(n-9)$ family is limited, leading to higher EFA status values. The EFA status was used instead of the classic triene/tetraene ratio (an indicator of an essential falty acid deficiency) (23), because this ratio does not account for changes in delta-5-desaturase activity (24).

\section{Statistical analyses}

During the gestational period ( 10 weeks through 40 weeks), it was not always possible to take all blood samples at exactly the intended days. Since we wanted to analyze values at specified gestational ages, the values of the fatty acid amounts and percentages at those days were estimated by lineair interpolation between the days when blood had been sampled. For blood samples taken within one week before or after the intended sampling day, interpolation was considered unnecessary. Because of remaining missing data, means were estimated with adjustment for missing data using the repeated measures analysis program BMDP $5 \mathrm{~V}(25,26)$. This program adjusts the means using the correlations between measurement times.

Using a model with a quadratic dependence of the fatty acid parameter on time, we tested whether a lineair or quadratic course was present. Data from blood samples at 10 weeks of gestation, immediately post-partum (pp), 6 months after delivery (ad), and from the umbilical vein (uv) were analysed in a similar model. The data from weeks 22-32 were included in this analysis to take full advantage of the missing data adjustment. Comparison of pp, ad, uv, and week 10 was done by the Wald test (26).

Pearson correlation were used to correlate maternal with neonatal values at delivery and to relate the parameters, gestational age, birthweight, head circumference and placental weight and size with maternal values early in pregnancy (week 10,14 and 18 ) and maternal and neonatal fatty acid values at delivery. Correlation coefficients were calculated for the CADI and EFA status and for the absolute and relative 


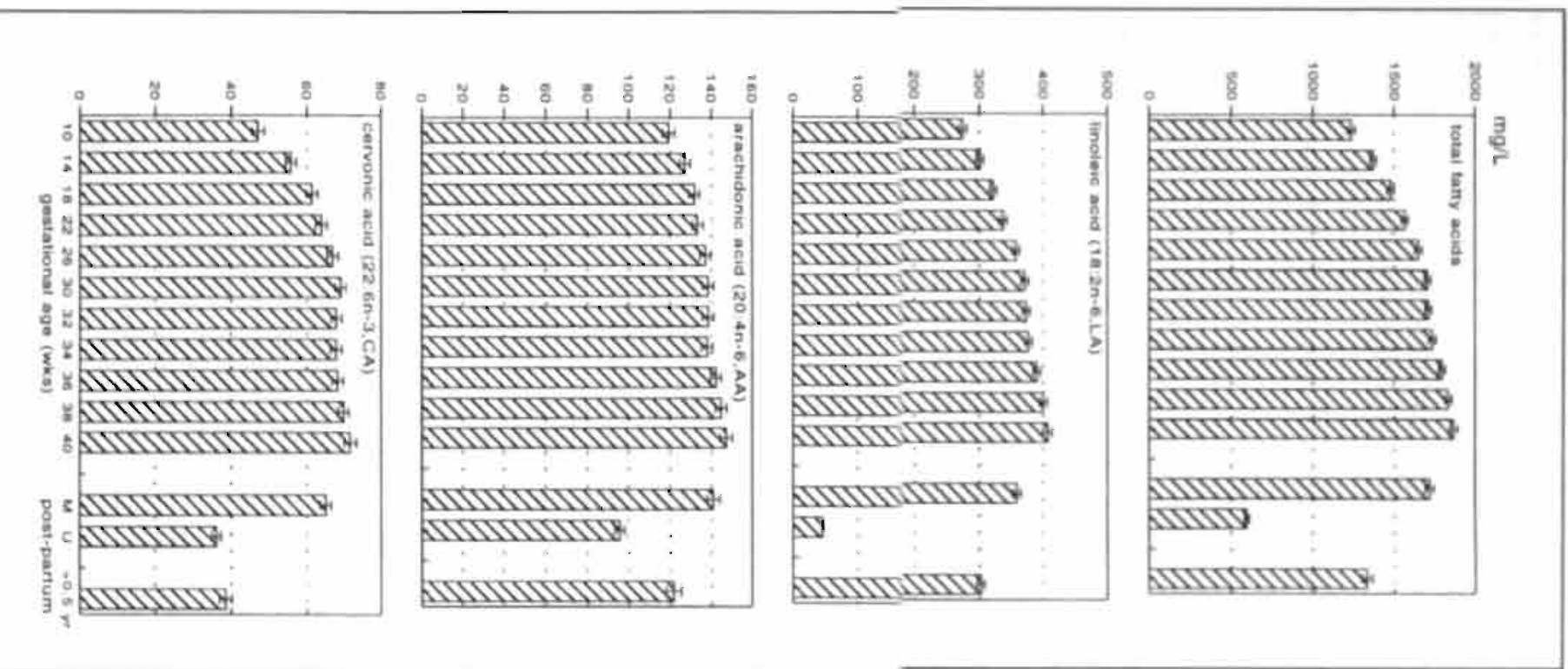

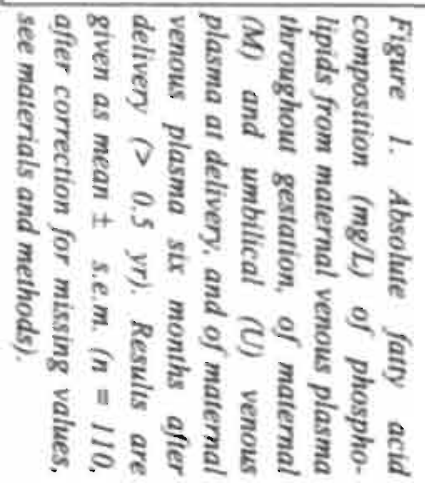



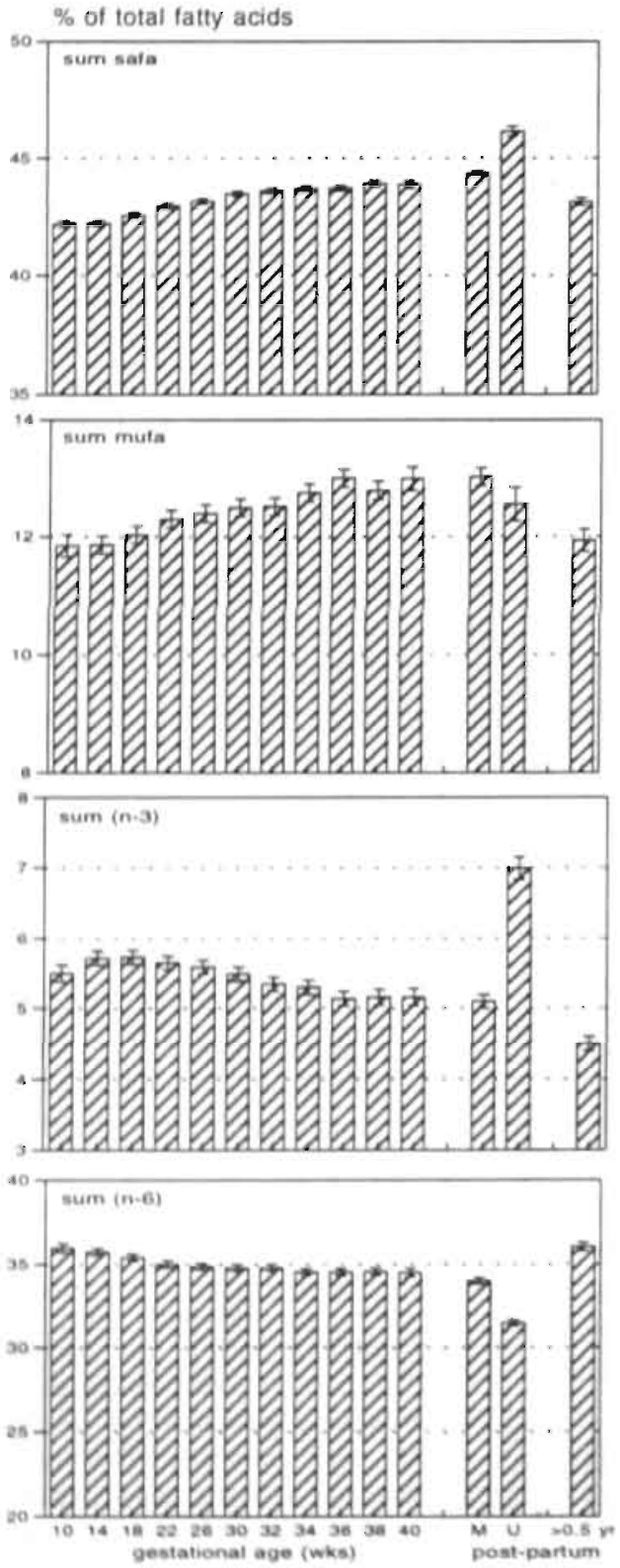

Figure 2. The relative $\%$ of total fatry acids) fatty acid composition of phospholipids from maternal venous plasma throughout gestation, of maternal $(M)$ and umbilical $(U)$ venous plasma at delivery, and of maternal venous plasma six months after delivery $(>0.5 \mathrm{yr}$ ). Results are given as mean \pm s.e.m. $(n=110$, after correction for missing values, see materials and methods).

sum SAFA, sum of saturated fatry acids: sum MUFA, sum of monounsaturated fatry acids: sum (n-3). sum of the fatty acids of the (n-3) family; sum (n-6). sum of the fatty acids of the (n-6) family. 
amounts of $\sum$ SAFA, $\sum$ MUFA, $\sum \mathrm{n}-3, \sum \mathrm{n}-6,18: 2(\mathrm{n}-6), 20: 4(\mathrm{n}-6)$ and $22: 6(\mathrm{n}-3)$. Multiple regression was performed to adjust for the potential confounding variables parity, maternal height, weight and age, smoking habits and educational level of the mother and sex of the newborn for the relationship between gestational age and fatty acid values. When studying the association between size of the newborm, placental weight and placental size and fatty acid levels, gestational age was also included as a potential confounder.

When groups were compared, Student's t-test was performed.

\section{RESULTS}

Plasma fatty acids of chain lenghts ranging from 14 to 24 carbon atoms were identified; however only the three major essential fatty acids linoleic acid (18:2(n-6), LA), arachidonic acid (20:4(n-6), AA) and cervonic acid (22:6(n-3), CA), the sum of the fatty acids of the $n-6$ family $\left(\sum n-6\right)$ and $n-3$ family $\left(\sum n-3\right)$, the sum of the saturated fatty acids ( $\left.\sum \mathrm{SAFA}\right)$ and mono-unsaturated fatty acids ( $\mathrm{MMUFA}$ ) and the two indices CADI and EFA status are discussed in this paper. The full data are given in appendices $\mathrm{B} 1$ and $\mathrm{B} 2$.

The results are presented mostly in figures, showing the mean amount ( \pm s.e.m.) of fatty acids in maternal venous plasma phospholipids (PLs) during gestation, in maternal (M) and umbilical (U) venous plasma PLs immediately after delivery, and in maternal venous plasma PLs at least six months post-partum.

\section{The maternal fatty acid patterns during pregnancy}

The average total amount of fatty acids (TF) in maternal venous plasma PLs increased significantly ( $p<0.0001$ ) during pregnancy (Figure 1), but the rise in TF became less strong towards the end of gestation $(\mathrm{p}<0.0001)$. The mean amount of TF increased by $51 \%$ from $1238.11 \mathrm{mg} / \mathrm{L}$ at week 10 till $1867.84 \mathrm{mg} / \mathrm{L}$ at week 40 of gestation. Al! the fatty acid families, when expressed as $\mathrm{mg} / \mathrm{L}$ plasma, showed a similar course: the $\sum n-6$ increased by $44 \%$, the $\sum n-3$ by $41 \%$, the $\sum$ SAFA by $57 \%$ and the $\sum M U F A$ by $65 \%$ from week 10 till week 40 (data not shown). When focussed on the individual fatty acids LA, A.A and CA (Figure 1), the highest increment was for CA (52\%), followed by LA ( $48 \%)$ and AA (23\%). Six months after delivery, TF in maternal plasma PLs had returned to levels comparable with those at the 14th week of pregnancy. The same applied to $\sum n-6, \Sigma S A F A, \Sigma M U F A, L A$ and AA. The mean absolute amounts of $C A$ and $\sum n-3$ had declined to levels even significantly $(p<0.01)$ lower than at 10 weeks of gestation.

The relative amounts of the fatty acids did show a different pattern as compared to the absolute amounts. For $\Sigma$ SAFA and $\Sigma$ MUFA in maternal plasma PLs, a significant ( $\mathrm{p}$ $<0.0001$ ) increase was observed throughout pregnancy (Figure 2). After a slight increase at the end of the first trimester, the $\sum \mathrm{n}-3$ decreased significantly $(\mathrm{p}<0.0001)$ during pregnancy and levelled off at the end of gestation. The mean relative amounts 

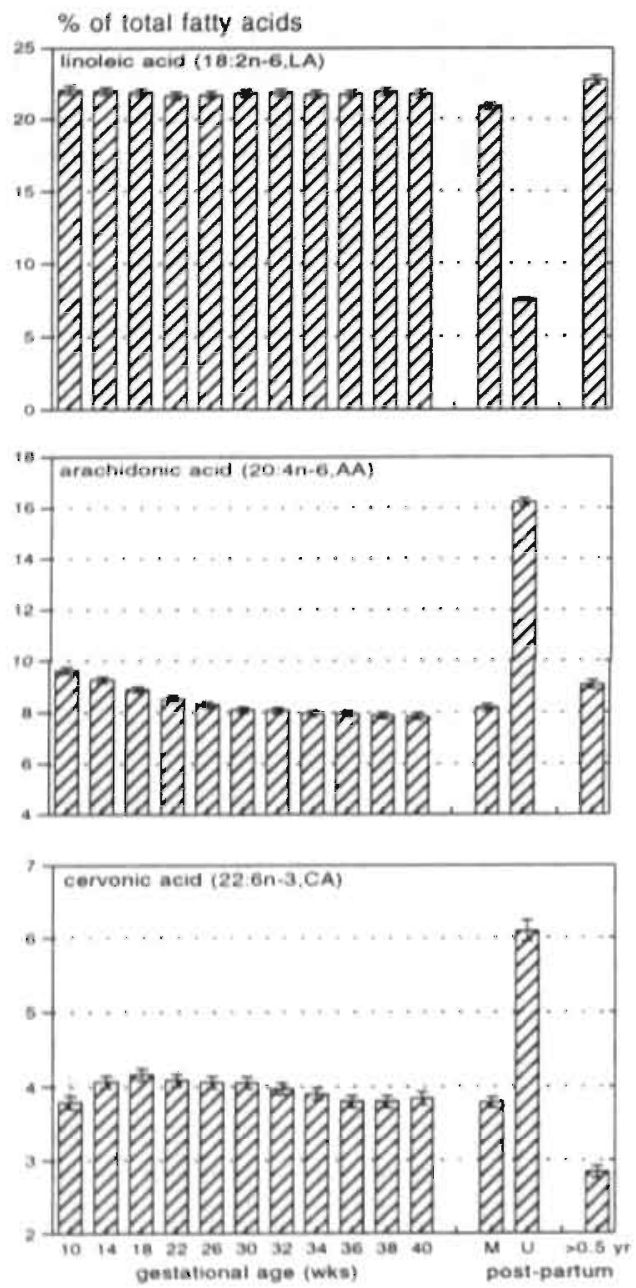

Figure 3. The relative $\%$ of total fatty acids) fatty acid composition of phospholipids from maternal venous plasma throughout gestation, of maternal $(M)$ and umbilical $(U)$ venous plasma at delivery, and of maternal venous plasma six months after delivery $(>0.5 \mathrm{yr}$ ). Results are given as mean \pm s.e.m. $(n=110$, after correction for missing values; see materials and methods).

of $\sum \mathrm{n}-6$ steadily diminished $(\mathrm{p}<0.0001)$ throughout pregnancy (Figure 2$)$. This latter observation was mainly due to the maternal AA status which declined from $9.6 \%$ at week 10 till $7.8 \%$ at week 40 (Figure 3). The maternal CA status also diminished, but only after a temporary increase until 18 weeks of gestation. In contrast, the maternal LA status did not change throughout pregnancy (Figure 3).

While six months after delivery the $\sum \mathrm{n}-6, \sum$ MUFA. (Figure 2) and the relative amounts of LA and AA in maternal plasma PLs (Figure 3) had returned to early pregnancy levels, the $\Sigma$ SAFA had levels comparable with those of midway gestation 


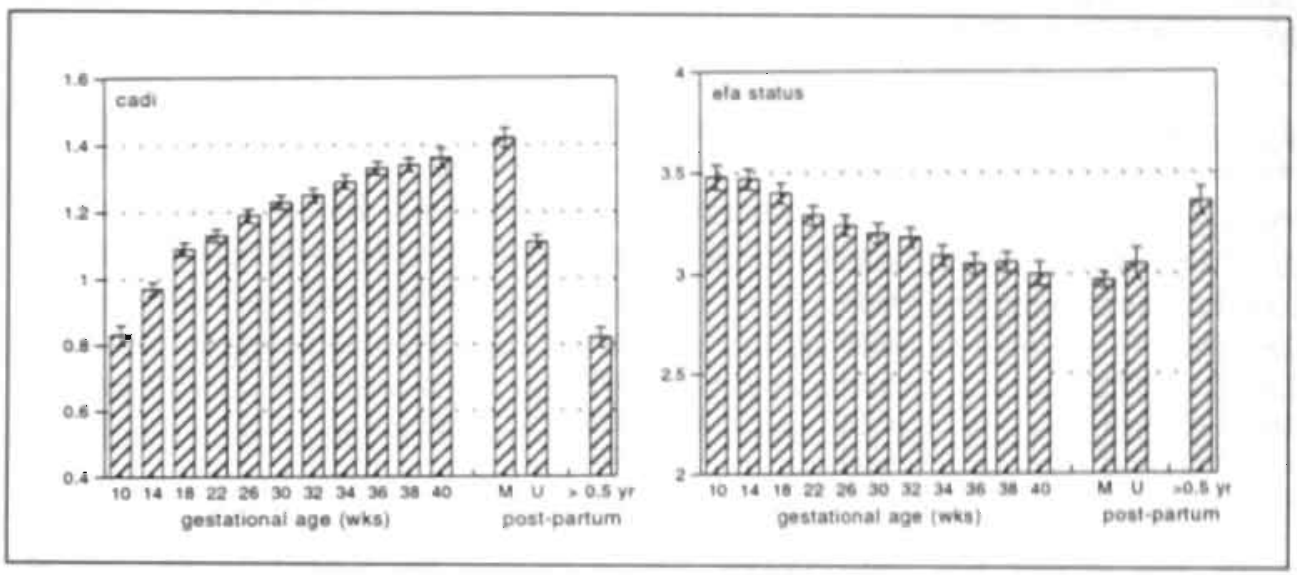

Figure 4. The essential fatry acid status parameters calculated from phospholipids of maternal venous plasma throughout gestation, of maternal $(M)$ and umbilical $(U)$ venous plasma at delivery. and of maternal venous plasma six months after delivery $(>0.5 \mathrm{yr})$. Results are given as mean \pm s.e.m. ( $n=110$, after correction for missing values, see materials and methods).

CADI, Cervonic Acid Deficiency Index [22:5(n-6)/22:4(n-6)]: EFA status, Essential Fatty Acid Status $\left[\left(\Sigma n-3+\sum n-6\right) /\left(\sum n-7+\sum n-9\right)\right]$.

(Figure 2). After delivery, the maternal CA status decreased further to $2.8 \%$ six months post-partum, which is significantly $(\mathrm{p}<0.0001)$ lower than at 10 weeks of gestation (Figure 3). A similar pattern was observed for the $\sum \mathrm{n}-3$ (Figure 2) which declined to $4.5 \%$ six months post-partum.

The cervonic acid deficiency index (CADI) increased significantly $(p<0.0001)$ throughout gestation (Figure 4) and levelled off towards the end of pregnancy ( $<<$ 0.0001 ). Six months after delivery, the CADI was equal to the CADI at 10 weeks of gestation. The essential fatty acid status (EFA status) declined continuously throughout the duration of pregnancy. Six months after birth, the maternal EFA status had returned to early pregnancy levels.

\section{Comparison between maternal and neonatal fatty acid values}

The mean amount of TF in umbilical plasma PLs was substantially lower $(p<0.0001)$ than all maternal values (Figure 1). This was observed for all four fatty acid families: for $\Sigma$ SAFA and $\Sigma$ MUFA the mean amount $(\mathrm{mg} / \mathrm{L})$ in umbilical plasma PLs was only about $35 \%$ of that in maternal plasma PLs at delivery; for $\sum \mathrm{n}-6$ and $\sum \mathrm{n}-3$ these proportions. were 32 and 47 , respectively (data not shown). The mean amount (mg/L) in umbilical plasma PLs (Figure 1) was for LA only 13\% of the maternal values at delivery, while for AA and CA the percentages were $68 \%$ and $56 \%$, respectively $(\mathrm{p}<$ 0.0001 for all three fatty acids). The neonatal value for CA was not significantly different from the maternal level six months after delivery (Figure 1).

In contrast to the absolute amounts for $\mathrm{AA}$ and $\mathrm{CA}$, the mean relative amounts of $\mathrm{AA}$ 
Table 2. Pearson correlation coefficients between maternal and umbilical venous plasma phospholipids fatty acids $(n=90)$.

\begin{tabular}{lll} 
Fatty acid & $\mathrm{r}$ & $\mathrm{p}$ \\
\hline TF $(\mathrm{mg} / \mathrm{L})$ & & $\mathrm{NS}$ \\
$\sum \mathrm{SAFA}(\%$ of TF) & 0.04 & $<0.0001$ \\
$\sum$ MUFA $(\%$ of TF) & 0.45 & $<0.0001$ \\
$\sum \mathrm{n}-6(\%$ of TF) & 0.60 & $<0.0001$ \\
$\sum \mathrm{n}-3(\%$ of TF) & 0.60 & $<0.0001$ \\
$18: 2(\mathrm{n}-6)(\%$ of TF) & 0.52 & $<0.0001$ \\
$20: 4(\mathrm{n}-6)(\%$ of TF) & 0.56 & $<0.0001$ \\
$22: 6(\mathrm{n}-3)(\%$ of TF) & 0.60 & $<0.0001$ \\
\hline
\end{tabular}

ף: TF, sum of total fatty acids; ¿SAFA, sum of saturated fatty acids: ¿MUFA, sum of monounsaturated fatty acids; $\sum n-6$, sum of fatty acids of the (n-6) family; $\sum n-3$, sum of fatty acids of the (n-3) family.

and CA in umbilical plasma PLs were significantly $(\mathrm{p}<0.0001)$ higher than all maternal values (Figure 3 ). However, the mean relative amounts of LA in umbilical venous plasma PLs was significantly $(\mathrm{p}<0.0001)$ lower than that of the mother (Figure 3). This resulted in a significant lower $\sum \mathrm{n}-6$ in umbilical plasma PLs compared to maternal plasma PLs, despite the higher neonatal AA levels (Figure 2). The $\sum \mathrm{n}-3$ and $\sum$ SAFA amounts in umbilical plasma PLs were significantly $(\mathrm{p}<$ $0.0001)$ higher than the maternal values. For $\sum$ MUFA no significant difference between mother and child was observed.

The mean CADI value in umbilical venous plasma PLs was significantly $(\mathrm{p}<0.0001)$ lower than the maternal CADI, immediately after delivery, but significantly ( $p<$ 0.0001 ) higher than the maternal CADI six months post-partum and at 10 weeks of gestation (Figure 4).

The neonatal EFA status did not differ significantly from the maternal value at delivery, but was significantly ( $\mathrm{p} \leq 0.005$ ) lower than the EFA status in maternal plasma PLs six months after birth and at early pregnancy (Figure 4).

In Table 2 Pearson correlation coefficients between maternal and umbilical venous plasma values, post-partum, are shown for the total amounts of fatty acids (TF), and for the relative amounts of $\Sigma$ SAFA, $\sum$ MUFA, $\sum n-6, \sum n-3, L A, A A$ and CA. No significant correlation was observed for $\mathrm{TF}$, but all the other fatty acids and fatty acid combinations did show a highly significant positive correlation.

Relationship of maternal and neonatal fatty acid composition in plasma PLs with some clinical variables and smoking habits of the mother

Because of the large number of comparisons made, only those with a $\mathrm{p} \leq 0.01$ are reported. For maternal values, only a significant positive correlation was observed 
between the amount of AA ( $\%$ of TF) in maternal plasma PLs at 10 weeks of gestation and birthweight $(r=+0.39, p=0.007, n=45)$. This correlation did not hold for the other time points.

The amount of LA ( $\%$ of TF) in umbilical plasma PLs was negatively correlated with gestational age $(\mathrm{r}=-0.37, \mathrm{p}=0.0001, \mathrm{n}=98)$. The relative as well as the absolute amounts for CA and $\Sigma \mathrm{n}-3$ in umbilical plasma PLs correlated positively with gestational age ( $\%$ of TF: $r=+0.38, p=0.0001$ for CA and $\Sigma n-3 ; m g / L: r=+0.42, p$ $<0.0001$ for $\mathrm{CA}$ and $\mathrm{r}=+0.43, \mathrm{p}<0.0001$ for $\sum \mathrm{n}-3$ ). Significant positive correlations were also observed between placental weight and the absolute amounts in umbilical plasma PLs for AA $(r=+0.27, p=0.007)$, CA $(r=+0.29, p=0.005), \Sigma n-3(r=$ $+0.29, \mathrm{p}=0.005)$ and $\sum \mathrm{SAFA}(\mathrm{r}=+0.28, \mathrm{p}=0.006, \mathrm{n}=96)$. These associations did not change when correcting for the potential confounders parity, maternal height, weight and age, smoking habits and educational level of the mother, sex of the newborn and gestational age.

After adjustment for parity, a significant negative correlation was found between the relative amounts of LA in umbilical plasma PLs and head circumference (partial $r=$. $0.36, p=0.001$ ). Introducing gestational age in the multiple regression analysis did not alter the above conclusion.

No differences were observed between smokers $(n=32)$ and non-smokers $(n=78)$ for the various fatty acids and fatty acid families in maternal and neonatai plasma PLs at delivery.

The mean absolute amount of CA and $\sum \mathrm{n}-3$ in umbilical plasma PL were significantly higher in girls than in boys (CA: $40 \pm 2.0$ vs $33 \pm 1.1, p=0.009 ; \sum n-3: 46 \pm 2.3$ vs 38 $\pm 1.5, p=0.008$ ). No significant differences in gestational age were observed between boys and girls.

\section{DISCUSSION}

To our knowledge, this is the first report about the essential fatty acid composition of maternai plasma phospholipids (PLs), measureci longitudinally throughout normal pregnancy, in an absolute $(\mathrm{mg} / \mathrm{L})$ and in a relative ( $\%$ of total fatty acids) manner. The decision to use the PL fraction was based on the fact that PLs are structural lipids, which are the richest source of polyunsaturated fatty acids (PUFA). Moreover, changes in PUFA profile are most pronounced in PLs (27) reflecting the essential fatty acid (EFA) status best.

To correct for the, hardly avoidable, missing values, an analysis model was chosen which estimated the means with adjustment: for the missing data. The uncorrected data, however, showed a similar course as the corrected data. Moreover, the correction factor was never more than $2.5 \%$ of the mean value.

The increase in absolute amounts of fatty acids in maternal plasma. PLs throughout normal pregnancy (Figure 1) is a direct consequence of the enhanced PL 
concentration during gestation (28). The total fatty acid increase during pregnancy cannot be calculated, because pre-pregnancy levels are not available. As an approximation, maternal blood sampies, taken 6 months after delivery, were analyzed. In these samples, the amounts of most of the fatty acids were comparable with their values at the end of the first trimester. From 18 women information was available at 8 weeks of gestation and the fatty acid concentrations in the plasma PLs of these samples were lower than at 10 weeks. This strongly indicates that the absolute maternal fatty acid values measured 6 months after delivery, do not yet reflect true pre-pregnancy levels which are still appreciably lower.

During pregnancy, the increment observed for CA in maternal plasma PLs was the highest for all polyunsaturated fatty acids, and compared to pre-pregnancy levels (which are most probably lower than the levels 6 months after delivery - see above) the absolute amounts doubled during gestation. This probably reflects the special requirement for $\mathrm{CA}$ by the developing brain and retina $(2,5,7,29)$.

In theory, the improved absolute maternal CA status can result from a change in dietary habits, an increase in fish consumption in particular. However, no differences in nutrient intake during gestation were observed (40). Another explanation can be an. increase in the activity of the enzymes involved in the synthesis of CA from its precursors. However, this process occurs at a very low rate only (30) and, therefore, it seems more likely that the improved maternal CA status during pregnancy is due to an increased mobilization from maternal stores, although a metabolic re-routing (from energy substrate to structural use) cannot be excluded.

When expressed in relative terms, the maternal CA increase lasted until 18 weeks of gestation. Thereafter a gradual decrease is seen, which may reflect the maternal inability to mobilize adequate amounts for optimal fetal development. This view is supported by the fact that the maternal cervonic acid deficiency index (CADI) increases gradually throughout pregnancy, and that the CADI value in umbilical plasma PLs (although lower than the matemal value at delivery) is significantly higher than the maternal value 6 months after delivery, which is the best available estimate for the value in the non-pregnant state. These observations indicate that the present diet of pregnant women is inadequate to guarantee an optimum CA status of the developing fetus. This may be a rationale for considering CA supplementation during pregnancy.

The AA status (\% of total fatty acids) in umbilical venous plasma PL is, just like CA, significantly higher than the maternal relative amounts, despite the decrease of the maternal AA status throughout pregnancy. This might point to a high neonatal need for AA which is the most abundant fatty acid of the (n-6) family in neural tissue and retina (31-33).

No changes were observed for the maternal LA status throughout pregnancy. The neonatal relative amounts of LA were almost three times less than the maternal 
plasma values. Results from a recent study demonstrated that the low fetal amounts of LA originate early in pregnancy (34). In spite of the low LA levels in umbilical venous plasma PLs, the neonatal EFA status did not differ from the maternal EFA status at delivery. However, since the neonatal EFA status was significantly lower than the maternal EFA status six months post-partum and at 10 weeks of gestation, the question arises whether the neonatal EFA status is optimal indeed.

The capacity of the placenta and fetal liver to synthesize the long chain polyenes (LCPs) AA and CA from their parent essential fatty acids LA and $\alpha$-linolenic acid $(18: 3(n-3), \operatorname{Ln} A)$ is very limited (35). Therefore, other mechanisms have to be responsible for the different fatty acid profiles for LA, AA and CA between maternal and umbilical plasma PLs. It could be due to preferential transport of LCPs across the placenta, but selective sequestering of $\mathrm{AA}$ and $\mathrm{CA}$, at the expense of $\mathrm{LA}$, into phospholipids on the fetal side of the placenta (36) may also be responsible. As a consequence, AA and CA are compartmentalized into a lipid fraction which does not recross the placental barrier (37) and therefore will remain available for the developing tissues, like brain and retina. A possible important role in the transport of LCPs in the fetal circulation may be reserved for $\alpha$-fetoprotein (AFP). This protein is mainly synthesized by the fetal liver and the yolk sac. Although the biological role of AFP is not completely elucidated, it binds polyunsaturated fatty acids, mainly AA and $\mathrm{CA}$, with high affinity. Because these fatty acids are important components of structural lipids, the transport and cell delivery of LCPs could be a major physiological activity of AFP (38).

The placenta is, for the greater part, a fetal organ which has a fatty acid composition more similar to that of fetal plasma than of matemal plasma $(21,35)$. This might explain why significant correlations were observed for placental weight with some fetal fatty acid values, but not with maternal fatty acid levels.

A significant positive correlation between $C A$ and $\sum n-3$ in umbilical plasma PLs and gestational age was observed. In a preterm population $(n=22)$, Leaf et al (39) also observed a significant positive correlation between $22: 6(n-3)$ in neonatal plasma cholinephosphoglyceride and gestational age. Negative correlations were demonstrated in the present study for linoleic acid (\% of TF) with gestational age and with head circumference. These associations were not reported by Leaf et al (39), although she found positive correlations for birthweight and head circumference with the sum of $20: 3(n-6)+20: 4(n-6)$ and with $22: 6(n-3)(39)$. These latter two associations, however, were not observed in our term population, where all infants were born between 37 and 42 weeks of gestation, while in the preterm population the range in gestational age was 12 weeks. This wider range in gestational age could partly explain the difference in result. Moreover, it is known that head circumference of the newborn, for instance, also depends on the head circumferences of the parents, duration of expulsion, the way of delivery, method of recording head cirumference, etc. Corrections for these possible confounders were not made. 
At the moment, the modification is discussed of the fatty acid composition of formulas to ensure an optimal administration of AA and CA after birth. On the basis of the results described in this paper, it can be concluded that lipid nutrition of high quality during gestation is important also, especially with respect to $\mathrm{CA}$. The correlations between the maternal and umbilical relative amounts for LA, AA and CA are strong and suggest that the neonatal essential fatty acid status can be influenced by the mother.

This study has yielded data both on the course of the maternal essential fatty acid profiles throughout normal pregnancy and on the EFA status of umbilical venous plasma and maternal plasma, six months after delivery. In addition, the fatty acid composition was determined absolute as $\mathrm{mg} / \mathrm{L}$ and relative as percentage of total fatty acids. These data will serve as reference values in a further comparison between uncomplicated and complicated pregnancies which is presently being executed.

\section{ACKNOWLEDGEMENT}

The authors wish to thank all mothers for their co-operation.

\section{REFERENCES}

1. Dobbing J. Vulnerable periods of brain development. In: Eiliott K. Knight J, eds. Lipids, malnutrition and the developing brain. Amsterdam (The Netherlands): Elsevier, 1972: 9-29.

2. Clandinin MT, Chappell JE, Leong S, Heim T, Swyer PR, Chance GW. Intrauterine futty acid accretion rates in human brain: implications for fatty acid requirements. Early Hum Dev 1980; 4: $121=9$.

3. Martinez M. Developmental profiles of polyunsaturated fatty acids in the brain of normal infants and patients with peroxisomal diseases: severe deficiency of docosahexaenoic acid in Zellweger's and Pseudo-Zellweger's syndromes. World Rev Nutr Diet 1991; 66: 87-102.

4. Martinez M, Ballabriga A. Gil-Gibernau JJ. Lipids of the developing human retina: I. Total fatty acids, plasmalogens, and fatty acid composition of ethanolamine and choline phosphoglycerids. J Neuroscience Res 1988; 20: 484-90.

5. Uauy R, Birch E, Birch D, Peirano P. Visual brain function measurements in studies of n-3 fatty acid requirements of infants. J Pediatr 1992; 120: S168-80.

6. Neuringer M, Connor WE, Lin DS, Barstad L, Luck S. Biochemical and functional effects of prenatal and postnatal w3 fatty acid deficiency on retina and brain in rhesus monkeys. Proc Natl Acad Sci 1986; 83:4021-5.

7. Makrides M, Simmer K, Goggin M, Gibson RA. Erythrocyte docosahexaenoic acid correlates with the visual response of healthy, term infants. Ped Res 1993; 34:425-7.

8. Olsen SF, Sorensen JD, Secher NJ, et al. Randomised controlled trial of effect of fish-oil supplementation on pregnancy duration. Lancet 1992; 339: 1003-7.

9. Dyerberg J, Bang HO. Pre-eclampsia and prostaglandins (letter). Lancet 1985; i: 1276.

10. Andersen HJ, Andersen LF, Fuchs AR. Diet, pre-eclampsia and intra-uterine growth retardation. Lancet 1989; i: 1146. 
11. Popeski D, Ebbeling LR, Brown PB, Hornstra G, Gerrard JM. Blood pressure during pregnancy in Canadian Inuit: community differences related to diet. Can Med Assoc J 1991; 145: 445-54.

12. Secher NJ, Olsen SF. Fish-oil and pre-eclampsia (commentaries). Br J Obstet Gynaecol 1990; 97: 1077-9.

13. Baker P, Broughton-Pipkin F. Fish-oil and pre-eclampsia (letter). Br J Obstet Gynaecol 1991; 98: 499-500.

14. Schouw vd YT, Al MDM, Hornstra G, Bulstra-Ramakers MTEW. Huisjes HJ. Fatty acid composition of serum lipids of mothers and their babies after normal and hypertensive pregnancies. Prost Leukotr Essential Fatty Acids 1991; 44: 247-52.

15. Wang Y, Kay HH, Killam AP. Decreased levels of polyunsaturated fatty acids in pre-eclampsia. Am J Obstet Gynecol 1991; 164: 812-8.

16. Vilbergsson G, Samsioe G, Wennergren M, Karlsson K. Essential fatty acids in pregnancies complicated by intrauterine growth retardation. Int J Gynecol Obstet 1991; 36: 277-86.

17. Folch J, Lees M, Sloane-Stanley GH. A simple method for the isolation and purification of total lipids from animal tissues. J Biol Chem 1957; 226: 497-509.

18. Hoving EB, Jansen G, Volmer $M_{4}$ van Doormaal JJ, Muskiet FAJ. Profiling of plasma triglyceride fatty acids as their methylesters by capillary gas chromatography, preceded by a rapid aminopropyl silica column chromatographic separation of lipid classes. J Chromatogr 1988; 434: 395-409.

19. Kaluzny MA, Duncan LA, Merritt MV, Epps DE. Rapid separation of lipid classes in high yield and purity using bonded phase columns. J Lipid Res 1985; 26: 135-40.

20. Morrisson WR, Smith LM. Preparation of fatty acid methyl esters and dimethylacetals from lipids with boron fluoride methanol. J Lipid Res 1964; 5: 600-8.

21. Al MDM, Hornstra G, vd Schouw YT, Bulstra-Ramakers MTEW. Huisjes HJ. Biochemical essential fatty acid status of mothers and their neonates after norma! pregnancy. Early Hum Dev 1990; 24: 239-48.

22. Hornstra G, Al MDM. Gerrard JM. Simonis MMG. Essential fatty acid status of neonates born to Inuit mothers: comparison with caucasian neonates and effect of diet. Prost Leukotr and Essential Fatty Acids 1992; 45: 125-30.

23. Holman RT. The ratio of trienoic:tetraenoic acids in tissue lipids as a measure of essential fatty acid requirement. I Nutr 1960; 70: 405-10.

24. Hornstra G. Essential fatty acids, pregnancy and pregnancy complications: a round table discussion. In: Sinclair A, Gibson R, eds. Essential fatty acids and eicosanoids. Invited papers from the third international congress. Champaign (IL): Am Oil Chem Soc, 1992: 177-82.

25. Jennrich RI, Schluchter MD. Unbalanced repeated-measures models with structured covariance matrices. Biometrics 1986; 42: 805-20.

26. Dixon WJ. BMDP statistical software manual: to accompany the 1990 software release. Berkely (CA): University of California Press, 1990.

27. Holman RT. Control of poly-unsaturated fatty acids in tissue lipids. J Am Coll Nutr 1986; 5 : 183-211.

28. Desoye G, Schweditsch MO, Pfeiffer KP, Zecher R, Kostner GM. Correlation of hormones with lipid and lipoprotein levels during normal pregnancy and post-partum. J Clin Endocrinol Metab 1987; 64: 704-12.

29. Martinez M. Dietary poly-unsaturated fatty acids in relation to neural development in humans. Prog Lipid Res 1989; 28: 123-33.

30. Voss, A, Reinhart M, Sprecher H. Differenses in the interconversion between 20- and 22-carbon (n-3): and (n-6) polyunsaturated fatty acids in rat liver. Biochim Biophys Acta 1992; 1127: 3340 .

31. Svennerholm L. Distribution and fatty acid composition of phosphoglycerides in normal human brain. J Lipid Res, 1968; 9: 570-9. 
32. Sastry PS. Lipids of nervous tissue:composition and metabolism. Prog Lipid Res 1985; 24: 69176.

33. Fliesler SJ, Anderson RE. Chemistry and metabolism of lipids in the vertebrate retina. Prog Lipid Res 1983; 22: 79-131.

34. Houwelingen AC v., Puls J, Hornstra G. Essential fatty acid status during early human development. Early Hum Dev 1992; 31: 97.111.

35. Chambaz J, Ravel D, Manier M-C, Pepin D, Mulliez N, Bereziat G. Essential fatty acids interconversion in the human fetal liver. Biol Neonate $1985 ; 47: 136-40$.

36. Kuhn DC, Crawford M. Placental essential fatty acid transport and prostaglandin synthesis. Prog Lipid Res 1986; 25: 345-53.

37. Coleman RA. The role of the placenta in lipid metabolism and transport. Sem Perinat 1989; 13: 180-91.

38. Subbiah MTR. Newly recognized lipid carrier proteins in fetal life. Proc Soc Exp Biol Med 1991; 198: 459-99.

39. Leaf AA, Leighfield MJ, Costeloe KL, Crawford MA. Long chain polyunsaturated fatty acids and fetal growth. Early Hum Dev 1992; 30: 183-91.

40. Al MDM, Badart-Smook A, Houwelingen AC v., Hasaart THM, Hornstra G. Nutrient intake of Dutch women during normal pregnancy with special emphasis on essential fatty acids. Submitted. 


\title{
CHAPTER 6
}

\section{The essential fatty acid status of mother and child in pregnancy-induced hypertension: a prospective longitudinal study}

\author{
Monique D.M. Al, Adriana C. v. Houwelingen, Anita Badart-Smook, Tom H.M. \\ Hasaart, Frans J.M.E. Roumen and Gerard Hornstra
}

Submitted for publication

\section{ABSTRACT}

To investigate the relationship between the essential fatty acid (EFA) status of mothers and their newborns and pregnancy-induced hypertension (PIH) in a prospective way, a longitudinal study was started. Pregnant women, healthy at the start of the study, were asked to give a blood sample before 16 weeks, at 22 weeks and at 32 weeks of gestation. After delivery, a blood sample from the umbilical vein, a piece of the umbilical cord and a maternal blood sample were collected. Fatty acid compositions were determined of the phospholipids (PLs) isolated from plasma and from umbilical arterial and venous vessel walls. The nutrient intake of the pregnant women was assessed with the aid of the dietary history method and using food frequency questionnaires. The results of each woman with PIH were compared with the results of three matched healthy controls. During pregnancy (16-32 weeks), no significant differences were observed in nutrient intake and maternal plasma fatty acid composition between the PIH $(n=52)$ and the control group $(n=156)$. After delivery, the relative amounts of $18: 2(n-6)$ and $18: 3(n-3)$ in maternal plasma were significantly lower in PIH than in normal pregnancy (NP). This was associated with significantly higher levels of (n-6) long chain polyenes and cervonic acid (22:6(n-3),CA). As compared to the situation at 32 weeks, the post-partum CA status increased in PIH whereas it decreased in NP. The CA levels in umbilical plasma PLs was significantly higher after PIH than after NP. No significant differences were observed for the umbilical vessel walls. The results indicate that the altered EFA status in PIH is a late phenomenon and is, therefore, unlikely to have contributed to the pathogenesis of PIH. Moreover, the neonatal EFA status is not negatively affected by PIH. 


\section{INTRODUCTION}

Pregnancy-induced hypertension (PIH) is one of the most frequently occurring disorders during pregnancy. Incidence rates of 6 to $30 \%$ have been reported $(1,2)$. The etiology of PIH is still unknown, but the pathophysiological events are becoming less enigmatic. There is considerable evidence that endothelial cell injury is involved in the pathogenesis (3). Dysfunctional endothelium will, among other things, produce less prostacyclin and activate platelets that subsequently release thromboxane $A_{2}$ $\left(\mathrm{TXA}_{2}\right)$, resulting in a disturbed balance between prostacyclin and TXA $2(4,5)$. It has been suggested that administration of low-doses of aspirin could correct this imbalance and reduce the occurrence of PIH (6). However, the results of three large clinical trials with aspirin do not support the prophylactic or therapeutic value of the routine administration of low-dose aspirin to women at increased risk of PIH (7-9).

Fish-oil, rich in (n-3) fatty acids, has also been considered as a remedy against PIH (10-13) and studies in normal pregnant women have shown that fish-oil supplementation in late pregnancy may be beneficial in the management of PIH by correcting the prostanoid imbalance $(14,15)$. However, we observed higher levels of cervonic acid (22:6(n-3), CA), one of the typical "fish fatty acids", in maternal venous plasma phospholipids, immediately after delivery, in thirteen women with PIH compared to fifteen women with an uncomplicated pregnancy (16). This raises the possibility that fish-oil "treatment" may be contra-indicated in pregnancy, since CA may theoretically be involved in the etiology of PIH. In the same study (16), lower maternal levels of linoleic acid (18:2(n-6), LA) were observed in PIH. This was also reported by Wang et al (17), who studied plasma polyunsaturated fatty acid (PUFA) levels in 9 preeclamptic women. However, these studies share the disadvantage that they are based on a retrospective design, a small number of subjects, and on material collected in late pregnancy or post-partum. As a consequence, no information is available whether the alterations of the essential fatty acid status took place before or after the development of PIH. Therefore, a prospective cohort study was started to investigate the relationship between the essential fatty acid status of mother and child, and the occurrence of PIH.

The essential fatty acid status was assessed by determining the fatty acid composition in plasma and/or tissue phospholipids, which are the richest source of PUFAs. Changes in PUFA profile are most pronounced in PLs, reflecting the general essential fatty acid status of an individual best (18).

\section{SUBJECTS, MATERIALS AND METHODS}

\section{Study population}

The cohort consisted of pregnant women, who did not suffer from hypertension, or any cardiovascular, neurological, renal or metabolic disorder at the beginning of 
pregnancy. Multiple pregnancies were excluded. At the time of entering the cohort, the women were less than 16 weeks pregnant. After delivery, the medical records of these women were examined and women who appeared to have developed pregnancyinduced hypertension (cases) were selected and matched for parity and hospital with three women who had an uncomplicated pregnancy (controls). Pregnancy-induced hypertension (PIH) was defined as an initial diastolic blood pressure (DBP) below 90 $\mathrm{mm} \mathrm{Hg}$, an increase during pregnancy of at least $25 \mathrm{~mm} \mathrm{Hg}$ or two consecutive measurements of $90 \mathrm{~mm} \mathrm{Hg}$ or more, 4 hours or more apart, or one measurement of $110 \mathrm{~mm} \mathrm{Hg}$ or more starting after 20 weeks of gestation (19).

Three hospitals participated in the study: University Hospital Maastricht, "De Wever" hospital Heerlen and School for Midwifery Kerkrade. The study protocol was approved by the Ethics Committee of the University and written consent was obtained from each participant.

\section{Nutrient intake}

Nutrient intake was assessed in the women living in the Maastricht region, only. To estimate their fat intake during gestation, the participants filled out a food frequency questionnaire (FFQ) each trimester. The returned FFQs were checked for completeness by the dietitian and, if necessary, corrected after a telephone interview with the participants concerned. Around 22 weeks of gestation, a cross-check dietary history (20) was carried out to collect extended dietary data. The participants were visited at home and questioned about their habitual food intake of the preceding two months. The amounts of food eaten were estimated using portion size models or pictures of foods. Products regularly consumed, and common household measures were weighed afterwards on a digital scale. The food consumption data thus obtained were encoded according to the system of the Netherlands Nutrient Databank and converted into data on individual daily nutrient intakes, using the extended computerized version of the Netherlands Food Table.

\section{Blood sampling}

Maternal venous blood samples were collected into EDTA tubes before the 16 th week of pregnancy, around 22 weeks and 32 weeks of gestation. Immediately after delivery, a maternal blood sample and a blood sample from the umbilical vein were collected as well. Plasma was separated from the red blood cells by centrifugation and stored at $80^{\circ} \mathrm{C}$, under nitrogen, until analysis.

\section{Umbilical vessel walls}

Immediately after delivery, a piece of the umbilical cord was collected, rinsed with saline $(\mathrm{NaCl}, 0.9 \% \mathrm{w} / \mathrm{v})$ and stored at $-80^{\circ} \mathrm{C}$ until further preparation. Segments of about $5 \mathrm{~cm}$ length were used to isolate the walls of both arteries and the veins. The arterial and venous vessel walls were frozen in liquid nitrogen and pulverized in an aluminum mortar with a stainless steel pestle, previously cooled in liquid nitrogen. The pulverized samples were freeze-dried and weighed before fatty acid analysis. 


\section{Fatty acid analyses}

The fatty acid composition of phospholipids (PLs) isolated from maternal and umbilical plasma, and from umbilical venous and arterial vessel walls was determined. Preparation of a total lipid extract from $100 \mu$ l plasma samples was performed with a modified Folch extraction $(21,22)$. L- $\alpha$-dinonadecanoyl lecithin was used as an internal standard to calculate the absolute fatty acid amounts. Aminopropyl bonded phase columns were used to separate phospholipids from the total lipid extract (23). The fatty acid constituents of the phospholipids were transmethylated to the corresponding methylesters (24), which were separated and quantified on a nonpolar CP-Sil 5 CB column (Chrompack $\AA$, Middelburg, The Netherlands). All blood samples of a women with pregnancy-induced hypertension and her matched controls were analysed simultaneously.

The total lipids of the umbilical vessel walls were extracted from $10-30 \mathrm{mg}$ freezedried tissue according to the method of Bligh and Dyer (25). Further analytical methodology was similar as for plasma lipid extracts, except that the fatty acid methylesters were separated on a polar capillary column (CP Sil 88 , Chrompack $\otimes_{\text {, }}$ Middelburg, The Netherlands).

An aliquot of control pooled plasma was analyzed as part of every run to check the quality of the methods.

The results were expressed in absolute ( $\mathrm{mg} / \mathrm{L}$ plasma or $\mathrm{mg} / \mathrm{g}$ diry tissue) as well as relative amounts ( $\%$ of total fatty acids).

\section{Statistical analyses}

The type of study was a "nested" case-control study, which means that within the cohort of pregnant women, a case-control study was conducted. Therefore, the data were analysed according to a case-control design. Data of each case were compared with the mean values of three controls (set). Differences between the PIH and control group were tested with paired t-tests. Apart from an analysis of the total group, the PIH group was divided into a group of women with an maximum DBP during gestation of less than 105 and a group with a maximum DBP of $\geq 105$, which is considered a critical value in the participating clinics. Paired t-tests were also used to test the differences in fatty acid compositions of maternal plasma phospholipids between the various sampling moments. The Chi-square test was applied to compare categorical data, expressed as frequencies. A number of significant correlations (Pearson correlation coefficients) was observed between fatty acids present in umbilical venous plasma, umbilical venous vessel or arterial vessel walls and gestational age. Therefore, multiple regression was performed to correct for gestational age if the fatty acid composition of neonatal material in the PIH group was compared with that of their matched controls.

Because of the many tests performed, a p-value of $\leq 0.01$ was considered significant.

\section{Selection bias}

To study to what extent selection bias was present, women who did not want to participate in the study and were under attendance at the University Hospital 
Table 1. Clinical characteristics of the study population $\$$.

\begin{tabular}{|c|c|c|}
\hline Variable & NP $(n=156)$ & PIH $(n=52)$ \\
\hline $\begin{array}{l}\text { Number of nulliparae, at entry } \\
\text { (before } 16 \mathrm{wks} \text { ) }\end{array}$ & 135 & 45 \\
\hline Age (years) & $28.5 \pm 0.35$ & $27.9 \pm 0.54$ \\
\hline Diastolic blood pressure, at entry & $67.4 \pm 0.61$ & $73.7 \pm 0.94 \mathrm{~d}$ \\
\hline Diastolic blood pressure (maximum) & $76.1 \pm 0.50$ & $100.5 \pm 1.31^{\mathrm{d}}$ \\
\hline Proteinuria (\%) & 0 & $34.6^{\mathrm{d}}$ \\
\hline Smoking (\%) & 31.4 & 23.1 \\
\hline Gestational age at delivery (days) & $279.9 \pm 0.59$ & $273.3 \pm 2.18^{c}$ \\
\hline Birthweight (grams) & $3290 \pm 30.2$ & $2941 \pm 99.5^{d}$ \\
\hline Small for gestational age ${ }^{¥}$ & 0 & 2 \\
\hline Apgar score (after $5 \mathrm{~min}$.) & $10(9-10)$ & $9.5(9-10)^{c}$ \\
\hline $\mathrm{pH}$ umbilical artery $\#$ & $7.22 \pm 0.01$ & $7.2 \| \pm 0.01$ \\
\hline Sex (male/female) (\%) & $53.8 / 46.2$ & $59.6 / 40.4$ \\
\hline
\end{tabular}

§: Results are expressed as mean \pm s.e.m., except for Apgar score (median with interquartile range) and when indicated otherwise; NP =normal pregnancy; PIH = pregnancy induced hypertension; significant difference between NP and PLH group, $b=p<0.01, c=p<0.005, d=p<0.001$.

\%: birthweight below 2.3rd percentile, based on the Dutch intrauterine growth curves, making allowance for sex and parity (Kloosterman GJ. On intrauterine growth. Int J Gynaecol 1970; 8: 895-912).

\#: $\mathrm{n}=133$ for NP and $\mathrm{n}=49$ for PIH.

Maastricht were asked to give a blood sample once, before 16 weeks of gestation. The fatty acid composition of their plasma phospholipids was determined and compared with that of the women who did participate in the "nested" case-control study by unpaired t-tests. No significant differences were observed in the maternal EFA status of the non-participants $(n=76)$ as compared with the participating women $(n=201)$ (data not shown). Although one can not exclude that the women who did agree to give a blood sample once is a selected group, the similar EFA status at entry indicates that selection bias, as far as the maternal EFA status is concerned, is negligible.

\section{RESULTS}

\section{Clinical characteristics}

In Table 1 the clinical characteristics of the study population are shown. Fifty-two women developed pregnancy-induced hypertension $(\mathrm{PIH})$ during gestation and were compared with three times as much women with an uncomplicated pregnancy. Of the 52 women with $\mathrm{PIH}, 45$ women were nulliparous at entry (before 16 weeks of gestation). The mean diastolic blood pressure (DBP) at entry was significantly higher in the PIH group, but none of the women had a DBP at entry above $90 \mathrm{~mm} \mathrm{Hg}$. The mean gestational age, birthweight and Apgar score (after 5 minutes) of the newborns 
Table 2. Difference (parturition-32 weeks of gestation) in fatty acid composition of maternal plasma phospholipids $(\mathrm{mg} / \mathrm{L})$ in normal pregnancy $(N P)$ compared to $P I H$ (mean \pm s.e.m., $n=42 \mathrm{sets}) \oint$.

\begin{tabular}{lll}
\hline Fatty acid & NP & PIH \\
\hline & & \\
$18: 2(\mathrm{n}-6)$ & $-2.6 \pm 7.23^{\mathrm{d}}$ & $-55.5 \pm 9.90^{* * *}$ \\
$\sum(\mathrm{n}-6)$ & $15.8 \pm 10.5^{\mathrm{C}}$ & $-52.1 \pm 16.3^{* * *}$ \\
$18: 3(\mathrm{n}-3)$ & $-0.3 \pm 0.17^{\mathrm{b}}$ & $-1.4 \pm 0.39^{* * *}$ \\
$\sum$ PUFA & $17.0 \pm 12.5^{\mathrm{C}}$ & $-54.1 \pm 18.8^{* *}$ \\
\hline
\end{tabular}

8: Significant difference between NP and PIH group, $b=p<0.01, c=p<0.005, d=p<0.001$; significant different from zero, ${ }^{* *}=p<0.01,{ }^{* *}=p<0.001$.

1: $\Sigma(n-6)$, sum of the fatty acids of the (n-6) family; $\Sigma$ PUFA, sum of the polyunsaturated fatty acids.

were significantly lower in the PIH group compared with the norma! group. In 13 women $(25 \%)$ of the PIH group and in 6 women $(3.8 \%)$ of the control group, labour was induced by prostaglandin-gel or oxytocin infusion $(p<0.001)$. Spontaneous delivery took place in 27 women $(51.9 \%)$, while in 22 of the PIH cases: delivery was either by cesarean section $(23.1 \%)$, forceps $(9.6 \%)$ ог vacuum extraction. $(9.6 \%)$. In the control group, these numbers were $113(72.4 \%), 7(4.5 \%), 17(10.9 \%)$ and $12(7.7 \%)$, respectively. The number of women who delivered spontaneously or by cesarean section was significantly different between the two groups.

\section{Nutrient intake}

The first FFQ was filled out by 30 sets (each set consists of one case and three controls) of women coming from the Maastricht region, the second by 32 , the third by 25 , and the dietary history was carried out on 29 sets. The nutrient intake of the women who developed PIH was not significantly different from the women with an uncomplicated pregnancy (see Chapter 4).

\section{Maternal fatty acid composition}

In total 39 fatty acids were identified, but to reduce the amount of data, only those fatty acids are reported for which significant $(\mathrm{p} \leq 0.01)$ differences between the PIH group and their matched controls were observed (full data are given in appendices $\mathrm{Cl}$ and $\mathrm{C} 2$ ).

During gestation (before 16, at 22 and 32 weeks), no significant differences in the absolute fatty acid composition (mg/L) of maternal plasma phospholipids (PLs) were observed between PIH and the group with a normal pregnancy (NP). Immediately after delivery, the amount of 18:3(n-3) was significantly ( $\mathrm{p}<0.01$ ) lower in PIH ( 3.89 $\pm 0.30)$ than in NP $(4.84 \pm 0.16)$. As compared to the situation at 32 weeks $(n=42$ sets), the amounts of $18: 2(\mathrm{n}-6), 18: 3(\mathrm{n}-3), \Sigma(\mathrm{n}-6)$ (sum of all (n-6) fatty acids), and $\Sigma$ PUFA (sum of the poly-unsaturated fatty acids) had significantly decreased after delivery in the PIH group, whereas in the group with an uncomplicated pregnancy no 
Table3. The fatty acid composition of maternal plasma phospholipids (\% of total fatry acids) in normal pregnancy (NP) compared to PIH (mean \pm s.e.m.) $\$$.

\begin{tabular}{|c|c|c|c|c|c|}
\hline Fatty acid & & $\begin{array}{l}<16 \text { weeks } \\
(\text { sets }=49)\end{array}$ & $\begin{array}{l} \pm 22 \text { weeks } \\
(\text { sets }=47)\end{array}$ & $\begin{array}{l} \pm 32 \text { weeks } \\
\text { (sets }=47)\end{array}$ & $\begin{array}{l}\text { After delivery } \\
(\mathrm{sets}=45)\end{array}$ \\
\hline \multirow[t]{2}{*}{$18: 2(n-6)$} & NP & $21.1 \pm 0.29$ & $21.0 \pm 0.24$ & $21.3 \pm 0.20$ & $20.4 \pm 0.24$ \\
\hline & PIH & $21.0 \pm 0.36$ & $21.0 \pm 0.46$ & $21.2 \pm 0.42$ & $19.1 \pm 0.35^{\mathrm{c}}$ \\
\hline \multirow[t]{2}{*}{$22: 4(n-6)$} & NP & $0.41 \pm 0.01$ & $0.41 \pm 0.01$ & $0.38 \pm 0.01$ & $0.39 \pm 0.01$ \\
\hline & PIH & $0.37 \pm 0.01^{\mathrm{c}}$ & $0.41 \pm 0.01$ & $0.40 \pm 0.01$ & $0.41 \pm 0.01$ \\
\hline \multirow[t]{2}{*}{$\Sigma(n-6) L C P s$} & NP & $13.4 \pm 0.15$ & $12.8 \pm 0.13$ & $12.3 \pm 0.13$ & $12.7 \pm 0.16$ \\
\hline & PIH & $13.2 \pm 0.19$ & $13.1 \pm 0.24$ & $12.6 \pm 0.23$ & $13.5 \pm 0.22^{\mathrm{c}}$ \\
\hline \multirow[t]{2}{*}{$18: 3(n-3)$} & NP & $0.25 \pm 0.01$ & $0.29 \pm 0.01$ & $0.29 \pm 0.01$ & $0.26 \pm 0.01$ \\
\hline & PIH & $0.25 \pm 0.01$ & $0.29 \pm 0.02$ & $0.28 \pm 0.01$ & $0.21 \pm 0.01^{\mathrm{c}}$ \\
\hline \multirow[t]{2}{*}{$22: 6(n-3)$} & NP & $4.21 \pm 0.08$ & $4.22 \pm 0.08$ & $4.13 \pm 0.07$ & $4.00 \pm 0.08$ \\
\hline & PIH & $4.36 \pm 0.12$ & $4.24 \pm 0.12$ & $4.18 \pm 0.11$ & $4.39 \pm 0.1 \mathrm{~J}^{\mathrm{c}}$ \\
\hline (n-6) desatu- & NP & $0.66 \pm 0.02$ & $0.63 \pm 0.01$ & $0.59 \pm 0.01$ & $0.64 \pm 0.01$ \\
\hline ration index & PIH & $0.65 \pm 0.02$ & $0.65 \pm 0.02$ & $0.61 \pm 0.02$ & $0.73 \pm 0.02^{\mathrm{c}}$ \\
\hline
\end{tabular}

§: Significant difference between NP and PIH group, $c=p<0.005$.

I: $\Sigma(n-6)$ LCPs, sum of (n-6) long chain polyenes, which are poly-unsaturated fatty acids with 20 or more carbon atoms and 3 or more double bonds; $(n-6)$ desaturation index, $\{[(18: 3(n-6)+20: 3(n-$ $6)+20: 4(n-6)+22: 4(n-6)+22: 5(n-6)] / 18: 2(n-6)\}$.

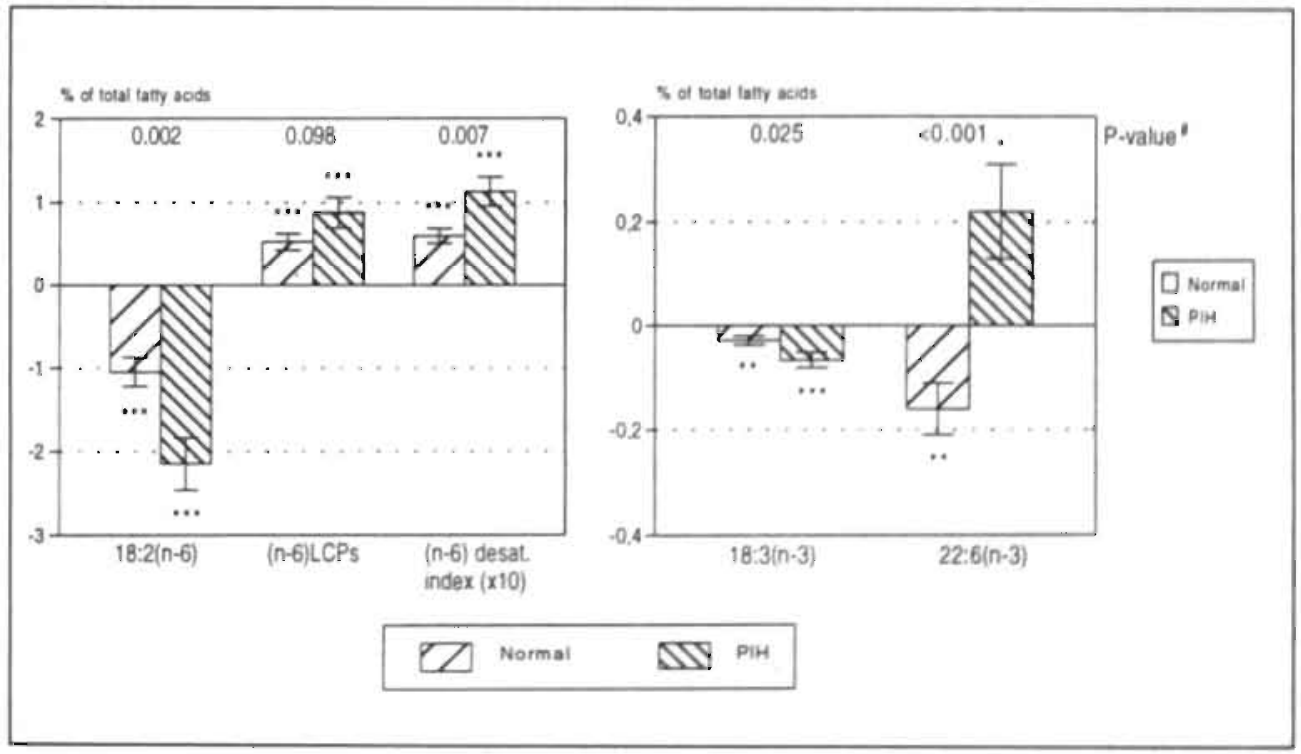

Figure 1. The difference in maternal fatty acid composition of plasma phospholipids between delivery and 32 weeks of gestation (mean \pm s.e.m. $n=42$ sets). Difference from zero, $*=p<0.05$, ${ }^{* *}=p<0.01, * * *=p<0.001$. \#: Difference between groups. 
Table 4. The fatty acid composition (\% of total fatty acids) of phospholipids isolated from

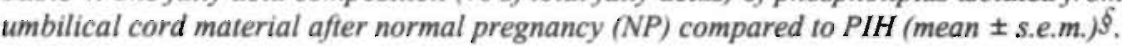

\begin{tabular}{lllll}
\hline Fatty acid & & $\begin{array}{l}\text { Venous plasma } \\
(\text { sets }=44)\end{array}$ & $\begin{array}{l}\text { Venous vessel wall } \\
(\text { sets }=45)\end{array}$ & $\begin{array}{l}\text { Arterial vessel wall } \\
\text { (sets = 45) }\end{array}$ \\
\hline \multirow{2}{*}{$22: 6(\mathrm{n}-3)$} & NP & $6.18 \pm 0.14$ & $5.24 \pm 0.09$ & $5.61 \pm 0.11$ \\
& PIH & $6.65 \pm 0.22^{\mathrm{c}}$ & $5.28 \pm 0.14$ & $5.57 \pm 0.15$ \\
$20: 3(\mathrm{n}-9)$ & NP & $0.62 \pm 0.03$ & $0.43 \pm 0.02$ & $3.00 \pm 0.09$ \\
& PIH & $0.50 \pm 0.04 \mathrm{c}$ & $0.42 \pm 0.03$ & $2.91 \pm 0.13$ \\
\hline
\end{tabular}

$\S$ : Significance was tested after correction for gestational age, uncorrected data are presented;

Significant difference between NP and PIH group, $c=p<0.005$.

significant changes took place (see Table 2).

In Table 3 the fatty acid composition of maternal plasma PLs, expressed as \% of total fatty acids, is presented. The first blood sample (before 16 weeks of gestation) was taken at a mean gestational age of 80 days in the control group and 82 days in the PIH group. At that moment, the mean relative amount of $22: 4(\mathrm{n}-6)$ was significantly lower in the PIH than in the NP group. At 22 and 32 weeks of gestation, no significant differences were observed between the two groups. After delivery, the values of the essential fatty acids $18: 2(n-6)$ and 18:3(n-3) were significantly lower, whereas the values of $\sum(n-6) L C P s$ (sum of (n-6) long chain polyenes, which are poly-unsaturated fatty acids with 20 or more carbon atoms and 3 or more double bonds), 22:6(n-3) and the $(n-6)$ desaturation index $\{[(18: 3(n-6)+20: 3(n-6)+20: 4(n-6)+22: 4(n-6)+22: 5(n-$ 6)] $/ 18: 2(\mathrm{n}-6)\}$ were significantly higher in PIH than in NP.

In Figure 1 the difference in fatty acid composition between the levels after parturition and at 32 weeks of gestation are given for 18:2(n-6), $\sum(n-6)$ LCPs and the (n-6) desaturation index, and for $18: 3(n-3)$ and $22: 6(n-3)$ in the PIH group and the control group ( $\mathrm{n}=42$ sets). The decrease in 18:2( $\mathrm{n}-6$ ) levels was significantly stronger in the PIH group than in the control group. The $(n-6)$ desaturation index was significantly more increased in PIH. The 22:6(n-3) values in the PIH group showed an increase from 32 weeks of gestation until delivery. This pattern was significantily different from that in the control group, where a significant decrease was observed.

\section{Neonatal fatty acid composition}

There were no significant differences in the absolute amounts of fatty acids in umbilical plasma and umbilical venous and arterial vessel wall PLs between PIH and NP (absolute data is given in appendix C3).

Table 4 only summarizes the mean relative amounts of those fatty acids in phospholipids of umbilical venous plasma, and umbilical venous and arterial vessel walls, which were found to be significantly different between PIH and NP (full data is given in appendix $\mathrm{C} 4)$. After correction for differences in gestational age between the groups, significantly higher levels of 22:6(n-3) and lower values of 20:3(n-9) were 
observed in umbilical plasma of the PIH group compared with their controls. The fatty acid composition of the umbilical arterial and venous vessel wall showed no significant differences between the PIH and control group.

\section{Comparison between severe and mild PIH}

The maximum DBP in the PIH group reached a value of 105 or more (severe PIH group) in 17 of the 52 women. Of these 17 women, 16 women were nulliparous at entry. Twelve women had also proteinuria. Their mean gestational age $(260 \pm 4.28$ days) and the mean birthweight of their babies $(2512 \pm 223)$ were significantly lower than of those in the group with a max. DBP of less than $105 \mathrm{~mm} \mathrm{Hg}(280 \pm 1.61$ and $3149 \pm 82$, respectively). Throughout gestation (16-32 weeks) and after delivery, no significant differences were observed in the maternal fatty acid composition of the severe PIH group as compared with the mild PIH group. Significantly lower relative amounts of 22:6(n-3) were observed in the umbilical plasma PLs of the severe as compared to the mild PIH group. However, this difference was no longer significant after correction for gestational age.

\section{DISCUSSION}

As was the case in an earlier pilot study (16), the maternal fatty acid profile of plasma phospholipids (PLs), immediately after parturition, of women with pregnancy-induced hypertension (PIH) is characterized by decreased levels of linoleic acid $(18: 2(n-6)$, LA) and increased proportions of cervonic acid (22:6(n-3), CA). In addition, the amounts of $\alpha$-linolenic acid (18:3(n-3), LnA) were shown to be decreased and the relative amounts of $\sum(n-6)$ LCPs were increased in PIH. At or before 32 weeks of gestation, we observed no major differences in maternal plasma fatty acid composition between cases and controls. This implies that, most probably, the different fatty acid levels in PIH developed either shortly before or possibly even after the clinical manifestation of the disease. Only in 5 women PIH had been diagnosed before the blood sample at 32 weeks was collected, but the fatty acid composition of these 5 sets did not show a different pattern than the other sets. Therefore, it appears that the observed change in fatty acid composition is rather a consequence of PIH than a causal or contributing factor.

When comparing the post-delivery values to the situation at 32 weeks, a decrease in the relative amounts of CA was observed in the control group, while in the PIH group an increase took place. Because no data are available on the fatty acid composition between 32 weeks of gestation and parturition, it is unknown at what moment in time the maternal CA status increased in PIH. The CA status of umbilical plasma PLs in the PIH group was also elevated while the CA status of umbilical vessel walls was not different between cases and controls. Since the fatty acid composition of vessel wall PLs is considered to give a longer term reflection of the essential fatty acid status than plasma PLs, this observation also points to the fact that the increased CA status in PIH 
is a late phenomenon and is, therefore, unlikely to have contributed to the pathogenesis of PIH.

In maternal plasma, the decreased levels of LA and LnA were associated with higher levels of $\sum(n-6) L C P$ s and CA, respectively. The (n-6) desaturation index, which is the ratio between the desaturation and elongation products of $18: 2(n-6)$, and $18: 2(n-6)$, was also elevated. The same was observed for LnA and its desaturation and elongation products, but the (n-3) desaturation index was not calculated because the majority of the (n-3) LCPs present in plasma PLs are likely to have been derived directly from the diet. However, the fact that LnA levels were reduced in PIH may imply more active desaturation and elongation of $\mathrm{LnA}$ also. Therefore, these observations suggest that the parent essential fatty acids, LA and $\operatorname{LnA}$, are more actively metabolized in PIH than in an uncomplicated pregnancy.

In PIH, the process of "placentation" is disturbed (26). As a consequence, the maternal-fetal blood flow may be reduced, which can result in an inadequate supply of nutrients. However, this did not result in deterioration of the neonatal EFA status. On the contrary, in PIH the overall EFA status of the neonate tends to be improved as is indicated by a lower amount of Mead acid, 20:3(n-9), in umbilical plasma PLs. In addition, the amount of CA in neonatai plasma PLs is even significantly higher than after normal pregnancy (Table 4). Notwithstanding the reduced uteroplacental perfusion and function in $\mathrm{PIH}$, the more active desaturation and elongation of maternal LA and LnA (Table 3) was obviously sufficient to guarantee an adequate fetal supply of (n-6) and (n-3) LCPs, which are important in fetal growth and development (27),

There may be some indications that the alterations in fatty acid composition of maternal plasma PLs after parturition are due to stress, related to PIH. In the literature several other stressful events have been described which were associated with increased CA levels (28). When moderate to severe stress was induced in male rats by repeated administration of catecholamines for 15 days, reduced $L A$ and increased $C A$ levels in heart muscle PLs have been observed. Elevated CA levels have also been reported in stressful situations like birth in rats and myocardial infarction in man (28).

All women who developed PIH in this study were hospitalized for this disorder. During their hospital stay, which varied from a few days till more than a month, the nutrient composition of their diet could very well be different than that at home. Moreover, one of the common complaints of women with PIH is a reduced appetite due to nausea and headache. So the reduced content of the parent EFAs, LA and LnA, in maternal plasma phospholipids ( $\mathrm{mg} / \mathrm{L}$ and $\%$ of total fatty acids) could also be a consequence of a change in dietary habits. However, since the derived EFAs were higher in PIH, this seems rather unlikely. 
There were significant differences between the PIH and control group in the mode of delivery and it is possible this has interfered with the results. However, in the PIH group, women who delivered their baby by cesarean section did not differ in their plasma levels of LA, $\Sigma(n-6)$ LCPs, LnA and CA from women who delivered otherwise (data not shown). Also, if all women who gave birth by cesarean section are excluded from the analyses, the results did not change. The same conclusions hold for the plasma fatty acid levels of women whose labor was induced.

It has been suggested that fish-oil, rich in CA, could have a possible preventive effect on PIH (12), because a high CA intake interferes with prostanoid metabolism $(14,15)$. This suggestion is supported by results from an epidemiological study performed in Northern Canada, showing that Inuit women eating a diet rich in marine food are 2.6 times less likely to develop PIH than Inuit women whose diet contain a greater proportion of terrestrial food (29). Whether or not CA supplementation during pregnancy is effective in reducing the incidence of PlH remains to be seen.

In conclusion, the altered maternal EFA status, observed at delivery, in PIH is most probably a late phenomenon, occurring after the development of PIH. Thanks to this adaptation in maternal EFA metabolism, the neonatal EFA status is not compromised by PIH.

\section{ACKNOWLEDGEMENT}

The authors like to thank Andre de Jong and Taco van de Berg, ABL, Assen, The Netherlands, for analysing the plasma samples and Marianne Simonis for her assistance in the fatty acid analyses of umbilical cord tissue. They also thank all mothers for their cooperation in this study.

\section{REFERENCES}

1. Friedman EA, Neff RK. Pregnancy hypertension: a systematic evaluation of clinical diagnostic criteria. Littleton, Massachusetts: PSG Publishing. 1977, 1-3.

2. Pritchard JA, MacDonald PC. Hypertensive disorders in pregnancy. In Williams' obstetrics. 16th ed. New York: Appleton-Century-Crofts, 1980, 665-95.

3. Roberts JM, Taylor RN, Musci JT, Rodgers GM, Hubel CA, McLaughlin MK. Preeclampsia: an endothelial cell disorder. Am J Obstet Gynecol 1989; 161: 1200-4.

4. Walsh SW. Pre-eclampsia: an imbalance in placental prostacyclin and thromboxane production. Am J Obstet Gynecol 1985; 152: 335-50.

5. Zahradnik HP, Schaffer W, Wetzka B, Breckwoldt M. Hypertensive disorders in pregnancy. The role of eicosanoids. Review. Eicosanoids 1991; 4; 123-36.

6. Dekker GA, Sibai BM. Low-dose aspirin in the prevention of preeclampsia and fetal growth retardation: Rationale, mechanisms, and clinical trials. Am J Obstet Gynecol 1993; 168: 214-27.

7. Italian study of aspirin in pregnancy. Low-dose aspirin in prevention and treatment of intrauterine growth retardation and pregnancy-induced hypertension. Lancet 1993; 341: 396-400. 
8. Sibai BM, Caritis SN, Thom E, et al. Prevention of pre-eclampsia with low-dose aspirin in healthy, nulliparous pregnant women. N Engl J Med 1993; 329: 1213-18.

9. CLASP (Collaborative Low-dose Aspirin Study in Pregnancy) Collaborative Gĩoup. CLASP: a randomised trial of low-dose aspirin for the prevention and treatment of pre-eclampsia among 9364 pregnant women. Lancet 1994; $343: 619-29$.

10. Dyerberg J, Bang HO. Preeclampsia and prostaglandins (letter). Lancet 1985; i: 1267.

11. England MJ, Atkinson PM. Sonnendecker EWW. Pregnancy-induced hypertension: will treatment with dietary eicosapentaenoic acid be effective. Med Hypotheses 1987; 24: 179-86.

12. Secher NJ, Olsen SF. Fish-oil and preeclampsia (commentaries). Br J Obstet Gynaecol 1990; 97 : 1077-79.

13. Baker P, Broughton-Pipkin F. Fish-oil and pre-eclampsia (letter). Br J Obstet Gynaecol 199 1;8: 499-500,

14. Dalby Sørensen J, Olsen SF, Pedersen AK, Boris J, Secher NJ, FitzGerald GA. Effects of fish oil supplementation in the third trimester of pregnancy on prostacyclin and thromboxane production. Am J Obstet Gynecol 1993; 168: 915-22.

15. Schiff E, Ben-Baruch G, Barkai G, Peleg, E, Rosenthal T, Mashiach S. Reduction of thromboxane A2 synthesis in pregnancy by polyunsaturated fatty acid supplements. Am J Obstet Gynecol 1993; 168: 122-4.

16. Schouw YT van, Al MDM, Hornstra G, Bulstra-Ramakers MTEW, Huisjes HJ. Fatty acid composition of serum lipids of mothers and their babies after nomal and hypertensive pregnancies. Prostaglandins Leukotr Essential Fatty Acids 1991; 44: $247-52$.

17. Wang Y, Kay HH, Killam AP. Decreased levels of polyunsaturated fatty acids in preeclampsia. Am J Obstet Gynecol 1991; 164: 812-8.

18. Holman RT. Control of polyunsaturated fatty acids. J Am Coll Nutr 1986; 5: 183-211.

19. Davey DA, MacGillivray 1. The classification and definition of the hypertensive disorders of pregnancy. Am J Obstet Gynecol 1988; 158: 892-8.

20. Beal VA. The nutritional history in longitudinal research. J Am Diet Assoc 1967; 51 : 426-32.

21. Folch J, Lees M. Sloane Stanley GH. A simple method for the isolation and purification of total lipides from animal tissues. J Biol Chem 1957; 226: 497-509.

22. Hoving EB, Jansen G, Volmer M, Doormaal van JJ, Muskiet FAJ. Profiling of plasma cholesterol esters and triglyceride fatty acids; as their methylesters by capillary gas chromatography, preceded by a rapid aminopropyl silica column chromatographic separation of lipid classes. J Chromatogr 1988; 434: 395-409.

23. Kaluzny MA, Duncan LA, Merritt MV, Epps DE. Rapid separation of lipid classes in high yield and purity using bonded phase columns. J Lipid Res 1985;26:135-40.

24. Morrison WR. Smith LM. Preparation of fatty acid methylesters and dimethylacetals from lipids with boron fluoride methanol. J Lipid Res 1964; 5: 600-8.

25. Bligh EG, Dyer WJ. A rapid method for total lipid extraction and purification. Can J Biochem Physiol 1959; 37: 911-17.

26. Gerretsen G, Huisjes HJ. Elema JD. Morphological changes of the spiral arteries in the placental bed in relation to pre-eclampsia and fetal growth retardation. Br J Obstet Gynaecol 1981; 88: 876-81.

27. Innis SM. Essential fatty acids in growth and develpment. Prog Lipid Res 1991; 30: $39-103$.

28. Gudbjarnason S. Dynamics of (n-3) and (n-6) fatty acids in phospholipids of heart muscle. J Int Med 1989; 225, suppl. 1: 117-28.

29. Popeski D, Ebbeling LR, Brown PB. Hornstra G, Gerrard JM. Blood pressure during pregnancy in Canadian Inuit: community differences related to diet. Can Med Assoc J 1991; 145: 445-54. 


\title{
CHAPTER 7
}

\section{The effect of linoleic acid supplementation during pregnancy on the neonatal essential fatty acid status}

Monique D.M. Al, Adriana C. v. Houwelingen, Anita Badart-Smook and Gerard Hornstra

Submitted for publication

\begin{abstract}
The essential fatty acid (EFA) status of newborns has been suggested to be marginal. To study the effect of maternal linoleic acid (18:2(n-6), LA) supplementation on the neonatal EFA status, pregnant women with relatively low plasma LA levels before 16 weeks of gestation $(n=21)$ were supplemented with approximately 10 gram of LA per day from the 20th week of gestation, until delivery. One of the two control groups consisted of pregnant women with comparably low plasma LA levels at the start of the study (LL-control group, $n=22$ ); the other consisted of women with habitual high plasma LA levels (HL-control group, $n=2 \mathrm{i}$ ). The neonatal EFA status was assessed by determining the fatty acid composition of phospholipids (PLs) isolated from umbilical plasma and umbilical vessel walls. LA supplementation resulted in significantly higher levels of the sum of ( $n-6)$ long chain polyenes (LCPs) in umbilical plasma and venous vessel wall PLs compared with the LL-control group. This increase was associated with lower (n-3) LCP levels. In the HL-control group the neonatal (n-3) LCP status was also lower as compared to the LL-control group. To improve the EFA status of newborns, both fatty acids of the $(\mathrm{n}-6)$ and $(\mathrm{n}-3)$ family have to be supplied.
\end{abstract}




\section{INTRODUCTION}

Results from earlier studies $(1,2)$ suggest that the essential fatty acid (EFA) status of newborns is marginal. This suggestion was based on the observation that phospholipids (PLs) isolated from the vessel walls of the umbilical arteries (the efferent blood vessels) contain relatively high levels of Mead acid (20:3(n-9), MA) and its elongation product dihomoMead acid (22:3(n-9), DHMA) as compared to the umbilical vein, the fetal supplying blood vessels. The presence of MA and DHMA are considered to reflect a general EFA deficiency (3). The high levels of MA and DHMA were associated with low values of linoleic acid $(18: 2(n-6), L A)$ in umbilical plasma and vessel wall PLs (2).

Significant inverse correlations were observed between birthweight and the EFA deficiency index (Mead acid/arachidonic acid) in the umbilical artery $(4,5)$, and this suggests that the presence of MA and DHMA indicates a marginal EFA status which might have pathological consequences. This led to the question whether maternal supplementation during pregnancy with LA could be useful to improve the fetal EFA status.

Since a significant, positive relationship exists between the maternal and neonatal LA status (6) and also between the neonatal LA status and the LA content of the maternal diet (unpublished observations), maternal supplementation is likely to improve the fetal EFA status. However, these relationships were for the greater part observed in cross-sectional studies and, therefore, they may be the result of conditions set in early pregnancy, already before or during the development of the placenta, the size and function of which may be "programmed" by the nutritional conditions of that particular period. So it is possible that LA, supplemented to pregnant women after complete development of the placenta, may not reach the developing fetus. Therefore, it was decided to test the efficacy of maternal LA supplementation to improve the feta! EFA status after the placenta had fully developed.

\section{SUBJECTS, MATERIALS AND METHODS}

\section{Subjects and diet in the LA supplemented group.}

At their first antenatal visit to the midwife, healthy pregnant women were asked at random to participate in the study. If they agreed, a venous blood sample was taken before the 16th week of pregnancy to assess the linoleic acid (18:2(n-6), LA) content of their plasma phospholipids (PLS). To prevent supplementation to result in unnaturally bigh linoleic acid contents of plasma PLs, only women with plasma LA levels not exceeding the P50 ( $\approx 22 \%$ of total fatty acids) were accepted for supplementation. This value of $22 \%$ followed from a previous study in which the EFA status of 110 normal pregnant women was followed throughout pregnancy (6). Another inclusion criterion was that the maternal diet had to contain sufficient saturated fat 
rich products, which could be replaced by LA rich products. Therefore, the dietary habits of the women were assessed by a dietitian (AB-S), using the dietary history method (7).

The supplementation period started at the 20th week of gestation and lasted until delivery. The diet of each participant was adjusted on the basis of the results of her dietary history. Products which were mainly used on bread (margarine, cheese, cheesespread and chocolate paste) or used in between meals (biscuits and milk) were substituted. The diet was adapted in such a way that an additional intake of approximately 10 gram linoleic acid per day was accomplished, and that the total energy intake did not change due to the substitution of products. Ten gram was the difference in LA intake between the P50 and P90, as assessed in an earlier study (unpublished observation), and was chosen to prevent that effects beyond the normal range were studied.

The participants were instructed not to change their other dietary habits and to list any deviations from their normal dietary pattern, particularly if products rich in linoleic acid, other than those of the study, were consumed. The LA-rich products were brought to the home of the women every week and what was left from the week before was taken back to the research institute. The difference in weight between the amount of products brought and taken back one week later, was recorded and the additional intake of linoleic acid per week calculated. Twenty-five women entered the experimental group. Two women did not complete the study: one woman did not like the LA-rich products and one woman was admitted to the hospital after one week of supplementation because of vaginal bleeding.

The study protocol was approved by the Ethics Committee of the University and written consent was obtained from each participant.

\section{Control groups}

There were two control groups, in which no intervention took place. These control groups were selected from a group of women who had participated in observational studies, which took place at our department at about the same time and which aimed at describing the normal course of the maternal EFA status during pregnancy. One control group consisted of women who, before 16 weeks of gestation, had plasma LA levels at or below $22 \%$ of total fatty acids and comparable with the initial values of the LA supplemented group (control group with low maternal LA levels: LL-control group). The other control group was made up of women who had plasma LA levels above $22 \%$ of total fatty acids (control group with habitual high plasma LA levels: HL-control group). This HL-control group was included to determine if the relationship between the maternal and neonatal EFA status in a group of women with habitual high plasma LA levels is different from a group of women with high plasma LA levels due to supplementation. The daily intake of linoleic acid in the control groups was assessed with the aid of the dietary history method (7), carried out around 22 weeks of gestation. The LA supplemented group and both control groups were matched for gestational age at birth. 


\section{Blood sampling}

Maternal venous blood samples were collected into EDTA tubes before the 16th week of pregnancy, at 20 weeks, and every 4 weeks thereafter, until delivery. In the HLcontrol group, maternal venous blood samples were collected before 16 weeks, at 22 , 32 and 40 weeks of gestation. Immediately after delivery, a blood sample from the umbilical vein was collected. Plasma was separated from red blood cells by centrifugation and stored at $-80^{\circ} \mathrm{C}$, under nitrogen, until analysis.

\section{Umbilical vessel walls}

Immediately after delivery, a piece of the umbilical cord was collected. The umbilical cords were rinsed with saline $(\mathrm{NaCl}, 0.9 \% \mathrm{w} / \mathrm{v})$ and segments of about $5 \mathrm{~cm}$ length were used to isolate the vessel wall of both arteries and the veins. The arterial and venous vessel walls were frozen in liquid nitrogen and pulverized in an aluminum mortar with a stainless steel pestle, previously cooled in liquid nitrogen. The pulverized samples were freeze-dried before fatty acid analysis was performed.

\section{Fatty acid analyses}

The fatty acid composition of plasma phospholipids (PLs) was determined as described earlier (6). Briefly, preparation of a total lipid extract from $100 \mu \mathrm{l}$ samples was

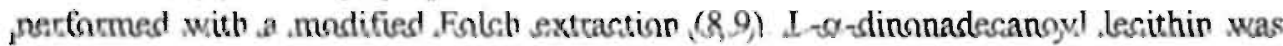
used as an internal standard to calculate the absolute fatty acid amounts. Aminopropyl bonded phase columns were used to separate phospholipids from the total lipid extract (10). The fatty acid constituents of the phospholipids were transmethylated to the corresponding methylesters (11), which were separated and quantified on a nonpolar CP-Sil 5 CB column (Chrompack ${ }^{2}$, Middelburg. The Netherlands). All blood samples of a given participant were analysed simultaneously.

The total lipids of the umbilical vessel walls were extracted from $10-30 \mathrm{mg}$ dry tissue according to the method of Bligh and Dyer (12). Further analytical methodology was similar as for plasma lipid extracts, except that the fatty acid methylesters were separated on a polar capillary column (CP Sil 88, Chrompack, Middelburg, The Netherlands).

The results were expressed in absolute (mg/L plasma or $\mathrm{mg} / \mathrm{g}$ dry tissue) as well as relative amounts ( $\%$ of total fatty acids). In total, 39 fatty acids were identified. However, for the sake of clarity, only the following 14 fatty acids and 8 fatty acid combinations are reported (full data are given in appendices D1-D6): 18:2(n-6), 20:2(n-6), 20:3(n-6), 20:4(n-6), 22:4(n-6), 22:5(n-6), 24:2(n-6), 18:3(n-3), 20:4(n-3), 20:5(n-3), 22:5(n-3), 22:6(n-3), 20:3(n-9), 22:3(n-9), $\Sigma(n-6)$ LCPs (sum of the (n-6) long chain polyenes, which are poly-unsaturated fatty acids with 20 or more carbon atoms and 3 or more double bonds), $\Sigma(n-6)$ (sum of all (n-6) fatty acids), $\Sigma(n-3) L C P s$ (sum of the (n-3) long chain polyenes), $\Sigma(n-3)$ (sum of all (n-3) fatty acids), $\Sigma(n-7)+\Sigma$ (n-9) (sum of all (n-7) and (n-9) fatty acids), $\Sigma$ SAFA (sum of all saturated fatty acids), EMUFA (sum of all mono-unsaturated fatty acids), and $\sum$ PUFA (sum of all polyunsaturated fatty acids). Moreover, three indices were calculated: the EFA status 


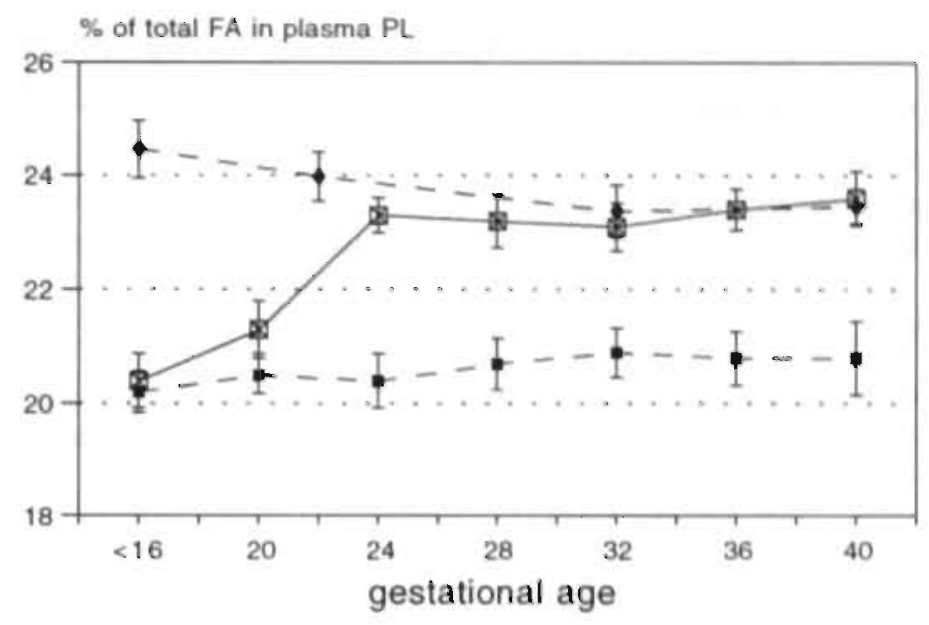
- LL-control group $\$$ LA-suppl. group - HL-control group $(n=22)$ $(n=21)$ $(n=21)$

Figure 1. The relative amounts of linoleic acid in maternal plasma phospholipids during pregnancy. At week 40: $L L$-control group ( $n=13)$, LA-supplemented group $(n=13)$ and HL-control group $(n=11)$.

$\left[\left(\sum(\mathrm{n}-3)+\sum(\mathrm{n}-6)\right) /\left(\sum(\mathrm{n}-7)+\sum(\mathrm{n}-9)\right)\right]$, the cervonic acid deficiency index [CADI, $22: 5(n-6) / 22: 4(n-6)]$ and the classic triene/tetraene ratio [EFA deficiency index, $20: 3(n-9) / 20: 4(n-6)](6,13)$.

\section{Compliance measurements and safety checks}

During the intervention period, the amount of linoleic acid in maternal plasma PLs in the LA supplemented group was determined within one week after the blood sample had been taken. This was done to measure compliance and to prevent the maternal LA status, from increasing above the P90. If the maternal LA status tended to raise over the P90, the amount of LA supplied was adjusted.

\section{Statistical analyses}

All date are presented as mean \pm s.e.m. Because the intake ( $\mathrm{g} /$ day) of linoleic acid was not normally distributed, this variable was analyzed non-parametrically. The differences in LA intake between the three groups were tested by means of the Kruskal Wallis test.

The effect of type of diet (LA supplemented or not) on the LA levels of maternal plasma PLs between the LA supplemented group and the LL-control group was evaluated by calculating the difference in fatty acid composition with regard to the 
Table I. Clinical characteristics of mothers and their newborns of the three study groups $\$$.

\begin{tabular}{lccc} 
& $\begin{array}{l}\text { LL-control } \\
(\mathrm{n}=22)\end{array}$ & $\begin{array}{l}\text { LA supplemented } \\
(\mathrm{n}=21)\end{array}$ & $\begin{array}{l}\text { HL-control } \\
(\mathrm{n}=21)\end{array}$ \\
\hline & & & \\
Age (years) & $29.9 \pm 0.98$ & $30.7 \pm 0.93$ & $28.3 \pm 0.78$ \\
Gestational age at delivery (days) & $281.5 \pm 2.53$ & $282.8 \pm 2.58$ & $277.7 \pm 1.64$ \\
Birthweight (grams) & $3317 \pm 90.3$ & $3443 \pm 117.0$ & $3260 \pm 91.0$ \\
Apgar score (after 5 min) & $9.5 \pm 0.17$ & $9.8 \pm 0.10$ & $9.8 \pm 0.09$ \\
Sex (boys/girls) & $14 / 8$ & $11 / 10$ & $12 / 9$ \\
\hline
\end{tabular}

§: Results are expressed as mean \pm s.e.m., except for sex. LL-control $=$ control group, low in linoleic acid; LA supplemented = linoleic acid supplemented group; HL-control = control group, high in linoleic acid (see material and methods for details).

values at 20 weeks of gestation. Within the groups, the differences were tested by paired t-tests and between the two groups by unpaired $t$-tests. In the HL-control group, the difference in maternal LA levels was calculated with regard to the values at 22 weeks and tested with a paired $t$-test. The difference in LA levels between the three groups was tested by use of Tukey's test, with $\mathrm{p}<0.05$ considered significant.

The effect of maternal LA supplementation on the neonatal EFA status was tested by comparing the fatty acid composition of PLs isolated from umbilical plasma, and from venous and arterial vessel walls in the three groups by means of Tukey's test.

To evaluate which other variables, apart from LA supplementation, contributed significantly to the fatty acid composition of umbilical plasma and vessel wall PLs, stepwise multiple regression analyses were performed in the two groups of women with low LA levels at entry. As independent variables, the fatty acid composition of maternal plasma PLs at the start of the intervention period, gestational age at birth, and the type of diet (LA or control) were used. Gestational age was added as a possible confounding factor because a significant negative correlation have been observed with 18:2(n-6) levels and a significant positive correlation with $22: 6(n-3)$ levels in umbilical plasma (6).

The relationship between the maternal EFA status during gestation and the neonatal EFA status was tested in the two control groups together by calculating the Pearson correlation coefficient between maternal plasma fatty acid. levels around 20 weeks of gestation and the corresponding fatty acid values in umbilical plasma, venous and arterial vessel walls. The partial correlation coefficient is calculated when gestational age at birth appeared a significantly confounding variable.

The statistical analyses were performed by use of the SPSS-PC program (14)

\section{RESULTS}

One woman from the LA supplemented group delivered her baby at 31 weeks of 
Table 2. Fatty acid composition (\% of TF) of umbilical plasma PLs\$.

\begin{tabular}{|c|c|c|c|}
\hline Fatty acid & $\begin{array}{l}\text { LL-control } \\
(\mathrm{n}=22)\end{array}$ & $\begin{array}{l}\text { LA supplemented } \\
(\mathrm{n}=21)\end{array}$ & $\begin{array}{l}\text { HL-control } \\
(n=21)\end{array}$ \\
\hline $18: 2(n-6)$ & $7.15 \pm 0.34$ & $7.80 \pm 0.25$ & $8.53 \pm 0.29$ (a) \\
\hline $20: 2(n-6)$ & $0.35 \pm 0.02$ & $0.36 \pm 0.01$ & $0.40 \pm 0.02$ \\
\hline $20: 3(n-6)$ & $4.83 \pm 0.20$ & $5.05 \pm 0.25$ & $5.12 \pm 0.19$ \\
\hline $20: 4(n-6)$ & $16.2 \pm 0.32$ & $17.2 \pm 0.30$ & $16.1 \pm 0.41$ \\
\hline $22: 4(n-6)$ & $0.76 \pm 0.02$ & $0.89 \pm 0.11$ & $0.76 \pm 0.04$ \\
\hline $22: 5(n-6)$ & $0.83 \pm 0.05$ & $0.86 \pm 0.05$ & $0.85 \pm 0.05$ \\
\hline $24: 2(n-6)$ & $0.58 \pm 0.04$ & $0.67 \pm 0.05$ & $0.75 \pm 0.04(\mathrm{a})$ \\
\hline$\Sigma(\mathrm{n}-6) \mathrm{LCPS}$ & $22.6 \pm 0.30$ & $24.0 \pm 0.29(\mathrm{a})$ & $22.8 \pm 0.36$ \\
\hline$\Sigma(n-6)$ & $30.8 \pm 0.46$ & $32.9 \pm 0.44(\mathrm{a})$ & $32.5 \pm 0.32(\mathrm{a})$ \\
\hline $18: 3(n-3)$ & $0.09 \pm 0.02$ & $0.03 \pm 0.01$ (a) & $0.07 \pm 0.01$ \\
\hline $20: 4(n-3)$ & $0.08 \pm 0.02$ & $0.06 \pm 0.01$ & $0.07 \pm 0.01$ \\
\hline $20: 5(n-3)$ & $0.2 .4 \pm 0.02$ & $0.23 \pm 0.03$ & $0.18 \pm 0.02$ \\
\hline $22: 5(n-3)$ & $0.50 \pm 0.04$ & $0.40 \pm 0.03$ (a) & $0.36 \pm 0.03(a)$ \\
\hline $22: 6(n-3)$ & $6.77 \pm 0.33$ & $5.80 \pm 0.26$ & $5.27 \pm 0.28$ (a) \\
\hline$\Sigma(n-3) L C P s$ & $7.59 \pm 0.37$ & $6.50 \pm 0.29$ (a) & $5.88 \pm 0.31$ (a) \\
\hline$\sum(n-3)$ & $7.68 \pm 0.36$ & $6.53 \pm 0.29$ (a) & $5.95 \pm 0.31(\mathrm{a})$ \\
\hline $20: 3(n-9)$ & $0.69 \pm 0.12$ & $0.52 \pm 0.03$ & $0.68 \pm 0.07$ \\
\hline$\Sigma(n-7)+\Sigma(n-9)$ & $12.6 \pm 0.54$ & $12.6 \pm 0.28$ & $13.7 \pm 0.57$ \\
\hline$\sum S A F A$ & $46.8 \pm 0.54$ & $45.8 \pm 0.22$ & $45.6 \pm 0.42$ \\
\hline$\sum M U F A$ & $11.9 \pm 0.50$ & $12.0 \pm 0.25$ & $13.0 \pm 0.56$ \\
\hline ¿PUFA & $39.2 \pm 0.46$ & $40.0 \pm 0.37$ & $39.2 \pm 0.37$ \\
\hline EFA status & $3.18 \pm 0.16$ & $3.18 \pm 0.10$ & $2.91 \pm 0.13$ \\
\hline EFA def. index & $0.05 \pm 0.01$ & $0.03 \pm 0.00$ & $0.04 \pm 0.00$ \\
\hline CADI & $1.08 \pm 0.05$ & $1.06 \pm 0.06$ & $1.12 \pm 0.05$ \\
\hline TOTAL $(\mathrm{mg} / \mathrm{L})$ & $606.0 \pm 30.3$ & $660.8 \pm 24.8$ & $592.4 \pm 33.3$ \\
\hline
\end{tabular}

§: LL-control = control group, low in linoleic acid; LA. supplemented = linoleic acid supplemented group; HL-control = control group, high in linoleic acid (see material and methods for details).

I: LCPs, long chain polyenes (poly-unsaturated fatty acids with 20 or more carbon atoms and 3 or more double bonds); $\Sigma$ SAFA, sum of all saturated fatty acids; $\Sigma$ MUFA, sum of all monounsaturated fatty acids; $\Sigma$ PUFA, sum of all polyunsaturated fatty acids; EFA status, $[\Sigma(n-6)+\Sigma(n-$ $3)] /[\Sigma(n-7)+\Sigma(n-9)] ;$ EFA def. index, 20:3(n-9)/20:4(n-6); CADI, 22:5(n-6)/22:4(n-6),

a: significantly different from the LL-control group, $\mathrm{p}<0.05$.

gestation, and from another participant material of the umbilical cord was missing. The data from these women were excluded from the data analyses. Clinical characteristics of the three groups are given in table 1. No significant differences were observed in age of the mother, gestational age at delivery, birthweight and Apgar score after 5 minutes, between the three groups. 
Table 3. Fatty acid composition (\% of TF) of umbilical venous vessel wall PLs $\$$.

\begin{tabular}{|c|c|c|c|}
\hline Fatty acidq & $\begin{array}{l}\text { LL-control } \\
(\mathrm{n}=22)\end{array}$ & $\begin{array}{l}\text { LA supplemented } \\
(\mathrm{n}=21)\end{array}$ & $\begin{array}{l}\text { HL-control } \\
(\mathrm{n}=2 \mathrm{1})\end{array}$ \\
\hline $18: 2(n-6)$ & $1.80 \pm 0.10$ & $1.96 \pm 0.08$ & $2.26 \pm 0.12(a)$ \\
\hline $20: 2(n-6)$ & $0.37 \pm 0.03$ & $0.39 \pm 0.02$ & $0.46 \pm 0.03$ \\
\hline $20: 3(n-6)$ & $1.76 \pm 0.06$ & $2.09 \pm 0.09$ (a) & $1.89 \pm 0.06$ \\
\hline $20: 4(n-6)$ & $19.0 \pm 0.35$ & $19.9 \pm 0.23(\mathrm{~b})$ & $18.1 \pm 0.35$ \\
\hline $22: 4(n-6)$ & $5.48 \pm 0.20$ & $5.71 \pm 0.21$ & $5.36 \pm 0.19$ \\
\hline $22: 5(n-6)$ & $2.85 \pm 0.14$ & $3.08 \pm 0.13$ & $2.97 \pm 0.15$ \\
\hline $24: 2(n-6)$ & $0.64 \pm 0.03$ & $0.74 \pm 0.04$ & $0.64 \pm 0.05$ \\
\hline$\Sigma(n-6) L C P s$ & $29.1 \pm 0.41$ & $30.7 \pm 0.33(a, b)$ & $28.3 \pm 0.44$ \\
\hline$\Sigma(n-6)$ & $32.0 \pm 0.44$ & $33.9 \pm 0.33(\mathrm{a}, \mathrm{b})$ & $31.8 \pm 0.44$ \\
\hline$\Sigma(n-3) L C P s$ & $6.26 \pm 0.16$ & $5.59 \pm 0.15(\mathrm{a}, \mathrm{b})$ & $4.63 \pm 0.20(a)$ \\
\hline $20: 3(n-9)$ & $0.50 \pm 0.07$ & $0.41 \pm 0.04$ & $0.39 \pm 0.04$ \\
\hline $22: 3(n-9)$ & $0.43 \pm 0.05$ & $0.38 \pm 0.03$ & $0.32 \pm 0.03$ \\
\hline$\Sigma(n-7)+\Sigma(n-9)$ & $15.8 \pm 0.46$ & $15.1 \pm 0.30$ & $15.7 \pm 0.31$ \\
\hline$\sum$ SAFA & $45.9 \pm 0.24$ & $45.4 \pm 0.23(\mathrm{~b})$ & $47.9 \pm 0.37$ (a) \\
\hline ¿MUFA & $14.8 \pm 0.36$ & $14.4 \pm 0.27$ & $15.0 \pm 0.29$ \\
\hline$\Sigma$ PUFA & $39.2 \pm 0.37$ & $40.3 \pm 0.27(b)$ & $37.1 \pm 0.52(a)$ \\
\hline EFA status & $2.48 \pm 0.09$ & $2.63 \pm 0.07(b)$ & $2.35 \pm 0.08$ \\
\hline EFA def index & $0.03 \pm 0.00$ & $0.02 \pm 0.00$ & $0.02 \pm 0.00$ \\
\hline CADI & $0.54 \pm 0.04$ & $0.56 \pm 0.04$ & $0.58 \pm 0.04$ \\
\hline TOTAL $(\mathrm{mg} / \mathrm{g})$ & $17.0 \pm 0.78^{\#}$ & $16.8 \pm 0.47$ & $15.0 \pm 0.62^{¥}$ \\
\hline
\end{tabular}

§: LL-control = control group, low in linoleic acid; LA supplemented $=$ linoleic acid supplemented group; HL-control = control group, high in linoleic acid (see material and methods for details).

9: LCPs, long chain polyenes (poly-unsaturated fatty acids with 20 or more carbon atoms and 3 or more double bonds): ¿SAFA, sum of all saturated fatty acids; ¿MUFA, sum of all monounsaturated fatty acids; $\Sigma$ PUFA, sum of all polyunsaturated fatty acids; EFA status, [ $\Sigma(\mathbf{n}-6)+\Sigma(\mathrm{n}-$ $3)] /[\Sigma(n-7)+\Sigma(n-9)]$; EFA def. index, 20:3(n-9)/20:4(n-6); CADI, 22:5(n-6)/22:4(n-6).

$\#: \mathrm{n}=21 ; \nvdash: \mathrm{n}=18$.

a: significantly different from the LL-control group, $\mathrm{p}<0.05$.

b: significantly different from the HL-control group. $\mathrm{p}<0.05$.

\section{Maternal LA status during gestation}

The mean relative amount ( $\%$ of total fatty acids) of linoleic acid in maternal plasma phospholipids (PLs), before 16 weeks of gestation, was $20.2 \pm 0.36$ in the LL-control group $(\mathrm{n}=22), 20.5 \pm 0.50$ in the LA supplementation group $(\mathrm{n}=21)$ and $24.5 \pm 0.51$ in the HL-control group $(\mathrm{n}=21)$, which was significantly higher than in the former two groups.

According to the dietary history, the mean linoleic acid intake before supplementation, was significantly lower in the LL-control group $(13.5 \pm 1.52 \mathrm{~g} /$ day, $\mathrm{n}=22)$ and the LA supplementation group $(14.0 \pm 1.03, \mathrm{n}=21)$ than in the HL-controlgroup $(23.5 \pm$ 
Table 4. Fatty acid composition (\% of TF) of umbilical arterial vessel wall PLs $\$$.

\begin{tabular}{|c|c|c|c|}
\hline Fatty acidf & $\begin{array}{l}\text { LL-control } \\
(\mathrm{n}=22)\end{array}$ & $\begin{array}{l}\text { LA supplemented } \\
(\mathrm{n}=21)\end{array}$ & $\begin{array}{l}\text { HL-control } \\
(n=21)\end{array}$ \\
\hline $18: 2(n-6)$ & $1.22 \pm 0.06$ & $1.27 \pm 0.04(b)$ & $1.60 \pm 0.11(\mathrm{a})$ \\
\hline $20: 2(n-6)$ & $0.17 \pm 0.02$ & $0.18 \pm 0.01(b)$ & $0.27 \pm 0.03(\mathrm{a})$ \\
\hline $20: 3(n-6)$ & $1.27 \pm 0.05$ & $1.41 \pm 0.06$ & $1.34 \pm 0.05$ \\
\hline $20: 4(n-6)$ & $15.1 \pm 0.51$ & $15.4 \pm 0.44$ & $14.3 \pm 0.43$ \\
\hline $22: 4(n-6)$ & $3.36 \pm 0.16$ & $3.57 \pm 0.16$ & $3.10 \pm 0.12$ \\
\hline $22: 5(n-6)$ & $3.28 \pm 0.13$ & $3.49 \pm 0.13$ & $3.50 \pm 0.12$ \\
\hline $24: 2(n-6)$ & $0.21 \pm 0.02$ & $0.24 \pm 0.02$ & $0.20 \pm 0.02$ \\
\hline$\Sigma(n-6) L C P s$ & $23.0 \pm 0.63$ & $23.9 \pm 0.55$ & $22.2 \pm 0.57$ \\
\hline$\Sigma(n-6)$ & $24.6 \pm 0.66$ & $25.6 \pm 0.58$ & $24.4 \pm 0.61$ \\
\hline$\Sigma(n-3) L C P s$ & $6.48 \pm 0.25$ & $5.74 \pm 0.16(a, b)$ & $4.99 \pm 0.22$ (a) \\
\hline $20: 3(n-9)$ & $2.66 \pm 0.24$ & $2.94 \pm 0.23$ & $2.87 \pm 0.18$ \\
\hline $22: 3(n-9)$ & $1.37 \pm 0.09$ & $1.59 \pm 0.12$ & $1.44 \pm 0.10$ \\
\hline$\Sigma(n-7)+\Sigma(n-9)$ & $22.4 \pm 0.87$ & $22.8 \pm 0.75$ & $23.7 \pm 0.70$ \\
\hline$\Sigma$ SAFA & $46.5 \pm 0.34$ & $45.9 \pm 0.25$ & $47.0 \pm 0.40$ \\
\hline$\Sigma M U F A$ & $18.3 \pm 0.59$ & $18.3 \pm 0.46$ & $19.3 \pm 0.50$ \\
\hline ¿PUFA & $35.1 \pm 0.59$ & $35.9 \pm 0.38(b)$ & $33.7 \pm 0.59$ \\
\hline EFA status & $1.47 \pm 0.10$ & $1.43 \pm 0.08$ & $1.28 \pm 0.07$ \\
\hline EFA def. index & $0.19 \pm 0.02$ & $0.20 \pm 0.02$ & $0.21 \pm 0.02$ \\
\hline CADI & $1.03 \pm 0.07$ & $1.02 \pm 0.06$ & $1.16 \pm 0.06$ \\
\hline TOTAL $(\mathrm{mg} / \mathrm{g})$ & $16.4 \pm 1.03^{\#}$ & $16.6 \pm 0.34$ & $14.6 \pm 0.71^{\frac{4}{*}}$ \\
\hline
\end{tabular}

§: see for legends Table 3.

$1.98 \mathrm{~g} /$ day, $\mathrm{n}=19$ ). The mean additional intake of linoleic acid in the LA supplemented group during the supplementation period was $10.7 \pm 0.11 \mathrm{~g} /$ day, which is almost similar to the difference between the LL-and HL-control group.

In figure 1 the mean relative amounts of linoleic acid in maternal plasma PLs of the three groups during pregnancy is given. After 4 weeks of supplementation, the LA levels in the LA supplemented group had significantly $(p<0.001)$ increased to $23.3 \pm$ $0.33 \%$ and remained significantly higher than in the LL-control group, but were not significantly different from the HL-control group. In the LL-control and HL-control, the relative amounts of LA did not change significantly from 20 , respectively 22 weeks of gestation until delivery.

\section{Neonatal EFA status}

The mean total amount of fatty acids in umbilical plasma, and in venous and arterial vessel. wall PLs was not significantly different between the three groups and therefore, only the relative amounts of the fatty acids are presented (absolute amounts are given in appendices D1, D3 and D4). 
Table 5. An overview of the variables contributing significantly to the neonatal essential fatty acid status.

\begin{tabular}{|c|c|c|}
\hline Dependent variablef & $\begin{array}{l}\text { Independent variables } \\
\text { tested, }\end{array}$ & $\begin{array}{l}\text { Significant explanatory variables } \\
\text { B§ (́p-value) }\end{array}$ \\
\hline 18:2(n-6)-up & $\begin{array}{l}\text { diet, gestational age, } \\
18: 2(\mathrm{n}-6) \cdot \mathrm{m} 20\end{array}$ & $\begin{array}{l}\text { 18:2(n-6)-m20: }+0.30(0.001) \\
\text { gestational age: }-0.05(0.0006)\end{array}$ \\
\hline$\Sigma(n-6)$ LCPs-up & $\begin{array}{l}\text { diet, gestational age, } \\
\sum(\mathrm{n}-6) \text { LCPs-m } 20\end{array}$ & diet: $+1.50(0.0007)$ \\
\hline$\Sigma(n-3)$ LCPS-up & $\begin{array}{l}\text { diet, gestational age, } \\
\sum(\mathrm{n}-3) \text { LCPs-m20 }\end{array}$ & $\begin{array}{l}\text { diet: }-1.16(0.009) \\
\sum(\mathrm{n}-3) \text { LCPS-m20:+0.32 }(0.03) \\
\text { gestational age: }+0.04(0.025)\end{array}$ \\
\hline 18:2(n-6)-ua & $\begin{array}{l}\text { diet. gestational age, } \\
18: 2(\mathrm{n}-6) \cdot \mathrm{m} 20\end{array}$ & gestational age: $+0.008(0.01)$ \\
\hline$\Sigma(\mathrm{n}-6)$ LCPs-ua & $\begin{array}{l}\text { diet, gestational age, } \\
\sum(n-6) L C P s-m 20\end{array}$ & gestational age: $+0.10(0.005)$ \\
\hline$\Sigma(\mathbf{n}-3)$ LCPs-ua & $\begin{array}{l}\text { diet, gestational age, } \\
\Sigma(n-3) L C P S-m 20\end{array}$ & $\begin{array}{l}\text { diet: }-0.75(0.01) \\
\sum(n-3) L C P s-m 20:+0.25(0.01)\end{array}$ \\
\hline 20:3(n-9)-ua & $\begin{array}{l}\text { diet, gestational age, } \\
\text { 18:2(n-6)-m20, -up, -uv, -ua }\end{array}$ & NS \\
\hline $18: 2(n-6)-u v$ & $\begin{array}{l}\text { diet, gestational age, } \\
18: 2(\mathrm{n}-6) \cdot \mathrm{m} 20\end{array}$ & NS \\
\hline$\sum(n-6)$ LCPs-uv & $\begin{array}{l}\text { diet, gestational age, } \\
\sum(\mathrm{n}-6) \text { LCPs-m20 }\end{array}$ & $\begin{array}{l}\text { diet: }+1.65(0.003) \\
\text { gestational age: }+0.05(0.05)\end{array}$ \\
\hline$\Sigma(n-3)$ LCPS-uv & $\begin{array}{l}\text { diet, gestational age, } \\
\Sigma(\mathrm{n}-3) \text { LCPs-m20 }\end{array}$ & diet: $-0.67(0.003)$ \\
\hline
\end{tabular}

9: up = umbilical plasma; ua = umbilical artery; uv = umbilical vein.

¥: die! =LA supplemented or LL-control; gestational age in days; $\mathrm{m} 20=$ maternal plasma values $(\%$ of total fatty acids) at week 20.

$\S$ : 3 =regression coefficient.

In table 2 the fatty acid composition of umbilical venous plasma PLs are given. Although maternal LA supplementation did not result in significantly higher LA values in umbilical venous plasma, it caused significantly higher relative amounts of $\Sigma(\mathrm{n}-6)$ LCPs compared with the LL-control group. The $\Sigma(\mathrm{n}-6)$ levels were significantly higher both in the LA supplemented group and in the HL-control group than in the LL-control group. In the HL-control group this was mainly due to significantly higher values of $18: 2(\mathrm{n}-6)$ compared with the LL-control group. The $\Sigma$ $(n-3) L C P$ and $\Sigma(n-3)$ values were significantly reduced in the LA supplemented and HL-control groups. The indices 'EFA status', 'EFA deficiency index' and 'CADI' were 
Table 6. Correlation coefficients between maternal plasma fatry acid levels at 20 weeks of gestation and fatry acid levels in umbilical plasma, venous and arterial vessel walls PLs, at delivery $(n=43)\}$.

\begin{tabular}{llll} 
Fatty acid & Umbilical plasma & Venous vessel wall & Arterial vessel wall \\
\hline $18: 2(\mathrm{n}-6)$ & $+0.51^{\mathrm{b}}$ & $+0.33^{\mathrm{a}}$ & $+0.35^{\mathrm{a}}$ \\
$\Sigma(\mathrm{n}-6)$ LCPs & $+0.33^{\mathrm{a}}$ & +0.16 & +0.10 \\
$\Sigma(\mathrm{n}-3)$ LCPs & $+0.54^{\mathrm{b}}$ & $+0.65^{\mathrm{b}}$ & $+0.51^{\mathrm{b}}$ \\
\hline
\end{tabular}

§: Partial correlation coefficient (after correction for gestational age at birth) is given for $18: 2(\mathrm{n}-6)$ in umbilical plasma, for $\Sigma(n-6)$ LCPs in umbilical venous and arterial vessel walls and for $\Sigma(n-3)$ LCPs in umbilical plasma, venous and arterial vessel walls.

a: $p<0.05 ;$ b: $p<0.001$.

not significantly affected by maternal LA supplementation, nor were they significantly different in the HL-control group compared to the LL-control group.

The fatty acid compositions of the umbilical venous and arterial vessel wall PLs are shown in table 3 and 4 , respectively. LA supplementation was again associated with a significantly higher $\Sigma(\mathrm{n}-6)$ LCP content (umbilical vein) and lower $\Sigma(\mathrm{n}-3)$ LCP amount, and not with significantly higher LA levels as compared with the LL-control group. In the HL-control group, in which the habitual LA intake is comparabie to the total daily LA intake in the LA supplemented group, LA levels were significantly higher than in the LL-control group. The LA content in the arterial vessel walls was even in the HL-control group significantly higher as compared with the LA supplemented group. The $\Sigma(\mathrm{n}-3)$ LCP levels in the HL-control group were, however, significantly lower than in the other two groups.

The significantly higher $\sum(\mathrm{n}-6)$ LCPs and $\sum(\mathrm{n}-3)$ LCPs in the LA supplemented group as compared with the HL-control group, resulted in a significantly higher EFA status in the venous vessel walls. Compared with the LL-control group, however, the difference in EFA status was not significant. The relative amounts of Mead acid (20:3(n-9), MA) and dihomoMead acid (22:3(n-9), DHMA) were not significantly different between the three groups, nor were the EFA deficiency index and CADI.

In table 5 the results of the multiple regression analyses for the relative values ( $\%$ of total fatty acids) are shown. LA supplementation was a significant positive explanatory variable for the relative amounts of $\sum(n-6) L C P s$ in umbilical plasma and venous vessel wall, and a significant negative explanatory variable for the $\sum(n-3) L C P$ levels in umbilical plasma, and in the arterial and venous vessel wall. The maternal LA status at 20 weeks of gestation explained in a significant and positive way the variation in the relative amounts of LA in umbilical plasma at delivery. The maternal $\Sigma(n-3)$ LCP status at 20 weeks of gestation contributed significantly and in a positive way to the $\Sigma(n-3)$ LCP levels in umbilical plasma as well as in arterial vessel walls. The high relative amounts of 20:3(n-9) in the umbilical artery were not associated with diet, gestational age, nor did they correlate significantly with the $18: 2(n-6)$ levels 
in maternal plasma, umbilical plasma, artery and vein.

In the control groups $(n=43)$, the fatty acid values in maternal plasma at week 20 were positively and significantly related to the fatty acids levels in umbilical plasma for 18:2(n-6), $\sum(\mathrm{n}-6)$ LCPs and $\sum(\mathrm{n}-3)$ LCPs, and in umbilical venous and arterial vessel walls for 18:2(n-6) and $\sum(n-3)$ LCPs (see table 6 ). The (partial) correlation coefficient ranged from $+0.33(\mathrm{p}<0.05)$ for $\sum(\mathrm{n}-6)$ LCPs in umbilical plasma to $+0.65(\mathrm{p}<$ $0.001)$ for $\sum(\mathrm{n}-3) \mathrm{LCPs}$ in umbilical venous vessel wall PLs.

\section{DISCUSSION}

There are two families of fatty acids, the (n-6) and (n-3), known to be essential for normal mammalian cell function (for a recent review: see ref. 15). Linoleic acid $(18: 2(n-6), L A)$ is the parent essential fatty acid of the (n-6) family and serves an essential function in the maintenance of the epidermal water barrier and as an ultimate dietary precursor fatty acid of eicosanoids, which include leukotrienes, prostaglandins, thromboxanes and related compounds. Because LA cannot be synthesized by man, it must be taken up by the diet. Clearly, the fetus must derive all LA from the maternal circulation by placental transfer.

The present study demonstrated that a linoleic acid enriched diet, used by pregnant women from 20 weeks of gestation until delivery, did not result in higher neonatal LA levels, but in higher amounts of the $\sum(\mathrm{n}-6) \mathrm{LCP}$ in umbilical plasma and venous vessel wall PLs. This was associated with lower $(n-3)$ fatty acid leveis in umbilical plasma and in venous and arterial vessel wall PLs compared with the LL-control group. This opposite effect on (n-6) and (n-3) fatty acids may explain why LA supplementation had no significant effect on the neonatal overall EFA status and the essential fatty acid deficiency indicators Mead acid (20:3(n-9), MA) and dihomoMead acid (22:3(n-9), DHMA) in the umbilical artery.

Tinoco et al (16) found that changes in fatty acid composition of retina, brain tissue and muscle PLs from linolenic acid deficient rats were most marked when the experimental diet was given to the mother from the time of mating or even earlier. So, it is possible that in the present study the maternal LA supplementation, started too late to have an effect on the neonatal LA status. Indeed, in the HL-control group with a habitual daily LA intake $(23.5 \pm 1.98)$ comparable with the total intake in the LA supplemented group $(24.7 \pm 0.96)$, the neonatal LA status did show significantly higher LA values than in the LL-control group. The LA levels in umbilical arteries of the HL-control group were also significantly higher when compared with the LA supplemented group. This suggests that the maternal LA status early in pregnancy, or even before conception, has a greater influence on the neonatal LA status than the increased maternal LA status later in pregnancy due to LA supplementation. This is supported by the significant positive association between the neonatal LA status and the maternal LA plasma levels at 20 weeks of gestation (table 5 and 6). Moreover, the 
observation that, apart from diet, the maternal $\Sigma(n-3)$ LCP status at 20 weeks of gestation (that is before the start of the supplementation period) already significantly and positively contributed to the levels of these fatty acids in umbilical plasma and arterial vessel wall PLs (table 5) points in the same direction.

Other factors which could have influenced the results, are the degree of compliance and the amount of LA supplemented. The increment of maternal plasma LA levels in the LA supplemented group was higher than expected on basis of the known relation between LA intake and LA levels in plasma PLs (17, unpublished observation), demonstrating that the dietary compliance of the women was good. The decision to supplement the diet with approximately 10 gram LA per day was based on previous studies (6, unpublished observation) in a group of healthy pregnant women, so that we were sure that effects were studied within a normal range.

Recently, it was observed that the LCP status at birth is a major determinant of the post-natal LCP status about 8 weeks after birth (18). This implies that, in order to ensure an optimal post-natal LCP status, the pre-natal LCP status should be optimal as well. Our present study demonstrates that maternal LA supplementation can result in a higher neonatal (n-6) LCP status. This may have beneficial effects, especially for children born prematurely, for which significant positive correlations have been described between the (n-6) long chain polyene 20:4(n-6) in plasma phosphatidyl choline, and growth in the first year of life (19).

In the LA supplemented group, the elevated (n-6) LCP status at birth was accompanied by a decreased (n-3) LCP status. It is known that high intakes of LA suppress the incorporation of (n-3) fatty acids in phospholipids (20-22). The (n-6) and (n-3) fatty acids compete for the same desaturase and elongase enzyme systems. So, increasing LA levels can result in a competitive inhibition of (n-3) LCP synthesis. Cervonic acid (22:6(n-3), CA), the major (n-3) fatty acid, is an important constituent of cell membranes, especially in brain and retina tissue and data are accumulating that CA is an essential fatty acid for a normal development of brain and retina functions (23-25). Hence, it is important that the maternal and neonatal (n-3) LCP status are optimal. Therefore, the lower (n-3) LCP content in umbilical plasma and tissue after LA supplementation may be a matter of some concern. In the group of women with habitual high plasma LA. levels (HL-control group) the (n-3) LCP status of umbilical plasma and vessel walls was also lower. For the umbilical vessel walls, this effect was even more pronounced than in the LA supplemented group. However, these high LA consumptions did not significantly affect the functional CA status, since the cervonic acid deficiency index was not significantly altered. Nevertheless, the reduced (n-3) LCP content in neonatal tissue after LA supplementation should be prevented and, therefore, not only the intake of LA, but also that of (n-3) LCPs during gestation deserves consideration.

The effect of an additional intake of (n-3) fatty acids during gestation was recently 
described by Houwelingen et al. (26). An increased neonatal CA status was observed, which was accompanied by a decrease in the neonatal (n-6) LCP status. So, again a competition between the (n-6) and (n-3) LCPs was evident. Therefore, if the general LCP status of the newborn needs to be improved, fatty acids of the (n-6) as well as of the (n-3) family have to be supplied. Further research should aim at finding the optimal fatty acid mixture of both families. Moreover, the time-period of supplementation should be considered. There is evidence that the maternal nutritional status during ovum maturation and early embryonic development has more effect on the fetus than the maternal nutritional status during the last two trimesters of pregnancy (27). This may be due, among other things, to the development of the placental barrier in early pregnancy. Events occurring at the time of placental implantation play a role in determining the ultimate size attained by the placenta (28). So it is possible that the nutritional status of the mother of that particular period has a significant influence on the composition and function of the placenta. The higher neonatal LA status in the HL-control group and the significant positive contribution of the maternal fatty acid levels (before supplementation) to the corresponding fatty acids in umbilical plasma and/or vessel wall PLs provide indications that the preconceptional maternal EFA status does have a significant influence on the neonatal EFA status. Therefore, as one might expect that early intervention will be more efficient in improving the neonatal EFA status than supplementation after complete development of the placenta, supplementation has to start very early in pregnancy, or even before conception.

\section{ACKNOWLEDGEMENT}

The authors like to thank the pregnant women for participating in the study. The assistence of Andre de Jong and Taco van de Berg in analysing the plasma samples and of Monique Heesterbeek and Marianne Simonis in analysing the umbilical cords is greatly appreciated.

\section{REFERENCES}

1. Hornstra G, Houwelingen AC v., Simonis M, Gerrard JM. Fatty acid composition of umbilical arteries and veins: possible implications for the fetal EFA status. Lipids 1989; 24: 511-7.

2. Al MDM, Hornstra G, vd Schouw YT, Bulstra-Ramakers MTEW, Huisjes HJ. Biochemical essential fatty acid status of mothers and their neonates after normal pregnancy. Early Hum Dev 1990; $24: 239-48$.

3. Mead JF. The metabolism of the polyunsaturated fatty acids. In: Holman RT, ed. Progress in the Chemistry of Fats and Other Lipids. Oxford: Pergamon Press, 1971: 161-89.

4. Ongari MA, Ritter JM, Orchard MA, Waddell KA, Blair IA, Lewis PJ. Correlation of prostacyclin synthesis by human umbilical artery with status of essential fatty acid. Am J Obstet Gynecol 1984; 149: 455-60. 
5. Crawford MA, Costeloe K, Doyle W, Leighfield MJ, Lennon EA, Meadows N. Potential diagnostic value of the umbilical artery as a definition of neural fatty acid status of the fetus during its growth: the umbilical artery as a diagnostic tool. Biochem Soc Trans 1990; 18: 761-6.

6. Al MDM, Houwelingen AC v., Kester ADM, Hasaart THM, Hornstra G. Maternal essential fatty acid patterns during normal pregnancy and its relationship with the neonatal essential fatry acid status. 1994, submitted.

7. Beal VA. The nutritional history in longitudinal research. J Am Diet Assoc 1967; 51: 426-32.

8. Folch J, Lees M, Sloane Stanley GH. A simple method for the isolation and purification of total lipides from animal tissues. J Biol Chem 1957; 226: 497-509.

9. Hoving EB, Jansen G, Volmer M, Doormaal van JJ, Muskiet FAJ. Profiling of plasma cholesterol esters and triglyceride fatty acids as their methylesters by capillary gas chromatography, preceded by a rapid aminopropyl silica column chromatographic separation of lipid classes. J Chromatogr 1988; 434: 395-409.

10. Kaluzny MA, Duncan LA, Merritt MV, Epps DE. Rapid separation of lipid classes in high yield and purity using bonded phase columns. J Lipid Res $1985 ; 26$ : 135-40.

11. Morrison WR, Smith LM. Preparation of fatty acid methylesters and dimethylacetals from lipids with boron fluoride methanol. J Lipid Res 1964; 5: 600-8.

12. Bligh EG, Dyer WJ. A rapid method for total lipid extraction and purification. Can J Biochem Physiol 1959; 37: 911-7.

13. Holman RT. The ratio of trienoic:tetraenoic acids in tissue lipids as a measure of essential fatty acid requirement. J Nutr 1960; 70: 405-10.

14. Nie NH, Hull CH, Jenkins JG, Steinbrenner K, Bent DH, eds. SPSS-X:statistical package for the social sciences. New York: McGraw-Hill. 1983.

15. Innis SM. Essential fatty acids in growth and development. Prog Lipid Res 1991; 30: 39-103.

16. Tinoco J, Babcock R. Hincenbergs I, Medwadowski B, Miljanich P. Linolenic acid deficiency: changes in fatty acid patterns in female and male rats raised on a linolenic acid deficient diet for two generations. Lipids 1979; 13: 6-17.

17. Houwelingen $\mathrm{AC}$ v., Kester ADM, Kromhout D, Hornstra G. Comparison between the habitual intake of polyunsaturated fatty acids and their concentrations in serum lipid fractions. Eur J Clin Nutr 1989; 43:11.20

18. Foreman-van Drongelen MMHP, Houwelingen AC v., Koopman-Esseboom C, Kester ADM, Sauer PJJ, Hornstra G: Does the long chain polyene status, at birth affect the post-natai long chain polyene status? World Rev Nutr Diet, 1994 in press.

19. Carisson SE, Werkman SH, Peeples JM, Cooke RJ, Tolley EA. Arachidonic acid status correlates with first year growth in preterm infarts. Proc Natl Acad Sci 1993; 90: 1073-7.

20. Sanders $T A B$, Mistry $M$, Naismith DI. The influence of a maternal diet rich in linoleic acid on brain and retinal docosahexaenoic acid in the rat. Br I Nutr 1984; $51: 57-66$.

21. Grọnn M, Gфrbitz C. Christensen E, et al. Dietary n-6 fatty acids inhibit the incorporation of dietary $\mathrm{n}-3$ fatty acids in thrombocyte and serum phospholipids in humans: a controlled dietetic study. Scand J Clin Lab Invest 199!; 51: 255-63.

22. McMurchie EJ, Rinaldi JA, Burnard SL, et al. Incorporation and effects of dietary eicosapentaenoate $(20: 5(n-3))$ on plasma and erythrocyte lipids of the marmoset following dietary supplementation with differing levels of linoleic acid. Biochim Biophys Acta 1990; 1045: $164-73$.

23. Neuringer M, WE, Connor, DS Lin, L Barstad, Luck S. Biochemical and functional effects of prenatal and postnatal w3 fatty acid deficiency on retina and brain in rhesus monkeys. Proc Natl Acad Sci 1986; 83: 4021-5.

24. Uauy R, Birch E, Birch D, Peirano P. Visual brain function measurements in studies of n-3 fatty acid requirements of infants. J Pediatr 1992; 120: S168-80.

25. Makrides M, Simmer K, Goggin M, Gibșon RA. Erythrocyte docosahexaenoic açid correlates with the visual response of healthy, term infants. Ped Res 1993; 34: 425-7. 
26. Houwelingen AC v., Hornstra G, Simonis MMG, et al. Essential fatty acid composition of umbilical arteries and veins after fish oil supplementation during pregnancy. In: Drevon CA, Baksaas I, Krokan HE, eds. Omega-3 fatty acids: metabolism \& biological effects. Basel (Switzerland): Birkhauser, 1993: 125-9.

27. Wynn M, Wynn A. The case for preconception care of men and women. Oxon (Great Britain): AB Acadernic, 1991: 64-84.

28. Battaglia FC, Meschia G. An introduction to fetal physiology. Orlando (FI): Academic Press, 1986: 20. 


\section{CHAPTER 8}

\section{General discussion}

The focus of this thesis is on the relationships between the essential fatty acid (EFA) composition of the maternal diet, and on the maternal and neonatal EFA status in normal pregnancy and in pregnancy-induced hypertension (PIH).

\section{Main findings}

EFAs are important structural components of all ce!l membranes. During pregnancy, accretion of maternal, placental and fetal tissue occurs and, consequently, the EFA requirements of pregnant women and their developing fetus are increased. Brain tissue is one of the tissues which contains relatively high levels of (n-3) and (n-6) long chain polyenes (LCPs), particularly cervonic acid (22:6(n-3), CA) and arachidonic acid $(20: 4(n-6), A A)(1,2)$. The last trimester of pregnancy is the most active period of EFA accumulation in the brain $(1,2)$, which is consistent with the rapid synthesis of brain tissue during this period (3). Therefore, it is important to guarantee an adequate EFA supply to the fetus. The fetus is mainly dependent on placental transfer to obtain EFAs and thus on the EFA status and/or supply of the mother (4,5). Data concerning. the maternal and neonatal EFA status in normal pregnancy are, however, surprisingly, limited. Hornstra et al (6) suggested that the neonatal EFA status at birth is marginal, if not insufficient. This view is supported by the results of the fatty acid analyses of phospholipids (PLs) from umbilical plasma and blood cells, and from umbilical arterial and venous vessel walls as described in the results of the first initial study reported in this thesis (Chapter 2). In this study, the neonatal EFA status was characterized by low linoleic acid $(18: 2(n-6), L A)$ levels, in all anaiyzed material and relatively high amounts of the essential fatty acid deficiency marker Mead acid $(20: 3(n-9), M A)$ in the walls of the umbilical arteries. Moreover, the CA status, as reflected by the cervonic acid deficiency index $(22: 5(n-6) / 22: 4(n-6), C A D I)$, was significantly higher in the walls from umbilical arteries (efferent blood vessel) as compared to umbilical veins (afferent blood vessel), which may point to a relative shortage of fetal CA.

A second initial study (Chapter 3) showed that in PIH, where the placental function may be reduced, the neonatal EFA status was not different from that of babies bom after a normal pregnancy. However, the serum PLs of the mothers with PIH, contained significantly lower LA, and higher CA levels as compared with uncomplicated pregnancies. This led to the question whether an altered maternal EFA status is involved in the etiology of PIH. The results of the study were based on a cross-sectional design using material collected immediately after delivery and, 
therefore, do not allow any conclusion with respect to a possible cause and effect relationship. Such a conclusion would require a prospective longitudinal comparison of the maternal EFA courses during normal and complicated pregnancies. As hardly any information is presently available with respect to the course of the maternal EFA status throughout gestation, a prospective longitudinal study was performed to describe the maternal EFA status in relation to the maternal diet during normal pregnancy and in PIH (Chapters 4-6). Immediately after delivery, the neonatal EFA status was assessed also. In a second study (Chapter 7), the efficacy of maternal LA supplementation to improve the neonatal EFA status at birth was investigated.

The maternal EFA intake and EFA status during normal pregnancy and its relationship with the neonatal EFA status

First, the maternal EFA intake and EFA status during normal pregnancy were studied (Chapters 4 and 5, respectively). In contrast to the stable EFA intake, the maternal EFA status was shown to change substantially throughout normal pregnancy, both absolute ( $\mathrm{mg}$ fatty acid present in PLs per $\mathrm{L}$ plasma) as well as relative ( $\%$ of total fatty acids of plasma PLs). A continuing increase was observed for the absolute amounts of all (n-6) and (n-3) fatty acids; the increment observed for CA was the highest, and compared to "pre-pregnancy" levels the absolute amounts almost doubled during pregnancy. When expressed in relative terms, the maternal LA status did not change significantly during pregnancy. The maternal AA and CA status, however, decreased significantlly (for $\mathrm{CA}$ after an initial increase). This was associated with a decrease of the overall EFA status (ratio between $\left[\sum(n-6)+\sum(n-3)\right]$ and $\left[\sum(n-7)+\sum(n-\right.$ 9)]) and an increase of the cervonic acid deficiency index. At the end of gestation, the maternal overall EFA status was significantly lower and the CADI significantly higher as compared to the non-pregnant state. These changes in the maternal EFA patterns during pregnancy may be normal physiological phenomena, characteristic of being pregnant. However, the continuous increase of the CADI may point to a progressive deterioration of the maternal CA status as well, suggesting that under the prevailing dietary conditions, the maternal capacity to meet the high fetal requirement for $\mathrm{CA}$ (5) is working on its limits or may even be inadequate. The significantly higher CADI values in umbilical plasma as compared to the maternal non-pregnant values also indicates that the mother is unable to provide an optimum CA status of the developing fetus.

At delivery, highly significant correlations were observed between umbilical venous and maternal venous plasma PLs for all EFAs, which suggests that the neonatal EFA status can be influenced by maternal dietary intervention. Whether mother and/or child would functionally benefit from such an intervention require further studies on the clinical relevance of an altered maternal and fetal EFA status.

\section{The maternal and neonatal EFA status in pregnancy-induced hypertension}

The observation in the second initial study (Chapter 3), regarding the higher maternal CA levels at delivery in PIH, could theoretically mean that CA is involved in the etiology of PIH. In that case, CA supplementation during pregnancy is probably 
contra-indicated. Whether the higher maternal CA status, at delivery, was a consequence of or a contributing factor to PlH, was studied in a longitudinal "nested" case-control study (Chapter 6). The results demonstrated that the higher maternal CA status in PIH is a late phenomenon, occurring after the clinical manifestations of the disease and, therefore, most probably is not causally related to the onset of PIH. Supplementing pregnant women with CA will thus most probably not contribute to the development of PIH. This suggestion is supported by results from an epidemiological study performed in Northern Canada, showing that Inuit women eating a diet rich in marine food are 2.6 times less likely to develop PIH than Inuit women whose diet contain a greater proportion of terrestrial food (7). Whether or not CA supplementation during pregnancy is effective in reducing the incidence of PIH remains to be investigated.

In the same study (Chapter 6), it was also investigated whether the lower maternal LA status in PIH preceded the clinical manifestations of the disease and could therefore, be involved in its etiology. Again no significant differences were observed between cases and controls during pregnancy. After delivery the LA levels in maternal plasma PLs were reduced in PIH. This was associated with significantly higher amounts of total (n-6) LCPs. In addition, the content of $\alpha$-linolenic acid (18:3(n-3), LnA) was significantly decreased. In PIH, the EFA status of umbilical vessel wall PLs was not different from normal. Since the fatty acid composition of these PLs gives a longer term reflection of the fetal EFA status, this observation supports the suggestion that the altered EFA status in mothers with PIH is a late phenomenon and, therefore, rather a consequence than a cause of this disease.

The decreased levels of the parent EFAs, LA and LnA, in combination with the higher levels of $\Sigma(n-6) L C P_{S}$ and $C A$ suggest that the parent EFAs are more actively metabolized in PIH than in an uncomplicated pregnancy, most probably to guarantee an adequate LCP supply to the fetus in spite of the compromised placental circulation. As a consequence, the neonatal EFA status in PIH is not significantly different from that in a normal pregnancy. On the contrary, the neonatal EFA status tends to be improved as is indicated by lower relative amounts of the EFA deficiency marker Mead acid (20:3(n-9), MA). Moreover, the levels of CA in neonatal plasma PLs are even significantly higher than after a normal pregnancy.

\section{The neonatal EFA status after maternal LA supplementation}

Maternal LA supplementation during pregnancy had no effect on the neonatal LA status (Chapter 7). A well known (and possibly the only) direct physiological function of LA is to control the permeability of the skin to water (8). A low fetal LA status will probably not be harmful, as during intra-uterine life, the fetus is surrounded by amniotic fluid and, therefore, this function of LA will probably be of minor importance during fetal life. Consequently, low LA levels in fetal life (9) will probably have no consequences, as far as this function of LA is concerned. 
Maternal LA supplementation did increase the (n-6) LCP status of the neonate, but at the expense of its (n-3) LCP status (Chapter 7). An intervention study, in which pregnant women were supplemented with (n-3) fatty acids (10) showed that an increased neonatal CA status is accompanied by a decreased (n-6) LCP status. So, again a competition between (n-6) and (n-3) fatty acids was evident. Therefore, if the general EFA status of the newborn needs to be improved, it is important to use diets or supplements containing balanced amounts of $(\mathrm{n}-6)$ and $(\mathrm{n}-3)$ fatty acids.

\section{Some methodological considerations}

The fatty acid composition of the umbilical vessel walls as a longer term reflection of the neonatal EFA status

To assess the neonatal EFA status, the fatty acid composition was determined of phospholipids (PLs) isolated from umbilical plasma and blood cells, and from umbilical venous and arterial vessel walls. The EFA composition of the umbilical vessel wall PLs is considered to give a longer term reflection of the neonatal EFA status than that of plasma or blood cells (6). This view is based on the fact that umbilical vessel walls have no vasa vasorum and, therefore, have to obtain their essential fatty acids from the blood they contain. Moreover, the turnover of vessel wall PLs may be expected to be slower than that of plasma or blood cells.

The PLs of the umbilical arterial vessel walls contain relatively high levels of the EFA deficiency markers Mead acid (20:3(n-9), MA) and dihomoMead acid (22:3(n-9), DHMA). This observation led to the suggestion that the fetal need for EFAs may not be adequately covered. Since data on fetal fatty acid biochemistry is limited, the results from umbilical material are all interpreted on the basis of biochemical relationships in adult material, which may be different in fetal cells and tissues. For instance, the fetal desaturase system could be much more active than the adult desaturase system, resulting in the formation of MA and DHMA even if adequate amounts of EFAs are available. However, even then, it still remains to be explained why these fatty acids are only present in high amounts in the umbilical artery and not in the umbilical vein, while the $(n-6)$ desaturation index $[(18: 3(n-6)+20: 3(n-$ $6)+20: 4(n-6)+22: 4(n-6)+22: 5(n-6) / 18: 2(n-6)]$ is not significantly different between these two types of vessel walls. An alternative explanation for the high MA and DHMA levels in the umbilical artery could be that the arterial vessel walls serve as the "dustbin" for the baby, to get rid of substances (MA and DHMA) it does not need. The question whether the EFA status of newborns is insufficient, marginal or adequate cannot be answered properly as long as there is no more information available on fetal fatty acid biochemistry.

\section{Absolute and relative fatty acid data.}

In most of our studies, we expressed the fatty acid composition in absolute (mg fatty acid present in PL per L plasma or per g dry weight tissue) and relative ( $\%$ of total 
ARACHIDONIC ACID, 20;4(n-6)

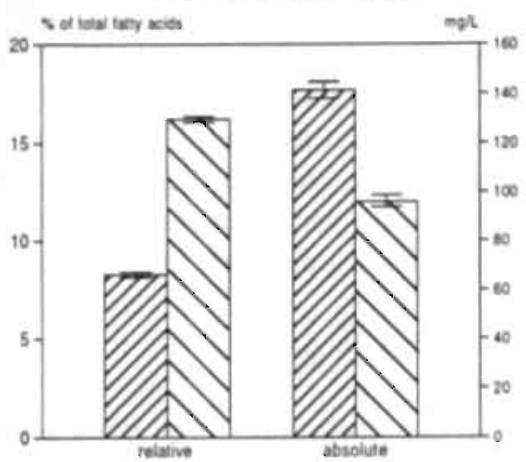

CERVONIC ACIO, 22:6(n-3)

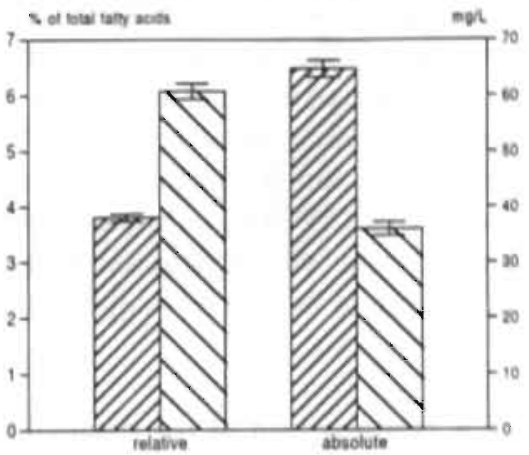

Figure I. The fatty acid composition (mean \pm s.e.m.). of maternal (closed hatched bars, $n=95$ ) and umbilical (open hatched bars, $n=98$ ) plasma phospholipids, at delivery.

fatty acids of plasma PLs) amounts. Different results were observed between both methods. Whereas the relative amounts of $A A$ and $C A$ are significantly higher in umbilical than in matemal plasma PLs, the absolute amounts are significantly lower, because the PL concentration is considerably lower in cord blood than in matemal blood at delivery (see also Figure 1). So when pool sizes are different (as is the case in mother/fetal comparisons) or when pool sizes are changing considerably over time (as happens in matemal blood during pregnancy), it may be preferable to base a comparison on absolute fatty acid amounts. However, one has to be careful when comparing absolute fatty acid amounts between mother and child and between pregnant women and non-pregnant women, because the (physiological) state of hyperlipidemia in pregnancy is likely to exaggerate the differences.

Since metabolic reactions of fatty acids occur in a lipid environment, it is the amount of a given fatty acid relative to the other fatty acids present that determines the rate of this reaction in that environment. Therefore, from a metabolic perspective, relative fatty acid compositions are just as important as absolute values. An additional advantage of relative fatty acid data above absolute amounts is that the measurement. error of the analytical procedure when determining relative concentrations is, usually, smaller.

\section{Biochemical versus functional parameters}

In this thesis, the studies were restricted to biochemical endpoints. It is, however, also essentia! to know whether an altered. EFA status is associated with functional changes. Studies in premature infants have shown that their CA status is positively associated with cognitive indicators derived from tests like the Baley Mental Development Index 
and Baley Psychomotor Developmental Index (11) and with visual functions, like visual-evoked-potential and forced-choice preferential looking $(12,13)$. Carlson et al (14) observed in premature children a significant positive correlation between arachidonic acid (20:4(n-6), AA) levels in plasma phosphatidyl choline and growth in the first year of life. Because premature children often experience conditions (chronic illness, intrauterine malnutrition) that could have adversely affected growth and/or development, studies in term infants should be carried out as well. The results of the few preliminary studies performed so far in term infants, support the evidence for an essential role of CA in visual function $(13,15)$. It will be very important to extend our biochemical data with functional parameters, so that conclusions can be drawn on aspects relating to human development.

\section{The EFA composition of the maternal diet during pregnancy: the pros and cons of EFA supplementation}

The studies reported in Chapters 2, 4, 5 and 7 represent for a great part observational research, among women with an uncomplicated pregnancy. Therefore, one can assume that the fatty acid data of these women and their newborn infants are; representing the average normal fatty acid patterns in pregnancy. However, the question whether or not these data also represent the optimal situation for pregnant women and their children is yet unanswered. Based on the results from the studies described in this thesis in combination with indications from the literature, in my opinion, supplementation of (n-6) and (n-3) LCPs to the maternal diet may have potential benefits.

During the last trimester of pregnancy, fetal $\mathrm{CA}$ demands are high due to rapid accumulation of CA in neural $(1,2)$ and retinal tissue $(2)$. As shown in figure 2 , fetal phospholipids show an increasing content of CA with increasing gestational age. Studies in preterm and term infarts have shown that their CA status is positively associated with visual $(2,12,13)$ and cognitive functions (11), indicating the relevance of an optimal CA status. During normal pregnancy the maternal CA status was shown to decrease (Chapter 5). It is possible that this results from the maternal attempt to meet the high fetal requirement for $\mathrm{CA}$. The maternal $\mathrm{CA}$ status seems to decrease even further with each following pregnancy (16), which may imply that the maternal CA status does not fully normalize after the first pregnancy. We observed no significant differences in the neonatal CA status of infants from primigravida as compared to that of multigravida after a normal pregnancy (Unpublished observation). Carlson et al (17), however, found in preterm children that birth order is a significant negative predictor of their red blood cell CA content, which suggests also that the CA supply to the fetus is depleted by repeated pregnancies. Although the functional implications of this "exhaustion-effect" of pregnancy on the maternal CA status is not yet known, it may be prudent to prevent this. As the neonatal CA status is significantly and positively correlated with the maternal CA status (Chapter 2 and 5), 


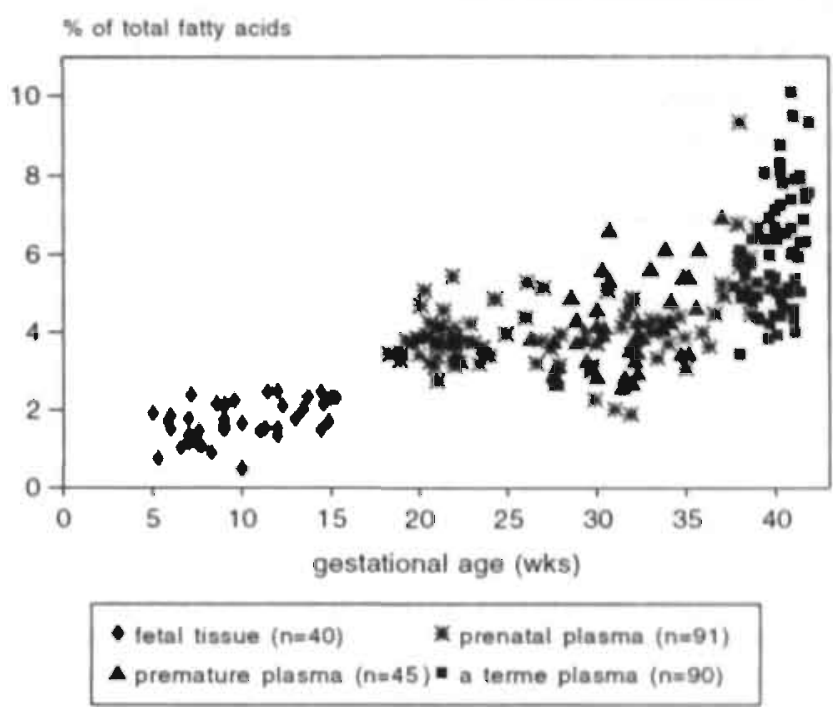

Figure 2. The course of the fetal cervonic acid (22:6(n-3), CA) status (\% of total fatty acids) during pregnancy (based on ref. 9,18, Chapter 5 and unpublished data from A.C. v. Houwelingen).

the CA status of the fetus will benefit from an improved maternal CA status. Premature children are prematurely deprived from their CA source in utero, and are thus dependent on artificial formula or breast-milk for their CA supply. This supply may not be as adequate as during intra-uterine life (18). Therefore, it is reasonable to expect that the premature infant will benefit from an improved CA status, at delivery already. This seems the more so, as the post-natal CA status, about eight weeks after birth, is still for a great part determined by the neonatal CA status at birth (19).

It has been shown that an increased maternal CA intake is associated with a reduced neonatal (n-6) LCP status (10). The major (n-6) LCP arachidonic acid (20:4(n-6), AA) is also one of the predominant fatty acids in the central nervous system (5), and therefore a reduced (n-6) LCP should be prevented. Since the AA status of premature infants positively predicts growth and cognitive development (Baley MDI, Fagan Infantest) in the first year of life (14,17), an adequate maternal supply of both CA and AA should be considered.

The EFAs in the diet of the pregnant women participating in our studies consisted largely of linoleic acid (more than $80 \%$ of the total polyunsaturated fat intake, Chapter 4). The amount of other polyunsaturated fatty acids, like arachidonic acid (20:4(n-6), AA) and cervonic acid (22:6n-3), CA), could not be calculated because the Netherlands Nutrient Databank does not contain information on the content of these 
fatty acids in food(s). Collecting and analyzing duplicate food portions will have to provide us with this important information. Dietary data from Crawford et al (20) showed that the AA plus CA content present in the diet of British pregnant women was less than one percent of the total fat intake. So, although there may be some AA and CA present in the maternal diet, it may, perhaps, not be enough to meet the need for these fatty acids by the developing fetus and to prevent the deterioration of the maternal CA status. The optimal EFA composition of the maternal diet - if there is such an optimum - can only be established by controlled clinical intervention studies. These studies have not yet been performed and, therefore, at this moment one can only speculate on this.

Some years ago, Eaton \& Konner (21) suggested that man should consume a diet more in accordance with the diet of its paleolithic ancestors, since this is the diet to which humans are genetically programmed for and on which they have developed during 4 million years of evolution. The diet of our remote ancestors included more structural fat and less depot fat with a $\mathrm{P} / \mathrm{S}$ ratio (ratio between polyunsaturated fat and saturated fat) of approximately $1.4(21)$. This figure differs considerable from the $\mathrm{P} / \mathrm{S}$ ratio of 0.4 in our present diet (Chapter 4 ). The difference in $\mathrm{P} / \mathrm{S}$ ratio is, among other things, due to the higher content of (n-6) and (n-3) LCPs present in meat of wild animals (consumed by our ancestors), as compared to that present in domestic livestock $(21,22)$. The lower $\mathrm{P} / \mathrm{S}$ ratio in our current diet is also explained by the high consumption of cooking fats and dairy products nowadays, which are rich in saturated fat (23). The paleolethic diet contained no dairy products whatsoever (21).

The changes in human genetic constitution have been relatively small over the last 40,000 years (21), whereas, due to developments in producing and processing food, major changes in the dietary patterns have occurred in the last few millenia (transition from a hunter-gatherer society to an agricultural society). During the last century, major developments in the food industry took place, allowing too short a time span to enable men to adapt genetically to the changed dietary patterns. Differences between the nutrient composition of our diet and of the diet to which our remote ancestors became accustomed to through evolution could very well account for at least part of the diet-related health problems we have nowadays. Therefore, it is perhaps better to raise the proportion of (n-3) and (n-6) long chain polyenes in our diet. This may be of special importance in the diet of pregnant women because of the high fetal requirements for these fatty acids.

The theory of Eaton \& Konner is in line with that put forward by Crawford $(24,25)$, regarding the availability of structural fats like AA and CA being a limiting factor in brain development and evolution. Crawford's theory of nutrient dependency supposes that man evolved at the land-water interface, which provided him with the appropriate nutrients to enable brain evolution to keep pace with increasing body size. As mentioned earlier, our diet contains hardly any (n-6) and (n-3) LCPs. As human brain growth largely takes place during intra-uterine life (3), it may have potential benefits to supplement ( $\mathrm{n}-6)$ and $(\mathrm{n}-3)$ LCPs to the maternal diet. Because of the competition 
between these two fatty acid families, one should try to find the optimal balance between them.

The ratio between (n-6) and (n-3) fatty acids in brain tissue varies between 1.5:1 to $2.8: 1(26,27)$. The mean $(n-6) /(n-3)$ ratio in the diet of 24 British pregnant women from higher social classes, as assessed by direct analysis of the foods which the mother were using, has been estimated at 7:1 (20). Fatty acid analyses of muscle and adipose fat of wild animals revealed a ratio of $1: 1$ to $4: 1$ (22). If the ideal dietary ratio should be more in accordance to that found in brain tissue, it should be closer to one (24). However, more research is necessary to determine the ideal dietary ratio, before making any recommendations.

The most active period of cell divisions is within the first weeks after conception. At this stage, nutrition of the embryo is exclusively dependent on its mother's health, nutrition and metabolism because the placenta has not yet been formed (25). It is therefore not unlikely that maternal nutrition in that particular period will have a great influence on pregnancy outcome. This view is supported by results from the "Dutch famine studies" as reported by Wynn \& Wynn (28) who stated that "if a woman was short of food before or around that she conceived, the risks to her baby (like congenital malformations or neural tube defects) were much more serious than if she was well fed at conception but short of food during pregnancy". We observed that the neonatal EFA status at birth (umbilical plasma) is positively correlated with the EFA status of maternal plasma at 14 weeks of gestation already. Correlation coefficients were +0.44 for $\mathrm{LA},+0.41$ for $\mathrm{AA}$ and +0.45 for $\mathrm{CA}(\mathrm{n}=85, \mathrm{p}<0.001$ for all three correlation coefficients given). Since the maternal fatty acid values at that time are significantly and positively related to their non-pregnant relative amounts (LA: $\mathrm{r}=$ $+0.53 ; \mathrm{AA}: \mathrm{r}=+0.52 ; \mathrm{CA}: \mathrm{r}=+0.67 ; \mathrm{n}=38, \mathrm{p}<0.001$ ), one may assume that the maternal EFA status early in pregnancy or even before conception is also positively associated with the neonatal EFA status. In the LA intervention study (Chapter 7) it was shown that maternal LA supplementation after the placenta had fully developed had no significant effect on the LA status. These observations suggest that when the EFA status of the developing fetus needs to be improved, supplementation very early in pregnancy or preferably before conception may have the most beneficial effects.

\section{Future research}

As already mentioned, the effect of maternal supplementation with (n-6) and (n-3) LCPs on the maternal and neonatal EFA status should be studied. This holds particularly for CA, since the maternal CA status decreases during gestation and seems to be lower with each following pregnancy. Therefore, supplementing CA may assist the mother in providing sufficient $C A$ to the fetus without depleting her own stores. It will be important to extend the biochemical data with clinical and functional parameters to study how infant development is affected. Since polyunsaturated fatty acids are easily peroxidized, an increased PUFA. intake could cause more peroxidation 
in the body which could present some major health risks (29). Therefore, special attention has to be given to the anti-oxidant status of mother and child.

To further elucidate the processes and mechanisms responsible for the differences between the EFA profile of mothers and of their newbom infants, more research has to be done on fetal fatty acid metabolism and placental fatty acid transfer in humans. The use of fatty acids labelled with stable isotopes combined with gas chromatography/mass spectometry (GC/MS) techniques will greatly expand the oppurtunities for in vivo research. Stable isotope studies in pregnant women will provide us with essential data required for designing optimal nutritional strategies for mother and fetus.

\section{REFERENCES}

1. Clandinin MT, Chappell JE, Leong S, Heim T, Swyer PR, Chance GW. Intrauterine fatty acid rates in human brain: implications for fatty acid requirements. Early Hum Dev 1980; 4: 121-9.

2. Martinez M. Tissue levels of polyunsaturated fatty acids during early human development. J Pediatr 1992;120: S129-38.

3. Dobbing J. Vulnerable periods of brain development. In: Elliott K, Knight K, eds. Lipids, malnutrition and the developing brain. Amsterdam: Elsevier. A Ciba Foundation symposium: 929.

4. Coleman RA. The role of the placenta in lipid metabolism and transport. Sem Perinat 1989; 13: 180-91.

5. Innis SM. Essential fatty acids in growth and development. Prog Lipid Res 1991;30: 39-i 03.

6. Hornstra G. Houwelingen AC v., Simonis M and Gerrard JM. Fatty acid composition of umbilical arteries and veins: possible implications for the fetal EFA-status. Lipids 1989; 24: $511-7$.

7. Popeski D, Ebbeling LR, Brown PB. Hornstra G, Gerrard JM. Blood pressure during pregnancy in Canadian inuit: community differences related to diet. Can Med Assoc J 1991; 145: 445-54.

8. Hansen HS. Jensen B. Essential function of linoleic acid esterified in acylglucosylceramide and acylceramide in maintaining the epidermal water permeability barrier. Evidence from feeding studies with oleate, linoleate, arachidonate, columbinate and $\alpha$-linolenate. Biochim Biophys Acta $1985 ; 834: 357-63$.

9. Houwelingen $\mathrm{AC} \vee$, Puls $\mathrm{J}$ and Hornstra G. Essential fatty acid status during early human development. Early Hum Dev 1992; 31: 97-111.

10. Houwelingen AC v., Hornstra G, Simonis MMG, et al. Essential fatty acid composition of umbilical arteries and veins after fish oil supplementation during pregnancy. In: Drevon CA, Baksaas I, Krokan HE, eds. Omega-3 fatty acids: metabolism \& biological effects. Basel (Switzerland): Birkhauser, 1993: 125-9.

II. Bjerve KS, Brubakk AM, Fougner KJ, Johnsen H, Midthjell K., Vik T. Omega-3 fatty acids: essential fatty acids with important biological effects, and serum phospholipids fatty acids as markers of dietary $\omega-3$ fatty acid intake. Am J Clin Nutr 1993; 57 (suppl): 801S-6S.

12. Carlson SE, Werkman SH, Rhodes PG, Tolley EA. Visual-acuity development in healthy preterm infants: effect of marine-oil supplementation. Am J Clin Nutr 1993; 58: 35-42.

13. Birch E, Birch D. Hoffman D, Hale D, Everett M, Uauy R. Breast-feeding and optimal visual development. J Pediatr Ophthalmol Strabismus 1993; 30: 33-8.

14. Carlsson SE, Werkman SH, Peeples JM, Cooke RJ, Tolley EA. Arachidonic acid status correlates with first year growth in preterm infants. Proc Natl Acad Sci 1993; 90: 1073-7. 
15. Makrides M, Simmer K, Goggin M, Gibson RA. Erythrocyte docosahexaenoic acid (DHA) correlates with the visual response of healthy, term infants. Ped Res 1993; 34: 425-7.

16. Al MDM, Houwelingen AC v., Hornstra G. Docosahexaenoic acid, (22:6(n-3), cervonic acid, CA) and hypertension in pregnancy: consequences for mother and child. Scientific conference on omega-3 fatty acids in nutrition, vascular biology, and medicine. Houston Texas, April 17-19. 1994 (poster).

17. Carlson SE, Salem N. Essentiality of $\omega 3$ fatty acids in growth and development of infants. In: Simopoulos AP, Kifer RR, Martin RE, Barlow SM, eds. Health effects of $\omega 3$ polyunsaturated fatty acids in seafoods. World Rev Nutr Diet 1994; 66: 74-86.

18. Foreman-van Drongelen MMHP, Houwelingen AC v., Kester ADM, et al. Long chain polyene status of pre-term infants with regard to the fatty acid composition of their diet: comparison between absolute and relative fatty acid amounts in plasma and red blood cell phospholipids. $\mathrm{Br}$ J Nutr 1994, in press.

19. Foreman-van Drongelen MMHP, Houwelingen AC v., Koopman-Esseboom C, Kester ADM. Sauer PJJ, Hornstra G: Does the long chain polyene status at birth affect the post-natal long chain polyene status? World Rev Nutr Diet 1994, in press.

20. Crawford MA, Doyle W, Drury P. Lennon A, Costeloe K, Leighfield M. N-6 and n-3 fatty acids during early human development. J Int Med 1989; 225 (suppl I): 159-69.

21. Eaton SB, Konner M. Paleolithic nutrition. A consideration of its nature and current implications. N Eng J Med 1985; 312; 283-9.

22. Crawford MA, Doyle W, Drury P, et al. The food chain for $n-6$ and $n-3$ fatty acids with special reference to animal products. In: Galli C, Simopoulos AP. eds. Dietary $\omega 3$ and $\omega 6$ fatty acids. Biological effects and nutritional essentiality. New York and London: Plenum Press, 1989: 5-19.

23. Badart-Smook JMT, Al MDM, Houwelingen AC v., Hornstra G. Essential fatty acid intake during pregnancy and contribution of various products. Fatty acids and lipids from cell biology to human disease, Ist internation congress ISSFAL, Lugano June 30-July 3: page 100 (abstract).

24. Crawford MA, Cunnane SC. Harbige LS. A new theory of evolution: quantum theory. In: Sinclair $\mathrm{A}$ and Gibson R, eds. Essential fatty acids and eicosanoids. Invited papers from the third international congress. Champaign (IL): Am Oil Chem Soc, 1992: 87-95.

25. Crawford MA. The role of essential fatty acids in neural development: implications for perinatal nutrition. Am J Clin Nutr 1993; 57(suppl): 703S-10S.

26. Crawford MA., Hassam AG, Williams G. Essential fatty acids and fetal brain growth. Lancet 1976; i: 452-3.

27. Martinez M. Developmental profiles of polyunsaturated fatty acids in the brain of normal infants and patients with peroxisomal diseases: severe deficiency of docosahexaenoic acid in Zellweger's and Pseudo-Zellweger's syndromes. In: Simopoulos AP, Kifer RR, Martin RE,

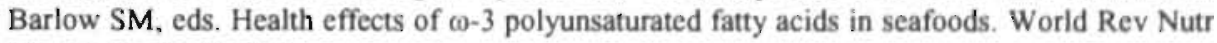
Diet 1994; 66: 87-102.

28. Wynn M, Wynn A. The case for preconception care of men and women. AB Academic, Oxon, Great Britain 1991: 64-84.

29. Halliwell B, Chirico S. Lipid peroxidation: its mechanism, measurement, and significance. Am J Clin Nutr 1993; 57(suppl.): 715S-25S. 



\section{SUMMARY}

Essential fatty acids (EFAs) are important constituents of all cell membranes. During pregnancy, when processes like fetal brain development and organogenesis are taking place in a limited time period, fetal EFA demand is high. The EFA status of babies born after a normal pregnancy seems not to be adequate, if not insufficient (see Chapter 1). The studies presented and discussed in this thesis were intended to obtain more information on the relationships between the neonatal and maternal EFA status in normal pregnancy and pregnancy-induced hypertension. In addition, the EFA composition of the maternal diet was studied.

First, the neonatal EFA status was compared with that of their mothers at delivery by determining the fatty acid compositions of phospholipids (PLs), isolated from umbilical arterial and venous vessel walls, blood cells (BC) and plasma, and from maternal venous plasma and BC. The fatty acid content of non-infarcted placental tissue was determined also (Chapter 2). The PLs of umbilical arterial tissue (efferent fetal vessels) contained fewer fatty acids of the (n-6) family and more of the (n-9) family than umbilical venous tissue (afferent fetal vessel). The relative amounts of ( $\mathrm{n}$ 6) and (n-3) fatty acids were less in arterial than in venous plasma. Mead acid, 20:3(n9), the presence of which indicates a poor EFA status, was 5 times higher in the efferent than in afferent cord vessels. In neonatal plasma and BC it was twice as high as compared with maternal levels. In general, the fatty acid composition of the placenta PLs showed a pattern comparable with neonatal venous plasma PLs. These findings indicate that the biochemical EFA status of neonates, born after a normal pregnancy may not be optimal. The significant correlations between neonatal and maternal EFAs indicate that the neonatal EFA status depends on the EFA content of the maternal diet.

In situations where the placental function is impaired, the transfer of nutrients from mother to fetus may be insufficient. To what extent the neonatal EFA status is affected by such an event was studied in cases with pregnancy-induced hypertension (PIH), which is, in a high percentage, characterized by a reduced placental perfusion (Chapter 3). The fatty acid composition was determined from PLs, triglycerides (TG) and cholesterolesters (CE) of umbilical cord serum and maternal serum. Relative contents of linoleic acid of serum PL and CE were significantly lower in mothers with PIH $(n=13)$ compared to normal pregnancies $(n=15)$. Most other $(n-6)$ polyenes in PL tended to be higher under hypertensive conditions. Total maternal $(n-3)$ polyenes of serum PL were significantly higher in PIH, mainly due to clupanodonic acid, 22:5(n3 ), and cervonic acid, 22:6(n-3). Total maternal $(n-7)$ and $(n-9)$ fatty acids were also significantly higher in PIH (PL and CE). The results indicate that PIH is associated with a relative increased unsaturation of maternal serum PL, which might facilitate the 
placental transfer of long-chain, polyunsaturated fatty acids. As a result, the neonatal EFA status after PIH only slightly differs from normal.

The altered maternal EFA status in PIH could theoretically mean that these fatty acids are involved in the etiology of PIH. The results of the study are based on a crosssectional design using material collected immediately after delivery and, therefore, do not allow any conclusion with respect to a possible cause and effect relationship. Such a conclusion would require a prospective longitudinal comparison of the maternal EFA courses during normal and complicated pregnancies. Therefore, a prospective longitudinal study was performed to describe the maternal EFA status in relation to the maternal diet during normal pregnancy and in PIH. Immediately after delivery, the neonatal EFA status was assessed also (Chapters 4-6).

The nutrient intake of 176 women throughout a normal pregnancy with special emphasis on the amount and type of fat consumed is described in Chapter 4. The subjects completed a food frequency questionnaire (FFQ) before 13, at 22, and at 32 weeks of gestation. At 22 weeks of gestation a diet history (DH) was carried out and a maternal blood sample was taken. No significant changes in the mean daily intake of saturated fat,mono-unsaturated fat, polyunsaturated fat, and linoleic acid during pregnancy were observed. Less than $30 \%$ of the women met the recommendations for amount and type of dietary fat. The intakes of linoleic acid and polyunsaturated fatty acids (\% of total fat intake) of pregnant women assessed with the FFQ and DH correlated well with the amounts of these fatty acids in plasma phospholipids. It is concluded that the fat content and composition of the maternal diet does not change during a normal pregnancy. In addition, the individual dietary composition with respect to these nutrients seems consistent during gestation.

Chapter 5 reports on maternal EFA patterns during normal pregnancy. Moreover, its relationship to the neonatal EFA status at birth is described. One-hundred-ten pregnant women gave repeatedly a blood sample from the 10th week of gestation until delivery. After birth, a blood sample from the umbilical vein and a maternal venous blood sample were collected as well, and six months after delivery a final blood sample from the mother was taken. The absolute ( $\mathrm{mg} / \mathrm{L}$ ) and relative (\% of total fatty acids) amounts of the fatty acids in plasma phospholipids were determined. The total amounts of fatty acids increased significantly during pregnancy. This pattern was similar for the individual fatty acids and fatty acid families. The relative amounts of linoleic acid [18:2(n-6)] did not change during pregnancy, whereas the relative amounts of arachidonic acid [20:4(n-6)] decreased. Despite a maternal mobilization of cervonic acid (22:6(n-3), CA), suggested by a temporarily increase in the CA status until 18 weeks of gestation, the CA status steadily declined thereafter. This was associated with an increase of the cervonic acid deficiency index $(22: 5(\mathrm{n}-6) / 22: 4(\mathrm{n}-6)$, CADI) in maternal blood throughout pregnancy. The overall maternal EFA status (ratio between $[\Sigma(n-6)+\Sigma(n-3)]$ and $[\Sigma(n-7)+\Sigma(n-9)])$ also declined during pregnancy. These changes in the maternal EFA patterns during pregnancy may be normal 
physiological phenomena. However, the continuous increase of the CADI may point to a progressive deterioration of the maternal CA status, suggesting that under the prevailing dietary conditions, the maternal capacity to meet the high fetal requirement for $\mathrm{CA}$ is working on its limits or may even be inadequate. The significantly higher CADI values in umbilical plasma as compared to the maternal non-pregnant values also indicates that the mother is unable to provide an optimum CA status of the developing fetus.

In Chapter 6 the maternal and neonatal EFA status in PIH is compared with that in uncomplicated pregnancies. Pregnant women, healthy at the start of the study, were asked to give a blood sample before 16 weeks, at 22 weeks and at 32 weeks of gestation. After delivery, a blood sample from the umbilical vein, a piece of the umbilical cord and a maternal blood sample were collected. Fatty acid compositions were determined of the PLs isolated from plasma and from umbilical arterial and venous vessel walls. The nutrient intake of the pregnant women was assessed with the aid of the dietary history method and using food frequency questionnaires. The results of each woman with PIH were compared with the results of three matched healthy controls. During pregnancy (16-32 weeks) no significant differences were observed in nutrient intake and maternal plasma fatty acid composition between the PIH ( $\mathrm{n}=52$ ) and the control group $(\mathrm{n}=156)$. After delivery, the relative amounts of $18: 2(\mathrm{n}-6)$ and 18:3(n-3) in maternal plasima were significantly lower in PIH than in normal pregnancy (NP). This was associated with significantly higher levels of (n-6) long chain polyenes and cervonic acid (22:6(n-3),CA). As compared to the situation at 32 weeks, the posi-partum CA status increased in PIH whereas it decreased in NP. The CA levels in umbilical plasma PLs were significantly higher after PIH than after NP. No significant differences were observed for the umbilical vessel walls. These results inclicate that the altered EFA status in PIH is a late phenomenon and is, therefore, unlikely to have contributed to the pathogenesis of PIH. Moreover, the neonatal EFA status is not negatively affected by PIH.

Finally, the effect of maternal linoleic acid (18:2(n-6), LA) supplementation on the neonatal EFA status was studied and the results are described in Chapter 7. Pregnant women with relatively low plasma LA levels before 16 weeks of gestation $(n=21)$ were supplemented with approximately 10 gram of LA per day from the 20 th week of gestation until delivery. One of the two control groups consisted of pregnant women with comparably low plasma LA levels at the start of the study (LL-control group, $\mathrm{n}=22$ ); the other consisted of women with habitual high plasma LA levels (HL-control group, $\mathrm{n}=21$ ). The neonatal EFA status was assessed by determining the fatty acid composition of PLs isolated from umbilical plasma and umbilical vessel walls. LA supplementation resulted in significantly higher levels of the sum of (n-6) long chain polyenes (LCPs) in umbilical plasma and venous vessel walls compared with the LLcontrol group. This increase was associated with lower (n-3) LCP levels. In the HLcontrol group the neonatal (n-3) LCP status was also lower as compared to the LLcontrol group. It is concluded that if. the EFA status of newborns needs to be improved, fatty acids of both the ( $\mathrm{n}-6)$ and ( $\mathrm{n}-3)$ family have to be supplied. 
In Chapter 8 the main findings and some methodological considerations of the studies in this thesis are discussed. Furthermore, the pros and cons of EFA supplementation during pregnancy is evaluated and some suggestions for future research are given. 


\section{SAMENVATTING}

Essentiële vetzuren ('essential fatty acids', EFAs) zijn belangrijke bouwstenen van alle celmembranen. Tijdens de zwangerschap is de behoefte van de foetus aan EFAs hoog omdat veel nieuw weefsel wordt gevormd. Biochemisch onderzoek suggereert dat de EFA status van gezonde pasgeborenen niet optimaal is en misschien zelfs wel onvoldoende (zie hoofdstuk 1). De in dit proefschrift beschreven onderzoeken zijn uitgevoerd om meer inzicht te krijgen in de relatie tussen de essentiële vetzuurstatus van het kind en die van de moeder. Dit is onderzocht bij normale zwangerschap en bij zwangerschapshypertensie. Bovendien is de essentiële vetzuursamenstelling van de voeding van vrouwen tijdens de zwangerschap bestudeerd.

Allereerst werd de EFA status van gezonde pasgeborenen vergeleken met die van hun moeders vlak na de bevalling. De EFA status werd vastgesteld door de vetzuursamenstelling van fosfolipiden ('phospholipids', PL) geïsoleerd uit arterieel en veneus vaatwandweefsel, erytrocyten en plasma van de navelstreng en uit veneus plasma en erytrocyten van de moeder te bepalen. De vetzuursamenstelling van niet geïnfarceerd placentaweefsel werd ook bepaald (Hoofdstuk 2). De PL van arterieel vaatwandweefsel (afvoerende vaten) bevatte minder vetzuren van de $(\mathrm{n}-6)$ familie en meer van de (n-9) familie dan veneus vaatwandweefsel (aanvoerende vaten). De relatieve hoeveelheden van de (n-6) en (n-3) vetzuren in arterieel navelstrengplasma waren lager dan in veneus navelstrengplasma. De aanwezigheid van relatief grote hoeveelheden Meadzuur, 20:3(n-9), wijst in de richting van een ongunstige EFA status. In de afvoerende vaten van de navelstreng was Meadzuur vijfmaal meer aanwezig dan in de aanvoerende vaten; in plasma en erytrocyten van de navelstreng was de hoeveelheid Meadzuur tweemaal zo hoog dan in plasma en erytrocyten van de moeder. De vetzuursamenstelling van placenta PL vertoonde over het algemeen een beeld vergelijkbaar met die in veneus navelstrengplasma PL. Deze resultaten bevestigen dat de biochemische EFA status van kinderen, geboren na een normale zwangerschap, niet optimaal lijkt te zijn. De significante correlaties tussen de EFAs van moeder en kind suggereren dat de EFA status van het kind afhankelijk is van de EFA samenstelling van de voeding van de moeder.

Wanneer de placentafunktie verminderd is kan de overdracht van voedingsstoffen van moeder naar kind onvoldoende zijn. Zo'n verminderde placentafunktie komt veel voor bij zwangerschapshypertensie. Welke gevolgen dit heeft voor de EFA status van het kind is onderzocht bij vrouwen en hun kinderen, waarvan de zwangerschap gecompliceerd werd door zwangerschapshypertensie (Hoofdstuk 3). De vetzuursamenstelling werd bepaald van $\mathrm{PL}$, triglyceriden $(\mathrm{TG})$ en cholesterolesters (CE), geïsoleerd uit veneus serum van de navelstreng en van de moeder. Relatieve hoeveelheden van linolzuur in serum PL en CE waren significant lager bij vrouwen 
met zwangerschapshypertensie ( $n=13)$ dan bij vrouwen met een normale zwangerschap $(n=15)$. De meeste andere $(n-6)$ vetzuren in PL hadden de neiging hoger te zijn bij zwangerschapshypertensie ('pregnancy-induced hypertension', PIH). De totale som van de (n-3) vetzuren in serum PL was significant hoger in PIH, voornamelijk door clupanodonzuur, 22:5(n-3), en cervonzuur, 22:6(n-3). De totale som van de (n-7) en (n-9) vetzuren was ook significant hoger in PIH (PL en CE). Deze resultaten geven aanwijzingen voor een toegenomen onverzadiging in de serum PL van vrouwen met PIH. Dit zou de overdracht van langketen meervoudig onverzadigde vetzuren ('long chain polyenes', LCPs) over de placenta kunnen vergemakkelijken. Dientengevolge verschilde de EFA status van de pasgeborenen van moeders met PIH niet significant van die van moeders met een normale zwangerschap.

De veranderde EFA status van vrouwen met PIH op het moment van de bevalling kan theoretisch betekenen dat deze vetzuren een rol spelen in het ontstaan van PIH. De resultaten zijn echter gebaseerd op materiaal dat direkt na de bevalling was verzameld. Op dat moment hadden de vrouwen al PIH en daarom kan geen uitspraak gedaan worden over een mogelijke oorzaak-effekt relatie. Om een antwoord te krijgen op de vraag of de gewijzigde EFA status een oorzaak of een gevolg is van PIH dient de EFA status van vrouwen tijdens de zwangerschap prospectief en longitudinaal te worden gevolgd, zowel tijdens normale zwangerschappen als bij PIH. In hoofdstuk 4 tot en met 6 wordt een dergelijk prospectief longitudinaal onderzoek beschreven. Bovendien is nagegaan hoe de relatie is tussen de EFA status van de moeder en de EFA samenstelling van hun voeding. Na de bevalling is ook de EFA status van het kind bepaald.

De nutrientinneming van 176 vrouwen gedurende een normale zwangerschap is beschreven in hoofdstuk 4. Hierbij is vooral aandacht besteed aan de hoeveelheid en het soort vet dat werd geconsumeerd. De deelnemers vulde vór 13 weken, en rond 22 en 32 weken van de zwangerschap een voedselfrequentielijst ('food frequency questionnaire', FFQ) in. Omstreeks de 22e week van de zwangerschap werd ook een dietary history (DH) uitgevoerd en een bloedmonster van de moeder verzameld. De inneming van totaal vet, verzadigd vet, enkelvoudig onverzadigd vet, meervoudig onverzadigd vet en linolzuur veranderde niet significant tijdens de zwangerschap. Minder dan $30 \%$ van de vrouwen voldeden aan de aanbevolen hoeveelheden voor hoeveelheid en soort voedingsvet. De inneming van linolzuur en meervoudig onverzadigd vet (\% van totaal vet inneming) volgens de FFQ en de DH correleerde goed met de hoeveelheid van deze vetzuren in de plasma fosfolipiden. Dit onderzoek. liet zien dat de hoeveelheid en soort vet in de voeding van zwangere vrouwen niet. significant veranderen gedurende een normale zwangerschap. De individuele vetsamenstelling van de voeding lijkt ook constant tijdens de zwangerschap.

Hoofdstuk 5 rapporteert over het verloop van de EFA status van moeders tijdens een normale zwangerschap. Tevens is de relatie tussen de EFA status van de moeder en die van het kind op het moment van geboorte onderzocht. Honderdtien zwangere 
vrouwen gaven vanaf de tiende week van de zwangerschap tot aan de bevalling regelmatig een bloedmonster. $\mathrm{Na}$ de bevalling werd een bloedmonster uit de navelstrengvene en van de moeder verzameld. Ongeveer een half jaar na de bevaliing werd bij een aantal vrouwen nog een bloedmonster afgenomen. De hoeveelheid vetzuren in plasma PL werd zowel absoluut $(\mathrm{mg} / \mathrm{L}$ ) als relatief (\% van totaal vetzuur) berekend. De totale hoeveelheid vetzuren steeg significant tijdens de zwangerschap. Dit beeld was vergelijkbaar voor de afzonderlijke vetzuren en vetzuurfamilies. De gemiddelde relatieve hoeveelheid linolzuur $[(18: 2(n-6)]$ veranderde niet significant tijdens de zwangerschap. De relatieve hoeveelheden arachidonzuur [20:4(n-6)], daarentegen, daalde significant. De cervonzuurstatus $(22: 6(n-3), C A)$ van de moeder steeg tot ongeveer de $18 \mathrm{e}$ week van de zwangerschap (mogelijk vanwege een mobilisatie van opgeslagen cervonzuur), om vervolgens gestadig af te nemen. Dit was geassocieerd met een toename in de cervonzuur deficiëntie index $(22: 5(n-6) / 22: 4(n-6)$, $\mathrm{CADI}$ ) in het plasma van de moeder. De "totale" EFA status (ratio tussen [ $\Sigma(\mathbf{n}-6)+\Sigma$ $(n-3)]$ en $[\Sigma(n-7)+\Sigma(n-9)])$ van de moeder daalde ook tijdens de zwangerschap. De waargenomen veranderingen in het verloop van de EFAs in het plasma van de moeder tijdens de zwangerschap kunnen normale fysiologische aanpassingen zijn. Echter, de continue toename van de CADI wijst in de richting van een verslechterde CA status van de moeder. Dit zou kunnen betekenen dat bij het huidige voedingspatroon, de moeder veel moeite heeft om tegemoet te komen aan de grote CA behoefte van de foetus. Dit wordt bevestigd door de significant hogere CADI waarde in het navelstrengplasma vergeleken met de waarde in het plasma van de moeder, zes maanden na de bevalling.

In hoofdstuk 6 is de EFA status van moeder en kind bij PIH vergeleken met die tijdens normale zwangerschap. Zwangere vrouwen, die gezond waren bij aanvang van het onderzoek, werden gevraagd een bloedmonster te geven vór 16 weken, rond 22 en 32 weken van de zwangerschap en direkt na de bevalling. Ook werd een bloedmonster uit de navelstreng en een stukje navelstreng verzameld. De vetzuursamenstelling van de fosfolipiden, geïsoleerd uit plasma en navelstrengweefsel. werd bepaald. De nutrienteninneming van de zwangere vrouwen werd geschat met behulp van voedselfrequentievragenlijsten en de dietary history methode. De resultaten van een vrouw die PIH had gekregen werd vergeleken met de resultaten van drie gezonde zwangere vrouwen. Matching vond plaats op de parameters pariteit en bevallingscentrum. Tijdens de zwangerschap (16-32. weken) werden geen significante verschillen in de nutrientinneming en de vetzuursamenstelling van het moederlijke plasma tussen de PIH groep $(n=52)$ en de controle groep $(n=156)$ waargenomen. $\mathrm{Na}$ de bevalling waren de relatieve hoeveelheden van 18:2(n-6) en 18:3(n-3) in het plasma van de moeder significant lager in de PIH dan in de normale groep ('normal pregnancy', NP). Dit was geassocieerd met significant hogere hoeveelheden van de (n-6) LCPs en cervonzuur (22:6(n-3), CA). Na 32 weken zwangerschap nam de CA status toe bij PIH, terwijl deze afnam bij NP. De hoeveelheden CA in navelstrengplasma waren significant hoger bij PIH dan in NP groep. Tussen de PIH en NP groep werden geen significante 
verschillen gevonden in de vetzuursamenstelling van het navelstrengvaatweefsel. De resultaten tonen aan dat de veranderde EFA status bij PIH een laat fenomeen is en daarom hoogstwaarschijnlijk niet heeft bijgedragen aan het ontstaan van PIH. De resultaten geven ook aan dat de EFA status van het kind niet verslechtert ten gevolge van PIH.

Tenslotte is het effect van linolzuursuppletie (18:2(n-6), LA) tijdens de zwangerschap onderzocht op de EFA status van het kind en de resultaten zijn beschreven in hoofdstuk 7. Zwangere vrouwen $(n=21)$ die minder dan 16 weken zwanger waren en een relatief lage LA status hadden werden gesupplementeerd met ongeveer 10 gram LA per dag vanaf de 20ste week van de zwangerschap tot aan de bevalling. Eén van de twee controle groepen bestond uit zwangere vrouwen met een vergelijkbare LA status aan het begin van het onderzoek (LL-controle groep, $n=22$ ); de andere controle groep bestond uit zwangere vrouwen met een habitueel hoge LA status (HL-controle groep, $n=21$ ). De EFA status van het kind werd vastgesteld middels het bepalen van de vetzuursamenstelling van fosfolipiden uit navelstrengplasma en -vaatwandweefsel. Het supplementeren van zwangere vrouwen met linolzuur resulteerde in significant hogere hoeveelheden van de (n-6) LCPs in navelstrengplasma en veneus vaatwandweefsel in vergelijking met de LL-controle groep. Deze toename was geassocieerd mel lagere hoeveelheden van de (n-3) LCPs. De gemiddelde hoeveelheid (n-3) LCPs in het navelstrengplasma en het -vaatwandweefsel van de HL-controle groep was ook significant lager dan in de LL-controle groep. Mocht het wenselijk worden geacht de EFA status van pasgeborenen te verbeteren, dan moeten zowel vetzuren van de (n-6) als de (n-3) familie worden gesupplementeerd.

Hoofdstuk 8 bevat de discussie van de belangrijkste resultaten die in dit proefschrift beschreven zijn, samen met een bespreking van een aantal methodologische overwegingen. 


\section{DANKWOORD}

Dit proefschrift is dankzij de medewerking, inzet en enthousiasme van vele mensen tot stand gekomen. Een aantal mensen wil ik graag met name noemen.

Mijn co-promotor Gerard Hornstra. Gerard, wie had ooit gedacht toen Yvonne van der Schouw en ik jou op één van de "voedingsavonden" in 1986 vroegen of jij nog een afstudeeropdracht had voor ons afstudeervak "Klinische Voeding", dit voor mij zou resulteren in dit proefschrift. Jouw enthousiasme en inventiviteit zijn aitijd een grote stimulans voor mij geweest. Ook de snelheid waarmee manuscripten, voorzien van kritische kanttekeningen, retour kwamen heeft mijn bewondering. Of je nu in Houston zat of in Maastricht, het leek voor jou allemaal niks uit te maken, maar ik begreep maar niet waar je de tijd vandaan haalde om de stukken door te nemen.

Mijn promotoren, Prof. F. ten Hoor en Prof. J. de Haan wil ik bedanken voor de deskundige en waardevolle adviezen tijdens het onderzoek, m.n. in de laatste fase van het proefschrift.

Rian van Houwelingen, die voor de dagelijkse begeleiding zorgde.. Rian, ik kon bijna altijd op ieder gewenst moment van de dag bij je langskomen om allerlei zaken te bespreken. Ik heb dit altijd als zeer prettig ervaren. Ook stond je altijd klaar als weer eens bij één van de onderzoekspersonen van het linolzuuronderzoek bloed moest worden afgenomen.

Voor de klinische begeleiding van het onderzoek en zijn waardevolle bijdragen ben ik Tom Hasaart zeer erkentelijk.

Marie-Louise den Rooyen, jouw begeleiding in het tweede jaar van mijn AiO aanstelling heeft enorm veel voor mij betekend. Ik ben je daar dan ook zeer dankbaar voor.

I want to thank Prof. J.G. van der Vusse, Prof. R.J.J. Hermus, Prof. D. Horrobin, Prof. H.J. Huisjes, Prof. F.J. Kok and Prof. P.W. de Leeuw for critically evaluating this thesis.

Alle proefpersonen - en dat zijn er inmiddels meer dan achthonderd - voor hun deelname aan het onderzoek. Zonder hun medewerking was het onderzoek niet mogelijk geweest.

ledereen van het Academisch Ziekenhuis Groningen die zijn medewerking heeft. verleend aan het onderzoek. Het onderzoek is daar begonnen, maar later hebben we 
het toch maar iets dichter bij huis gezocht, namelijk het Academisch Ziekenhuis Maastricht. Later zijn daar de Vroedvrouwenschool Kerkrade en de Wever Ziekenhuis Heerlen bijgekomen. Ik wil Dr. Roumen en de verloskundigen mw. Sonnemans en mw. Raumanns (Vroedvrouwenschool) en Dr. Heineman (Wever Ziekenhuis) bedanken voor hun inzet toen we met het onderzoek in de desbetreffende ziekenhuizen begonnen. Het hoofd van de verloskamers van het AZM (Claire Petillo), van de Vroedvrouwenschool (Cara Simons) en van de Weverziekenhuis (Margriet van Hasselt) wil ik bedanken voor de wijze waarop zij mede zorg hebben gedragen voor het verzamelen van het "bevallingsmateriaal" voor het onderzoek. Natuurlijk gaat dit niet zonder de medewerking van de arts-assistenten, co-assistenten, gynaecologen, verloskundigen en verpleegkundigen van de betrokken ziekenhuizen. Velen van jullie hebben ook hun best gedaan om vrouwen te motiveren voor dit onderzoek. Bedankt voor jullie medewerking! Ook wil ik alle poli-assistenten bedanken voor hun inzet en alle medewerkers van de prikdiensten voor de vele buizen bloed die zij hebben afgenomen.

Alle verloskundigen uit de regio die hun medewerking hebben verleend aan het vetzuuronderzoek, waarvan in het bijzonder Zr. Bernardi, Desirée Kramer en Astrid Merkx voor hun inspanningen tijdens het linolzuuronderzoek.

Saskia Nienhuis en Jacqueline Pieters voor de goede samenwerking tussen het "moederkoek-onderzoek" en het "vetzuur-onderzoek". Jullie lette er nauwgezet op dat elke zwangere vrouw na haar echo voor het moederkoekonderzoek nog even bij mij langs kwam, zodat ze ook aan het vetzuuronderzoek kon meedoen. Tijdens deze periode hebben we vele nieuwe proefpersonen mogen verwelkomen. Ook wil ik alle arts-assistenten bedanken die tijdens het echo-spreekuur op woensdagmiddag in het nieuwe AZM samen met mij getracht hebben om de "intake" van het onderzoek. op peil te houden.

Agnès Gerretsen van de Vroedvrouwenschool voor haar betrokkenheid bij het onderzoek en het nauwkeurig invullen van de vele medische vragenlijsten. Ik hoop dat ik nu eindelijk je naam goed heb geschreven.

De student-assistenten Ingrid van Hees, Ingrid Gisbertz en Laury de Jonge voor hun assistentie bij het verzamelen van de medische gegevens in Maastricht en omgeving.

De vele studenten die betrokken waren bij het totale "perinat-project" en in het bijzonder Monique Heesterbeek voor haar enthousiaste bijdrage aan het linolzuuronderzoek.

Marianne Simonis, Threa Cremers en Hasibe Aydeniz voor alle hulp bij het bloed afdraaien en opslaan, de vetzuuranalyses en niet te vergeten de weekendidiensten (!).

André de Jong en Taco van de Berg van ABL Assen voor de vele vetzuuranalyses en hun belangstelling in het onderzoek. 


\section{Arnold Kester voor de statistische adviezen.}

Jan Talmon voor het schrijven van een aantal computerprogramma's zodat mijn data makkelijker toegankelijk werden.

Remco, Philippe, Eva, Jony, Rens, Max, Maddy, Julia, Ingeborg, Youp, Yuri, Astrid en Alison. Alhoewel jullie er nog niet van bewust zijn, maar er zijn maar weinig mensen die zo jong al op een "cover" staan.

Anouk Cuypers, die gedurende mijn schrijfperiode in Den Haag heel wat faxjes voor mij heeft ontvangen, verstuurd en gecopieerd.

Mijn kamergenoten in het oude BMC, Ellen Blaak en Riette van Elburg. Bedankt voor alle keren dat jullie als mijn persoonlijke "klaagmuur" fungeerde. Riette ook bedankt voor de vele T-shirtjes die je van namen hebt voorzien.

Mijn (ex) kamergenoten Anita Badart en Margret Foreman. Eigenlijk zouden jullie als eerste genoemd moeten worden. Het is niet te beschrijven hoeveel wij de afgelopen jaren voor elkaar hebben betekend, zowel op het werk als daar buiten. Ik zal jullie missen!

Klaas, eindelijk na vijf en half jaar pendelen tussen Wageningen, Den Haag en Maastricht wonen we weer bij elkaar. We hebben veel in te halen

Verder wil ik alle familie, vrienden en bekenden bedanken voor de getoonde belangstelling. 



\section{CURRICULUM VITAE}

Monique Al werd op 8 september 1964 in Wormerveer geboren. In 1982 behaalde zij het VWO-B diploma op het St. Michaèl College te Zaandam. In datzelfde jaar begon zij haar studie "Voeding van de Mens" aan de Landbouwuniversiteit te Wageningen. Tijdens haar studie deed zij een afstudeervak Klinische Voeding bij de vakgroep Biochemie van de Rijksuniversiteit Limburg (Dr. G. Hornstra), een afstudeervak Gezondheidsleer bij TNO-Voeding in Zeist (Dr. Ir. S. Bausch en Prof. Dr. Ir. F.J. Kok) en een afstudeervak Gegevensverwerking in de Geneeskunde bij de vakgroep Sociale Geneeskunde van de Rijksuniversiteit Leiden (Ir. M. Verschuren en Prof. Dr. Ir. D. Kromhout). In juni 1988 behaalde zij het diploma van landbouwkundig ingenieur. Op 1 juli 1988 trad zij als onderzoeksassistente in dienst bij de vakgroep Humane Biologie van de Rijksuniversiteit Limburg. Van oktober 1989 tot en met december 1993 was zij werkzaam als assistent-in-opleiding bij dezelfde vakgroep, alwaar het in dit proefschrift beschreven onderzoek werd uitgevoerd. 
ヨATIV MU」UOIRคบอ 


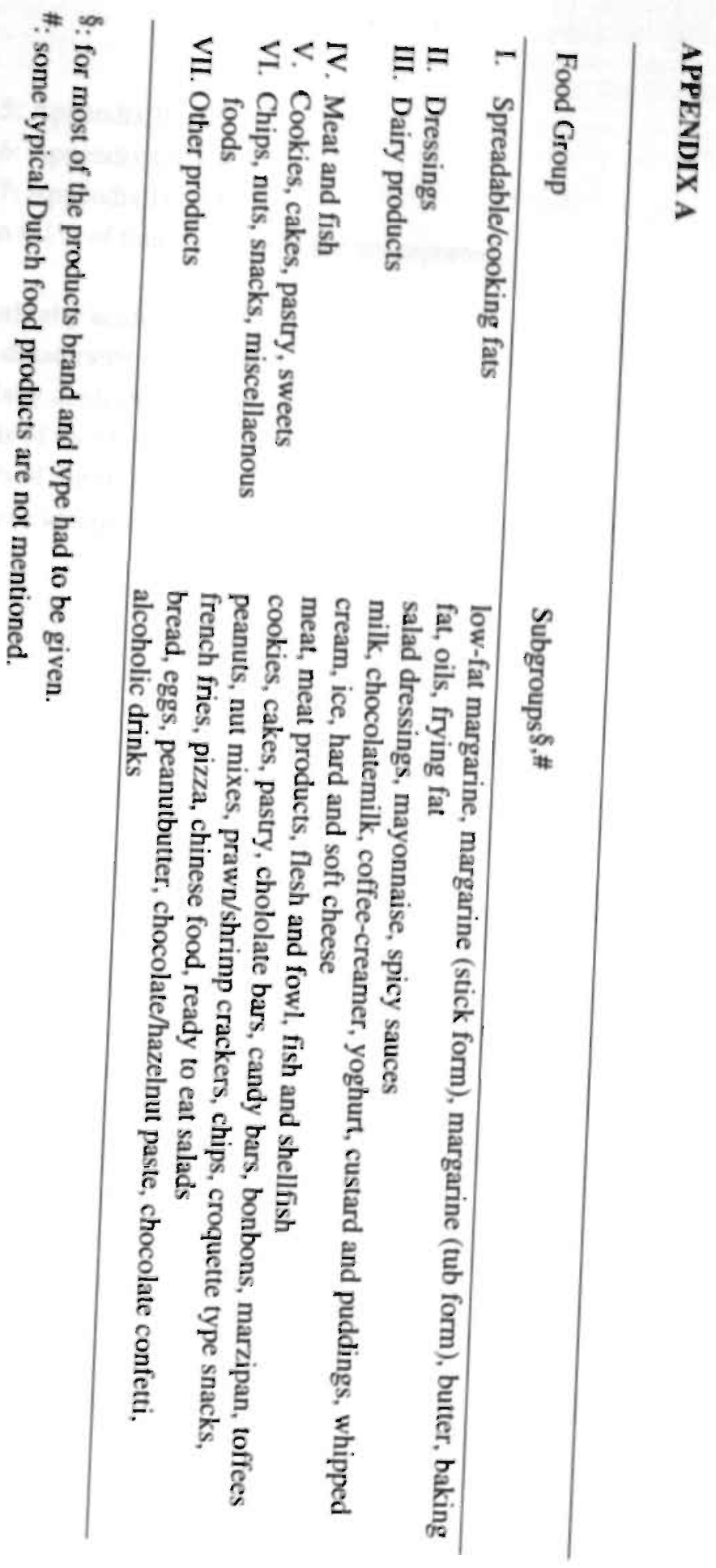


Legend Appendix B-D.

Fatty acid data of Chapter 5: Appendix B1-B2.

Fatty acid data of Chapter 6: Appendix C1-C4.

Fatty acid data of Chapter 7: Appendix D1-D6.

Fatty acids present less than $0.1 \%$ of total fatty acids are not reported.

¿SAFA: sum of all saturated fatty acids

¿MUFA: sum of all mono-unsaturated fatty acids

$\Sigma(n-7)+\Sigma(n-9)$ : sum of all fatty acids of the (n-7) and (n-9) family

$\Sigma(n-6)$ : sum of all fatty acids of the (n-6) family

$\Sigma(n-3)$ : sum of all fatty acids of the (n-3) family dma: dimethyl acetal (tentative identification)

nd: not detectable 
Appendix B1. The absolute fatty acid composition $(\mathrm{mg} / \mathrm{L})$ of phospholipids from maternal venous plasma during pregnancy (gestational age in weeks), from maternal (M) and umbilicail (U) venous plasma at delivery, and from maternal venous plasma six months after delivery ( $>0.5 \mathrm{yr}$ ). Results are given as mean \pm s.e.m. ( $\mathbf{n}=110$, after correction for missing values).

\begin{tabular}{|c|c|c|c|c|c|c|c|}
\hline Fatty acid & 10 & 14 & 18 & 22 & 26 & 30 & 32 \\
\hline $14: 0$ & $3.56 \pm 0.21$ & $3.98 \pm 0.17$ & $4.59 \pm 0.17$ & $5.33 \pm 0.17$ & $5.83 \pm 0.17$ & $5.77 \pm 0.17$ & $5.55 \pm 0.17$ \\
\hline $15: 0$ & $2.39 \pm 0.16$ & $2.84 \pm 0.14$ & $3.19 \pm 0.14$ & $3.19 \pm 0.14$ & $3.34 \pm 0.14$ & $3.40 \pm 0.14$ & $3.45 \pm 0.14$ \\
\hline $16: 0$ & $326.7 \pm 7.53$ & $371.9 \pm 6.62$ & $410.8 \pm 6.58$ & $446.1 \pm 6.61$ & $476.5 \pm 6.60$ & $500.4 \pm 6.56$ & $505.5 \pm 6.57$ \\
\hline $18: 0$ & $147.9 \pm 2.86$ & $154.7 \pm 2.49$ & $160.3 \pm 2.48$ & $164.3 \pm 2.49$ & $168.9 \pm 2.49$ & $172.7 \pm 2.47$ & $171.8 \pm 2.47$ \\
\hline $20: 0$ & $6.37 \pm 0.17$ & $6.79 \pm 0.15$ & $7.35 \pm 0.15$ & $7.84 \pm 0.15$ & $8.33 \pm 0.15$ & $8.74 \pm 0.15$ & $9.05 \pm 0.15$ \\
\hline 22:0 & $18.8 \pm 0.51$ & $20.3 \pm 0.47$ & $21.8 \pm 0.47$ & $23.5 \pm 0.47$ & $25.0 \pm 0.47$ & $25.8 \pm 0.46$ & $26.1 \pm 0.47$ \\
\hline 23:0 & $6.39 \pm 0.20$ & $7.25 \pm 0.18$ & $8.03 \pm 0.18$ & $8.80 \pm 0.18$ & $9.33 \pm 0.18$ & $9.55 \pm 0.18$ & $9.65 \pm 0.18$ \\
\hline $24: 0$ & $11.3 \pm 0.36$ & $12.4 \pm 0.33$ & $13.3 \pm 0.32$ & $14.3 \pm 0.32$ & $15.2 \pm 0.32$ & $15.4 \pm 0.32$ & $15.3 \pm 0.32$ \\
\hline ¿SAFA & $523.6 \pm 10.7$ & $580.0 \pm 9.44$ & $629.4 \pm 9.39$ & $673.4 \pm 9.42$ & $712.5 \pm 9.4 !$ & $741.9 \pm 9.35$ & $746.4 \pm 9.37$ \\
\hline $16: 1(\mathrm{n}-7)$ & $2.74 \pm 0.41$ & $3.18 \pm 0.33$ & $3.74 \pm 0.32$ & $4.76 \pm 0.33$ & $5.46 \pm 0.33$ & $5.88 \pm 0.32$ & $5.77 \pm 0.32$ \\
\hline I8: I(n-7) & $27.3 \pm 0.75$ & $30.4 \pm 0.61$ & $31.9 \pm 0.61$ & $32.8 \pm 0.61$ & $34.4 \pm 0.61$ & $34.4 \pm 0.60$ & $34.0 \pm 0.60$ \\
\hline 18: 1(n-9) & $97.2 \pm 3.85$ & $107.5 \pm 3.02$ & $118.1 \pm 2.99$ & $130.3 \pm 3.03$ & $138.1 \pm 3.02$ & $145.6 \pm 2.96$ & $146.4 \pm 2.98$ \\
\hline 20: $1(n-9)$ & {$[.99 \pm 0.08$} & $2.36 \pm 0.06$ & $2.56 \pm 0.06$ & $2.64 \pm 0.06$ & $2.73 \pm 0.06$ & $2.67 \pm 0.06$ & $2.65 \pm 0.06$ \\
\hline $24: 1(n-9)$ & $16.4 \pm 0.62$ & $18.2 \pm 0.56$ & $20.5 \pm 0.56$ & $21.7 \pm 0.56$ & $23.1 \pm 0.56$ & $24.0 \pm 0.56$ & $24.7 \pm 0.56$ \\
\hline ¿MUFA & $146.1 \pm 4.82$ & $162.3 \pm 3.80$ & $177.6 \pm 3.77$ & $192.9 \pm 3.8 \rrbracket$ & $204.6 \pm 3.79$ & $213.4 \pm 3.73$ & $214.4 \pm 3.75$ \\
\hline $16: 0 \mathrm{dma}$ & $8.16 \pm 0.25$ & $8.39 \pm 0.22$ & $8.46 \pm 0.22$ & $8.39 \pm 0.22$ & $8.38 \pm 0.22$ & $8.10 \pm 0.21$ & $7.99 \pm 0.21$ \\
\hline 18:0 dma & $6.36 \pm 0.22$ & $6.25 \pm 0.19$ & $6.32 \pm 0.19$ & $6.54 \pm 0.19$ & $6.48 \pm 0.19$ & $6.65 \pm 0.19$ & $6.71 \pm 0.19$ \\
\hline 18:1 dma & $2.07 \pm 0.08$ & $2.15 \pm 0.07$ & $2.22 \pm 0.07$ & $2.21 \pm 0.07$ & $2.16 \pm 0.07$ & $2.04 \pm 0.07$ & $2.03 \pm 0.07$ \\
\hline $20: 3(n-9)$ & $3.22 \pm 0.21$ & $3.56 \pm 0.18$ & $3.95 \pm 0.18$ & $4.39 \pm 0.18$ & $4.73 \pm 0.18$ & $4.96 \pm 0.18$ & $5.10 \pm 0.18$ \\
\hline$\sum(n-7)+\sum(n-9)$ & $149.7 \pm 4.95$ & $166.4 \pm 3.91$ & $182.0 \pm 3.88$ & $197.8 \pm 3.92$ & $209.8 \pm 3.90$ & $218.9 \pm 3.84$ & $220.0 \pm 3.86$ \\
\hline $18: 2(n-6)$ & $274.2 \pm 6.66$ & $301.5 \pm 5.78$ & $322.4 \pm 5.75$ & $338.3 \pm 5.77$ & $357.7 \pm 5.77$ & $371.4 \pm 5.72$ & $373.8 \pm 5.74$ \\
\hline $20: 2(n-6)$ & $5.50 \pm 0.18$ & $6.65 \pm 0.15$ & $7.57 \pm 0.15$ & $8.30 \pm 0.15$ & $8.67 \pm 0.15$ & $8.62 \pm 0.15$ & $8.39 \pm 0.15$ \\
\hline $20: 3(n-6)$ & $36.3 \pm 1.35$ & $41.6 \pm 1.17$ & $45.9 \pm 1.16$ & $50.8 \pm 1.17$ & $54.3 \pm 1.17$ & $56.5 \pm 1.16$ & $56.0 \pm 1.16$ \\
\hline $20: 4(n-6)$ & $119.4 \pm 2.91$ & $127.2 \pm 2.68$ & $131.8 \pm 2.67$ & $133.3 \pm 2.68$ & $137.0 \pm 2.67$ & $138.5 \pm 2.66$ & $138.5 \pm 2.67$ \\
\hline $22: 4(n-6)$ & $4.84 \pm 0.16$ & $5.28 \pm 0.14$ & $5.65 \pm 0.14$ & $6.11 \pm 0.14$ & $6.25 \pm 0.14$ & $6.29 \pm 0.14$ & $6.19 \pm 0.14$ \\
\hline $22: 5(n-6)$ & $4.06 \pm 0.26$ & $5.14 \pm 0.23$ & $6.17 \pm 0.23$ & $6.90 \pm 0.23$ & $7.50 \pm 0.23$ & $7.76 \pm 0.23$ & $7.81 \pm 0.23$ \\
\hline $24: 2(n-6)$ & $2.39 \pm 0.11$ & $2.68 \pm 0.09$ & $2.93 \pm 0.09$ & $3.17 \pm 0.09$ & $3.38 \pm 0.09$ & $3.52 \pm 0.09$ & $3.59 \pm 0.09$ \\
\hline$\Sigma(n-6)$ & $446.3 \pm 8.85$ & $490.7 \pm 7.84$ & $523.1 \pm 7.80$ & $547.5 \pm 7.82$ & $575.5 \pm 7.81$ & $593.3 \pm 7.77$ & $595.1 \pm 7.78$ \\
\hline
\end{tabular}




\begin{tabular}{|c|c|c|c|c|c|c|c|}
\hline Fatty acid & 34 & 36 & 38 & 40 & $\mathrm{M}$ & $\mathrm{U}$ & $>0.5 \mathrm{yr}$ \\
\hline $14: 0$ & $5.53 \pm 0.17$ & $5.89 \pm 0.17$ & $6.06 \pm 0.17$ & $5.91 \pm 0.22$ & $5.13 \pm 0.18$ & $1.34 \pm 0.08$ & $3.87 \pm 0.26$ \\
\hline $15: 0$ & $3.32 \pm 0.14$ & $3.33 \pm 0.14$ & $3.31 \pm 0.14$ & $3.30 \pm 0.16$ & $3.23 \pm 0.16$ & $0.55 \pm 0.04$ & $2.29 \pm 0.14$ \\
\hline $16: 0$ & $516.0 \pm 6.59$ & $535.0 \pm 6.59$ & $549.6 \pm 6.73$ & $561.8 \pm 7.81$ & $528.2 \pm 8.00$ & $163.1 \pm 3.57$ & $356.0 \pm 10.6$ \\
\hline $18: 0$ & $173.9 \pm 2.48$ & $179.5 \pm 2.48$ & $185.4 \pm 2.54$ & $187.8 \pm 2.97$ & $165.7 \pm 2.90$ & $85.2 \pm 1.96$ & $162.2 \pm 4.09$ \\
\hline $20: 0$ & $9.08 \pm 0.15$ & $9.23 \pm 0.15$ & $9.40 \pm 0.16$ & $9.65 \pm 0.17$ & $9.14 \pm 0.18$ & $5.10 \pm 0.15$ & $6.62 \pm 0.22$ \\
\hline 22:0 & $26.1 \pm 0.47$ & $26.4 \pm 0.47$ & $26.5 \pm 0.47$ & $27.0 \pm 0.53$ & $25.8 \pm 0.57$ & $8.59 \pm 0.25$ & $21.6 \pm 0.80$ \\
\hline $23: 0$ & $9.58 \pm 0.18$ & $9.62 \pm 0.18$ & $9.67 \pm 0.18$ & $9.92 \pm 0.20$ & $9.48 \pm 0.21$ & $1.20 \pm 0.05$ & $7.30 \pm 0.29$ \\
\hline $24: 0$ & $15.4 \pm 0.32$ & $15.6 \pm 0.32$ & $15.7 \pm 0.33$ & $16.1 \pm 0.37$ & $15.3 \pm 0.36$ & $8.24 \pm 0.24$ & $14.6 \pm 0.54$ \\
\hline$\Sigma S A F A$ & $758.9 \pm 9.40$ & $784.5 \pm 9.40$ & $805.6 \pm 9.60$ & $821.6 \pm 11.1$ & $761.4 \pm 11.4$ & $273.4 \pm 5.95$ & $575.1 \pm 14.5$ \\
\hline $16: 1(n-7)$ & $6.38 \pm 0.32$ & $7.66 \pm 0.32$ & $7.49 \pm 0.34$ & $7.73 \pm 0.43$ & $7.40 \pm 0.39$ & $3.15 \pm 0.19$ & $3.45 \pm 0.42$ \\
\hline $18: 1(n-7)$ & $34.6 \pm 0.61$ & $34.8 \pm 0.61$ & $33.9 \pm 0.63$ & $34.8 \pm 0.78$ & $32.9 \pm 0.65$ & $15.7 \pm 0.47$ & $28.3 \pm 0.73$ \\
\hline $18: 1(n-9)$ & $152.2 \pm 3.00$ & $163.7 \pm 3.00$ & $163.0 \pm 3.13$ & $167.4 \pm 4.06$ & $154.4 \pm 3.26$ & $44.2 \pm 2.38$ & $105.2 \pm 3.75$ \\
\hline $20: 1(n-9)$ & $2.57 \pm 0.06$ & $2.63 \pm 0.06$ & $2.63 \pm 0.06$ & $2.73 \pm 0.08$ & $2.43 \pm 0.06$ & $0.30 \pm 0.03$ & $2.03 \pm 0.08$ \\
\hline $24: 1(n-9)$ & $25.2 \pm 0.56$ & $25.3 \pm 0.56$ & $26.1 \pm 0.57$ & $26.9 \pm 0.64$ & $25.6 \pm 0.63$ & $12.2 \pm 0.35$ & $19.1 \pm 0.75$ \\
\hline ¿MUFA & $221.8 \pm 3.78$ & $235.0 \pm 3.77$ & $234.0 \pm 3.94$ & $240.9 \pm 5.09$ & $223.6 \pm 4.10$ & $75.6 \pm 3.17$ & $158.6 \pm 4.99$ \\
\hline i 6:0 dma & $8.01 \pm 0.22$ & $8.48 \pm 0.22$ & $8.62 \pm 0.22$ & $8.57 \pm 0.26$ & $7.74 \pm 0.20$ & $3.83 \pm 0.16$ & $8.33 \pm 0.25$ \\
\hline $18: 0 \mathrm{dma}$ & $6.40 \pm 0.19$ & $6.68 \pm 0.19$ & $6.80 \pm 0.20$ & $6.84 \pm 0.23$ & $5.58 \pm 0.18$ & $1.31 \pm 0.10$ & $5.80 \pm 0.23$ \\
\hline 18:1 dma & $2.05 \pm 0.07$ & $2.12 \pm 0.07$ & $2.13 \pm 0.07$ & $2.08 \pm 0.08$ & $1.82 \pm 0.06$ & $0.19 \pm 0.02$ & $2.17 \pm 0.09$ \\
\hline $20: 3(n-9)$ & $5.43 \pm 0.18$ & $5.96 \pm 0.18$ & $6.12 \pm 0.18$ & $6.19 \pm 0.22$ & $6.07 \pm 0.24$ & $3.93 \pm 0.20$ & $4.92 \times 0.28$ \\
\hline$\Sigma(n-7)+\Sigma(n-9)$ & $227.7 \pm 3.89$ & $241.5 \pm 3.88$ & $240.6 \pm 4.05$ & $247.6 \pm 5.22$ & $230.0 \pm 4.24$ & $79.8 \pm 3.26$ & $163.7 \pm 5.21$ \\
\hline $18: 2(n-6)$ & $377.1 \pm 5.76$ & $390.7 \pm 5.76$ & $400.8 \pm 5.90$ & $407.9 \pm 6.91$ & $358.6 \pm 6.69$ & $45.3 \pm 1.49$ & $302.3 \pm 6.35$ \\
\hline $20: 2(n-6)$ & $8.22 \pm 0.15$ & $8.25 \pm 0.15$ & $8.28 \pm 0.15$ & $8.54 \pm 0.18$ & $7.58 \pm 0.17$ & $2.22 \pm 0.07$ & $5.32 \pm 0.25$ \\
\hline $20: 3(n-6)$ & $56.7 \pm 1.17$ & $58.6 \pm \mathbf{i . 1 7}$ & $59.6 \pm 1.20$ & $61.8 \pm 1.41$ & $57.9 \pm 1.39$ & $29.5 \pm 0.83$ & $39.0 \pm 2.01$ \\
\hline $20: 4(n-6)$ & $138.0 \pm 2.67$ & $142.3 \pm 2.67$ & $144.9 \pm 2.71$ & $147.4 \pm 2.97$ & $141.1 \pm 3.13$ & $95.7 \pm 2.21$ & $121.8 \pm 3.74$ \\
\hline $22: 4(n-6)$ & $6.26 \pm 0.14$ & $6.50 \pm 0.14$ & $6.52 \pm 0.14$ & $6.65 \pm 0.17$ & $6.09 \pm 0.15$ & $4.56 \pm 0.13$ & $4.27 \pm 0.14$ \\
\hline $22: 5(n-6)$ & $8.15 \pm 0.23$ & $8.72 \pm 0.23$ & $8.90 \pm 0.24$ & $9.17 \pm 0.27$ & $8.72 \pm 0.31$ & $5.09 i \pm 0.18$ & $3.43 \pm 0.17$ \\
\hline $24: 2(n-6)$ & $3.63 \pm 0.09$ & $3.58 \pm 0.09$ & $3.68 \pm 0.10$ & $3.82 \pm 0.11$ & $3.60 \pm 0.10$ & $3.67 \pm 0.14$ & $1.87 \pm 0.09$ \\
\hline$\sum(n-6)$ & $598.9 \pm 7.80$ & $619.5 \pm 7.80$ & $633.5 \pm 7.98$ & $644.6 \pm 9.14$ & $584.8 \pm 9.67$ & $186.7 \pm 4.33$ & $476.9 \pm 10.6$ \\
\hline
\end{tabular}


Appendix Bi continued

\begin{tabular}{llllllll}
\hline Fatty acid & 10 & 14 & 18 & 22 & 26 & 30 & 32 \\
\hline $18: 3(\mathrm{n}-3)$ & $3.31 \pm 0.21$ & $3.82 \pm 0.17$ & $4.20 \pm 0.17$ & $4.63 \pm 0.17$ & $4.78 \pm 0.17$ & $4.98 \pm 0.17$ & $4.89 \pm 0.17$ \\
$20: 4(\mathrm{n}-3)$ & $1.75 \pm 0.14$ & $1.99 \pm 0.11$ & $2.27 \pm 0.11$ & $2.59 \pm 0.11$ & $2.62 \pm 0.11$ & $2.64 \pm 0.10$ & $2.59 \pm 0.11$ \\
$20: 5(\mathrm{n}-3)$ & $6.31 \pm 0.59$ & $6.84 \pm 0.48$ & $6.80 \pm 0.47$ & $6.92 \pm 0.48$ & $7.20 \pm 0.48$ & $6.69 \pm 0.47$ & $6.28 \pm 0.47$ \\
$22: 5(\mathrm{n}-3)$ & $9.31 \pm 0.29$ & $9.28 \pm 0.24$ & $9.42 \pm 0.24$ & $9.83 \pm 0.24$ & $9.99 \pm 0.24$ & $9.92 \pm 0.24$ & $9.58 \pm 0.24$ \\
$22: 6(\mathrm{n}-3)$ & $47.1 \pm 1.69$ & $55.8 \pm 1.48$ & $61.3 \pm 1.47$ & $63.8 \pm 1.48$ & $66.8 \pm 1.48$ & $69.1 \pm 1.47$ & $67.9 \pm 1.47$ \\
$\Sigma(\mathrm{n}-3)$ & $68.4 \pm 2.35$ & $78.4 \pm 2.00$ & $84.5 \pm 1.99$ & $88.3 \pm 2.00$ & $91.9 \pm 2.00$ & $93.7 \pm 1.98$ & $91.7 \pm 1.99$
\end{tabular}


Appendix B1 continued

\begin{tabular}{llllllll}
\hline Fatty acid & 34 & 36 & 38 & 40 & $\mathrm{M}$ & $\mathrm{U}$ & \multicolumn{2}{c}{$\mathrm{M} y \mathrm{yr}$} \\
\hline $18: 3(\mathrm{n}-3)$ & $5.17 \pm 0.17$ & $5.26 \pm 0.17$ & $5.26 \pm 0.18$ & $5.13 \pm 0.22$ & $4.60 \pm 0.20$ & $0.61 \pm 0.03$ & $4.10 \pm 0.18$ \\
$20: 4(\mathrm{n}-3)$ & $2.85 \pm 0.11$ & $2.78 \pm 0.11$ & $2.91 \pm 0.11$ & $2.89 \pm 0.14$ & $2.65 \pm 0.11$ & $0.65 \pm 0.04$ & $2.07 \pm 0.15$ \\
$20: 5(\mathrm{n}-3)$ & $6.44 \pm 0.47$ & $6.13 \pm 0.47$ & $6.72 \pm 0.50$ & $6.44 \pm 0.62$ & $5.95 \pm 0.34$ & $1.31 \pm 0.06$ & $8.10 \pm 0.70$ \\
$22: 5(\mathrm{n}-3)$ & $9.45 \pm 0.24$ & $9.63 \pm 0.24$ & $9.74 \pm 0.25$ & $9.96 \pm 0.30$ & $9.11 \pm 0.26$ & $2.71 \pm 0.12$ & $9.19 \pm 0.34$ \\
$22: 6(\mathrm{n}-3)$ & $67.8 \pm 1.48$ & $68.2 \pm 1.47$ & $69.8 \pm 1.51$ & $71.7 \pm 1.75$ & $65.0 \pm 1.50$ & $36.1 \pm 1.21$ & $38.6 \pm 1.61$ \\
$\Sigma(\mathrm{n}-3)$ & $92.1 \pm 1.99$ & $92.4 \pm 1.99$ & $94.8 \pm 2.05$ & $96.1 \pm 2.45$ & $87.7 \pm 2.00$ & $41.4 \pm 1.35$ & $62.3 \pm 2.35$ \\
\hline
\end{tabular}


Appendix B2. The relative fatty acid composition (\% of total fatty acids) of phospholipids from maternal venous plasma during pregnancy (gestational age in weeks), from maternal $(M)$ and umbilical $(U)$ venous plasma at delivery, and from maternal venous plasma six months after delivery ( $>0.5 \mathrm{yr}$ ). Results are given as mean \pm s.e.m. $(n=110$, after correction for missing values).

\begin{tabular}{|c|c|c|c|c|c|c|c|}
\hline Fatty acid & 10 & 14 & 18 & 22 & 26 & 30 & 32 \\
\hline $14: 0$ & $0.28 \pm 0.01$ & $0.29 \pm 0.01$ & $0.31 \pm 0.01$ & $0.34 \pm 0.01$ & $0.35 \pm 0.01$ & $0.34 \pm 0.01$ & $0.32 \pm 0.01$ \\
\hline $15: 0$ & $0.19 \pm 0.01$ & $0.21 \pm 0.01$ & $0.21 \pm 0.01$ & $0.20 \pm 0.01$ & $0.20 \pm 0.01$ & $0.20 \pm 0.0 x$ & $0.20 \pm 0.01$ \\
\hline $16: 0$ & $26.3 \pm 0.14$ & $27.0 \pm 0.12$ & $27.7 \pm 0.12$ & $28.4 \pm 0.12$ & $28.9 \pm 0.12$ & $29.3 \pm 0.12$ & $29.5 \pm 0.12$ \\
\hline $18: 0$ & $11.9 \pm 0.09$ & $11.3 \pm 0.07$ & $10.9 \pm 0.07$ & $10.5 \pm 0.07$ & $10.2 \pm 0.07$ & $10.1 \pm 0.07$ & $10.0 \pm 0.07$ \\
\hline $20: 0$ & $0.52 \pm 0.01$ & $0.49 \pm 0.01$ & $0.50 \pm 0.01$ & $0.50 \pm 0.01$ & $0.51 \pm 0.01$ & $0.51 \pm 0.01$ & $0.53 \pm 0.01$ \\
\hline $22: 0$ & $1.52 \pm 0.03$ & $1.49 \pm 0.03$ & $1.48 \pm 0.03$ & $1.51 \pm 0.03$ & $1.53 \pm 0.03$ & $1.52 \pm 0.03$ & $1.53 \pm 0.03$ \\
\hline $23: 0$ & $0.51 \pm 0.01$ & $0.53 \pm 0.01$ & $0.54 \pm 0.01$ & $0.56 \pm 0.01$ & $0.57 \pm 0.01$ & $0.56 \pm 0.01$ & $0.56 \pm 0.01$ \\
\hline $24: 0$ & $0.91 \pm 0.02$ & $0.91 \pm 0.02$ & $0.90 \pm 0.02$ & $0.91 \pm 0.02$ & $0.93 \pm 0.02$ & $0.91 \pm 0.02$ & $0.90 \pm 0.02$ \\
\hline$\Sigma S A F A$ & $42.2 \pm 0.13$ & $42.2 \pm 0.11$ & $42.6 \pm 0.11$ & $43.0 \pm 0.11$ & $43.2 \pm 0.11$ & $43.5 \pm 0.11$ & $43.6 \pm 0.11$ \\
\hline $16: 1(n-7)$ & $0.22 \pm 0.02$ & $0.23 \pm 0.02$ & $0.25 \pm 0.02$ & $0.30 \pm 0.02$ & $0.32 \pm 0.02$ & $0.34 \pm 0.02$ & $0.33 \pm 0.02$ \\
\hline $18: 1(n-7)$ & $2.21 \pm 0.04$ & $2.22 \pm 0.03$ & $2.17 \pm 0.03$ & $2.11 \pm 0.03$ & $2.10 \pm 0.03$ & $2.03 \pm 0.03$ & $1.99 \pm 0.03$ \\
\hline $18: 1(n-9)$ & $7.91 \pm 0.16$ & $7.86 \pm 0.13$ & $8 \Omega 0+3.13$ & $8.29+5.13$ & $8.35+0.13$ & $8.5 i^{\prime} \pm 0.12$ & $8.54 \pm 0.15$ \\
\hline $20: 1(n-9)$ & $0.16 \pm 0.00$ & $0.17 \pm 0.00$ & $0.17 \pm 0.00$ & $0.17 \pm 0.00$ & $0.17 \pm 0.00$ & $0.16 \pm 0.00$ & $0.15 \pm 0.00$ \\
\hline $24: 5(n-9)$ & $1.33 \pm 0.04$ & $1.33 \pm 0.03$ & $1.38 \pm 0.03$ & $1.39 \pm 0.03$ & $1.40 \pm 0.03$ & $1.41 \pm 0.03$ & $1.45 \pm 0.03$ \\
\hline EMUFA & $11.9 \pm 0.19$ & $11.9 \pm 0.15$ & $12.0 \pm 0.15$ & $12.3 \pm 0.15$ & $12.4 \pm 0.15$ & $12.5 \pm 0.15$ & $12.5 \pm 0.15$ \\
\hline $16: 0 \mathrm{dma}$ & $0.66 \pm 0.01$ & $0.61 \pm 0.01$ & $0.57 \pm 0.01$ & $0.54 \pm 0.01$ & $0.51 \pm 0.01$ & $0.48 \pm 0.01$ & $0.47 \pm 0.01$ \\
\hline $18.0 \mathrm{dma}$ & $0.50 \pm 0.01$ & $0.46 \pm 0.01$ & $0.43 \pm 0.01$ & $0.42 \pm 0.01$ & $0.40 \pm 0.01$ & $0.39 \pm 0.01$ & $0.39 \pm 0.01$ \\
\hline $18: 1 \mathrm{dma}$ & $0.16 \pm 0.00$ & $0.16 \pm 0.00$ & $0.15 \pm 0.00$ & $0.14 \pm 0.00$ & $0.13 \pm 0.00$ & $0.12 \pm 0.00$ & $0.12 \pm 0.00$ \\
\hline $20: 3\{n-9\}$ & $0.26 \pm 0.01$ & $0.26 \pm 0.01$ & $0.27 \pm 0.01$ & $0.28 \pm 0.01$ & $0.29 \pm 0.01$ & $0.29 \pm 0.01$ & $0.30 \pm 0.01$ \\
\hline$\Sigma(n-7)+\Sigma(n-9)$ & $12.1 \pm 0.19$ & $12.2 \pm 0.16$ & $12.3 \pm 0.16$ & $12.6 \pm 0.16$ & $12.7 \pm 0.16$ & $12.8 \pm 0.16$ & $12.9 \pm 0.16$ \\
\hline $18: 2(n-6)$ & $22.1 \pm 0.29$ & $22.0 \pm 0.25$ & $21.9 \pm 0.25$ & $21.7 \pm 0.25$ & $21.7 \pm 0.25$ & $21.8 \pm 0.25$ & $21.9 \pm 0.25$ \\
\hline $20: 2(n-6)$ & $0.44 \pm 0.01$ & $0.48 \pm 0.01$ & $0.51 \pm 0.01$ & $0.53 \pm 0.01$ & $0.53 \pm 0.01$ & $0.51 \pm 0.01$ & $0.49 \pm 0.01$ \\
\hline $20: 3(n-6)$ & $2.91 \pm 0.06$ & $3.01 \pm 0.05$ & $3.09 \pm 0.05$ & $3.22 \pm 0.05$ & $3.28 \pm 0.05$ & $3.30 \pm 0.05$ & $3.27 \pm 0.05$ \\
\hline $20: 4(n-6)$ & $9.63 \pm 0.13$ & $9.26 \pm 0.12$ & $8.89 \pm 0.11$ & $8.51 \pm 0.11$ & $8.29 \pm 0.11$ & $8.10 \pm 0.11$ & $8.08 \pm 0.11$ \\
\hline $22: 4(n-6)$ & $0.39 \pm 0.01$ & $0.38 \pm 0.01$ & $0.38 \pm 0.01$ & $0.39 \pm 0.01$ & $0.38 \pm 0.01$ & $0.37 \pm 0.01$ & $0.36 \pm 0.01$ \\
\hline $22: 5\{n-6)$ & $0.33 \pm 0.01$ & $0.37 \pm 0.01$ & $0.42 \pm 0.01$ & $0.44 \pm 0.01$ & $0.46 \pm 0.01$ & $0.46 \pm 0.01$ & $0.46 \pm 0.01$ \\
\hline $24: 2(n-6)$ & $0.19 \pm 0.01$ & $0.19 \pm 0.01$ & $0.20 \pm 0.01$ & $0.20 \pm 0.01$ & $0.21 \pm 0.01$ & $0.21 \pm 0.01$ & $0.21 \pm 0.01$ \\
\hline$\Sigma(n-6)$ & $36.0 \pm 0.24$ & $35.7 \pm 0.20$ & $35.4 \pm 0.20$ & $35.0 \pm 0.20$ & $34.9 \pm 0.20$ & $34.8 \pm 0.20$ & $34.8 \pm 0.20$ \\
\hline
\end{tabular}


Appendix B2. The relative fatty acid composition (\% of total fatty acids) of phospholipids from maternal venous plasma during pregnancy (gestational age in weeks), from maternal $(M)$ and umbilical (U) venous plasma at delivery, and from maternal venous plasma six months after delivery ( $>0.5 \mathrm{yr})$. Results are given as mean \pm s.e.m. $(n=110$, after correction for missing values).

\begin{tabular}{|c|c|c|c|c|c|c|c|}
\hline Fatty acid & 10 & 14 & 18 & 22 & 26 & 30 & 32 \\
\hline $14: 0$ & $0.28 \pm 0.01$ & $0.29 \pm 0.01$ & $0.31 \pm 0.01$ & $0.34 \pm 0.01$ & $0.35 \pm 0.01$ & $0.34 \pm 0.01$ & $0.32 \pm 0.01$ \\
\hline $15: 0$ & $0.19 \pm 0.01$ & $0.21 \pm 0.01$ & $0.21 \pm 0.01$ & $0.20 \pm 0.01$ & $0.20 \pm 0.01$ & $0.20 \pm 0.01$ & $0.20 \pm 0.01$ \\
\hline $16: 0$ & $26.3 \pm 0.14$ & $27.0 \pm 0.12$ & $27.7 \pm 0.12$ & $28.4 \pm 0.12$ & $28.9 \pm 0.12$ & $29.3 \pm 0.12$ & $29.5 \pm 0.12$ \\
\hline 18:0 & $11.9 \pm 0.09$ & $11.3 \pm 0.07$ & $10.9 \pm 0.07$ & $10.5 \pm 0.07$ & $10.2 \pm 0.07$ & $10.1 \pm 0.07$ & $10.0 \pm 0.07$ \\
\hline $20: 0$ & $0.52 \pm 0.01$ & $0.49 \pm 0.01$ & $0.50 \pm 0.01$ & $0.50 \pm 0.01$ & $0.51 \pm 0.01$ & $0.51 \pm 0.01$ & $0.53 \pm 0.01$ \\
\hline $22: 0$ & $1.52 \pm 0.03$ & $1.49 \pm 0.03$ & $1.48 \pm 0.03$ & $1.51 \pm 0.03$ & $1.53 \pm 0.03$ & $1.52 \pm 0.03$ & $1.53 \pm 0.03$ \\
\hline $23: 0$ & $0.51 \pm 0.01$ & $0.53 \pm 0.01$ & $0.54 \pm 0.01$ & $0.56 \pm 0.01$ & $0.57 \pm 0.01$ & $0.56 \pm 0.01$ & $0.56 \pm 0.01$ \\
\hline $24: 0$ & $0.91 \pm 0.02$ & $0.91 \pm 0.02$ & $0.90 \pm 0.02$ & $0.91 \pm 0.02$ & $0.93 \pm 0.02$ & $0.91 \pm 0.02$ & $0.90 \pm 0.02$ \\
\hline$\Sigma S A F A$ & $42.2 \pm 0.13$ & $42.2 \pm 0.11$ & $42.6 \pm 0.11$ & $43.0 \pm 0.11$ & $43.2 \pm 0.11$ & $43.5 \pm 0.11$ & $43.6 \pm 0.11$ \\
\hline $16: 1(n-7)$ & $0.22 \pm 0.02$ & $0.23 \pm 0.02$ & $0.25 \pm 0.02$ & $0.30 \pm 0.02$ & $0.32 \pm 0.02$ & $0.34 \pm 0.02$ & $0.33 \pm 0.02$ \\
\hline $18: 1(n-7)$ & $2.21 \pm 0.04$ & $2.22 \pm 0.03$ & $2.17 \pm 0.03$ & $2.11 \pm 0.03$ & $2.10 \pm 0.03$ & $2.03 \pm 0.03$ & $1.99 \pm 0.03$ \\
\hline $18: 1(n-9)$ & $7.91 \pm 0.16$ & $7.86 \pm 0.13$ & $8 \Omega 0+39.13$ & $8.29+5.13$ & $8.35 \pm 0.13$ & $8.51^{\prime} \pm 0.12$ & $8.54 \pm 0.15$ \\
\hline 20: $1(n-9)$ & $0.16 \pm 0.00$ & $0.17 \pm 0.00$ & $0.17 \pm 0.00$ & $0.17 \pm 0.00$ & $0.17 \pm 0.00$ & $0.16 \pm 0.00$ & $0.15 \pm 0.00$ \\
\hline $24: I(n-9)$ & $1.33 \pm 0.04$ & $1.33 \pm 0.03$ & $1.38 \pm 0.03$ & $1.39 \pm 0.03$ & $1.40 \pm 0.03$ & $1.41 \pm 0.03$ & $1.45 \pm 0.03$ \\
\hline ¿MUFA & $11.9 \pm 0.19$ & $11.9 \pm 0.15$ & $12.0 \pm 0.15$ & $12.3 \pm 0.15$ & $12.4 \pm 0.15$ & $12.5 \pm 0.15$ & $12.5 \pm 0.15$ \\
\hline $16: 0 \mathrm{dma}$ & $0.66 \pm 0.01$ & $0.61 \pm 0.01$ & $0.57 \pm 0.01$ & $0.54 \pm 0.01$ & $0.51 \pm 0.01$ & $0.48 \pm 0.01$ & $0.47 \pm 0.01$ \\
\hline 18:0 dma & $0.50 \pm 0.01$ & $0.46 \pm 0.01$ & $0.43 \pm 0.01$ & $0.42 \pm 0.01$ & $0.40 \pm 0.01$ & $0.39 \pm 0.01$ & $0.39 \pm 0.01$ \\
\hline 18:1 dma & $0.16 \pm 0.00$ & $0.16 \pm 0.00$ & $0.15 \pm 0.00$ & $0.14 \pm 0.00$ & $0.13 \pm 0.00$ & $0.12 \pm 0.00$ & $0.12 \pm 0.00$ \\
\hline $20: 3(n-9)$ & $0.26 \pm 0.01$ & $0.26 \pm 0.01$ & $0.27 \pm 0.01$ & $0.28 \pm 0.01$ & $0.29 \pm 0.01$ & $0.29 \pm 0.01$ & $0.30 \pm 0.01$ \\
\hline$\Sigma(n-7)+\Sigma(n-9)$ & $12.1 \pm 0.19$ & $12.2 \pm 0.16$ & $12.3 \pm 0.16$ & $12.6 \pm 0.16$ & $12.7 \pm 0.16$ & $12.8 \pm 0.16$ & $12.9 \pm 0.16$ \\
\hline $18: 2(n-6)$ & $22.1 \pm 0.29$ & $22.0 \pm 0.25$ & $21.9 \pm 0.25$ & $21.7 \pm 0.25$ & $21.7 \pm 0.25$ & $21.8 \pm 0.25$ & $21.9 \pm 0.25$ \\
\hline $20: 2(n-6)$ & $0.44 \pm 0.01$ & $0.48 \pm 0.01$ & $0.51 \pm 0.01$ & $0.53 \pm 0.01$ & $0.53 \neq 0.01$ & $0.51 \pm 0.01$ & $0.49 \pm 0.01$ \\
\hline $20: 3(n-6)$ & $2.91 \pm 0.06$ & $3.01 \pm 0.05$ & $3.09 \pm 0.05$ & $3.22 \pm 0.05$ & $3.28 \pm 0.05$ & $3.30 \pm 0.05$ & $3.27 \pm 0.05$ \\
\hline $20: 4(n-6)$ & $9.63 \pm 0.13$ & $9.26 \pm 0.12$ & $8.89 \pm 0.11$ & $8.51 \pm 0.11$ & $8.29 \pm 0.11$ & $8.10 \pm 0.11$ & $8.08 \pm 0.11$ \\
\hline $22: 4(n-6)$ & $0.39 \pm 0.01$ & $0.38 \pm 0.01$ & $0.38 \pm 0.01$ & $0.39 \pm 0.01$ & $0.38 \pm 0.01$ & $0.37 \pm 0.01$ & $0.36 \pm 0.01$ \\
\hline $22: 5(n-6)$ & $0.33 \pm 0.01$ & $0.37 \pm 0.01$ & $0.42 \pm 0.01$ & $0.44 \pm 0.01$ & $0.46 \pm 0.01$ & $0.46 \pm 0.01$ & $0.46 \pm 0.01$ \\
\hline $24: 2(n-6)$ & $0.19 \pm 0.01$ & $0.19 \pm 0.01$ & $0.20 \pm 0.01$ & $0.20 \pm 0.01$ & $0.21 \pm 0.01$ & $0.21 \pm 0.01$ & $0.21 \pm 0.01$ \\
\hline$\Sigma(n-6)$ & $36.0 \pm 0.24$ & $35.7 \pm 0.20$ & $35.4 \pm 0.20$ & $35.0 \pm 0.20$ & $34.9 \pm 0.20$ & $34.8 \pm 0.20$ & $34.8 \pm 0.20$ \\
\hline
\end{tabular}




\begin{tabular}{|c|c|c|c|c|c|c|c|}
\hline Fatty acid & 34 & 36 & 38 & 40 & $\mathrm{M}$ & $\mathrm{U}$ & $>0.5 \mathrm{yr}$ \\
\hline $14: 0$ & $0.32 \pm 0.01$ & $0.32 \pm 0.01$ & $0.33 \pm 0.01$ & $0.32 \pm 0.01$ & $0.30 \neq 0.01$ & $0.22 \pm 0.01$ & $0.28 \pm 0.01$ \\
\hline 15:0 & $0.19 \pm 0.01$ & $0.18 \pm 0.01$ & $0.18 \pm 0.01$ & $0.17 \pm 0.01$ & $0.19 \pm 0.01$ & $0.09 \pm 0.01$ & $0.16 \pm 0.01$ \\
\hline $16: 0$ & $29.7 \pm 0.12$ & $29.8 \pm 0.12$ & $29.9 \pm 0.12$ & $30.0 \pm 0.14$ & $30.7 \pm 0.13$ & $27.6 \pm 0.15$ & $26.6 \pm 0.27$ \\
\hline $18: 0$ & $10.0 \pm 0.07$ & $10.0 \pm 0.07$ & $10.1 \pm 0.07$ & $10.0 \pm 0.09$ & $9.65 \pm 0.08$ & $14.4 \pm 0.12$ & $12.3 \pm 0.18$ \\
\hline $20: 0$ & $0.53 \pm 0.01$ & $0.52 \pm 0.01$ & $0.51 \pm 0.01$ & $0.52 \pm 0.01$ & $0.53 \pm 0.01$ & $0.86 \pm 0.02$ & $0.49 \pm 0.01$ \\
\hline $22: 0$ & $1.51 \pm 0.03$ & $1.48 \pm 0.03$ & $1.45 \pm 0.03$ & $1.45 \pm 0.03$ & $1.50 \pm 0.03$ & $1.44 \pm 0.03$ & $1.63 \pm 0.05$ \\
\hline 23:0 & $0.55 \pm 0.01$ & $0.54 \pm 0.01$ & $0.53 \pm 0.01$ & $0.53 \pm 0.01$ & $0.55 \pm 0.01$ & $0.20 \pm 0.01$ & $0.55 \pm 0.02$ \\
\hline $24: 0$ & $0.89 \pm 0.02$ & $0.87 \pm 0.02$ & $0.86 \pm 0.02$ & $0.87 \pm 0.02$ & $0.90 \pm 0.02$ & $1.39 \pm 0.03$ & $1.11 \pm 0.04$ \\
\hline ¿SAFA & $43.7 \pm 0.11$ & $43.7 \pm 0.11$ & $43.9 \pm 0.12$ & $43.9 \pm 0.14$ & $44.4 \pm 0.11$ & $46.2 \pm 0.21$ & $43.1 \pm 0.16$ \\
\hline $16: 1(n-7)$ & $0.36 \pm 0.02$ & $0.42 \pm 0.02$ & $0.41 \pm 0.02$ & $0.41 \pm 0.02$ & $0.43 \pm 0.02$ & $0.52 \pm 0.02$ & $0.25 \pm 0.02$ \\
\hline $18: 1(n-7)$ & $2.00 \pm 0.03$ & $1.94 \pm 0.03$ & $1.86 \pm 0.03$ & $1.88 \pm 0.04$ & $1.92 \pm 0.03$ & $2.63 \pm 0.05$ & $2.14 \pm 0.05$ \\
\hline $18: 1(n-9)$ & $8.75 \pm 0.13$ & $9.05 \pm 0.13$ & $8.91 \pm 0.13$ & $9.02 \pm 0.17$ & $8.98 \pm 0.13$ & $7.26 \pm 0.24$ & $7.90 \pm 0.15$ \\
\hline $20: 1(n-9)$ & $0.15 \pm 0.00$ & $0.15 \pm 0.00$ & $0.15 \pm 0.00$ & $0.15 \pm 0.00$ & $0.14 \pm 0.00$ & $0.05 \pm 0.00$ & $0.16 \pm 0.01$ \\
\hline $24: 1(n-9)$ & $1.45 \pm 0.03$ & $1.41 \pm 0.03$ & $1.43 \pm 0.03$ & $1.45 \pm 0.04$ & $1.50 \pm 0.03$ & $2.06 \pm 0.04$ & $1.45 \pm 0.05$ \\
\hline EMUFA & $12.8 \pm 0.15$ & $13.0 \pm 0.15$ & $12.8 \pm 0.16$ & $13.0 \pm 0.20$ & $13.0 \pm 0.15$ & $12.6 \pm 0.29$ & $11.9 \pm 0.19$ \\
\hline $16: 0 \mathrm{dma}$ & $0.46 \pm 0.01$ & $0.47 \pm 0.01$ & $0.47 \pm 0.01$ & $0.46 \pm 0.01$ & $0.45 \pm 0.01$ & $0.64 \pm 0.02$ & $0.63 \pm 0.01$ \\
\hline $18: 0 \mathrm{dma}$ & $0.37 \pm 0.01$ & $0.38 \pm 0.01$ & $0.37 \pm 0.01$ & $0.37 \pm 0.01$ & $0.33 \pm 0.01$ & $0.22 \pm 0.01$ & $0.44 \pm 0.02$ \\
\hline 18:1 dma & $0.12 \pm 0.00$ & $0.12 \pm 0.00$ & $0.12 \pm 0.00$ & $0.11 \pm 0.01$ & $0.11 \pm 0.00$ & $0.03 \pm 0.00$ & $0.16 \pm 0.01$ \\
\hline $20: 3(n-9)$ & $0.31 \pm 0.01$ & $0.33 \pm 0.01$ & $0.33 \pm 0.01$ & $0.33 \pm 0.01$ & $0.35 \pm 0.01$ & $0.67 \pm 0.03$ & $0.37 \pm 0.02$ \\
\hline$\Sigma(n-7)+\Sigma(n-9)$ & $13.1 \pm 0.16$ & $13.4 \pm 0.16$ & $13.2 \pm 0.16$ & $13.3 \pm 0.20$ & $13.4 \pm 0.15$ & $13.3 \pm 0.30$ & $12.3 \pm 0.20$ \\
\hline $18: 2(n-6)$ & $21.8 \pm 0.25$ & $21.8 \pm 0.25$ & $21.9 \pm 0.26$ & $21.8 \pm 0.30$ & $20.9 \pm 0.23$ & $7.53 \pm 0.12$ & $22.8 \pm 0.32$ \\
\hline $20: 2(n-6)$ & $0.47 \pm 0.01$ & $0.46 \pm 0.01$ & $0.45 \pm 0.01$ & $0.46 \pm 0.01$ & $0.44 \pm 0.01$ & $0.37 \pm 0.01$ & $0.40 \pm 0.01$ \\
\hline $20: 3(n-6)$ & $3.26 \pm 0.05$ & $3.26 \pm 0.05$ & $3.23 \pm 0.05$ & $3.30 \pm 0.06$ & $3.35 \pm 0.06$ & $5.01 \pm 0.09$ & $2.84 \pm 0.09$ \\
\hline $20: 4(n-6)$ & $7.95 \pm 0.11$ & $7.93 \pm 0.11$ & $7.88 \pm 0.12$ & $7.84 \pm 0.13$ & $8.18 \pm 0.13$ & $16.2 \pm 0.14$ & $9.07 \pm 0.17$ \\
\hline $22: 4(n-6)$ & $0.36 \pm 0.01$ & $0.36 \pm 0.01$ & $0.36 \pm 0.01$ & $0.35 \pm 0.01$ & $0.35 \pm 0.01$ & $0.77 \pm 0.01$ & $0.32 \pm 0.01$ \\
\hline $22: 5(n-6)$ & $0.47 \pm 0.01$ & $0.49 \pm 0.01$ & $0.48 \pm 0.01$ & $0.49 \pm 0.01$ & $0.51 \pm 0.02$ & $0.86 \pm 0.02$ & $0.26 \pm 0.01$ \\
\hline $24: 2(n-6)$ & $0.21 \pm 0.01$ & $0.20 \pm 0.01$ & $0.20 \pm 0.01$ & $0.21 \pm 0.01$ & $0.21 \pm 0.01$ & $0.62 \pm 0.02$ & $0.14 \pm 0.01$ \\
\hline$\Sigma(n-6)$ & $34.5 \pm 0.20$ & $34.5 \pm 0.20$ & $34.6 \pm 0.21$ & $34.5 \pm 0.25$ & $34.0 \pm 0.19$ & $31.5 \pm 0.18$ & $36.0 \pm 0.25$ \\
\hline
\end{tabular}




\begin{tabular}{llllllll}
\hline Fatty acid & 10 & 14 & 18 & 22 & 26 & 30 & 32 \\
\hline $18: 3(n-3)$ & $0.27 \pm 0.01$ & $0.28 \pm 0.01$ & $0.29 \pm 0.01$ & $0.30 \pm 0.01$ & $0.29 \pm 0.01$ & $0.29 \pm 0.01$ & $0.29 \pm 0.01$ \\
$20: 4(\mathrm{n}-3)$ & $0.14 \pm 0.01$ & $0.14 \pm 0.01$ & $0.15 \pm 0.01$ & $0.16 \pm 0.01$ & $0.16 \pm 0.01$ & $0.15 \pm 0.01$ & $0.15 \pm 0.01$ \\
$20: 5(\mathrm{n}-3)$ & $0.50 \pm 0.04$ & $0.51 \pm 0.03$ & $0.46 \pm 0.03$ & $0.44 \pm 0.03$ & $0.44 \pm 0.03$ & $0.39 \pm 0.03$ & $0.36 \pm 0.03$ \\
$22: 5(\mathrm{n}-3)$ & $0.75 \pm 0.01$ & $0.68 \pm 0.01$ & $0.64 \pm 0.01$ & $0.63 \pm 0.01$ & $0.61 \pm 0.01$ & $0.58 \pm 0.01$ & $0.56 \pm 0.01$ \\
$22: 6(\mathrm{n}-3)$ & $3.79 \pm 0.09$ & $4.07 \pm 0.08$ & $4.16 \pm 0.08$ & $4.09 \pm 0.08$ & $4.06 \pm 0.08$ & $4.05 \pm 0.08$ & $3.97 \pm 0.08$ \\
$\Sigma(\mathrm{n}-3)$ & $5.50 \pm 0.12$ & $5.72 \pm 0.10$ & $5.73 \pm 0.10$ & $5.65 \pm 0.10$ & $5.59 \pm 0.10$ & $5.49 \pm 0.10$ & $5.35 \pm 0.10$ \\
\hline
\end{tabular}


Appendix B2 continued

\begin{tabular}{llllllll}
\hline Fatty acid & 34 & 36 & 38 & 40 & $\mathrm{M}$ & $\mathrm{U}$ & $>0.5 \mathrm{yr}$ \\
\hline $18: 3(\mathrm{n}-3)$ & $0.30 \pm 0.01$ & $0.29 \pm 0.01$ & $0.29 \pm 0.01$ & $0.28 \pm 0.01$ & $0.27 \pm 0.01$ & $0.11 \pm 0.01$ & $0.30 \pm 0.01$ \\
$20: 4(\mathrm{n}-3)$ & $0.16 \pm 0.01$ & $0.15 \pm 0.01$ & $0.16 \pm 0.01$ & $0.15 \pm 0.01$ & $0.15 \pm 0.01$ & $0.11 \pm 0.01$ & $0.15 \pm 0.01$ \\
$20: 5(\mathrm{n}-3)$ & $0.37 \pm 0.03$ & $0.34 \pm 0.03$ & $0.37 \pm 0.03$ & $0.35 \pm 0.04$ & $0.35 \pm 0.02$ & $0.23 \pm 0.01$ & $0.57 \pm 0.05$ \\
$22: 5(\mathrm{n}-3)$ & $0.54 \pm 0.01$ & $0.54 \pm 0.01$ & $0.53 \pm 0.01$ & $0.53 \pm 0.02$ & $0.53 \pm 0.01$ & $0.46 \pm 0.02$ & $0.68 \pm 0.02$ \\
$22: 6(\mathrm{n}-3)$ & $3.90 \pm 0.08$ & $3.80 \pm 0.08$ & $3.80 \pm 0.08$ & $3.84 \pm 0.09$ & $3.79 \pm 0.07$ & $6.10 \pm 0.14$ & $2.84 \pm 0.08$ \\
$\Sigma(n-3)$ & $5.30 \pm 0.10$ & $5.14 \pm 0.10$ & $5.16 \pm 0.11$ & $5.16 \pm 0.12$ & $5.10 \pm 0.10$ & $6.99 \pm 0.16$ & $4.50 \pm 0.10$ \\
\hline
\end{tabular}


Appendix $\mathrm{Cl}$. The fatty acid composition of maternal plasma phospholipids $(\mathrm{mg} / \mathrm{L})$ in normal pregnancy (NP) and pregnancy-induced hypertension (PIH) (mean \pm s.e.m.).

\begin{tabular}{|c|c|c|c|c|}
\hline Fatty acid & $\begin{array}{l}<16 \text { weeks } \\
(\text { sets }=49)\end{array}$ & $\begin{array}{l} \pm 22 \text { weeks } \\
\text { (sets }=47)\end{array}$ & $\begin{array}{l} \pm 32 \text { weeks } \\
\text { (sets=47) }\end{array}$ & $\begin{array}{l}\text { After delivery } \\
\text { (sets }=45)\end{array}$ \\
\hline $\begin{array}{r}14: 0 \quad \mathrm{NP} \\
\text { PIH }\end{array}$ & $\begin{array}{l}4.01 \pm 0.14 \\
4.41 \pm 0.24\end{array}$ & $\begin{array}{l}5.94 \pm 0.18 \\
6.34 \pm 0.41\end{array}$ & $\begin{array}{l}5.96 \pm 0.15 \\
6.44 \pm 0.36\end{array}$ & $\begin{array}{l}5.45 \pm 0.18 \\
5.07 \pm 0.36\end{array}$ \\
\hline $15: 0$ & $\begin{array}{l}2.57 \pm 0.08 \\
2.81 \pm 0.13\end{array}$ & $\begin{array}{l}3.34 \pm 0.09 \\
3.53 \pm 0.19\end{array}$ & $\begin{array}{l}3.28 \pm 0.07 \\
3.41 \pm 0.17\end{array}$ & $\begin{array}{l}3.11 \pm 0.08 \\
2.89 \pm 0.17\end{array}$ \\
\hline $16: 0$ & $\begin{array}{l}362.2 \pm 6.34 \\
373.4 \pm 10.1\end{array}$ & $\begin{array}{l}472.4 \pm 7.44 \\
497.4 \pm 15.2\end{array}$ & $\begin{array}{l}524.4 \pm 6.55 \\
561.7 \pm 14.0\end{array}$ & $\begin{array}{l}564.5 \pm 9.07 \\
567.0 \pm 20.5\end{array}$ \\
\hline 18:0 & $\begin{array}{l}155.8 \pm 2.28 \\
158.8 \pm 3.89\end{array}$ & $\begin{array}{l}170.0 \pm 2.35 \\
183.3 \pm 4.96\end{array}$ & $\begin{array}{l}175.6 \pm 2.13 \\
190.4 \pm 4.54\end{array}$ & $\begin{array}{l}173.9 \pm 3.04 \\
174.3 \pm 6.32\end{array}$ \\
\hline $20: 0$ & $\begin{array}{l}6.73 \pm 0.19 \\
6.96 \pm 0.28\end{array}$ & $\begin{array}{l}8.12 \pm 0.16 \\
8.12 \pm 0.27\end{array}$ & $\begin{array}{l}9.15 \pm 0.21 \\
9.11 \pm 0.31\end{array}$ & $\begin{array}{l}9.37 \pm 0.21 \\
8.71 \pm 0.32\end{array}$ \\
\hline $22: 0$ & $\begin{array}{l}20.6 \pm 0.36 \\
21.3 \pm 0.70\end{array}$ & $\begin{array}{l}24.8 \pm 0.43 \\
25.2 \pm 0.80\end{array}$ & $\begin{array}{l}26.8 \pm 0.49 \\
26.7 \pm 0.83\end{array}$ & $\begin{array}{l}27.2 \pm 0.58 \\
23.9 \pm 0.99\end{array}$ \\
\hline $23: 0$ & $\begin{array}{l}7.32 \pm 0.16 \\
7.97 \pm 0.33\end{array}$ & $\begin{array}{l}9.26 \pm 0.19 \\
9.70 \pm 0.43\end{array}$ & $\begin{array}{l}9.82 \pm 0.20 \\
10.2 \pm 0.37\end{array}$ & $\begin{array}{l}10.1 \pm 0.22 \\
9.03 \pm 0.42\end{array}$ \\
\hline $24: 0$ & $\begin{array}{l}13.9 \pm 0.35 \\
14.1 \pm 0.54\end{array}$ & $\begin{array}{l}16.4 \pm 0.38 \\
16.5 \pm 0.77\end{array}$ & $\begin{array}{l}17.1 \pm 0.37 \\
16.7 \pm 0.63\end{array}$ & $\begin{array}{l}17.0 \pm 0.39 \\
14.5 \pm 0.67\end{array}$ \\
\hline ¿SAFA & $\begin{array}{l}573.1 \pm 9.08 \\
589.7 \pm 14.5\end{array}$ & $\begin{array}{l}710.3 \pm 10.3 \\
750.0 \pm 21.3\end{array}$ & $\begin{array}{l}772.1 \pm 9.14 \\
824.7 \pm 18.9\end{array}$ & $\begin{array}{l}810.6 \pm 12.6 \\
805.4 \pm 27.9\end{array}$ \\
\hline $16: 1(n-7)$ & $\begin{array}{l}3.21 \pm 0.19 \\
3.34 \pm 0.20\end{array}$ & $\begin{array}{l}5.66 \pm 0.35 \\
6.16 \pm 0.64\end{array}$ & $\begin{array}{l}6.44 \pm 0.31 \\
8.23 \pm 0.91\end{array}$ & $\begin{array}{l}8.63 \pm 0.44 \\
9.84 \pm 0.93\end{array}$ \\
\hline $18: 1(n-7)$ & $\begin{array}{l}29.8 \pm 0.55 \\
29.8 \pm 0.97\end{array}$ & $\begin{array}{l}35.6 \pm 0.84 \\
36.7 \pm 1.22\end{array}$ & $\begin{array}{l}36.2 \pm 0.72 \\
37.4 \pm 1.10\end{array}$ & $\begin{array}{l}35.2 \pm 0.78 \\
35.6 \pm 1.47\end{array}$ \\
\hline $18: 1(n-9)$ & $\begin{array}{l}104.7 \pm 2.10 \\
106.8 \pm 3.58\end{array}$ & $\begin{array}{l}138.9 \pm 3.02 \\
144.0 \pm 6.67\end{array}$ & $\begin{array}{l}150.9 \pm 2.52 \\
163.0 \pm 6.53\end{array}$ & $\begin{array}{l}161.7 \pm 3.44 \\
163.8 \pm 8.10\end{array}$ \\
\hline $20: 1(n-9)$ & $\begin{array}{l}2.20 \pm 0.06 \\
2.34 \pm 0.12\end{array}$ & $\begin{array}{l}2.68 \pm 0.07 \\
2.84 \pm 0.11\end{array}$ & $\begin{array}{l}2.66 \pm 0.07 \\
2.72 \pm 0.08\end{array}$ & $\begin{array}{l}2.62 \pm 0.12 \\
2.43 \pm 0.09\end{array}$ \\
\hline $24: 1(n-9)$ & $\begin{array}{l}21.3 \pm 0.64 \\
22.4 \pm 0.90\end{array}$ & $\begin{array}{l}25.2 \pm 0.75 \\
26.7 \pm 1.12\end{array}$ & $\begin{array}{l}27.5 \pm 0.86 \\
28.3 \pm 1.04\end{array}$ & $\begin{array}{l}28.5 \pm 0.81 \\
29.2 \pm 1.23\end{array}$ \\
\hline ¿MUFA & $\begin{array}{l}161.9 \pm 2.91 \\
165.5 \pm 4.97\end{array}$ & $\begin{array}{l}208.8 \pm 4.17 \\
217.3 \pm 8.73\end{array}$ & $\begin{array}{l}224.6 \pm 3.34 \\
240.7 \pm 8.48\end{array}$ & $\begin{array}{l}237.8 \pm 4.47 \\
242.2 \pm 10.7\end{array}$ \\
\hline $16: 0 \mathrm{dma}$ & $\begin{array}{l}9.02 \pm 0.23 \\
8.96 \pm 0.29\end{array}$ & $\begin{array}{l}9.09 \pm 0.23 \\
9.51 \pm 0.34\end{array}$ & $\begin{array}{l}8.62 \pm 0.19 \\
9.45 \pm 0.30\end{array}$ & $\begin{array}{l}8.55 \pm 0.22 \\
8.20 \pm 0.28\end{array}$ \\
\hline $18: 0 \mathrm{dma}$ & $\begin{array}{l}6.30 \pm 0.20 \\
6.07 \pm 0.30\end{array}$ & $\begin{array}{l}6.05 \pm 0.19 \\
6.57 \pm 0.28\end{array}$ & $\begin{array}{l}5.85 \pm 0.18 \\
6.07 \pm 0.29\end{array}$ & $\begin{array}{l}5.05 \pm 0.18 \\
4.36 \pm 0.24\end{array}$ \\
\hline $18: 1 \mathrm{dma}$ & $\begin{array}{l}2.43 \pm 0.08 \\
2.42 \pm 0.12\end{array}$ & $\begin{array}{l}2.51 \pm 0.08 \\
2.46 \pm 0.12\end{array}$ & $\begin{array}{l}2.26 \pm 0.06 \\
2.28 \pm 0.11\end{array}$ & $\begin{array}{l}2.05 \pm 0.07 \\
1.76 \pm 0.11\end{array}$ \\
\hline
\end{tabular}




\begin{tabular}{|c|c|c|c|c|}
\hline Fatty acid & $\begin{array}{l}<16 \text { weeks } \\
(\text { sets }=49)\end{array}$ & $\begin{array}{l} \pm 22 \text { weeks } \\
(\text { sets }=47)\end{array}$ & $\begin{array}{l} \pm 32 \text { weeks } \\
(\text { sets }=47)\end{array}$ & $\begin{array}{l}\text { After delivery } \\
(\operatorname{set} s=45)\end{array}$ \\
\hline $20: 3(n-9)$ & $\begin{array}{l}3.69 \pm 0.13 \\
3.82 \pm 0.19\end{array}$ & $\begin{array}{l}4.94 \pm 0.20 \\
5.08 \pm 0.35\end{array}$ & $\begin{array}{l}5.69 \pm 0.20 \\
6.46 \pm 0.44\end{array}$ & $\begin{array}{l}6.61 \pm 0.27 \\
7.35 \pm 0.62\end{array}$ \\
\hline$\Sigma(n-7)+\Sigma(n-9)$ & $\begin{array}{l}166.2 \pm 3.00 \\
169.8 \pm 5.08\end{array}$ & $\begin{array}{l}214.3 \pm 4.28 \\
222.9 \pm 9.00\end{array}$ & $\begin{array}{l}230.8 \pm 3.42 \\
247.7 \pm 8.84\end{array}$ & $\begin{array}{l}244.8 \pm 4.64 \\
250.0 \pm 11.2\end{array}$ \\
\hline $18: 2(n-6)$ & $\begin{array}{l}283.2 \pm 5.38 \\
291.0 \pm 10.0\end{array}$ & $\begin{array}{l}345.0 \pm 5.40 \\
364.7 \pm 12.0\end{array}$ & $\begin{array}{l}375.8 \pm 4.81 \\
396.1 \pm 9.56\end{array}$ & $\begin{array}{l}372.7 \pm 7.62 \\
343.8 \pm 12.1\end{array}$ \\
\hline $20: 2(n-6)$ & $\begin{array}{l}6.31 \pm 0.16 \\
6.67 \pm 0.32\end{array}$ & $\begin{array}{l}8.76 \pm 0.20 \\
9.21 \pm 0.36\end{array}$ & $\begin{array}{l}8.58 \pm 0.16 \\
9.31 \pm 0.31\end{array}$ & $\begin{array}{l}8.13 \pm 0.19 \\
7.90 \pm 0.41\end{array}$ \\
\hline $20: 3(n-6)$ & $\begin{array}{l}41.0 \pm 1.11 \\
43.3 \pm 1.58\end{array}$ & $\begin{array}{l}54.7 \pm 1.40 \\
62.2 \pm 2.89\end{array}$ & $\begin{array}{l}58.8 \pm 1.32 \\
67.3 \pm 2.98\end{array}$ & $\begin{array}{l}63.0 \pm 1.59 \\
69.1 \pm 4.03\end{array}$ \\
\hline $20: 4(n-6)$ & $\begin{array}{l}129.1 \pm 2.51 \\
129.4 \pm 3.73\end{array}$ & $\begin{array}{l}142.3 \pm 2.64 \\
150.9 \pm 4.99\end{array}$ & $\begin{array}{l}144.0 \pm 2.41 \\
153.8 \pm 5.54\end{array}$ & $\begin{array}{l}152.9 \pm 3.00 \\
158.0 \pm 6.40\end{array}$ \\
\hline $22: 4(n-6)$ & $\begin{array}{l}5.55 \pm 0.15 \\
5.17 \pm 0.19\end{array}$ & $\begin{array}{l}6.75 \pm 0.16 \\
7.21 \pm 0.33\end{array}$ & $\begin{array}{l}6.80 \pm 0.14 \\
7.59 \pm 0.32\end{array}$ & $\begin{array}{l}7.10 \pm 0.19 \\
7.51 \pm 0.42\end{array}$ \\
\hline $22: 5(n-6)$ & $\begin{array}{l}5.00 \pm 0.19 \\
4.75 \pm 0.24\end{array}$ & $\begin{array}{l}7.82 \pm 0.21 \\
7.89 \pm 0.43\end{array}$ & $\begin{array}{l}8.86 \pm 0.26 \\
9.72 \pm 0.58\end{array}$ & $\begin{array}{l}9.97 \pm 0.33 \\
11.0 \pm 0.74\end{array}$ \\
\hline $24: 2(n-6)$ & $\begin{array}{l}2.41 \pm 0.10 \\
2.51 \pm 0.13\end{array}$ & $\begin{array}{l}2.73 \pm 0.12 \\
3.15 \pm 0.19\end{array}$ & $\begin{array}{l}3.15 \pm 0.16 \\
3.38 \pm 0.16\end{array}$ & $\begin{array}{l}3.29 \pm 0.15 \\
3.60 \pm 0.19\end{array}$ \\
\hline$\Sigma(n-6)$ & $\begin{array}{l}473.3 \pm 7.61 \\
483.5 \pm 13.4\end{array}$ & $\begin{array}{l}568.9 \pm 7.74 \\
606.1 \pm 16.1\end{array}$ & $\begin{array}{l}606.9 \pm 6.65 \\
648.2 \pm 13.9\end{array}$ & $\begin{array}{l}618.0 \pm 10.4 \\
602.0 \pm 20.8\end{array}$ \\
\hline $18: 3(n-3)$ & $\begin{array}{l}3.32 \pm 0.12 \\
3.51 \pm 0.22\end{array}$ & $\begin{array}{l}4.82 \pm 0.14 \\
5.10 \pm 0.34\end{array}$ & $\begin{array}{l}5.09 \pm 0.18 \\
5.37 \pm 0.30\end{array}$ & $\begin{array}{l}4.84 \pm 0.16 \\
3.89 \pm 0.30\end{array}$ \\
\hline $20: 4(n-3)$ & $\begin{array}{l}1.89 \pm 0.09 \\
2.00 \pm 0.11\end{array}$ & $\begin{array}{l}2.61 \pm 0.12 \\
2.94 \pm 0.25\end{array}$ & $\begin{array}{l}2.60 \pm 0.11 \\
3.02 \pm 0.22\end{array}$ & $\begin{array}{l}2.67 \pm 0.12 \\
2.63 \pm 0.25\end{array}$ \\
\hline $20: 5(n-3)$ & $\begin{array}{l}7.32 \pm 0.45 \\
7.97 \pm 0.59\end{array}$ & $\begin{array}{l}7.25 \pm 0.45 \\
8.16 \pm 0.69\end{array}$ & $\begin{array}{l}6.57 \pm 0.33 \\
6.86 \pm 0.59\end{array}$ & $\begin{array}{l}6.96 \pm 0.69 \\
5.87 \pm 0.44\end{array}$ \\
\hline $22: 5(n-3)$ & $\begin{array}{l}10.4 \pm 0.23 \\
10.2 \pm 0.36\end{array}$ & $\begin{array}{l}10.9 \pm 0.33 \\
11.7 \pm 0.63\end{array}$ & $\begin{array}{l}10.4 \pm 0.26 \\
11.1 \pm 0.48\end{array}$ & $\begin{array}{l}10.6 \pm 0.30 \\
10.8 \pm 0.69\end{array}$ \\
\hline $22: 6(n-3)$ & $\begin{array}{l}57.0 \pm 1.51 \\
60.2 \pm 2.04\end{array}$ & $\begin{array}{l}69.8 \pm 1.70 \\
73.3 \pm 2.70\end{array}$ & $\begin{array}{l}73.1 \pm 1.62 \\
78.3 \pm 2.56\end{array}$ & $\begin{array}{l}73.2 \pm 1.70 \\
78.3 \pm 2.74\end{array}$ \\
\hline$\sum(\mathbf{n}-3)$ & $\begin{array}{l}80.4 \pm 1.94 \\
84.6 \pm 2.53\end{array}$ & $\begin{array}{c}96.0 \pm 2.41 \\
101.9 \pm 4.04\end{array}$ & $\begin{array}{c}98.3 \pm 2.17 \\
105.3 \pm 3.47\end{array}$ & $\begin{array}{c}98.7 \pm 2.50 \\
101.9 \pm 3.83\end{array}$ \\
\hline
\end{tabular}


Appendix C2. The fatty acid composition of maternal plasma phospholipids ( $\%$ of total fatty acids) in normal pregnancy (NP) and pregnancy-induced hypertension (PIH) (mean \pm s.e.m.).

\begin{tabular}{|c|c|c|c|c|}
\hline Fatty acid & $\begin{array}{l}<16 \text { weeks } \\
(\text { sets }=49)\end{array}$ & $\begin{array}{l} \pm 22 \text { weeks } \\
(\text { sets }=47)\end{array}$ & $\begin{array}{l} \pm 32 \text { weeks } \\
(\text { sets }=47)\end{array}$ & $\begin{array}{l}\text { After delivery } \\
\text { (sets }=45)\end{array}$ \\
\hline $\begin{array}{r}\text { 14:0 NP } \\
\text { PIH }\end{array}$ & $\begin{array}{l}0.29 \pm 0.01 \\
0.31 \pm 0.01\end{array}$ & $\begin{array}{l}0.36 \pm 0.01 \\
0.35 \pm 0.01\end{array}$ & $\begin{array}{l}0.33 \pm 0.01 \\
0.34 \pm 0.01\end{array}$ & $\begin{array}{l}0.29 \pm 0.01 \\
0.27 \pm 0.01\end{array}$ \\
\hline $15: 0$ & $\begin{array}{l}0.19 \pm 0.00 \\
0.20 \pm 0.01\end{array}$ & $\begin{array}{l}0.20 \pm 0.00 \\
0.20 \pm 0.01\end{array}$ & $\begin{array}{l}0.19 \pm 0.00 \\
0.18 \pm 0.01\end{array}$ & $\begin{array}{l}0.17 \pm 0.00 \\
0.16 \pm 0.01\end{array}$ \\
\hline $16: 0$ & $\begin{array}{l}26.8 \pm 0.13 \\
26.9 \pm 0.20\end{array}$ & $\begin{array}{l}28.6 \pm 0.12 \\
28.5 \pm 0.20\end{array}$ & $\begin{array}{l}29.6 \pm 0.11 \\
29.8 \pm 0.16\end{array}$ & $\begin{array}{l}30.9 \pm 0.10 \\
31.3 \pm 0.16\end{array}$ \\
\hline $18: 0$ & $\begin{array}{l}11.6 \pm 0.09 \\
11.5 \pm 0.15\end{array}$ & $\begin{array}{l}10.3 \pm 0.07 \\
10.6 \pm 0.11\end{array}$ & $\begin{array}{l}9.94 \pm 0.07 \\
10.1 \pm 0.12\end{array}$ & $\begin{array}{l}9.51 \pm 0.09 \\
9.65 \pm 0.13\end{array}$ \\
\hline $20: 0$ & $\begin{array}{l}0.50 \pm 0.01 \\
0.50 \pm 0.02\end{array}$ & $\begin{array}{l}0.50 \pm 0.01 \\
0.47 \pm 0.01\end{array}$ & $\begin{array}{l}0.52 \pm 0.01 \\
0.49 \pm 0.02\end{array}$ & $\begin{array}{l}0.52 \pm 0.01 \\
0.49 \pm 0.02\end{array}$ \\
\hline $22: 0$ & $\begin{array}{l}1.54 \pm 0.02 \\
1.55 \pm 0.04\end{array}$ & $\begin{array}{l}1.51 \pm 0.02 \\
1.46 \pm 0.04\end{array}$ & $\begin{array}{l}1.52 \pm 0.02 \\
1.43 \pm 0.04\end{array}$ & $\begin{array}{l}1.49 \pm 0.02 \\
1.34 \pm 0.05\end{array}$ \\
\hline 23:0 & $\begin{array}{l}0.54 \pm 0.01 \\
0.58 \pm 0.02\end{array}$ & $\begin{array}{l}0.56 \pm 0.01 \\
0.56 \pm 0.02\end{array}$ & $\begin{array}{l}0.56 \pm 0.01 \\
0.54 \pm 0.02\end{array}$ & $\begin{array}{l}0.55 \pm 0.01 \\
0.50 \pm 0.02\end{array}$ \\
\hline $24: 0$ & $\begin{array}{l}1.03 \pm 0.02 \\
1.03 \pm 0.03\end{array}$ & $\begin{array}{l}0.99 \pm 0.02 \\
0.95 \pm 0.04\end{array}$ & $\begin{array}{l}0.97 \pm 0.02 \\
0.90 \pm 0.04\end{array}$ & $\begin{array}{l}0.93 \pm 0.02 \\
0.81 \pm 0.03\end{array}$ \\
\hline ¿SAFA & $\begin{array}{l}42.5 \pm 0.12 \\
42.7 \pm 0.17\end{array}$ & $\begin{array}{l}43.0 \pm 0.12 \\
43.0 \pm 0.17\end{array}$ & $\begin{array}{l}43.7 \pm 0.11 \\
43.7 \pm 0.12\end{array}$ & $\begin{array}{l}44.4 \pm 0.09 \\
44.5 \pm 0.14\end{array}$ \\
\hline $16: 1(n-7)$ & $\begin{array}{l}0.23 \pm 0.01 \\
0.24 \pm 0.01\end{array}$ & $\begin{array}{l}0.33 \pm 0.02 \\
0.33 \pm 0.03\end{array}$ & $\begin{array}{l}0.36 \pm 0.02 \\
0.42 \pm 0.04\end{array}$ & $\begin{array}{l}0.47 \pm 0.02 \\
0.52 \pm 0.04\end{array}$ \\
\hline $18: 1(n-7)$ & $\begin{array}{l}2.23 \pm 0.03 \\
2.16 \pm 0.05\end{array}$ & $\begin{array}{l}2.16 \pm 0.04 \\
2.11 \pm 0.05\end{array}$ & $\begin{array}{l}2.05 \pm 0.04 \\
1.99 \pm 0.04\end{array}$ & $\begin{array}{l}1.93 \pm 0.03 \\
1.97 \pm 0.04\end{array}$ \\
\hline $18: 1(n-9)$ & $\begin{array}{l}7.77 \pm 0.10 \\
7.68 \pm 0.13\end{array}$ & $\begin{array}{l}8.39 \pm 0.11 \\
8.13 \pm 0.18\end{array}$ & $\begin{array}{l}8.53 \pm 0.10 \\
8.55 \pm 0.18\end{array}$ & $\begin{array}{l}8.83 \pm 0.11 \\
8.93 \pm 0.21\end{array}$ \\
\hline $20: 1(n-9)$ & $\begin{array}{l}0.16 \pm 0.00 \\
0.17 \pm 0.01\end{array}$ & $\begin{array}{l}0.16 \pm 0.00 \\
0.17 \pm 0.01\end{array}$ & $\begin{array}{l}0.15 \pm 0.00 \\
0.15 \pm 0.00\end{array}$ & $\begin{array}{l}0.14 \pm 0.01 \\
0.14 \pm 0.00\end{array}$ \\
\hline $24: 1(n-9)$ & $\begin{array}{l}1.58 \pm 0.04 \\
1.63 \pm 0.05\end{array}$ & $\begin{array}{l}1.53 \pm 0.04 \\
1.54 \pm 0.06\end{array}$ & $\begin{array}{l}1.56 \pm 0.04 \\
1.52 \pm 0.06\end{array}$ & $\begin{array}{l}1.58 \pm 0.04 \\
1.65 \pm 0.07\end{array}$ \\
\hline$\Sigma$ MUFA. & $\begin{array}{l}12.0 \pm 0.11 \\
11.9 \pm 0.16\end{array}$ & $\begin{array}{l}12.6 \pm 0.13 \\
12.3 \pm 0.21\end{array}$ & $\begin{array}{l}12.7 \pm 0.11 \\
12.7 \pm 0.22\end{array}$ & $\begin{array}{l}13.0 \pm 0.13 \\
13.3 \pm 0.25\end{array}$ \\
\hline 16:0 dma & $\begin{array}{l}0.67 \pm 0.02 \\
0.65 \pm 0.02\end{array}$ & $\begin{array}{l}0.55 \pm 0.01 \\
0.55 \pm 0.01\end{array}$ & $\begin{array}{l}0.49 \pm 0.01 \\
0.50 \pm 0.01\end{array}$ & $\begin{array}{l}0.47 \pm 0.01 \\
0.46 \pm 0.01\end{array}$ \\
\hline $18: 0 \mathrm{dma}$ & $\begin{array}{l}0.47 \pm 0.01 \\
0.44 \pm 0.02\end{array}$ & $\begin{array}{l}0.37 \pm 0.01 \\
0.38 \pm 0.02\end{array}$ & $\begin{array}{l}0.33 \pm 0.01 \\
0.32 \pm 0.02\end{array}$ & $\begin{array}{l}0.28 \pm 0.01 \\
0.24 \pm 0.01\end{array}$ \\
\hline $18: 1 \mathrm{dma}$ & $\begin{array}{l}0.18 \pm 0.01 \\
0.18 \pm 0.01\end{array}$ & $\begin{array}{l}0.15 \pm 0.01 \\
0.14 \pm 0.01\end{array}$ & $\begin{array}{l}0.13 \pm 0.00 \\
0.12 \pm 0.01\end{array}$ & $\begin{array}{l}0.11 \pm 0.00 \\
0.10 \pm 0.01\end{array}$ \\
\hline
\end{tabular}




\begin{tabular}{|c|c|c|c|c|}
\hline Fatty acid & $\begin{array}{l}<16 \text { weeks } \\
(\text { sets }=49)\end{array}$ & $\begin{array}{l} \pm 22 \text { weeks } \\
\text { (sets }=47 \text { ) }\end{array}$ & $\begin{array}{l} \pm 32 \text { weeks } \\
(\text { sets }=47)\end{array}$ & $\begin{array}{l}\text { After delivery } \\
(s e t s=45)\end{array}$ \\
\hline $20: 3(n-9)$ & $\begin{array}{l}0.27 \pm 0.01 \\
0.28 \pm 0.01\end{array}$ & $\begin{array}{l}0.30 \pm 0.01 \\
0.29 \pm 0.02\end{array}$ & $\begin{array}{l}0.32 \pm 0.01 \\
0.34 \pm 0.02\end{array}$ & $\begin{array}{l}0.36 \pm 0.01 \\
0.39 \pm 0.03\end{array}$ \\
\hline$\Sigma(n-7)+\Sigma(n-9)$ & $\begin{array}{l}12.3 \pm 0.12 \\
12.2 \pm 0.16\end{array}$ & $\begin{array}{l}13.0 \pm 0.13 \\
12.7 \pm 0.21\end{array}$ & $\begin{array}{l}13.1 \pm 0.12 \\
13.0 \pm 0.23\end{array}$ & $\begin{array}{l}13.4 \pm 0.13 \\
13.7 \pm 0.27\end{array}$ \\
\hline $18: 2(n-6)$ & $\begin{array}{l}21.1 \pm 0.29 \\
21.0 \pm 0.36\end{array}$ & $\begin{array}{l}21.0 \pm 0.24 \\
21.0 \pm 0.46\end{array}$ & $\begin{array}{l}21.3 \pm 0.20 \\
21.2 \pm 0.42\end{array}$ & $\begin{array}{l}20.4 \pm 0.24 \\
19.1 \pm 0.35\end{array}$ \\
\hline $20: 2(n-6)$ & $\begin{array}{l}0.46 \pm 0.01 \\
0.48 \pm 0.01\end{array}$ & $\begin{array}{l}0.53 \pm 0.01 \\
0.53 \pm 0.02\end{array}$ & $\begin{array}{l}0.49 \pm 0.01 \\
0.49 \pm 0.01\end{array}$ & $\begin{array}{l}0.44 \pm 0.01 \\
0.43 \pm 0.01\end{array}$ \\
\hline $20: 3(n-6)$ & $\begin{array}{l}3.02 \pm 0.06 \\
3.12 \pm 0.08\end{array}$ & $\begin{array}{l}3.30 \pm 0.06 \\
3.54 \pm 0.11\end{array}$ & $\begin{array}{l}3.31 \pm 0.06 \\
3.54 \pm 0.11\end{array}$ & $\begin{array}{l}3.43 \pm 0.06 \\
3.74 \pm 0.13\end{array}$ \\
\hline $20: 4(n-6)$ & $\begin{array}{l}9.58 \pm 0.11 \\
9.39 \pm 0.17\end{array}$ & $\begin{array}{l}8.63 \pm 0.12 \\
8.71 \pm 0.20\end{array}$ & $\begin{array}{l}8.14 \pm 0.11 \\
8.14 \pm 0.19\end{array}$ & $\begin{array}{l}8.37 \pm 0.12 \\
8.80 \pm 0.22\end{array}$ \\
\hline $22: 4(n-6)$ & $\begin{array}{l}0.41 \pm 0.01 \\
0.37 \pm 0.01\end{array}$ & $\begin{array}{l}0.41 \pm 0.01 \\
0.41 \pm 0.01\end{array}$ & $\begin{array}{l}0.38 \pm 0.01 \\
0.40 \pm 0.01\end{array}$ & $\begin{array}{l}0.39 \pm 0.01 \\
0.41 \pm 0.01\end{array}$ \\
\hline $22: 5(\mathrm{n}-6)$ & $\begin{array}{l}0.37 \pm 0.01 \\
0.34 \pm 0.01\end{array}$ & $\begin{array}{l}0.47 \pm 0.01 \\
0.45 \pm 0.02\end{array}$ & $\begin{array}{l}0.50 \pm 0.01 \\
0.51 \pm 0.02\end{array}$ & $\begin{array}{l}0.54 \pm 0.02 \\
0.60 \pm 0.03\end{array}$ \\
\hline $24: 2(n-6)$ & $\begin{array}{l}0.18 \pm 0.01 \\
0.18 \pm 0.01\end{array}$ & $\begin{array}{l}0.17 \pm 0.01 \\
0.18 \pm 0.01\end{array}$ & $\begin{array}{l}0.18 \pm 0.01 \\
0.18 \pm 0.01\end{array}$ & $\begin{array}{l}0.18 \pm 0.01 \\
0.20 \pm 0.01\end{array}$ \\
\hline$\Sigma(n-6)$ & $\begin{array}{l}35.1 \pm 0.20 \\
34.9 \pm 0.25\end{array}$ & $\begin{array}{l}34.5 \pm 0.18 \\
34.9 \pm 0.30\end{array}$ & $\begin{array}{l}34.4 \pm 0.15 \\
34.5 \pm 0.29\end{array}$ & $\begin{array}{l}33.8 \pm 0.16 \\
33.3 \pm 0.30\end{array}$ \\
\hline $18: 3(\mathrm{n}-3)$ & $\begin{array}{l}0.25 \pm 0.01 \\
0.25 \pm 0.01\end{array}$ & $\begin{array}{l}0.29 \pm 0.01 \\
0.29 \pm 0.02\end{array}$ & $\begin{array}{l}0.29 \pm 0.01 \\
0.28 \pm 0.01\end{array}$ & $\begin{array}{l}0.26 \pm 0.01 \\
0.21 \pm 0.01\end{array}$ \\
\hline $20: 4(n-3)$ & $\begin{array}{l}0.14 \pm 0.01 \\
0.14 \pm 0.01\end{array}$ & $\begin{array}{l}0.16 \pm 0.01 \\
0.16 \pm 0.01\end{array}$ & $\begin{array}{l}0.15 \pm 0.01 \\
0.16 \pm 0.01\end{array}$ & $\begin{array}{l}0.14 \pm 0.01 \\
0.14 \pm 0.01\end{array}$ \\
\hline $20: 5(n-3)$ & $\begin{array}{l}0.55 \pm 0.03 \\
0.59 \pm 0.49\end{array}$ & $\begin{array}{l}0.43 \pm 0.02 \\
0.46 \pm 0.03\end{array}$ & $\begin{array}{l}0.37 \pm 0.02 \\
0.37 \pm 0.03\end{array}$ & $\begin{array}{l}0.38 \pm 0.04 \\
0.32 \pm 0.02\end{array}$ \\
\hline $22: 5(n-3)$ & $\begin{array}{l}0.77 \pm 0.02 \\
0.74 \pm 0.02\end{array}$ & $\begin{array}{l}0.65 \pm 0.01 \\
0.66 \pm 0.02\end{array}$ & $\begin{array}{l}0.59 \pm 0.01 \\
0.58 \pm 0.02\end{array}$ & $\begin{array}{l}0.57 \pm 0.01 \\
0.59 \pm 0.02\end{array}$ \\
\hline $22: 6(n-3)$ & $\begin{array}{l}4.21 \pm 0.08 \\
4.36 \pm 0.12\end{array}$ & $\begin{array}{l}4.22 \pm 0.08 \\
4.24 \pm 0.12\end{array}$ & $\begin{array}{l}4.13 \pm 0.07 \\
4.18 \pm 0.11\end{array}$ & $\begin{array}{l}4.00 \pm 0.08 \\
4.391 \pm 0.11\end{array}$ \\
\hline$\Sigma(n-3)$ & $\begin{array}{l}5.95 \pm 0.11 \\
6.14 \pm 0.14\end{array}$ & $\begin{array}{l}5.80 \pm 0.10 \\
5.85 \pm 0.16\end{array}$ & $\begin{array}{l}5.55 \pm 0.10 \\
5.59 \pm 0.14\end{array}$ & $\begin{array}{l}5.391 \pm 0.11 \\
5.67 \pm 0.12\end{array}$ \\
\hline
\end{tabular}


Appendix C3. The fatty acid composition ( $\mathrm{mg} / \mathrm{L}$ plasma or $\mathrm{mg} / \mathrm{g}$ dry tissue) of phospholipids isolated from umbilical cord in normal pregnancy (NP) and pregnancy-induced hypertension (PIH) (mean \pm s.e.m.).

\begin{tabular}{|c|c|c|c|}
\hline Fatty acid & $\begin{array}{l}\text { Venous plasma } \\
\text { (sets }=44 \text { ) }\end{array}$ & $\begin{array}{l}\text { Venous vessel wall } \\
\text { (sets }=43 \text { ) }\end{array}$ & $\begin{array}{l}\text { Arterial vessel wall } \\
\text { (sets }=43 \text { ) }\end{array}$ \\
\hline $\begin{array}{r}14: 0 \text { NP } \\
\text { PIH }\end{array}$ & $\begin{array}{l}1.39 \pm 0.09 \\
1.32 \pm 0.09\end{array}$ & $\begin{array}{l}0.17 \pm 0.01 \\
0.17 \pm 0.01\end{array}$ & $\begin{array}{l}0.18 \pm 0.01 \\
0.20 \pm 0.01\end{array}$ \\
\hline $15: 0$ & $\begin{array}{l}0.61 \pm 0.05 \\
0.65 \pm 0.06\end{array}$ & $\begin{array}{l}0.11 \pm 0.00 \\
0.12 \pm 0.00\end{array}$ & $\begin{array}{l}0.10 \pm 0.00 \\
0.11 \pm 0.00\end{array}$ \\
\hline $16: 0$ & $\begin{array}{l}165.7 \pm 3.13 \\
164.5 \pm 5.05\end{array}$ & $\begin{array}{l}4.30 \pm 0.06 \\
4.37 \pm 0.08\end{array}$ & $\begin{array}{l}3.76 \pm 0.07 \\
3.83 \pm 0.09\end{array}$ \\
\hline $17: 0$ & $\begin{array}{l}\text { nd } \\
\text { nd }\end{array}$ & $\begin{array}{l}0.16 \pm 0.00 \\
0.17 \pm 0.01\end{array}$ & $\begin{array}{l}0.14 \pm 0.00 \\
0.14 \pm 0.00\end{array}$ \\
\hline $18: 0$ & $\begin{array}{l}84.8 \pm 1.53 \\
85.0 \pm 2.77\end{array}$ & $\begin{array}{l}2.12 \pm 0.03 \\
2.04 \pm 0.04\end{array}$ & $\begin{array}{l}2.06 \pm 0.04 \\
2.05 \pm 0.05\end{array}$ \\
\hline $20: 0$ & $\begin{array}{l}5.01 \pm 0.15 \\
4.70 \pm 0.23\end{array}$ & $\begin{array}{l}0.06 \pm 0.00 \\
0.07 \pm 0.00\end{array}$ & $\begin{array}{l}0.07 \pm 0.00 \\
0.07 \pm 0.00\end{array}$ \\
\hline $22: 0$ & $\begin{array}{l}8.87 \pm 0.22 \\
8.08 \pm 0.40\end{array}$ & $\begin{array}{l}0.17 \pm 0.01 \\
0.16 \pm 0.01\end{array}$ & $\begin{array}{l}0.22 \pm 0.01 \\
0.22 \pm 0.01\end{array}$ \\
\hline 23:0 & $\begin{array}{l}1.19 \pm 0.06 \\
1.25 \pm 0.08\end{array}$ & $\begin{array}{l}\text { nd } \\
\text { nd }\end{array}$ & $\begin{array}{l}\text { nd } \\
\text { nd }\end{array}$ \\
\hline $24: 0$ & $\begin{array}{l}8.90 \pm 0.24 \\
8.17 \pm 0.42\end{array}$ & $\begin{array}{l}0.32 \pm 0.01 \\
0.30 \pm 0.01\end{array}$ & $\begin{array}{l}0.40 \pm 0.01 \\
0.40 \pm 0.02\end{array}$ \\
\hline ¿SAFA & $\begin{array}{l}276.4 \pm 4.94 \\
272.6 \pm 8.30\end{array}$ & $\begin{array}{l}7.41 \pm 0.11 \\
7.40 \pm 0.13\end{array}$ & $\begin{array}{l}6.93 \pm 0.13 \\
7.03 \pm 0.17\end{array}$ \\
\hline $16: 1(n-7)$ & $\begin{array}{l}2.86 \pm 0.13 \\
2.94 \pm 0.27\end{array}$ & $\begin{array}{l}0.07 \pm 0.00 \\
0.08 \pm 0.00\end{array}$ & $\begin{array}{l}0.06 \pm 0.00 \\
0.07 \pm 0.00\end{array}$ \\
\hline $18: 1(n-7)$ & $\begin{array}{l}15.9 \pm 0.36 \\
16.2 \pm 0.67\end{array}$ & $\begin{array}{l}0.36 \pm 0.01 \\
0.38 \pm 0.11\end{array}$ & $\begin{array}{l}0.41 \pm 0.01 \\
0.42 \pm 0.01\end{array}$ \\
\hline $18: 1(n-9)$ & $\begin{array}{l}39.3 \pm 1.09 \\
38.3 \pm 1.61\end{array}$ & $\begin{array}{l}1.21 \pm 0.02 \\
1.27 \pm 0.04\end{array}$ & $\begin{array}{l}1.58 \pm 0.04 \\
1.69 \pm 0.06\end{array}$ \\
\hline $20: 1(n-9)$ & $\begin{array}{l}0.31 \pm 0.01 \\
0.29 \pm 0.02\end{array}$ & $\begin{array}{l}0.05 \pm 0.00 \\
0.05 \pm 0.00\end{array}$ & $\begin{array}{l}0.07 \pm 0.00 \\
0.08 \pm 0.00\end{array}$ \\
\hline $24: 1(n-9)$ & $\begin{array}{l}13.1 \pm 0.32 \\
12.5 \pm 0.59\end{array}$ & $\begin{array}{l}0.59 \pm 0.02 \\
0.58 \pm 0.03\end{array}$ & $\begin{array}{l}0.64 \pm 0.02 \\
0.63 \pm 0.03\end{array}$ \\
\hline ¿MUFA & $\begin{array}{l}71.8 \pm 1.67 \\
70.4 \pm 2.79\end{array}$ & $\begin{array}{l}2.29 \pm 0.04 \\
2.38 \pm 0.07\end{array}$ & $\begin{array}{l}2.78 \pm 0.06 \\
2.89 \pm 0.09\end{array}$ \\
\hline $16: 0 \mathrm{dma}$ & $\begin{array}{l}4.29 \pm 0.17 \\
4.09 \pm 0.21\end{array}$ & $\begin{array}{l}\text { nd } \\
\text { nd }\end{array}$ & $\begin{array}{l}\text { nd } \\
\text { nd }\end{array}$ \\
\hline 18:0 dma & $\begin{array}{l}1.24 \pm 0.10 \\
1.00 \pm 0.11\end{array}$ & $\begin{array}{l}\text { nd } \\
\text { nd }\end{array}$ & $\begin{array}{l}\text { nd } \\
\text { nd }\end{array}$ \\
\hline
\end{tabular}




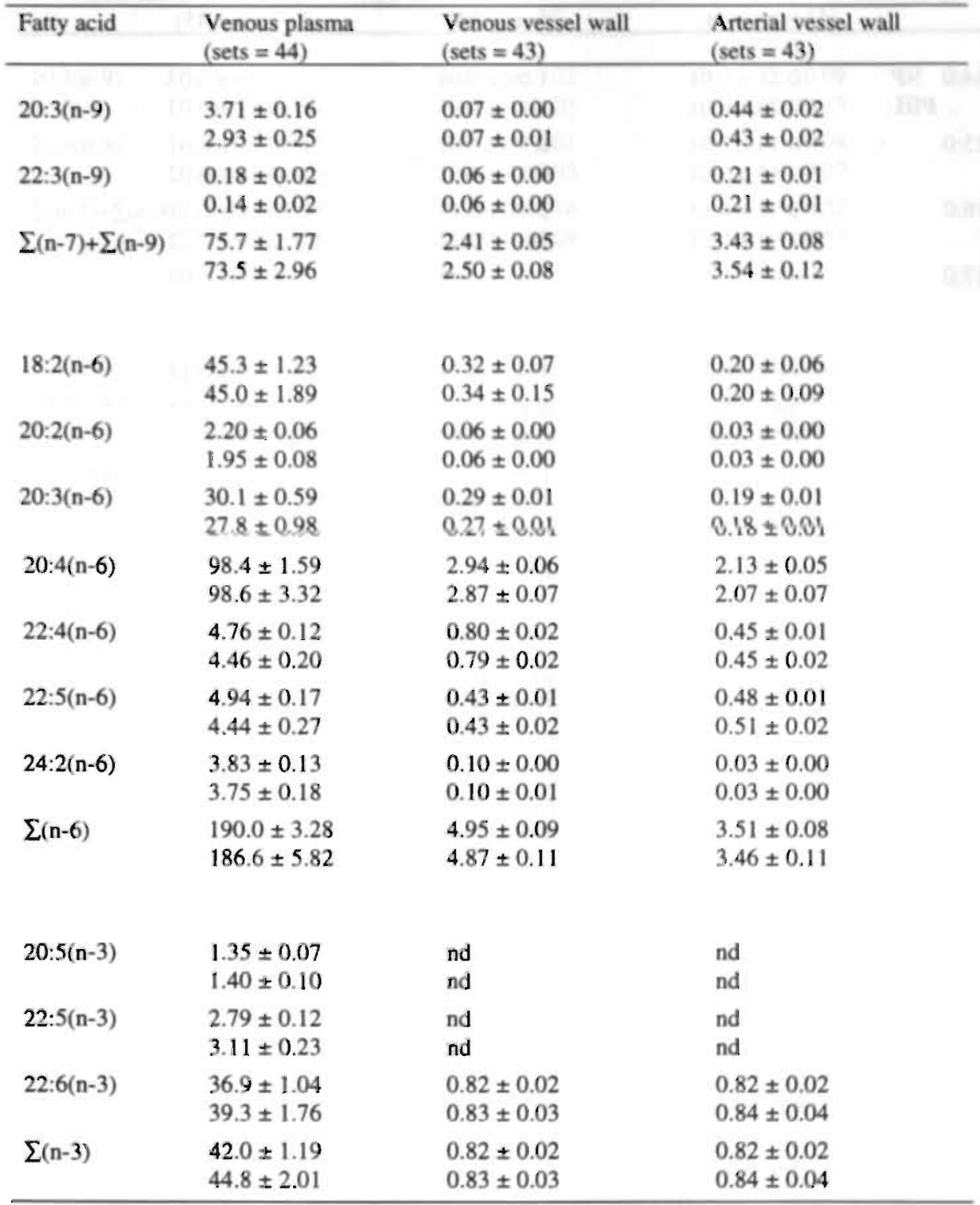


Appendix C4. The fatty acid composition (\% of total fatty acids) of phospholipids isolated from umbilical cord in normal pregnancy (NP) and pregnancy-induced hypertension (PIH) (mean \pm s.e.m.).

\begin{tabular}{|c|c|c|c|}
\hline Fatty acid & $\begin{array}{l}\text { Venous plasma } \\
(\text { sets }=44)\end{array}$ & $\begin{array}{l}\text { Venous vessel wall } \\
(\text { sets }=45)\end{array}$ & $\begin{array}{l}\text { Arterial vessel wall } \\
(\text { sets }=45)\end{array}$ \\
\hline $\begin{array}{r}14: 0 \text { NP } \\
\text { PIH }\end{array}$ & $\begin{array}{l}0.23 \pm 0.01 \\
0.22 \pm 0.01\end{array}$ & $\begin{array}{l}1.09 \pm 0.04 \\
1.11 \pm 0.05\end{array}$ & $\begin{array}{l}1.26 \pm 0.03 \\
1.37 \pm 0.07\end{array}$ \\
\hline $15: 0$ & $\begin{array}{l}0.10 \pm 0.01 \\
0.11 \pm 0.01\end{array}$ & $\begin{array}{l}0.73 \pm 0.02 \\
0.75 \pm 0.02\end{array}$ & $\begin{array}{l}0.71 \pm 0.01 \\
0.74 \pm 0.02\end{array}$ \\
\hline $16: 0$ & $\begin{array}{l}27.7 \pm 0.15 \\
27.9 \pm 0.21\end{array}$ & $\begin{array}{l}27.7 \pm 0.17 \\
28.1 \pm 0.22\end{array}$ & $\begin{array}{l}25.6 \pm 0.11 \\
25.9 \pm 0.22\end{array}$ \\
\hline $17: 0$ & $\begin{array}{l}\text { nd } \\
\text { nd }\end{array}$ & $\begin{array}{l}1.06 \pm 0.02 \\
1.07 \pm 0.03\end{array}$ & $\begin{array}{l}0.97 \pm 0.02 \\
0.95 \pm 0.03\end{array}$ \\
\hline 18:0 & $\begin{array}{l}14.2 \pm 0.11 \\
14.2 \pm 0.17\end{array}$ & $\begin{array}{l}13.6 \pm 0.10 \\
13.1 \pm 0.14\end{array}$ & $\begin{array}{l}14.0 \pm 0.09 \\
13.8 \pm 0.13\end{array}$ \\
\hline $20: 0$ & $\begin{array}{l}0.84 \pm 0.02 \\
0.79 \pm 0.03\end{array}$ & $\begin{array}{l}0.41 \pm 0.01 \\
0.44 \pm 0.04\end{array}$ & $\begin{array}{l}0.48 \pm 0.02 \\
0.50 \pm 0.03\end{array}$ \\
\hline $22: 0$ & $\begin{array}{l}1.48 \pm 0.03 \\
1.36 \pm 0.05\end{array}$ & $\begin{array}{l}1.08 \pm 0.03 \\
1.05 \pm 0.03\end{array}$ & $\begin{array}{l}1.46 \pm 0.03 \\
1.45 \pm 0.04\end{array}$ \\
\hline $23: 0$ & $\begin{array}{l}0.20 \pm 0.01 \\
0.21 \pm 0.01\end{array}$ & $\begin{array}{l}\text { nd } \\
\text { nd }\end{array}$ & $\begin{array}{l}\text { nd } \\
\text { nd }\end{array}$ \\
\hline $24: 0$ & $\begin{array}{l}1.49 \pm 0.03 \\
1.38 \pm 0.06\end{array}$ & $\begin{array}{l}2.04 \pm 0.05 \\
1.94 \pm 0.06\end{array}$ & $\begin{array}{l}2.70 \pm 0.06 \\
2.70 \pm 0.08\end{array}$ \\
\hline ¿SAFA & $\begin{array}{l}46.3 \pm 0.14 \\
46.2 \pm 0.21\end{array}$ & $\begin{array}{l}47.7 \pm 0.21 \\
47.6 \pm 0.29\end{array}$ & $\begin{array}{l}47.2 \pm 0.17 \\
47.4 \pm 0.33\end{array}$ \\
\hline $16: i(n-7)$ & $\begin{array}{l}0.48 \pm 0.02 \\
0.49 \pm 0.04\end{array}$ & $\begin{array}{l}0.46 \pm 0.01 \\
0.52 \pm 0.03\end{array}$ & $\begin{array}{l}0.43 \pm 0.01 \\
0.47 \pm 0.03\end{array}$ \\
\hline $18: 1(n-7)$ & $\begin{array}{l}2.66 \pm 0.04 \\
2.74 \pm 0.07\end{array}$ & $\begin{array}{l}2.34 \pm 0.03 \\
2.44 \pm 0.05\end{array}$ & $\begin{array}{l}2.81 \pm 0.04 \\
2.83 \pm 0.06\end{array}$ \\
\hline $18: 1(n-9)$ & $\begin{array}{l}6.59 \pm 0.13 \\
6.55 \pm 0.27\end{array}$ & $\begin{array}{l}7.72 \pm 0.08 \\
8.09 \pm 0.15\end{array}$ & $\begin{array}{l}10.7 \pm 0.16 \\
11.3 \pm 0.28\end{array}$ \\
\hline $20: 1(n-9)$ & $\begin{array}{l}0.05 \pm 0.00 \\
0.05 \pm 0.00\end{array}$ & $\begin{array}{l}0.30 \pm 0.01 \\
0.31 \pm 0.02\end{array}$ & $\begin{array}{l}0.50 \pm 0.01 \\
0.52 \pm 0.02\end{array}$ \\
\hline $24: 1(n-9)$ & $\begin{array}{l}2.19 \pm 0.03 \\
2.10 \pm 0.07\end{array}$ & $\begin{array}{l}3.75 \pm 0.09 \\
3.72 \pm 0.12\end{array}$ & $\begin{array}{l}4.33 \pm 0.10 \\
4.21 \pm 0.13\end{array}$ \\
\hline ¿MUFA & $\begin{array}{l}12.0 \pm 0.16 \\
12.0 \pm 0.33\end{array}$ & $\begin{array}{l}14.7 \pm 0.14 \\
15.2 \pm 0.25\end{array}$ & $\begin{array}{l}18.9 \pm 0.22 \\
19.4 \pm 0.38\end{array}$ \\
\hline $16: 0 \mathrm{dma}$ & $\begin{array}{l}0.71 \pm 0.02 \\
0.68 \pm 0.03\end{array}$ & $\begin{array}{l}\text { nd } \\
\text { nd }\end{array}$ & $\begin{array}{l}\text { nd } \\
\text { nd }\end{array}$ \\
\hline 18:0 dma & $\begin{array}{l}0.20 \pm 0.01 \\
0.17 \pm 0.02\end{array}$ & $\begin{array}{l}\text { nd } \\
\text { nd }\end{array}$ & $\begin{array}{l}\text { nd } \\
\text { nd }\end{array}$ \\
\hline
\end{tabular}




\begin{tabular}{|c|c|c|c|}
\hline Fatty acid & $\begin{array}{l}\text { Venous plasma } \\
(\text { sets }=44)\end{array}$ & $\begin{array}{l}\text { Venous vessel wall } \\
\text { (sets }=45 \text { ) }\end{array}$ & $\begin{array}{l}\text { Arterial vessel wall } \\
(\text { sets }=45)\end{array}$ \\
\hline $20: 3(n-9)$ & $\begin{array}{l}0.62 \pm 0.03 \\
0.50 \pm 0.04\end{array}$ & $\begin{array}{l}0.43 \pm 0.02 \\
0.42 \pm 0.03\end{array}$ & $\begin{array}{l}3.00 \pm 0.09 \\
2.91 \pm 0.13\end{array}$ \\
\hline $22: 3(n-9)$ & $\begin{array}{l}0.03 \pm 0.00 \\
0.02 \pm 0.00\end{array}$ & $\begin{array}{l}0.35 \pm 0.01 \\
0.36 \pm 0.03\end{array}$ & $\begin{array}{l}1.46 \pm 0.04 \\
1.40 \pm 0.07\end{array}$ \\
\hline$\Sigma(n-7)+\Sigma(n-9)$ & $\begin{array}{l}12.7 \pm 0.18 \\
12.5 \pm 0.36\end{array}$ & $\begin{array}{l}15.4 \pm 0.16 \\
16.0 \pm 0.29\end{array}$ & $\begin{array}{l}23.3 \pm 0.32 \\
23.7 \pm 0.53\end{array}$ \\
\hline & & & \\
\hline $18: 2(n-6)$ & $\begin{array}{l}7.55 \pm 0.11 \\
7.66 \pm 0.22\end{array}$ & $\begin{array}{l}2.04 \pm 0.04 \\
2.18 \pm 0.09\end{array}$ & $\begin{array}{l}1.37 \pm 0.04 \\
1.33 \pm 0.06\end{array}$ \\
\hline $20: 2(n-6)$ & $\begin{array}{l}0.37 \pm 0.01 \\
0.33 \pm 0.01\end{array}$ & $\begin{array}{l}0.38 \pm 0.01 \\
0.41 \pm 0.02\end{array}$ & $\begin{array}{l}0.20 \pm 0.01 \\
0.19 \pm 0.01\end{array}$ \\
\hline $20: 3(n-6)$ & $\begin{array}{l}5.05 \pm 0.07 \\
4.74 \pm 0.13\end{array}$ & $\begin{array}{l}1.86 \pm 0.03 \\
1.76 \pm 0.05\end{array}$ & $\begin{array}{l}1.30 \pm 0.02 \\
1.23 \pm 0.04\end{array}$ \\
\hline $20: 4(n-6)$ & $\begin{array}{l}16.5 \pm 0.13 \\
16.7 \pm 0.18\end{array}$ & $\begin{array}{l}18.8 \pm 0.18 \\
18.4 \pm 0.24\end{array}$ & $\begin{array}{l}14.5 \pm 0.20 \\
13.9 \pm 0.32\end{array}$ \\
\hline $22: 4(n-6)$ & $\begin{array}{l}0.80 \pm 0.02 \\
0.76 \pm 0.03\end{array}$ & $\begin{array}{l}5.16 \pm 0.08 \\
5.08 \pm 0.13\end{array}$ & $\begin{array}{l}3.02 \pm 0.06 \\
3.01 \pm 0.10\end{array}$ \\
\hline $22: 5(n-6)$ & $\begin{array}{l}0.82 \pm 0.02 \\
0.75 \pm 0.04\end{array}$ & $\begin{array}{l}2.73 \pm 0.06 \\
2.75 \pm 0.10\end{array}$ & $\begin{array}{l}3.25 \pm 0.06 \\
3.40 \pm 0.10\end{array}$ \\
\hline $24: 2(n-6)$ & $\begin{array}{l}0.64 \pm 0.02 \\
0.64 \pm 0.03\end{array}$ & $\begin{array}{l}0.62 \pm 0.02 \\
0.62 \pm 0.03\end{array}$ & $\begin{array}{l}0.18 \pm 0.01 \\
0.18 \pm 0.01\end{array}$ \\
\hline$\Sigma(n-6)$ & $\begin{array}{l}31.8 \pm 0.16 \\
31.7 \pm 0.28\end{array}$ & $\begin{array}{l}31.6 \pm 0.23 \\
31.2 \pm 0.28\end{array}$ & $\begin{array}{l}23.9 \pm 0.30 \\
23.3 \pm 0.45\end{array}$ \\
\hline $20: 5(n-3)$ & $\begin{array}{l}0.23 \pm 0.01 \\
0.24 \pm 0.02\end{array}$ & $\begin{array}{l}\text { nd } \\
\text { nd }\end{array}$ & $\begin{array}{l}\text { nd } \\
\text { nd }\end{array}$ \\
\hline $22: 5(n-3)$ & $\begin{array}{l}0.47 \pm 0.02 \\
0.52 \pm 0.03\end{array}$ & $\begin{array}{l}\text { nd } \\
\text { nd }\end{array}$ & $\begin{array}{l}\text { nd } \\
\text { nd }\end{array}$ \\
\hline $22: 6(n-3)$ & $\begin{array}{l}6.18 \pm 0.14 \\
6.65 \pm 0.22\end{array}$ & $\begin{array}{l}5.24 \pm 0.09 \\
5.28 \pm 0.14\end{array}$ & $\begin{array}{l}5.61 \pm 0.11 \\
5.57 \pm 0.15\end{array}$ \\
\hline$\sum(n-3)$ & $\begin{array}{l}7.05 \pm 0.16 \\
7.59 \pm 0.25\end{array}$ & $\begin{array}{l}5.24 \pm 0.09 \\
5.28 \pm 0.14\end{array}$ & $\begin{array}{l}5.61 \pm 0.11 \\
5.57 \pm 0.15\end{array}$ \\
\hline
\end{tabular}


Appendix D1. The fatty acid composition of umbilical plasma phospholipids (mg/L) $\frac{\mathrm{Y}}{2}$.

\begin{tabular}{|c|c|c|c|}
\hline Fatty acid & $\begin{array}{l}\text { LL-control } \\
(n=22)\end{array}$ & $\begin{array}{l}\text { LA supplemented } \\
(\mathrm{n}=21)\end{array}$ & $\begin{array}{l}\text { HL-control } \\
(\mathrm{n}=21)\end{array}$ \\
\hline $14: 0$ & $1.35 \pm 0.15$ & $1.62 \pm 0.11$ & $1.04 \pm 0.17$ \\
\hline $15: 0$ & $0.43 \pm 0.10$ & $0.66 \pm 0.05$ & $0.41 \pm 0.07$ \\
\hline $16: 0$ & $169.9 \pm 8.11$ & $181.4 \pm 7.23$ & $163.7 \pm 9.20$ \\
\hline $18: 0$ & $87.8 \pm 4.56$ & $92.4 \pm 3.14$ & $81.3 \pm 3.70$ \\
\hline $20: 0$ & $5.11 \pm 0.27$ & $5.20 \pm 0.30$ & $5.15 \pm 0.40$ \\
\hline $22: 0$ & $8.54 \pm 0.46$ & $9.23 \pm 0.49$ & $8.33 \pm 0.62$ \\
\hline $23: 0$ & $1.18 \pm 0.11$ & $1.30 \pm 0.10$ & $1.21 \pm 0.14$ \\
\hline $24: 0$ & $8.21 \pm 0.51$ & $10.6 \pm 1.63$ & $8.12 \pm 0.43$ \\
\hline ¿SAFA & $282.5 \pm 13.3$ & $302.4 \pm 11.2$ & $269.2 \pm 13.7$ \\
\hline $16: 1(n-7)$ & $2.91 \pm 0.31$ & $3.48 \pm 0.27$ & $3.54 \pm 0.47$ \\
\hline $18: 1(n-7)$ & $14.7 \pm 1.41$ & $17.6 \pm 0.85$ & $16.4 \pm 1.06$ \\
\hline 18:1(n-9) & $43.2 \pm 3.68$ & $42.8 \pm 2.38$ & $45.4 \pm 5.79$ \\
\hline $24: 1(n-9)$ & $11.6 \pm 0.61$ & $14.9 \pm 0.95$ & $13.0 \pm 0.85$ \\
\hline ¿MUFA & $72.8 \pm 5.20$ & $79.8 \pm 4.01$ & $78.8 \pm 7.83$ \\
\hline 16:0dma & $3.95 \pm 0.42$ & $5.32 \pm 0.67$ & $4.24 \pm 0.24$ \\
\hline 18:0xlma & $1.60 \pm 0.25$ & $2.46 \pm 1.01$ & $1.36 \pm 0.24$ \\
\hline $20: 3(n-9)$ & $4.00 \pm 0.64$ & $3.51 \pm 0.28$ & $4.10 \pm 0.48$ \\
\hline$\Sigma(n-7)+\Sigma(n-9)$ & $76.9 \pm 3.29$ & $83.7 \pm 4.28$ & $83.1 \pm 8.05$ \\
\hline $18: 2(n-6)$ & $43.8 \pm 3.33$ & $51.4 \pm 2.52$ & $51.6 \pm 4.36$ \\
\hline $20: 2(n-6)$ & $2.12 \pm 0.13$ & $2.38 \pm 0.10$ & $2.39 \pm 0.18$ \\
\hline $20: 3(n-6)$ & $28.8 \pm 1.55$ & $33.0 \pm 1.77$ & $30.3 \pm 1.98$ \\
\hline $20: 4(n-6)$ & $98.7 \pm 5.83$ & $113.1 \pm 4.22$ & $94.3 \pm 4.68$ \\
\hline $22: 4(n-6)$ & $4.66 \pm 0.30$ & $6.04 \pm 1.06$ & $4.38 \pm 0.19$ \\
\hline $22: 5(n-6)$ & $5.05 \pm 0.42$ & $5.63 \pm 0.36$ & $4.95 \pm 0.34$ \\
\hline $24: 2(n-6)$ & $3.44 \pm 0.26$ & $4.46 \pm 0.39$ & $4.49 \pm 0.43$ \\
\hline$\Sigma(n-6)$ & $186.9 \pm 10.23$ & $216.7 \pm 7.69$ & $192.9 \pm 10.8$ \\
\hline $20: 5(n-3)$ & $1.43 \pm 0.14$ & $1.53 \pm 0.26$ & $1.03 \pm 0.10$ \\
\hline $22: 5(n-3)$ & $3.00 \pm 0.24$ & $2.63 \pm 0.24$ & $2.04 \pm 0.12$ \\
\hline
\end{tabular}


Appendix D1 continued

\begin{tabular}{llll}
\hline Fatty acid & $\begin{array}{l}\text { LL-control } \\
(\mathrm{n}=22)\end{array}$ & $\begin{array}{l}\text { LA supplemented } \\
(\mathrm{n}=21)\end{array}$ & $\begin{array}{l}\text { HL-control } \\
(\mathrm{n}=21)\end{array}$ \\
\hline $22: 6(\mathrm{n}-3)$ & $41.2 \pm 3.19$ & $38.2 \pm 2.31$ & $30.3 \pm 1.49$ \\
$\Sigma(\mathrm{n}-3)$ & $46.7 \pm 3.42$ & $43.1 \pm 2.66$ & $34.2 \pm 1.58$ \\
\hline
\end{tabular}

Y: $\mathrm{LL}$-control $=$ control group, low in linoleic acid; LA supplemented $=$ linoleic acid supplemented group; HL-control = control group, high in linoleic acid. 
Appendix D2. Fatty acid composition (\% of total fatty acids) of umbilical plasma PLs ${ }^{Y}$.

\begin{tabular}{|c|c|c|c|}
\hline Fatty acid & $\begin{array}{l}\text { LL-control } \\
(n=22)\end{array}$ & $\begin{array}{l}\text { LA supplemented } \\
(n=21)\end{array}$ & $\begin{array}{l}\text { HL-control } \\
(\mathrm{n}=21)\end{array}$ \\
\hline $14: 0$ & $0.22 \pm 0.02$ & $0.24 \pm 0.01$ & $0.17 \pm 0.02$ \\
\hline $15: 0$ & $0.07 \pm 0.02$ & $0.10 \pm 0.01$ & $0.07 \pm 0.01$ \\
\hline $16: 0$ & $28.1 \pm 0.34$ & $27.4 \pm 0.24$ & $27.6 \pm 0.41$ \\
\hline $18: 0$ & $14.5 \pm 0.34$ & $14.1 \pm 0.28$ & $13.9 \pm 0.28$ \\
\hline $20: 0$ & $0.86 \pm 0.04$ & $0.79 \pm 0.04$ & $0.86 \pm 0.04$ \\
\hline $22: 0$ & $1.43 \pm 0.06$ & $1.40 \pm 0.05$ & $1.41 \pm 0.08$ \\
\hline $23: 0$ & $0.19 \pm 0.02$ & $0.20 \pm 0.01$ & $0.201 \pm 0.02$ \\
\hline $24: 0$ & $1.37 \pm 0.07$ & $1.55 \pm 0.17$ & $1.40 \pm 0.07$ \\
\hline ESAFA & $46.8 \pm 0.54$ & $45.8 \pm 0.22$ & $45.6 \pm 0.42$ \\
\hline $16: 1(n-7)$ & $0.49 \pm 0.05$ & $0.52 \pm 0.03$ & $0.57 \pm 0.05$ \\
\hline $18: 1(n-7)$ & $2.38 \pm 0.18$ & $2.67 \pm 0.07$ & $2.76 \pm 0.08$ \\
\hline 18: 1(n-9) & $7.06 \pm 0.39$ & $6.42 \pm 0.17$ & $7.38 \pm 0.50$ \\
\hline $24: 1(n-9)$ & $1.93 \pm 0.07$ & $2.24 \pm 0.08$ & $2.191 \pm 0.07$ \\
\hline ¿MUFA & $11.9 \pm 0.50$ & $12.0 \pm 0.25$ & $13.0 \pm 0.56$ \\
\hline $16: 0 \mathrm{dma}$ & $0.64 \pm 0.05$ & $0.79 \pm 0.07$ & $0.74 \pm 0.04$ \\
\hline $18: 0 \mathrm{dma}$ & $0.26 \pm 0.04$ & $0.34 \pm 0.12$ & $0.23 \pm 0.03$ \\
\hline $20: 3(n-9)$ & $0.69 \pm 0.12$ & $0.52 \pm 0.03$ & $0.68 \pm 0.07$ \\
\hline$\Sigma(n-7)+\Sigma(n-9)$ & $12.6 \pm 0.54$ & $12.6 \pm 0.28$ & $13.7 \pm 0.57$ \\
\hline $18: 2(n-6)$ & $7.15 \pm 0.34$ & $7.80 \pm 0.25$ & $8.53 \pm 0.29$ \\
\hline $20: 2(n-6)$ & $0.35 \pm 0.02$ & $0.36 \pm 0.01$ & $0.40 \pm 0.02$ \\
\hline $20: 3(n-6)$ & $4.83 \pm 0.20$ & $5.05 \pm 0.25$ & $5.12 \pm 0.19$ \\
\hline $20: 4(n-6)$ & $16.2 \pm 0.32$ & $17.2 \pm 0.30$ & $16.1 \pm 0.41$ \\
\hline $22: 4(n-6)$ & $0.76 \pm 0.02$ & $0.89 \pm 0.11$ & $0.76 \pm 0.04$ \\
\hline $22: 5(n-6)$ & $0.83 \pm 0.05$ & $0.86 \pm 0.05$ & $0.85 \pm 0.05$ \\
\hline $24: 2(n-6)$ & $0.58 \pm 0.04$ & $0.67 \pm 0.05$ & $0.75 \pm 0.04$ \\
\hline$\Sigma(n-6)$ & $30.8 \pm 0.46$ & $32.9 \pm 0.44$ & $32.5 \pm 0.32$ \\
\hline $20: 5(n-3)$ & $0.24 \pm 0.02$ & $0.23 \pm 0.03$ & $0.18 \pm 0.02$ \\
\hline $22: 5(n-3)$ & $0.50 \pm 0.04$ & $0.40 \pm 0.03$ & $0.36 \pm 0.03$ \\
\hline
\end{tabular}


Appendix D2 continued

\begin{tabular}{llll}
\hline Fatty acid & $\begin{array}{l}\text { L-control } \\
(\mathrm{n}=22)\end{array}$ & $\begin{array}{l}\text { LA supplemented } \\
(\mathrm{n}=21)\end{array}$ & $\begin{array}{l}\text { HL-control } \\
(\mathrm{n}=21)\end{array}$ \\
\hline $22: 6(\mathrm{n}-3)$ & $6.77 \pm 0.33$ & $5.80 \pm 0.26$ & $5.27 \pm 0.28$ \\
$\Sigma(n-3)$ & $7.68 \pm 0.36$ & $6.53 \pm 0.29$ & $5.95 \pm 0.31$ \\
\hline
\end{tabular}

₹: see appendix D1. 
Appendix D3. Fatty acid composition ( $\mathrm{mg} / \mathrm{g}$ dry tissue) of umbilical venous vessel wall PLs ${ }^{\sharp}$.

\begin{tabular}{|c|c|c|c|}
\hline Fatty acid & $\begin{array}{l}\text { LL-control } \\
(\mathrm{n}=2.1)\end{array}$ & $\begin{array}{l}\text { LA supplemented } \\
(\mathrm{n}=21)\end{array}$ & $\begin{array}{l}\text { HL control } \\
(n=18)\end{array}$ \\
\hline $14: 0$ & $0.15 \pm 0.01$ & $0.14 \pm 0.01$ & $0.20 \pm 0.02$ \\
\hline $15: 0$ & $0.10 \pm 0.01$ & $0.11 \pm 0.01$ & $0.12 \pm 0.01$ \\
\hline $16: 0$ & $4.47 \pm 0.23$ & $4.28 \pm 0.12$ & $4.21 \pm 0.17$ \\
\hline $17: 0$ & $0.17 \pm 0.01$ & $0.16 \pm 0.01$ & $0.18 \pm 0.01$ \\
\hline 18:0 & $2.25 \pm 0.09$ & $2.29 \pm 0.07$ & $1.98 \pm 0.08$ \\
\hline $20: 0$ & $0.07 \pm 0.00$ & $0.07 \pm 0.00$ & $0.06 \pm 0.01$ \\
\hline $22: 0$ & $0.22 \pm 0.01$ & $0.21 \pm 0.01$ & $0.15 \pm 0.01$ \\
\hline $24: 0$ & $0.39 \pm 0.02$ & $0.38 \pm 0.02$ & $0.28 \pm 0.03$ \\
\hline$\Sigma S A F A$ & $7.82 \pm 0.36$ & $7.64 \pm 0.23$ & $7.19 \pm 0.30$ \\
\hline $16: 1(n-7)$ & $0.08 \pm 0.00$ & $0.08 \pm 0.00$ & $0.07 \pm 0.00$ \\
\hline $18: 1(n-7)$ & $0.38 \pm 0.02$ & $0.37 \pm 0.01$ & $0.39 \pm 0.02$ \\
\hline $18: 1(n-9)$ & $1.29 \pm 0.09$ & $1.23 \pm 0.05$ & $1.20 \pm 0.06$ \\
\hline $20: 1(n-9)$ & $0.05 \pm 0.00$ & $0.04 \pm 0.00$ & $0.05 \pm 0.01$ \\
\hline $24: 1(n-9)$ & $0.74 \pm 0.06$ & $0.69 \pm 0.04$ & $0.56 \pm 0.04$ \\
\hline ¿MUFA & $2.56 \pm 0.17$ & $2.42 \pm 0.09$ & $2.28 \pm 0.11$ \\
\hline $20: 3(n-9)$ & $0.09 \pm 0.02$ & $0.07 \pm 0.01$ & $0.06 \pm 0.01$ \\
\hline $22: 3(n-9)$ & $0.08 \pm 0.01$ & $0.06 \pm 0.01$ & $0.05 \pm 0.01$ \\
\hline$\Sigma(n-7)+\Sigma(n-9)$ & $2.73 \pm 0.20$ & $2.56 \pm 0.10$ & $2.38 \pm 0.12$ \\
\hline $18: 2(\mathrm{n}-6)$ & $0.31 \pm 0.02$ & $0.33 \pm 0.02$ & $0.35 \pm 0.02$ \\
\hline $20: 2(n-6)$ & $0.06 \pm 0.00$ & $0.07 \pm 0.00$ & $0.07 \pm 0.01$ \\
\hline $20: 3(n-6)$ & $0.30 \pm 0.02$ & $0.35 \pm 0.02$ & $0.29 \pm 0.02$ \\
\hline $20: 4(n-6)$ & $3.23 \pm 0.14$ & $3.33 \pm 0.08$ & $2.72 \pm 0.12$ \\
\hline $22: 4(n-6)$ & $0.92 \pm 0.04$ & $0.96 \pm 0.04$ & $0.80 \pm 0.04$ \\
\hline $22: 5(n-6)$ & $0.49 \pm 0.04$ & $0.52 \pm 0.02$ & $0.44 \pm 0.03$ \\
\hline $24: 2(n-6)$ & $0.10 \pm 0.01$ & $0.12 \pm 0.01$ & $0.10 \pm 0.01$ \\
\hline$\Sigma(n-6)$ & $5.43 \pm 0.21$ & $5.68 \pm 0.14$ & $4.78 \pm 0.20$ \\
\hline $22: 6(n-3)$ & $1.06 \pm 0.05$ & $0.94 \pm 0.04$ & $0.69 \pm 0.05$ \\
\hline
\end{tabular}

¥: see appendix D1. 
Appendix D4. Fatty acid composition (mg/g dry tissue) of umbilical arterial vessel wall PLs*.

\begin{tabular}{|c|c|c|c|}
\hline Fatty acid & $\begin{array}{l}\text { LL-control } \\
(\mathrm{n}=21)\end{array}$ & $\begin{array}{l}\text { LA supplemented } \\
(\mathrm{n}=21)\end{array}$ & $\begin{array}{l}\text { HL-control } \\
(\mathrm{n}=18)\end{array}$ \\
\hline $14: 0$ & $0.17 \pm 0.01$ & $0.16 \pm 0.01$ & $0.21 \pm 0.02$ \\
\hline 15:0 & $0.10 \pm 0.01$ & $0.10 \pm 0.01$ & $0.11 \pm 0.00$ \\
\hline $16: 0$ & $4.03 \pm 0.25$ & $3.99 \pm 0.10$ & $3.70 \pm 0.16$ \\
\hline $17: 0$ & $0.16 \pm 0.01$ & $0.16 \pm 0.01$ & $0.16 \pm 0.01$ \\
\hline 18:0 & $2.31 \pm 0.15$ & $2.32 \pm 0.04$ & $1.98 \pm 0.10$ \\
\hline $20: 0$ & $0.08 \pm 0.01$ & $0.08 \pm 0.00$ & $0.07 \pm 0.00$ \\
\hline $22: 0$ & $0.28 \pm 0.02$ & $0.29 \pm 0.01$ & $0.20 \pm 0.02$ \\
\hline $24: 0$ & $0.51 \pm 0.04$ & $0.52 \pm 0.03$ & $0.37 \pm 0.03$ \\
\hline ¿SAFA & $7.64 \pm 0.47$ & $7.61 \pm 0.17$ & $6.79 \pm 0.32$ \\
\hline $16: 1(n-7)$ & $0.07 \pm 0.00$ & $0.07 \pm 0.00$ & $0.07 \pm 0.00$ \\
\hline $18: 1(n-7)$ & $0.43 \pm 0.03$ & $0.44 \pm 0.01$ & $0.44 \pm 0.02$ \\
\hline $18: 1(n-9)$ & $1.67 \pm 0.14$ & $1.62 \pm 0.07$ & $1.63 \pm 0.09$ \\
\hline $20: 1(n-9)$ & $0.08 \pm 0.01$ & $0.07 \pm 0.00$ & $0.08 \pm 0.01$ \\
\hline $24: 1(n-9)$ & $0.80 \pm 0.07$ & $0.82 \pm 0.04$ & $0.61 \pm 0.05$ \\
\hline ¿MUFA & $3.06 \pm 0.24$ & $3.04 \pm 0.12$ & $2.84 \pm 0.16$ \\
\hline $20: 3(n-9)$ & $0.44 \pm 0.05$ & $0.48 \pm 0.04$ & $0.42 \pm 0.03$ \\
\hline $22: 3(n-9)$ & $0.22 \pm 0.02$ & $0.26 \pm 0.02$ & $0.21 \pm 0.02$ \\
\hline$\sum(n-7)+\sum(n-9)$ & $3.72 \pm 0.30$ & $3.78 \pm 0.15$ & $3.47 \pm 0.20$ \\
\hline $18: 2(n-6)$ & $0.20 \pm 0.01$ & $0.21 \pm 0.01$ & $0.24 \pm 0.02$ \\
\hline $20: 2(n-6)$ & $0.03 \pm 0.00$ & $0.03 \pm 0.00$ & $0.04 \pm 0.00$ \\
\hline $20: 3(n-6)$ & $0.21 \pm 0.02$ & $0.23 \pm 0.01$ & $0.20 \pm 0.02$ \\
\hline $20: 4(n-6)$ & $2.44 \pm 0.17$ & $2.56 \pm 0.09$ & $2.10 \pm 0.12$ \\
\hline $22: 4(n-6)$ & $0.54 \pm 0.04$ & $0.59 \pm 0.03$ & $0.46 \pm 0.04$ \\
\hline $22: 5(n-6)$ & $0.55 \pm 0.04$ & $0.58 \pm 0.02$ & $0.51 \pm 0.03$ \\
\hline $24: 2(n-6)$ & $0.03 \pm 0.00$ & $0.04 \pm 0.00$ & $0.03 \pm 0.00$ \\
\hline$\Sigma(n-6)$ & $4.01 \pm 0.25$ & $4.24 \pm 0.12$ & $3.59 \pm 0.20$ \\
\hline $22: 6(n-3)$ & $1.01 \pm 0.08$ & $0.95 \pm 0.04$ & $0.73 \pm 0.06$ \\
\hline
\end{tabular}

¥: see appendix DI. 
Appendix D5. Fatty acid composition (\% of total fatty acids) of umbilical venous vessel wall PLs $\mathbf{s}^{\nsucceq}$.

\begin{tabular}{|c|c|c|c|}
\hline Fatty acid & $\begin{array}{l}\text { LL-control } \\
(\mathrm{n}=22)\end{array}$ & $\begin{array}{l}\text { LA supplemented } \\
(\mathrm{n}=21)\end{array}$ & $\begin{array}{l}\text { HL-control } \\
(n=21)\end{array}$ \\
\hline $14: 0$ & $0.87 \pm 0.04$ & $0.80 \pm 0.04$ & $1.38 \pm 0.12$ \\
\hline 15:0 & $0.59 \pm 0.02$ & $0.641 \pm 0.04$ & $0.83 \pm 0.06$ \\
\hline $16: 0$ & $26.1 \pm 0.27$ & $25.4 \pm 0.23$ & $28.0 \pm 0.26$ \\
\hline $17: 0$ & $0.99 \pm 0.04$ & $0.97 \pm 0.03$ & $1.17 \pm 0.04$ \\
\hline 18:0 & $13.3 \pm 0.12$ & $13.6 \pm 0.18$ & $13.3 \pm 0.16$ \\
\hline 20:0 & $0.44 \pm 0.01$ & $0.44 \pm 0.02$ & $0.41 \pm 0.02$ \\
\hline $22: 0$ & $1.31 \pm 0.04$ & $1.27 \pm 0.04$ & $1.01 \pm 0.06$ \\
\hline $24: 0$ & $2.34 \pm 0.08$ & $2.22 \pm 0.11$ & $1.90 \pm 0.11$ \\
\hline$\sum S A F A$ & $45.9 \pm 0.24$ & $45.4 \pm 0.23$ & $47.9 \pm 0.37$ \\
\hline $16: 1(n-7)$ & $0.46 \pm 0.02$ & $0.45 \pm 0.01$ & $0.47 \pm 0.02$ \\
\hline $18: 1(\bar{n}-7)$ & $2.23 \pm 0.06$ & $2.21 \pm 0.04$ & $2.55 \pm 0.07$ \\
\hline $1 \overline{8}: 1(n-9)$ & $7.46 \pm 0.18$ & $7.30 \pm 0.18$ & $7.89 \pm 0.16$ \\
\hline $20: 1(n-9)$ & $0.30 \pm 0.02$ & $0.24 \pm 0.02$ & $0.31 \pm \overline{0.03}$ \\
\hline $24: 1(n-9)$ & $4.28 \pm 0.13$ & $4.07 \pm 0.16$ & $3.67 \pm 0.18$ \\
\hline ¿MUFA & $14.8 \pm 0.36$ & $14.4 \pm 0.27$ & $15.0 \pm 0.29$ \\
\hline $20: 3(n-9)$ & $0.50 \pm 0.07$ & $0.41 \pm 0.04$ & $0.39 \pm 0.04$ \\
\hline $22: 3(n-9)$ & $0.43 \pm 0.05$ & $0.38 \pm 0.03$ & $0.32 \pm 0.03$ \\
\hline$\Sigma(n-7)+\Sigma(n-9)$ & $15.8 \pm 0.46$ & $15.1 \pm 0.30$ & $15.7 \pm 0.31$ \\
\hline $18: 2(n-6)$ & $1.80 \pm 0.10$ & $1.96 \pm 0.08$ & $2.26 \pm 0.12$ \\
\hline $20: 2(n-6)$ & $0.37 \pm 0.03$ & $0.39 \pm 0.02$ & $0.46 \pm 0.03$ \\
\hline $20: 3(n-6)$ & $1.76 \pm 0.06$ & $2.09 \pm 0.09$ & $1.89 \pm 0.06$ \\
\hline $20: 4(n-6)$ & $19.0 \pm 0.35$ & $19.9 \pm 0.23$ & $18.1 \pm 0.35$ \\
\hline $22: 4(n-6)$ & $5.48 \pm 0.20$ & $5.71 \pm 0.21$ & $5.36 \pm 0.19$ \\
\hline $22: 5(n-6)$ & $2.85 \pm 0.14$ & $3.08 \pm 0.13$ & $2.97 \pm 0.15$ \\
\hline $24: 2(n-6)$ & $0.64 \pm 0.03$ & $0.74 \pm 0.04$ & $0.64 \pm 0.05$ \\
\hline$\Sigma(n-6)$ & $32.0 \pm 0.44$ & $33.9 \pm 0.33$ & $31.8 \pm 0.44$ \\
\hline $22: 6(n-3)$ & $6.26 \pm 0.16$ & $5.59 \pm 0.15$ & $4.63 \pm 0.20$ \\
\hline
\end{tabular}

W: see appendix D1. 
Appendix D6. Fatty acid composition (\% of total fatty acids) of umbilical arterial vessel wall PLs ${ }^{X}$.

\begin{tabular}{|c|c|c|c|}
\hline Fatty acid & $\begin{array}{l}\text { LL-control } \\
(\mathrm{n}=22)\end{array}$ & $\begin{array}{l}\text { LA supplemented } \\
(\mathrm{n}=21)\end{array}$ & $\begin{array}{l}\text { HL-control } \\
(n=21)\end{array}$ \\
\hline 14:0 & $1.04 \pm 0.05$ & $0.94 \pm 0.03$ & $1.52 \pm 0.11$ \\
\hline $15: 0$ & $0.61 \pm 0.02$ & $0.62 \pm 0.03$ & $0.79 \pm 0.06$ \\
\hline $16: 0$ & $24.6 \pm 0.34$ & $24.0 \pm 0.23$ & $25.7 \pm 0.29$ \\
\hline $17: 0$ & $0.96 \pm 0.03$ & $0.91 \pm 0.02$ & $1.07 \pm 0.04$ \\
\hline 18:0 & $14.1 \pm 0.18$ & $14.0 \pm 0.12$ & $13.6 \pm 0.17$ \\
\hline $20: 0$ & $0.49 \pm 0.01$ & $0.50 \pm 0.02$ & $0.48 \pm 0.02$ \\
\hline 22:0 & $1.67 \pm 0.05$ & $1.72 \pm 0.05$ & $1.36 \pm 0.07$ \\
\hline $24: 0$ & $3.10 \pm 0.10$ & $3.10 \pm 0.12$ & $2.52 \pm 0.12$ \\
\hline ¿SAFA & $46.5 \pm 0.34$ & $45.9 \pm 0.25$ & $47.0 \pm 0.40$ \\
\hline $16: 1(n-7)$ & $0.44 \pm 0.02$ & $0.41 \pm 0.01$ & $0.45 \pm 0.02$ \\
\hline $18: 1(n-7)$ & $2.58 \pm 0.09$ & $2.64 \pm 0.06$ & $3.00 \pm 0.08$ \\
\hline $18: 1(n-9)$ & $9.96 \pm 0.42$ & $9.75 \pm 0.30$ & $11.0 \pm 0.37$ \\
\hline $20: 1(n-9)$ & $0.44 \pm 0.03$ & $0.45 \pm 0.03$ & $0.55 \pm 0.06$ \\
\hline $24: I(n-9)$ & $4.81=0.15$ & $4.90 \pm 0.18$ & $4.21+0.17$ \\
\hline$\sum M U F A$ & $18.3 \pm 0.59$ & $18.3 \pm 0.46$ & $19.3 \pm 0.50$ \\
\hline $20: 3(n-9)$ & $2.66 \pm 0.24$ & $2.94 \pm 0.23$ & $2.87 \pm 0.18$ \\
\hline $22: 3(n-9)$ & $1.37 \pm 0.09$ & $1.59 \pm 0.12$ & $1.44 \pm 0.10$ \\
\hline$\Sigma(n-7)+\Sigma(n-9)$ & $22.4 \pm 0.87$ & $22.8 \pm 0.75$ & $23.7 \pm 0.70$ \\
\hline $18: 2(n-6)$ & $1.22 \pm 0.06$ & $1.27 \pm 0.04$ & $1.60 \pm 0.11$ \\
\hline $20: 2(n-6)$ & $0.17 \pm 0.02$ & $0.18 \pm 0.01$ & $0.27 \pm 0.03$ \\
\hline $20: 3(n-6)$ & $1.27 \pm 0.05$ & $1.41 \pm 0.06$ & $1.34 \pm 0.05$ \\
\hline $20: 4(n-6)$ & $15.1 \pm 0.51$ & $15.4 \pm 0.44$ & $14.3 \pm 0.43$ \\
\hline $22: 4(n-6)$ & $3.36 \pm 0.16$ & $3.57 \pm 0.16$ & $3.10 \pm 0.12$ \\
\hline $22: 5(n-6)$ & $3.28 \pm 0.13$ & $3.49 \pm 0.13$ & $3.50 \pm 0.12$ \\
\hline $24: 2(n-6)$ & $0.21 \pm 0.02$ & $0.24 \pm 0.02$ & $0.20 \pm 0.02$ \\
\hline$\sum(n-6)$ & $24.6 \pm 0.66$ & $25.6 \pm 0.58$ & $24.7 \pm 0.63$ \\
\hline $22: 6(n-3)$ & $6.48 \pm 0.25$ & $5.74 \pm 0.16$ & $4.99 \pm 0.22$ \\
\hline
\end{tabular}

¥: see appendix D1. 
